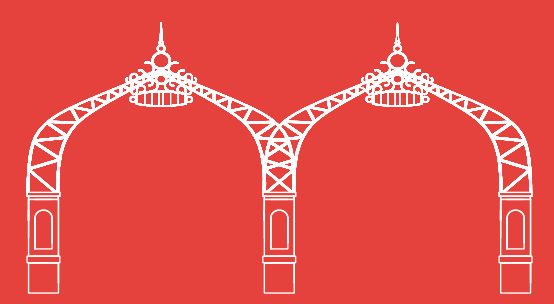

\title{
THE CROSS ROADS OF HERITAGE
}

Philippa Dalgety 


\section{THE CROSS ROADS OF HERITAGE}

\section{THE ADAPTIVE REUSE OF HERITAGE BUILDINGS IN PROVINCIAL CITIES OF NEW ZEALAND. PHILIPPA DALGETY}

An 120 point thesis submitted in partial fulfillment of the requirements for the degree of Masters of Architecture (Professional)

Victoria University of Wellington, School of Architecture. 
"The better we know our unique human made heritage, the better we shall preserve its best aspects and the better we shall build today."

- Lewis E. Marton 1987 


\section{ACKNOWWLEDGEMENTS}

Firstly, I would like to thank my supervisor's Hans-Christian Wilhelm and Emina Petrovic. You have both provided great support, advice and reassurance throughout this project.

To my friends, the last five years would not have been as fun without your laughter and support. Finally to my amazing family, thanks for the continued support through the highs and lows. I couldn't have done it without you.

Thank you. 


\section{HOW CAN THE ADAPTIVE REUSE OF INDUSTRIAL HERITAGE BUILDINGS REVITALIZE A CITIE'S IDENTITY?}




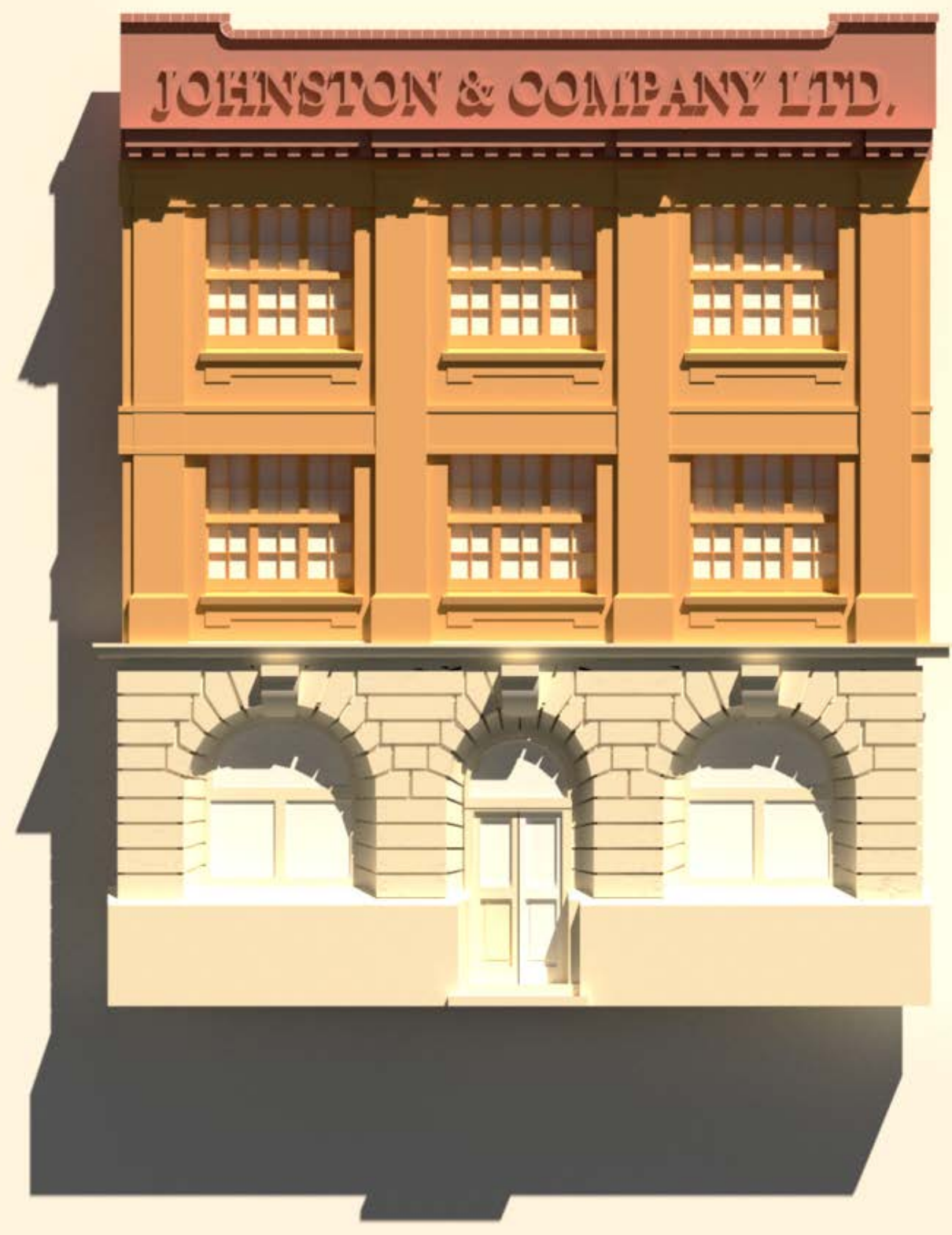

Fig. 0.02: Johnson \& Co Facade 


\subsection{ABSTRACT}

This research explores an approach for adaptive reuse to enhance livability and greater connection to place within provincial towns of New Zealand. There are existing buildings which are often left in disrepair or considered too expensive to refurbish or strengthen. They are often demolished with little consideration to the building's significance, therefore adaptive reuse has become a missed opportunity in New Zealand.

Many of our provincial cities have uninhabited large-scale buildings, which need upgrading due to being outdated and no longer fit for purpose. Seismic upgrading is a key factor in why these buildings are left uninhabited. One of the urban areas which this is prevalent is Whanganui. Whanganui has the opportunity to blend the old and the new built form to create a revitalized and timeless street appearance.

The regeneration of Whanganui can be achieved through adaptive reuse to enhance the crafted beauty of the town through its architecture. The revitalization of Whanganui can give guidance to other provincial cities in New Zealand while enhancing the quality of life within the town.

An in-depth analysis of the history of Whanganui, will allow for heritage significance to play a major role in the redesign. This design will be developed at three different scales to demonstrate how the built form can enhance connection to place and livability. These scales are at an urban, a built and a detailed scale.

The main cross roads linking the city of Whanganui to its river is surrounded by character and historical buildings. It will be used as a key area illustrating Whanganui's past to better inform the future. 


\section{CONTENTS}

1.0

01. INTRODUCTION

1.1 Background and Problem Statement

1.2 Research Question and Hypothesis

1.3 Aims + Objectives

1.4 Societal, scientific and practical relevance

1.5 Methodology

1.6 Adaptive reuse

\section{LITERATURE REVIEW}

2.1 Adaptive Reuse Design Approaches

2.2 The Art of Copying

2.3 Enhancing connection to place

2.4 Sustainable Methods

2.5 Adaptive reuse in New Zealand

2.6 Principles for adaptive reuse
03 CONTEXTUAL POSITIONING

3.1 Building Form 37

3.2 Corner Building analysis 39

3.3 Comparison Images 41

3.4 Victoria Avenue Heritage Analysis 43

3.5 Historic Cross roads Sketch Analysis 47

3.6 Potential site adaptations 51

xi

\section{PRECEDENT STUDY}

3

4.1 Grosvenor Tavern

57

4.2 Abbotsford Warehouse Apartments

61

4.3 The Green Building fer studio

65

4.4 Paramount House Hotel

71

4.5 Standard Building

\section{SITE ANALYSIS}

15

20

25

27

29

31
$5.1 \quad$ Whanganui

European Settlement

Whanganui Demographics

Whanganui Currently

Making Whanganui Visible

River Identity
83

85

87

89

90

103 


\section{EXISTING BUILDING APPRAISAL 09}

6.1 Johnston and Company Building

119

6.2 Fosters Hotel Building

131

6.3 Thain's and Company Building

141

6.4

Property Brokers Building
9.1 Johnston \& Company Building

199

9.2 Property Brokers Building

9.3

Dalgety / Thains Building

219

9.4

Fosters Hotel

229

9.5 Renders
07 POSITIONING STRATEGY

7.1 Potential Civic Developments

153

7.2 Urban Design Changes

161

7.3 Building Programmes

166

7.4 Design Considerations

169

7.5 Site Issues

7.6 River connection
10 DESIGN DETAIL

10.1 Column Design

10.2 Earthquake strengthening in New Zealand 248

10.3 The origin of Ancient Greek columns 251

10.4 The Theory of Gottfried Semper 251

10.5 Column Design Concepts

253

\section{DESIGN EXPLANATIONS}

8.1 Program Concept Designs

8.2 Johnston \& Co Building Exploration

8.3 Thains / Dalgety Building Concept

8.4 Property Brokers Building Concept

8.5 Fosters Hotel Concept
181

183

190

191

193

\section{CONCLUSIONS}

11.1 Conclusion

265

11.2 Limitations

266

11.3 Further research

267

Bibliography

269

List of Figures 


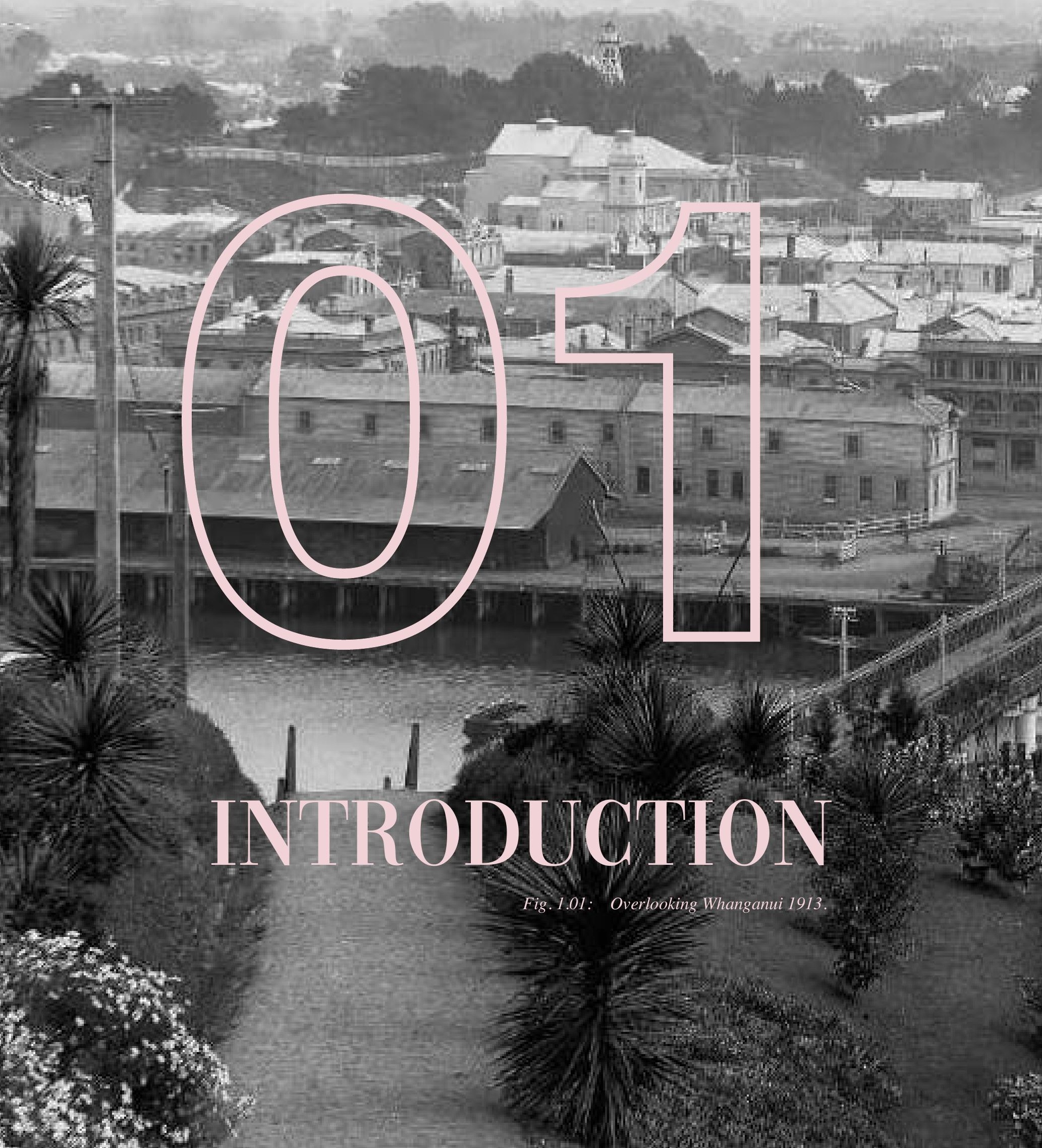




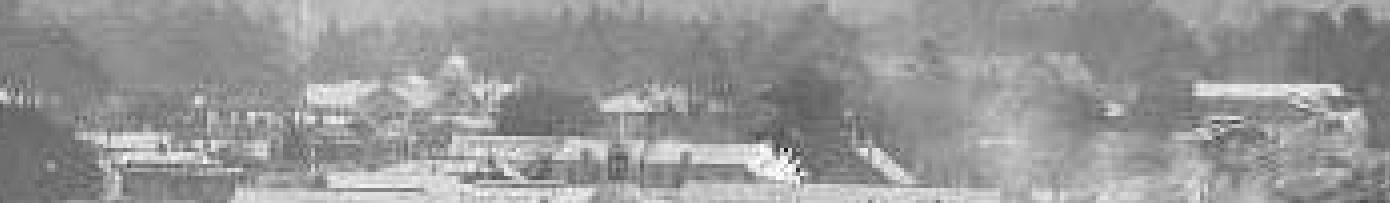

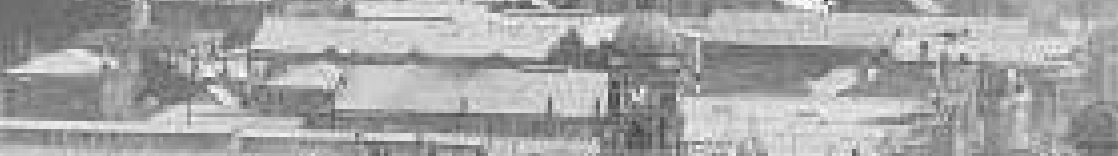

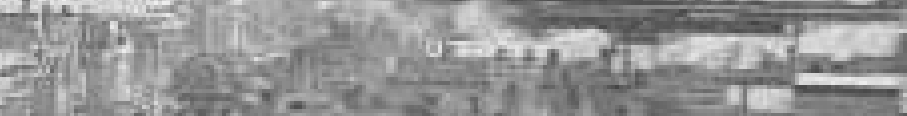

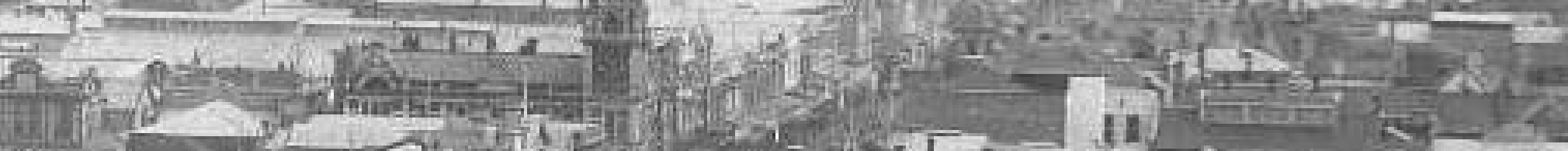

सा

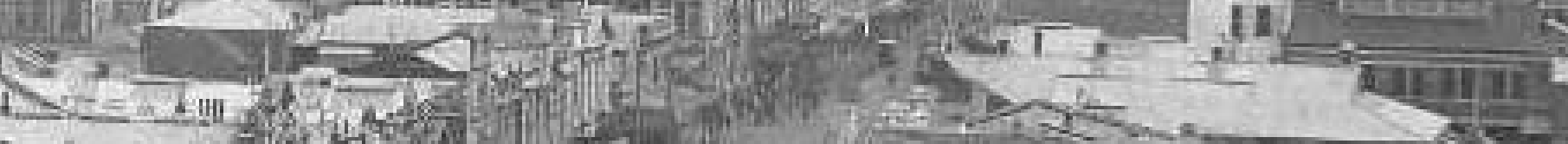

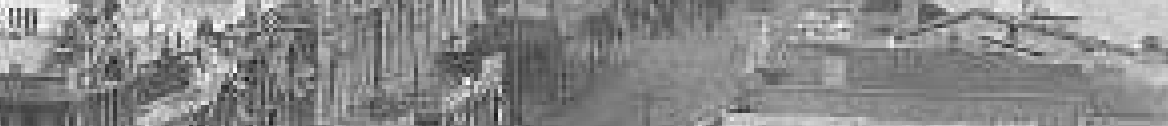

Qtenande

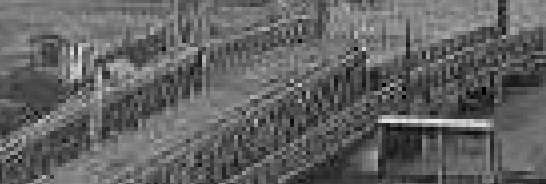

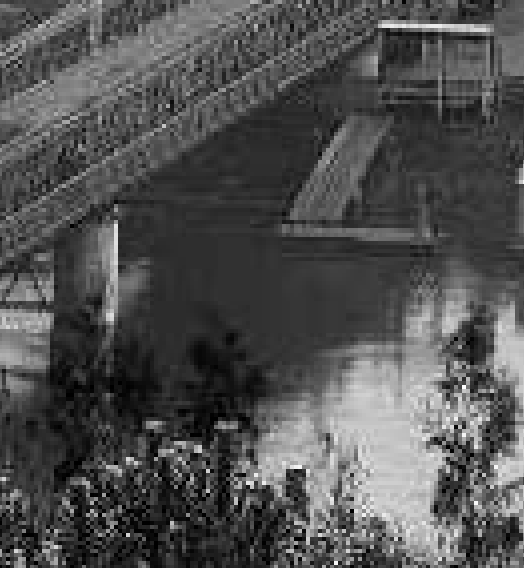

d.

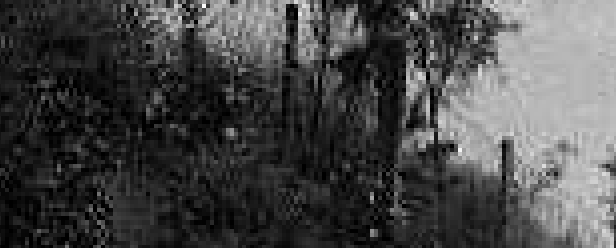

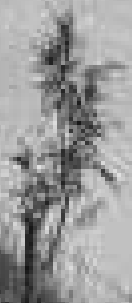

tis

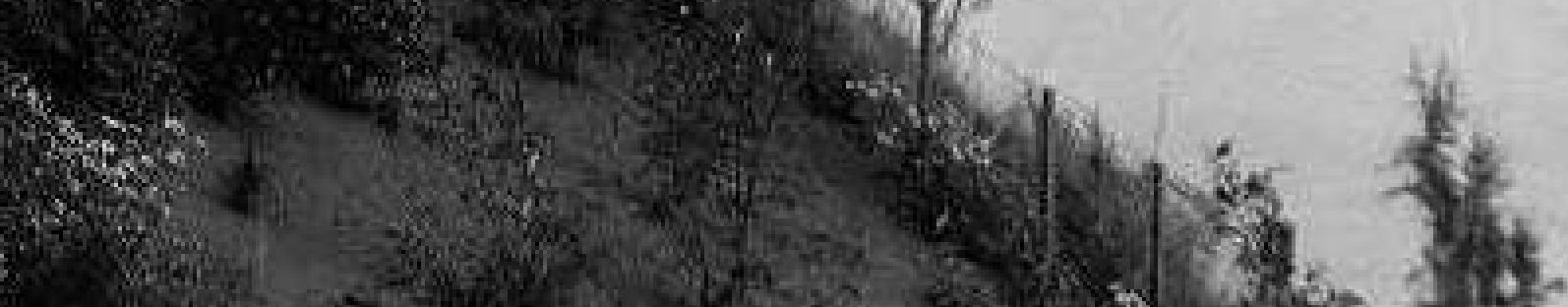




\subsection{BACKGROUND AND PROBLEM STATEMENT}

Whanganui's centre is currently underutilized with many vacant areas and lack of connection within the community (Martin, 2017) This is exemplified through the lack of connection between the main street and the river (Urbanismplus, 2016). This issue stems from the changing way our society lives and works within these provincial cities(Urbanismplus, 2016).

The centre of these cities are often left unused or under developed leading to poor urban design and buildings not being used to their best potential. This suggests that the strategy of adaptive reuse can be employed to help revitalise provincial cities, to better connect the communities to their city's centre (Douglas, 2006).

Throughout this project there is a personal connection to Whanganui as I once lived there and believe in its potential. In the context of heritage, Whanganui can be used to stand as an exemplar for other New Zealand provincial towns due to its large variety of heritage buildings which are largely concentrated to make up its town centre.

Whanganui has a strong heritage connection with its large variety of heritage buildings located in a close proximity (Whanganui Heritage Guide 2017). This heritage is, however, being lost due to the lack of knowledge and heritage funds that often do not reach our provincial towns (Making Whanganui visible 2016). Its main street is underutilized due to the need to earthquake strengthen and retrofit a vast amount of its buildings.

Like many provincial cities it faces a loss of heritage due to being identified as a high risk earthquake prone zone (Kilmister, 2018). There is a growing gap between the benefits of leasing the building and the cost of the renovation. The steep costs to strengthen or demolish is too high for building owners, these buildings become vulnerable to abandonment. The result of this sees business occupy spaces outside the character area, while these 


\section{REDACTED}

\section{REDACTED}

\section{Fig. 1.02: Fig. 1.03: Invercargill building before and during demolition.}

character buildings remain vacant (Martin, issue. This thesis looks to use Whanganui as 2017). This raises the issue where there is an urgent need to make retrofitting and reuse of heritage buildings commercially viable (Egbelakin, n.d.).

Figure 1.02 shows a building in Invercargill before demolition while Figure 1.03 illustrates the demolition in preparation for the construction of an eight-story hotel. The local heritage building, and preservation society were disappointed at the loss of a heritage building but acknowledged the financial difficulties in retention and reuse (ILT, 2018). This is a typical example of the fate of many heritage buildings in our provincial cities today. The lack of knowledge around retrofitting and adaptive reuse is part of the an example to showcase how these strategies can be utilized to save these buildings.

There is often a loss of identity in our heritage buildings due to adaptations with little architectural thought towards the buildings original character (Plevoets \& Cleempoel). In retrofitting and adaptive reuse, there is a fine line between a successful restoration that respects the building's history and one that loses its identity. An example of the loss of identity in Whanganui's historic buildings can be seen after the Napier earthquakes. This event resulted in the removal of most decorative features off the facades, creating a stripped back, simplified facade (Urbanismplus, 2016). 


\subsection{RESEARCH QUESTION AND HYPOTHESIS}

How can the adaptive reuse of heritage buildings revitalize a provincial city's identity and enhance connection to place?

Figure 1.04 illustrates the how the research question relates to the number of relevant areas of study summarised a diagram.

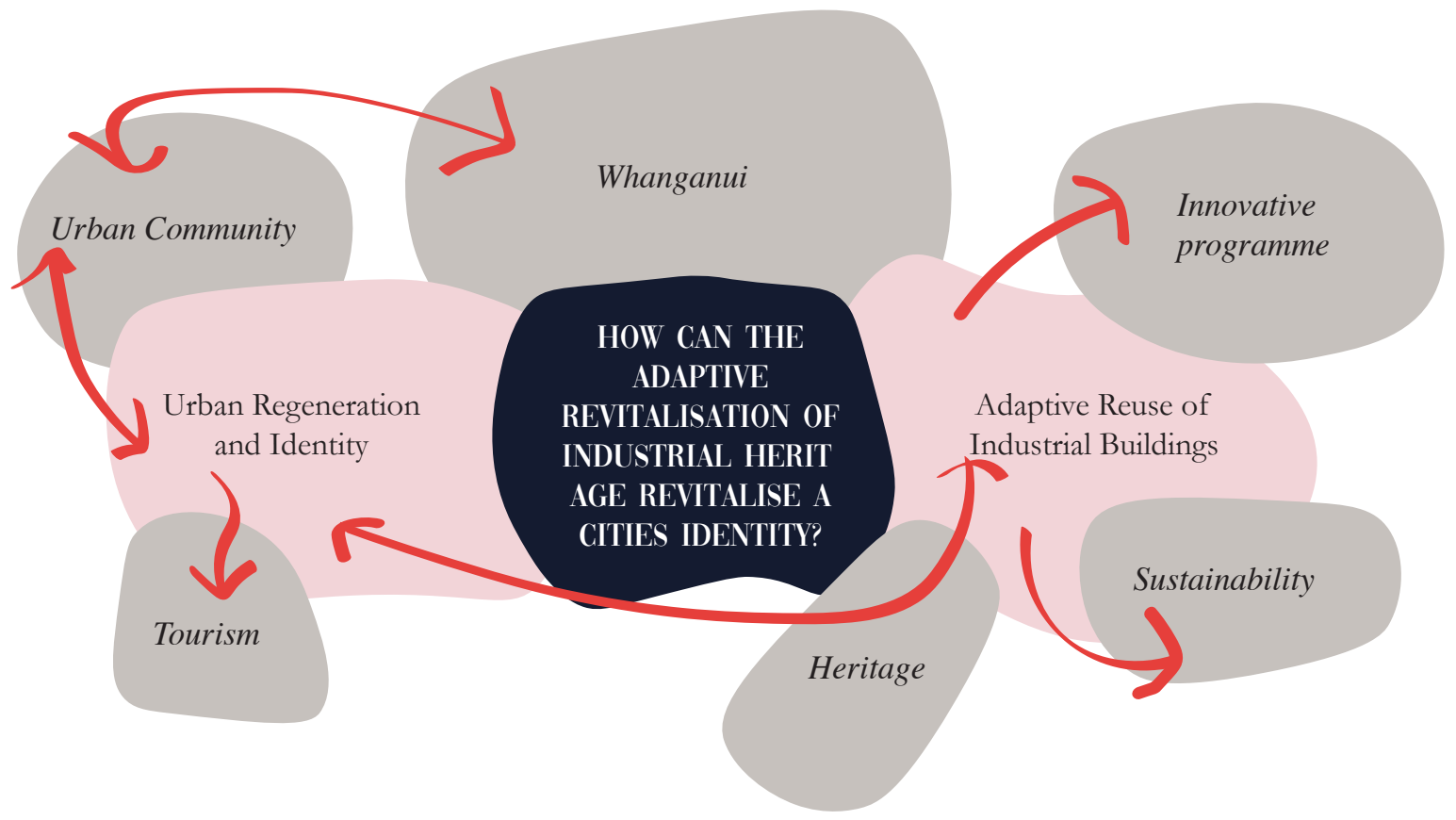

Fig. 1.04: Key words surrounding the research question 


\subsection{AIMS AND OBJECTIVE}

To achieve a successful design of an urban precinct to better connect the Whanganui river with the main street of Whanganui, Victoria Avenue. Through analysing adaptive reuse design strategies to showcase how the built heritage can be used to enhance connection to place.

- To create an urban precinct design which acts as a model for other provincial cities in New Zealand.

- To rejuvenate the built heritage of Whanganui through adaptive reuse architecture.

- To strengthen provincial towns through connection to place

- Propose a cohesive adaptive reuse program that builds upon the cultural heritage of Whanganui while also using sustainable solutions.

- Add connection to place at three scales, urban, building and detail to allow for multiple relationships to the designed spaces. 


\subsection{SOCIETAL, SCIENTIFIC AND PRACTICAL REVELANCE}

Many of New Zealand's old town buildings along the river banks were designed to face the river as that was the mode of transport. Due to the automobile the main street then turned to face the city. Leaving little design through to the connection between the city and river. Today with times changing the buildings again have the opportunity to turn around, as its proven people enjoy looking at rivers.

In the past it has often been found that the heritage quality wasn't seen as relevant until it was too late. There needs to be more understanding of how adding character adds connection to place. While designing more vibrant community spaces will bring the community together. There is no advice for building owners who have little knowledge of the work necessary or the cost of structural strengthening as well as retaining heritage detail. 


\subsection{METHODOLOGY}

A literature review will be completed to gain knowledge around the topic as well as what has been done before. This should then allow for more understanding of where more research could be undertaken.
Case studies will be used to learn from past retrofits of old recycled buildings. They collect qualitative data allowing the generation of quick design through precedential concepts. A variation of case studies gives the ability to create causal links between each study

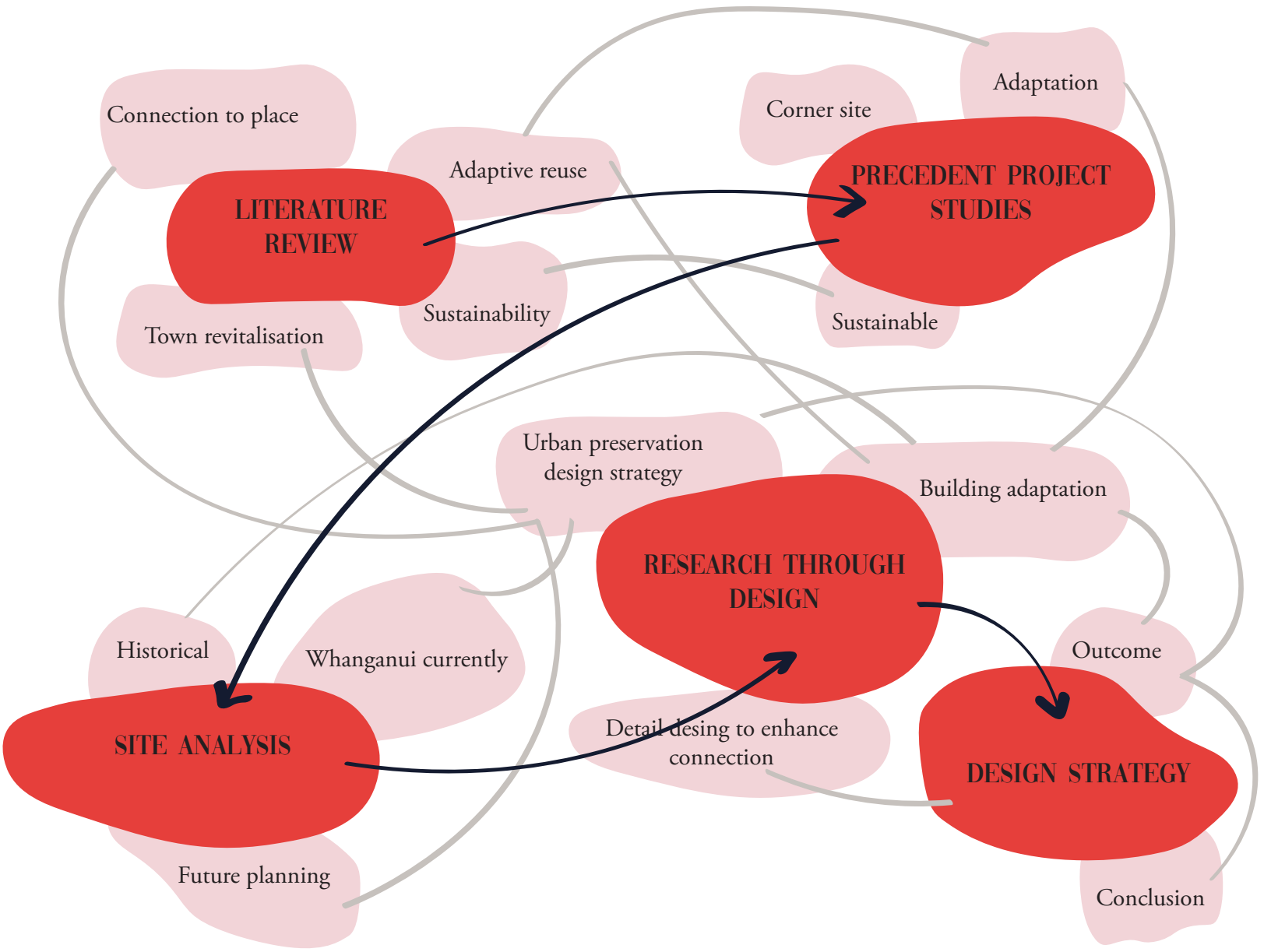

Fig. 1.05: Flow diagram of key topics. 
and they also have the power to generalize theory which will be useful for theory-based design. Case Studies allow a lot of detail to be collected which can't usually be attained by other research strategies. (Groat \& Wang)

Historical research is useful to extract evidence from a past time bringing into view an interpretation of that time. Advantages are you can learn from the past and it will allow for the investigation of topics which couldn't be studied in any other way. It could create more meaning within the design concept linking the design to the cities past.

Site analysis and the collection of relevant information, to initiate potential building uses within each building. Also through case studies and literature reviews to enhance the reasoning behind design decisions.

The design will inform the research through reflection and critique of the design work and assess the validity of using international precedents to inspire the adaptive reuse approaches in New Zealand.

The intended purpose of this thesis is to propose change within the four chosen buildings at the cross-roads linking the city to the river will be retrofitted to accommodate the need to revitalize our heritage cities. Through adaptive reuse the chosen buildings should provide more a necessary programme suited to the site itself through understanding its context.

The design needs to respect the cities past but also not be stuck in it, therefore a careful design strategy of possible solutions needs to be identified. A series of sketching, digital and physical modelling, and mapping to develop designs which will value the spaces will be carried out.

Hand drawing was used as a tool to gain a better understanding of the context of the site. The tool gives another perspective of depth and understanding of the built form.

The project will be informed by analysis of the existing site, historic importance and context, therefore cannot be replicated in another provincial city, however the same methodology could be repeated and used on other industrial sites. 
The design will be illustrated at three scales to create better connection at different levels for the users. The scales include designing at an urban scale, fitting within the surrounding context of the site. At building scale to create an adaptive reuse project to be use the building. Lastly at detail level to create a physical connection at human scale. All of these scales inform each other and creating a cohesive outcome which should be easily read.

\section{METHODOLOGY DIAGRAM}

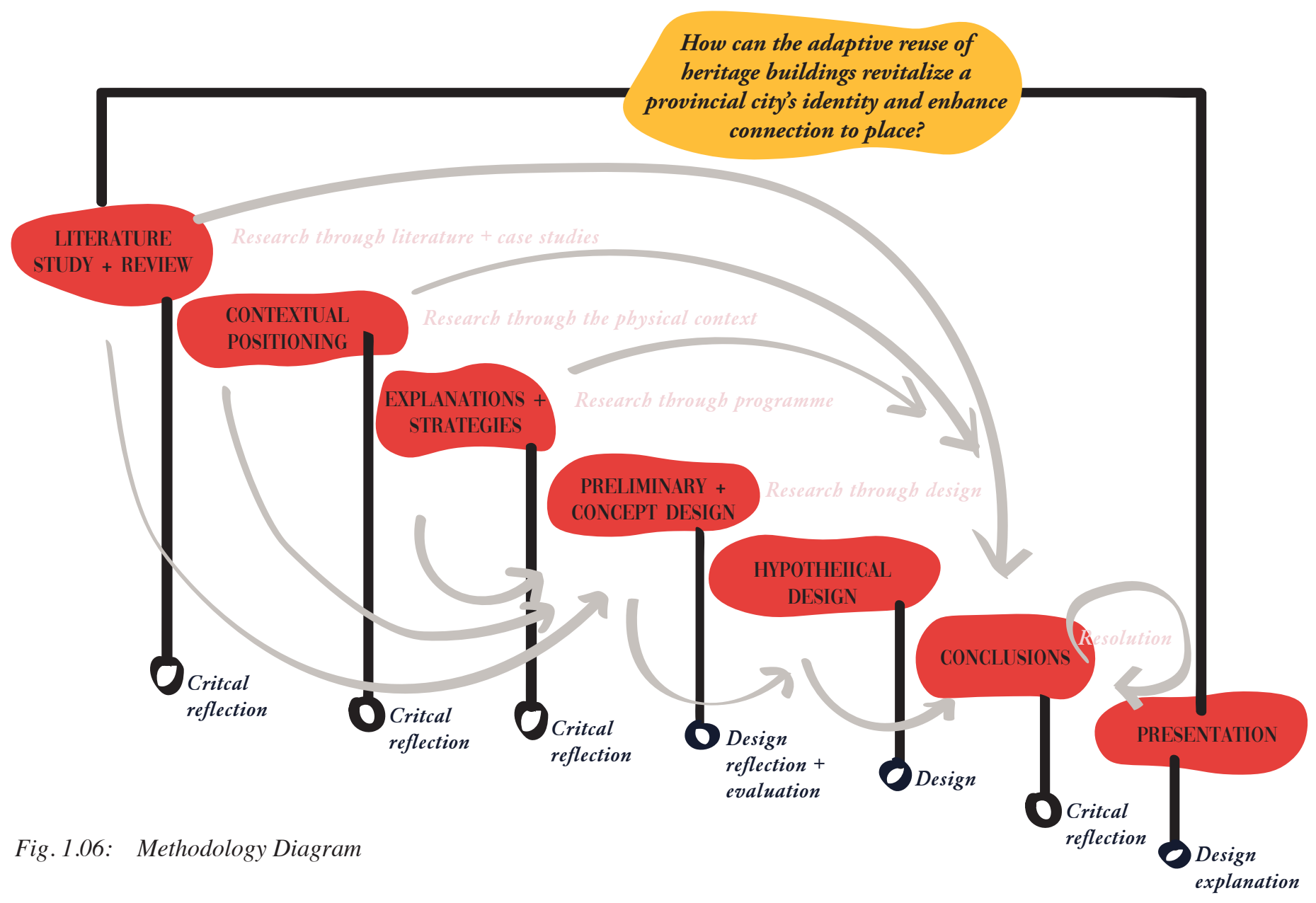




\subsection{ADAPTIVE REUSE}

Adaptive reuse is a broad term associated with the change in use of a space. However different theorists have different definitions for the term. Robiglio uses the definition
"The process of reusing an old site or building for the purpose other than what it was built or designed for."

This is the most commonly used definition of adaptive reuse (Robiglio, 2017).

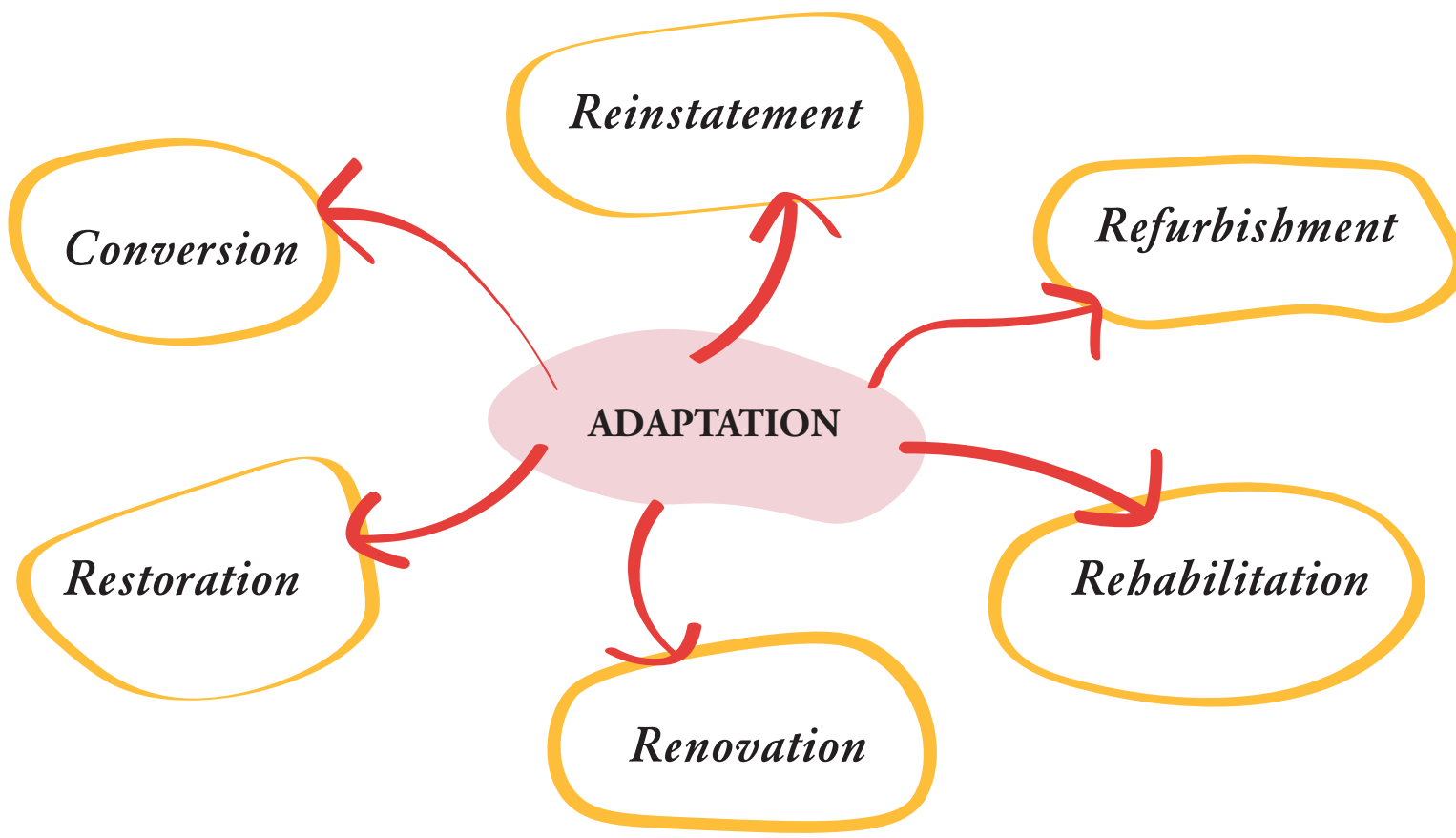

Fig. 2.07: Vocabulary surrounding adaptive reuse. 
Plevoets and Cleempoel state that adaptive reuse is the process of repairing and restoring existing buildings for new or continued use.

Today this approach is becoming much more common in architectural practice (Plevoets \& Cleempoel, 2019).Plevoets and Cleempoel believe it includes a physical and functional component, adaptive reuse is the most suitable term to name the discipline of working with existing buildings as an emerging field, that intersects the more established disciplines of architecture, interior architecture, conservation, engineering and planning (Plevoets \& Cleempoel, 2019). This thesis uses Plevoets and Cleempoel's ideas of restoraton, being a process of repair and restore of existing buildings which intersects the wide range of disciplines.

On the other hand Douglas in 'Building adaptation' describes adaptive reuse to include any work to a building over and above maintenance to change its capacity, function or performance (Douglas, 2006). Douglas also acknowledges the wide range of terms used around adaptive reuse, such as refurbishment, rehabilitation, renovation, restoration which are often misused. (Douglas, 2006)

Vocabulary surrounding adaptive reuse:

Renovation: can be defined as the improvement of a building to meet contemporary standards of comfort, safety, aesthetics and environmental impact. (Plevoets \& Cleempoel, 2019)

Adaptation: any work to a building that goes over and beyond maintenance to change its capacity, function or performance (Douglas, 2006).

Alteration: implies significant changes to the buildings use, aesthetics and possibly its function.

Remodeling: emphasizes the physical intervention to the building and as such, tends to describe strong architectural gesture.

Refurbishment: extensive maintenance and repair as well as improvements to bring it up to modern standards.

Rehabilitation: The process of making possible a compatible use for a property through repair, alterations, and additions while preserving those proportions or features, which convey its historical, cultural or architectural value. (Douglas, 2006) 


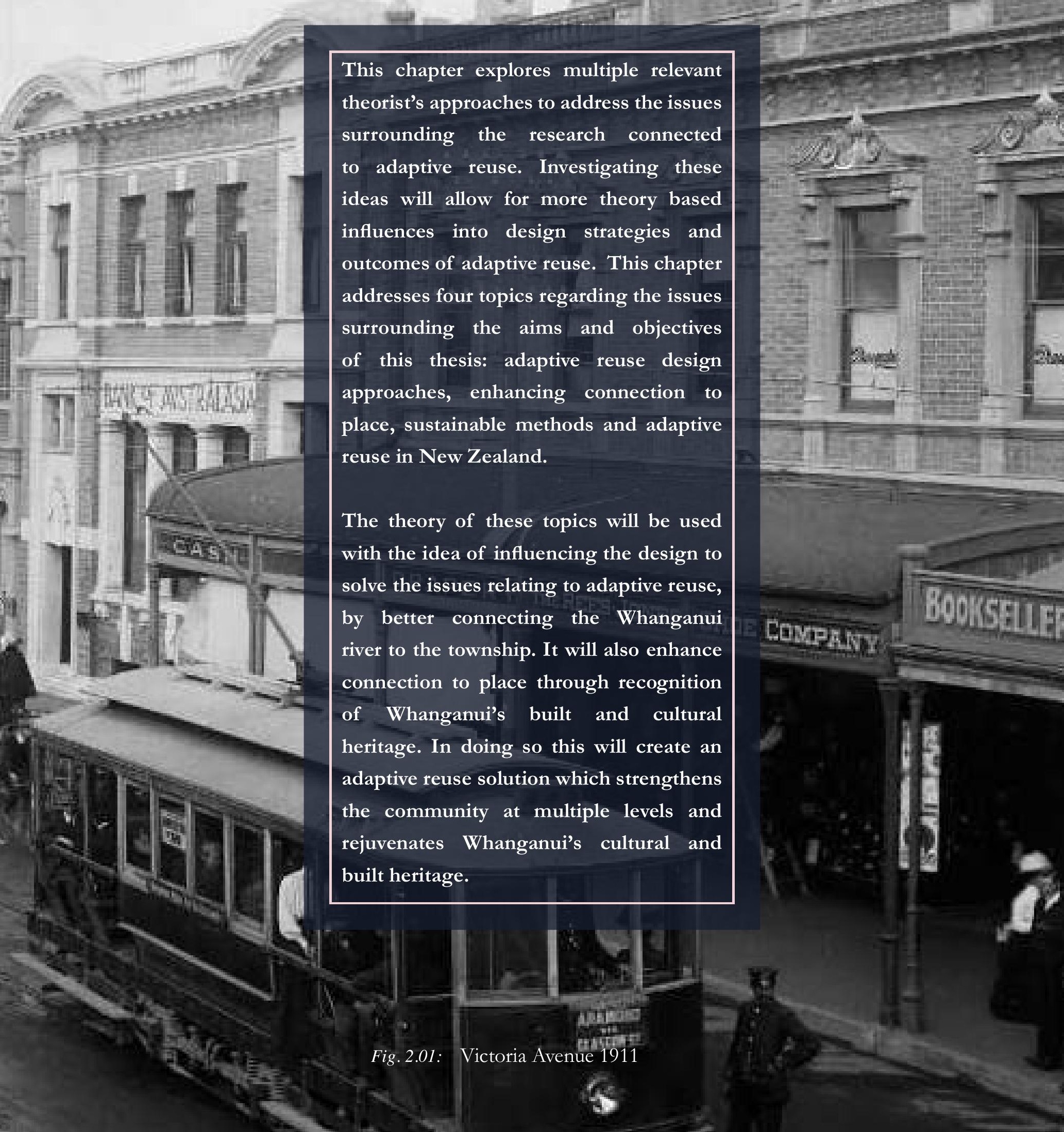




\subsection{ADAPTIVE REUSE DESIGN APPROACHES}

Adaptive reuse is becoming more of a common practice in architecture. Enabling better connection to place through design by using the existing layers of materials, history and narratives making the reuse more successful. When designing spaces through adapting or reusing it is always accompanied by the process of revaluation of its values and meanings. (Plevoets \& Cleempoel, 2019)

With all adaptive reuse projects there is a risk of the project failing, in figure 2.02, the graph shows the amount of risk associated with each level of intervention from basic maintenance to total reconstruction.

Reversibility is key to a successful adaptive reuse, to allow for the building to be reversed, to bring it back to its earlier condition. Today it is seen as both valuable and even necessary as technology is forever updating and therefore less intrusive designs could be created. (ICOMOS, 2013) 


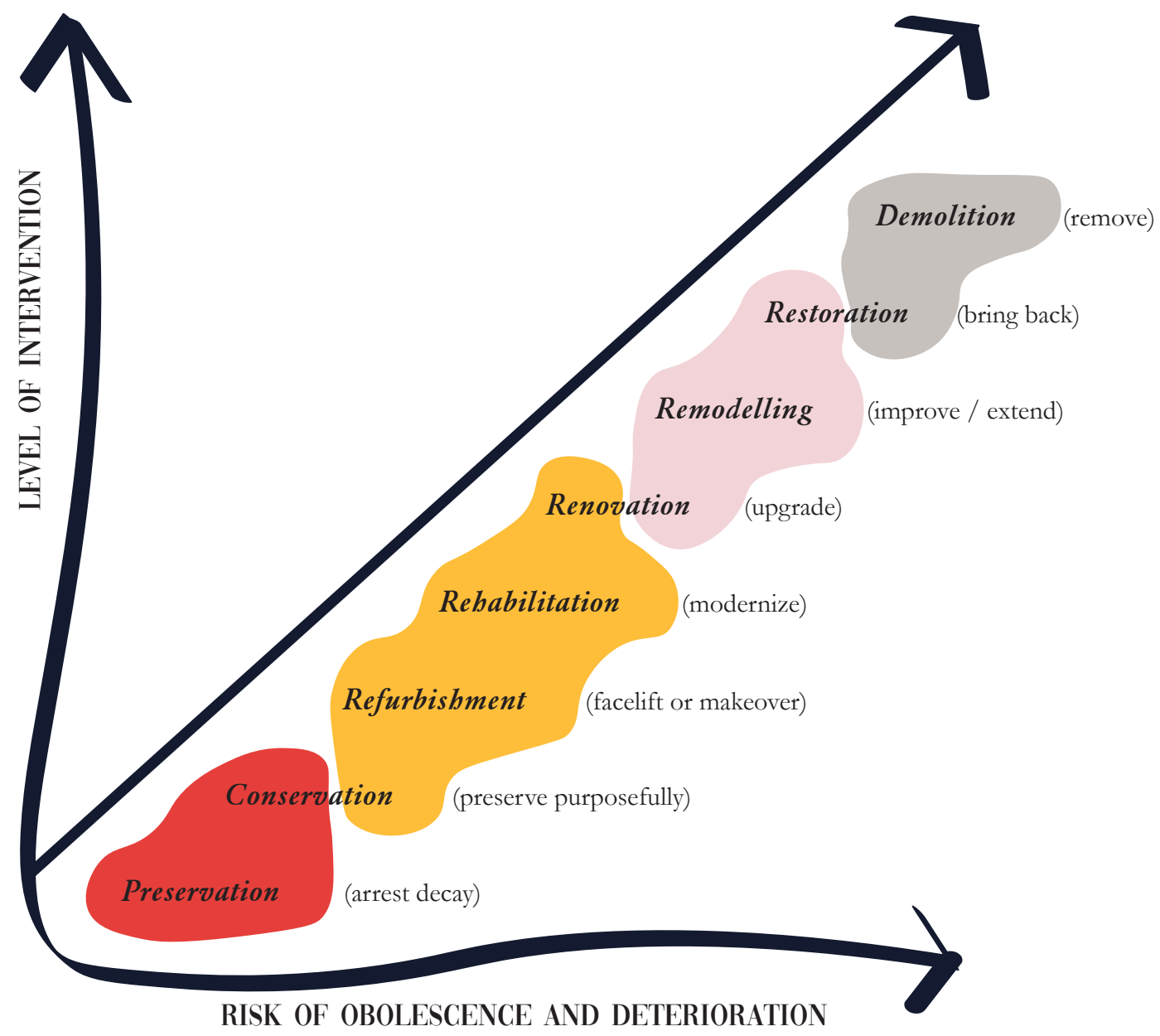

Maintenance basic adaptation

Stabilization strengthening and major improvements

Consolidation medium adaption and maintainence work

Reconstruction substantial rebuilding of part or parts of the building 


\section{Pbilosopbical considerations Policy articulated by client, conservation}

requirements, local policy.

Location Present and proposed location within the new scheme.

Dominance Relationship of building to other buildings and functions.

Site space required by the change in use.

Conservation Degree of the building being protected.

Significance Historical and architectural significance.

Condition The buildings condition and flexibility to change.

Scale size and form of the existing building.

Economics Viability, current asset value, value after adaption, costs in use.

Function Potential of facilities and services.

Legislation Building regulations, fire requirements, health and saftey, disability access.

Fig. 2.03: Things to consider around adaptation. 
Layers of history created over long periods of time can be used as an architectural design tool to allow different layers to be visible. Symbolic processes that can be reconstructed that will then leave representation that can inform the design's past creates a sucessful adaptive reuse (Plevoets \& Cleempoel, 2019).

Physical intervention is where a specific element of the chosen space, which could include building within, building over, building around, building alongside, recycling of materials or vestiges, adapts the building to a new function (Robert, 1989). Other words commonly used around the term intervention include, insertion, installation, addition, transformation, conversion, modernisation, adaptation, replacement, corrective maintenance, reprogramming, intervention, superuse, artifice and installation.

Aesthetic relationship is the visual connection that describes the relationship between the old and new, building in the style of either. (Robert, 1989)
Figure 2.03 lists some basic considerations around adaptive reuse. These give an overall representation of some of the considerations which could limit an adaptive reuse project.

Douglas James created a flow diagram of the relationships between the different factors needed to take into consideration in an adaptive reuse project. Figure 2.04 illustrates the relationships between the design decision making factors. 


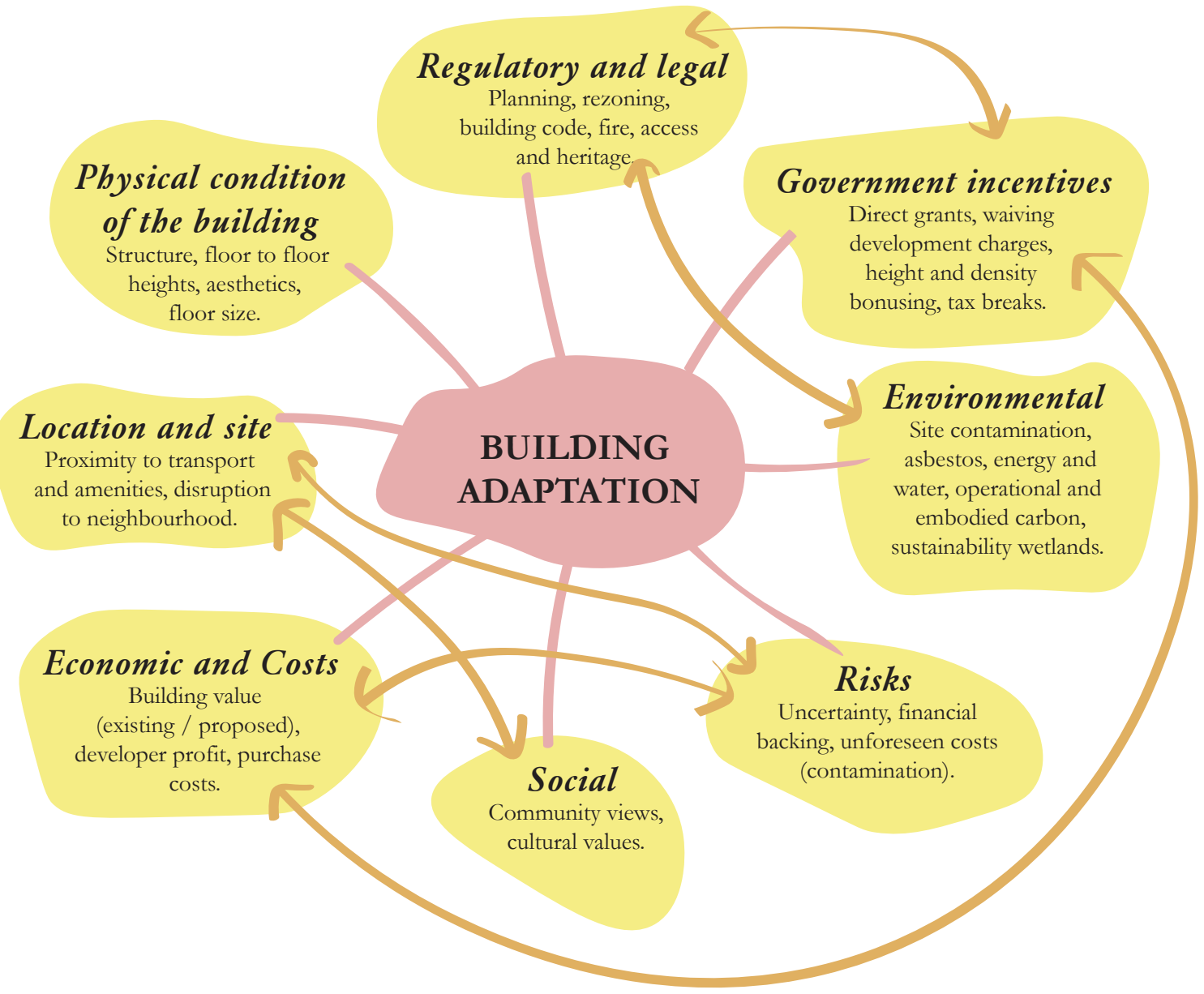

Fig. 2.04: Relationships of decision making factors in building adaptation from Fig 2.2 in the Sustainable building adaptation book. 


\subsection{THE ART OF COPYING}

Aemulatio - Copy and Improvement

To respect the historic and architectural significance of the adaptive reuse, a clear division between old and new is essential. Restoring a building is a highly specialised operation with a common aim to preserve and reveal the aesthetic and historic values of the building, respecting its original materials and historic documents (ICOMOS, 1964). New work, to places with cultural significance, should be readily identifiable as such, but must respect and have minimal impact on the cultural significance of the place (ICOMOS, 2013).

Over time many iconic adaptive reuse projects manifest the contrast between old and new, although in the past decade a new more poetic relationship with the existing building has been explored successfully. A relationship between old and new, which strives for similarity rather than contrast, incorporating the existing, hidden or lost qualities of the building and re-establishing them in a novel way. Using the buildings 'inner spirit' to build further into the 'interiority' of the space. (Plevoets \&
Cleempoel, 2019)

Translation is showing parallels to the act of restoration. Returning a place to a known earlier state by removing accretions or by reassembling existing elements without the introduction of new material (ICOMOS, 2013). Restoration is interpreted to bring a building from a past existence into the present. Imitation is a more liberal adaptation of the building which becomes a more selective restoration. Aemulatio is the aim of attempting to surpass the original aesthetically as well as functionally.

There are many reasons for different forms of adaptive reuse projects. Figure 2.05 exemplifies the common adaptive reuse functions and forms related through the flow diagram. 


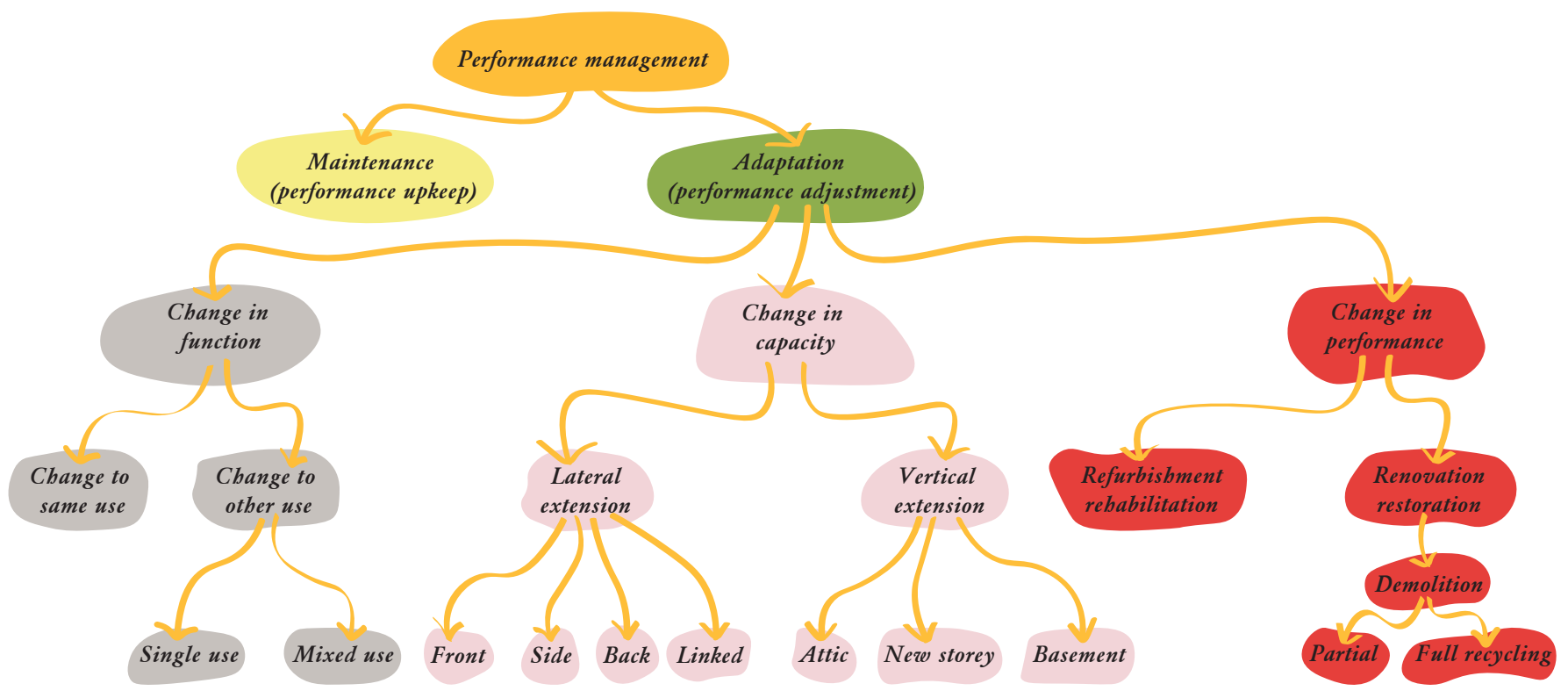

Fig. 2.05: Forms of building adaptation graph. 


\section{FACADISM}

Today facadism is a common term used in urban design. Traditionally it was used in urban conservation to describe the practice of preserving historic facades and the construction of new buildings behind it, or the creation of replicas or facsimiles of historical facades. (Plevoets \& Cleempoel, 2019) The facades can also be used to make new buildings fit in with the current streetscape. Although it has been heavily criticized due to it potentially causing the loss of the buildings integrity from a conservation perspective. A loss of the values captured within the fabric behind the facade and a facade that is left out of context. (Plevoets \& Cleempoel, 2019)

Retaining a historical facade may limit the opportunity for integrating contemporary architecture and may on a longer term lead to a process of 'disneyfication' of the historic core. It could also be seen as being a poor compromise between conservation and development towards a valuable strategy for adaptive reuse (Plevoets \& Cleempoel, 2019).
The facade as a vertical division of space can be considered humans' first invention to create an enclosure (Schumacher, 2002). Its design is about symmetry and balance, about the elevation of the centre and about maintaining the balance between blank wall and transparency. (Schumacher, 2002)

Due to technological advancements, the meaning of the facade as an architectural element may have been fully lost due to the invention of steel framing. This allows for large spans therefore the ability to design a wall which is entirely a window. (Plevoets \& Cleempoel, 2019). Facadism has been used as a strategy to improve a buildings functionality, aesthetics and urban performance (Plevoets \& Cleempoel, 2019). 


\section{REUSING THE RUIN}

Acknowledging the building's ruins as 'Beauty of decay' can be successful as an adaptation and reuse strategy. People have been intrigued by ruins for many years, but their underlying motives and reasons for their interest have changed over time. It was previously for its archaeological and historical values, but more recently its been more emotionally appreciated. (Plevoets \& Cleempoel, 2019)

The visible signs of aging is often described as imperfections as it is the most obvious due to its immediate emotional effect. Decay, patina, crumbling and overgrown by nature are all effects of aging.

A different notion arises when the decay is not the result of gradual natural processes but is caused by an abrupt natural disaster or violent destruction by man (Sulfaro, 2014). Ruins which represent a trauma, are not merely a trace of tragic memory, they also become a sign to transmit a certain message to the future. Such ruins may become a commemorative monument, a place for remembrance or forgetting. How they are dealt with also determines the particular message passed on (Plevoets \& Cleempoel, 2019).

A main characteristic of a ruin is that it is abandoned and often has no use, therefore an informal, spontaneous or utilitarian adaptive reuse project could be executed. They are not planned therefore user-led often require minimal intervention and also done in a step by step trial and error basis. 


\section{DEMOLITION}

"Deconstruction is the deepest form of adaptive reuse. When a whole building cannot be reused, there is still a way its components can." (ReUSA)

In some instances adaptive reuse has been proved to be a cheaper alternative to demolition and reconstruction. Demolition in general is an expansive wasteful, messy, disruptive and dangerous process that can cause a lot of nuisance and expends more energy and waste than adaptation (Douglas, 2006).

Depending on a building's state, it shouldn't require demolition, although it may need to be earthquake strengthened. If buildings segments need to be deconstructed, the materials could be reused to make the project sustainable.

There is a need to preserve the existing built environment, whether these are fantastic structures of great historical or cultural significance or simply old buildings that have merely outlived their original use. There is a common need to retain them. They are valued for their essential history, their intrinsic sense of collective memory, and the physical contribution they make to the built environment (Plevoets \& Cleempoel, 2019).

Today it is seen as unacceptable to just knock a building down and start again, but actually finding a suitable function for the building is not as straightforward as it may at first seem. They are often in the wrong place for contemporary needs, of an appropriate size and shape for modern life, and unsuitable for the dynamic exchange necessary within the digital age (Plevoets \& Cleempoel, 2019). 


\subsection{ENHANCING CONNECTION TO PLACE}

The aging of an object is considered to contain the greatest value, the wear, the discoloration over time and the tarnish that repeated contact with buman activity can produce, are the more pleasing characteristics. These cannot be created with a computer, constructed with an algorithm or manufactured in an offsite factory and shipped in. (Plevoets \& Cleempoel, 2019)

The appearance of age, especially within an existing building is created over time by repeated efforts of ordinary people, by the community who lived and worked in the particular situation and who infused the sense of life into it. (Plevoets \& Cleempoel, 2019)

Weathering also contributes to the sense of value, the rain and win of the harsh winters or the relentless heat of summer tarnish the building. While other factors that contribute to the deterioration and decolourization that age bestows are pollution, contamination, and the carelessness of previous ages. Thus the wear and tear of many years of abuse imparts a great authenticity to the place. (Plevoets \& Cleempoel, 2019)

All existing buildings contain that sense of yearning for a time or place that is just beyond immediate memory. A move away from the artificial towards the real, the genuine, hand crafted rather than factory produced, towards things that contain character and worth rather than the anonymity of mass production. in a world of false truths and easy access to unlimited information, reality is highly prized. (Plevoets \& Cleempoel, 2019)

'Cultural heritage is today a key driver for urban regeneration in many historic towns and regions all over the world. Urban regeneration occurs through the functional use and reuse of historical buildings and sites but also as a means to create or strengthen a sense of 
local identity and enhance public well-being and social inclusion'. (Plevoets \& Cleempoel, 2019)

Buildings could be considered as a physical embodiment of cultural memory and historical narratives in terms of their conditions and materiality. (Fernandez-Galiano, 2000) Providing traces of our past in some cases it is hard to achieve the standards required in old existing buildings like air quality, acoustic and thermal performance requirements, fire safety and accessibility which often limit the extent of adaptation. (Langston et al., 2008)

The retention of places with 'cultural significance' has become an important consideration, and this significance impacts not only what is retained, but also how it is retained and what new, compatible uses can be accommodated. Where a building is considered significant, contemporary conservation policies describe compatible uses as those involving changes that require minimal impact to the significant fabric or ones where the changes can be substantially reversible (Australia ICOMOS 1988)

Graffiti, a marker of time as a derelict site, can be preserved. This represents an attempt to avoid the erasing or obscuring of the layers of the past. Retaining these layers from the past, no matter how 'ugly', helps to communicate the full life of the building, and in so doing, add to its value to society. (Douglas)

Buildings are valued for their essential history, their intrinsic sense of collective memory, and the physical contribution they make to the built environment. 


\subsection{SUSTAINABLE METHODS}

\author{
'The 'adaptive reuse' not only extends \\ a building's life, but also provides the \\ potential to improve its environmental \\ performance and usefulness - thereby \\ increasing its value (Ward, 2012).
}

The recycling of a building improves its value, use and performance. Adaptive reuse provides the opportunity to reduce the overall amount of energy consumed, to cut the amount of waste generated in construction and also to decrease the amount of operational energy used in an existing building by improving its environmental performance (Ward, 2012).

Life expectancy is an extensive issue with our built environment, as many buildings today are not built to last. 'A buildings longevity is dependent on many factors including the components of which it is assembled, its 'build quality', flexibility to accommodate change in use, its location and the maintenance undertaken. External factors like rapid development in technologies as well as economic, social and political factors are hard to predict and all have an effect on buildings life expectancy (Ward, 2012).

Today there is a need to consider alternatives to new build projects as there is widespread recognition that the construction industry has a significant impact on economies and the environment. Construction and demolition waste makes up half of New Zealand's total waste going to landfill and each home construction generates an average of four tonnes of waste. A study done in Auckland found that construction waste is made up of timber $(20 \%)$, plasterboard (13\%), packaging $(5 \%)$, metal (5\%), and other (45\%) (Material waste).

It is common practice to measure the energy consumed by buildings as the amount 'embodied' in their materials and construction, and the 'operational' energy consumed in their use. It is the 'net energy' of the building that provides an overall indication of its environmental impact. The net energy is determined by its combined embodied and 
operational energy as well as its longevity. Therefore the longer a building lasts, the less its relative environmental impact (Ward, 2012). As industrial buildings are being left empty due to rapid advances in technology, changing consumer behaviour, the availability of labour and economic impacts these buildings have earned themselves their own terminology, often referred to as 'vips' (vacant industrial premises) or 'brown buildings' an adaption of the term 'brown field site' used to describe neglected and often contaminated industrial land.

Rick Ball (2002) noted that many of the old industrial buildings occupied prime and central locations compared with later development. Owing to their original functions, their occupation of sites such as waterfronts is seen as both desirable and valuable.

Recycling is one strategy to minimise the amount of construction waste, although there has been a slower uptake of recycling in construction compared to other industries due to the cost and energy associated with sorting and cleaning. The disposal of wastewater, the separation of materials without damage, the need to exclude foreign materials impairing performance, and doubts about the performance standard of recycled materials.

The building's performance is not dependent on the building alone, but also the services and occupants within that building. Changing the use of the building provides opportunity to 'retune' it. When heritage and cost are constraints limiting major alterations to the building envelope, some strategies to improve thermal efficiency include, the introduction of a thermal labyrinth for pre-cooling of supply air and radiant heating as an alternative to the conditioning of the large volume.

At a larger scale one way to reduce energy consumption and pollution is through compact cities and urban containment. Adaptive reuse can also contribute to the development (and retention) of skills and knowledge at a local level. When old buildings are conserved, careful repair and reconstruction is required. This work usually uses traditional skills and locally sourced materials and can be labour rather than material intensive. 


\subsection{ADAPTIVE REUSE IN NEW ZEALAND}

There are few examples of retrofits of buildings written about in New Zealand, although the paper 'An evaluation of successfully seismically retrofitted URM buildings in New Zealand and their relevance to Australia' evaluates the true success of existing retrofits in terms of seismic design, architectural appeal, heritage preservation, economic viability and observed performance which will provide good criteria to follow (Dizhur \& Ingham, 2017).

Kiroff and Tan wrote a paper at the Institute of Technology in Auckland providing 'The foundations for an overall integrated approach to adaptive reuse' providing the factors which need to be considered when implementing an adaptive reuse policy as part of a sustainability strategy (Kiroff \& Tan, 2015).

For the research of this thesis the use of international case studies in chapter four has been used to allow us to look at quality adaptive reuse projects from across the globe as New Zealand heritage is only recent history.
"Building conversion nowadays has been influenced by the ever-increasing demand for residential and commercial space." (Douglas, 2006).

Building conversions aim for economic use of materials, space, energy and a better utilization of the infrastructure, while also having the added benefits of shorter construction time, a safer and sustainable building site and reduced down time from inclement weather Although the ongoing maintenance costs of an reuse project would usually be higher than a new build project. (Douglas, 2006)

It could be considered to be a greater employment generator in comparison to new construction, as the work is generally more labour intensive requiring 25\% more employment per square meter of floor area that new builds.(Wilkinson et al., 2014) The adaptation of existing buildings offers sustainable long term social benefits architectural, cultural and historic aiming to suit the ever-changing community. Demolishing 
an old building can now be seen as eradication of local identity, cultural heritage and socioeconomic values. (Cramer \& Breitling, 2007) Communities continue to recognise that future generations can profit from the conservation of heritage buildings through addressing the ever-increasing demand for properties and land. (Douglas, 2006)

It cannot be assumed that adaptive reuse projects naturally lead to improved social sustainability, gentrification of some sites, although successful in the physical regeneration of previously underused areas, can exclude people or segments of society who may have previously lived or worked there. 


\subsection{PRINCIPLES FOR ADAPTIVE REUSE}

Based on the undertaken literature review it is possible to identify a set of key principles to consider when undertaking this adaptive reuse project, which are introduced here and then summarized in a checklist.

To gain an adaptive reuse approach which has been well designed and suits the needs of both the community and built environment a broad range of strategies should be simultaneously considered. These include conservation, the art of copying, facadism, reusing the ruin, and at the very least demolition are among the strategies discussed all to facilitate a more successful relationship between the user and designed adaptively reused space.

By creating a better connection to place the strategies identified from the literature include identifying and retaining any appearance of age which builds upon collective memory and strengthen a sense of local identity. While also reducing the stigma of it being hard to achieve current building standards in old existing buildings through adaptive reuse.
Standards consist of air quality, acoustic and thermal performance requirements, fire safety and accessibility which often limit the extent of adaptation.

When designing sustainable methods should be considered as they have the potential to reduce the amount of building waste generated or reuse elements of the existing built environment.

The main challenges surrounding adaptive reuse are the planning restrictions set by the council, the cost as many who do not believe in the benefits don't see it as an justifiable option. The earthquake strengthening of this building is also a very common threat to architectural heritage as all buildings built before 1970 are looking to be needing strengthening. Circulation, natural lighting and thermal performance are all common issues when using an existing building and changing its use. With well thought out programming and design these design issues can be mitigated. 


\section{CONCLUSION}

The discussion and design that follow aspire to respond to the reviewed literature and especially to the key principles established through this literature review and discussed in section 2.5.

An checklist for adaptive reuse considerations were also conducted to address if adaptive reuse is a possible solution to revitalize a chosen building. The elements on this checklist should be conducted to gain a thorough understanding of the risks and possible outcomes. 


\section{CHECKLIST FOR ADAPTIVE REUSE CONSIDERATIONS}

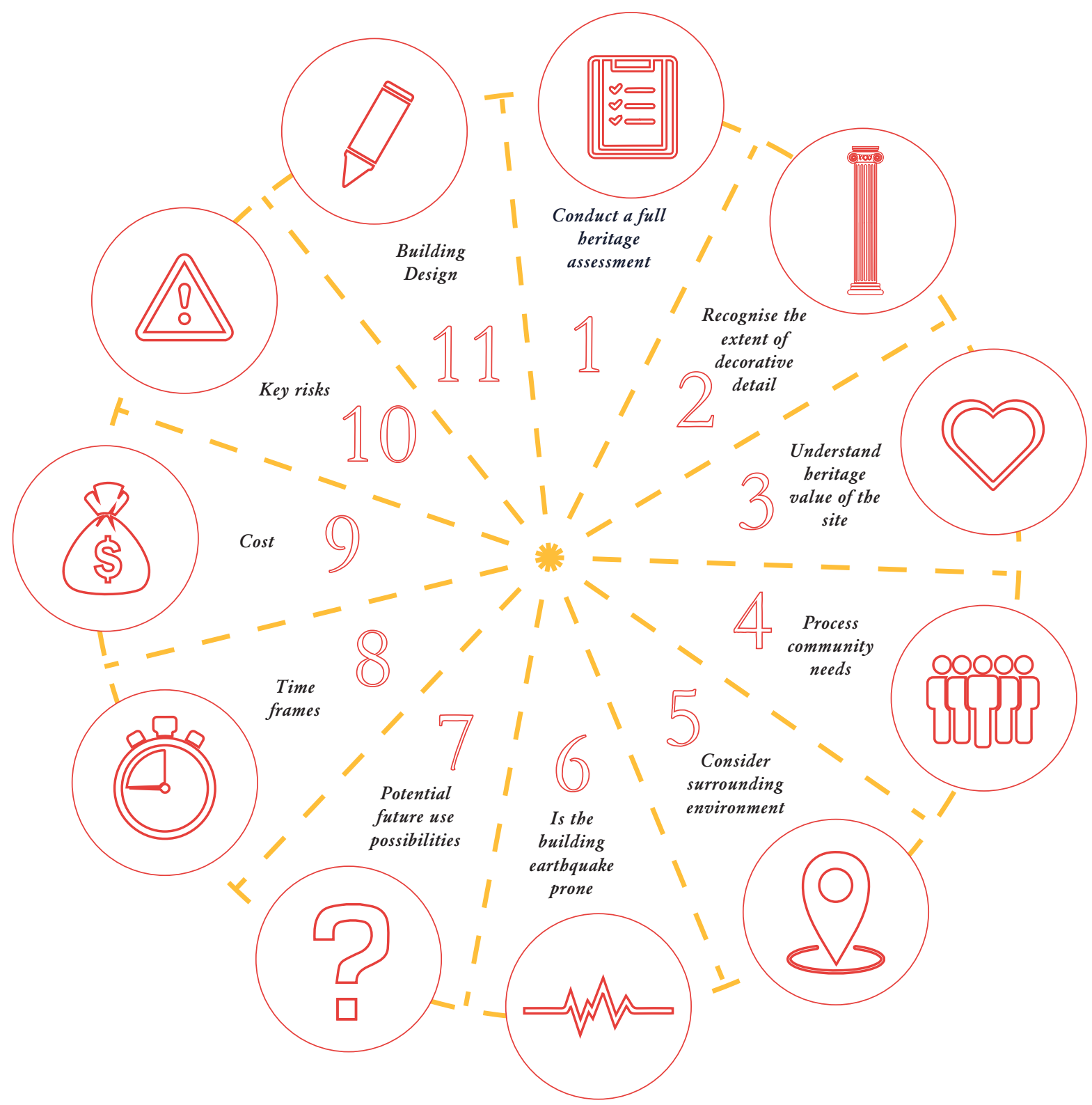

Fig. 2.06: Checklist Considerations. 


\section{CONDUCT A FULL HERITAGE ASSESSMENT}

- Conditions of integrity and authenticity.

RECOGNISE THE EXTENT OF DECORATIVE DETAIL

2

- Solution being able to consult an regional heritage specialist.

UNDERSTANDING HERITAGE VALUE OF THE SITE

- Is this a flagship building featuring an architectural style that needs to be retained?

\section{PROCESS COMMUNITY NEEDS}

- Who to consult with: public, iwi, council, families, schools, experts in the field or enthusiasts.

5

\section{CONSIDER SURROUNDING ENVIRONMENT}

- Has character been retained in the neighbourbood?

IS THE BUILDING EARTHQUAKE PRONE?

- Cost and will it change the historic integrity of the building.

\section{POTENTIAL FUTURE USE POSSIBILITIES}

- Options, Mixed use, creating connection to place. Encourage first floor residential where possible.

\section{TIME FRAMES}

- Achievability, objective achieved, statutory compliance, strategic fit.

\section{COST}

- Project funding

\section{KEY RISKS}

- Archaeological,Ground conditions, Asbestos / Lead paint, Access to site, Party walls (surrounding site), Lack of info on existing buildings

\section{BUILDING DESIGN}

- Building core, Circulation, Natural light, Services, Fire safety design, Building code requirements, Accessibility, Connection to place, Structural requirements, Architectural features, Character / style 


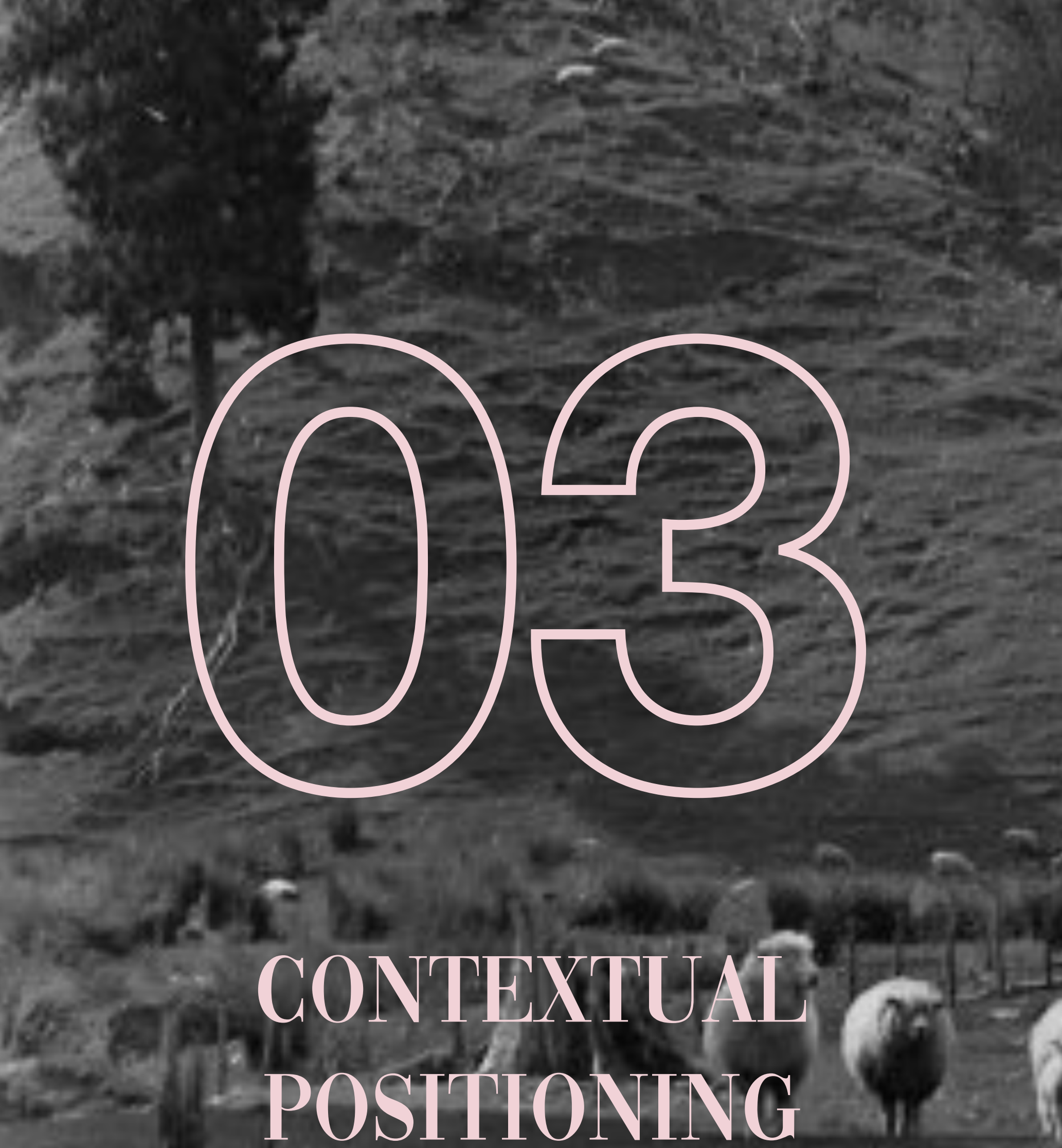


In order to understand how to apply the information acquired through the literature review on the context, it was very important to do an analysis of the context and start positioning the project in relation to the chosen context.

Some explorations of the context, of the site, potential for the design iterations were undertaken in this chapter.

Within the contextual positioning chapter, there are two main explorations which have been explored through the analysis of existing and historic buildings . 


\subsection{BUILDING FORM}

In order to understand how to engage and work with heritage architecture its best to understand their architectural characteristics to retain the character of the existing building.

Heritage decoration includes any additions to the facade which adds detail beyond the structure. This is some of the more common decorative features which add heritage integrity if used appropriately.

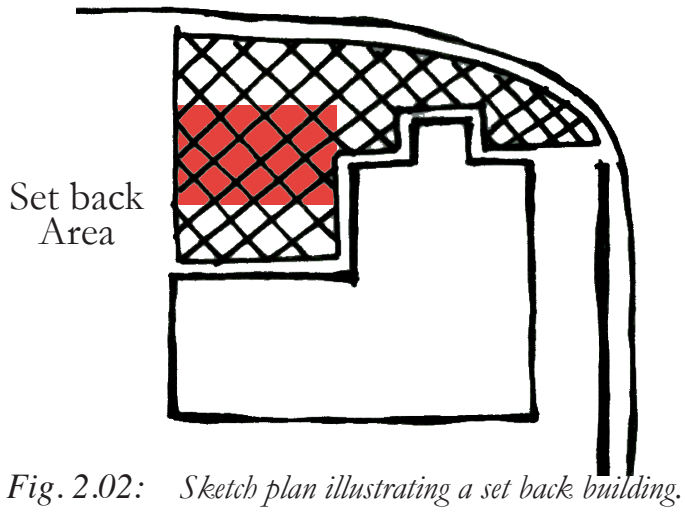

$\underline{\text { Set backs vs no set backs }}$

Setbacks are usually used in architecture as the recession in the profile of a larger building allows more sunlight to reach the lower floors or streets below.

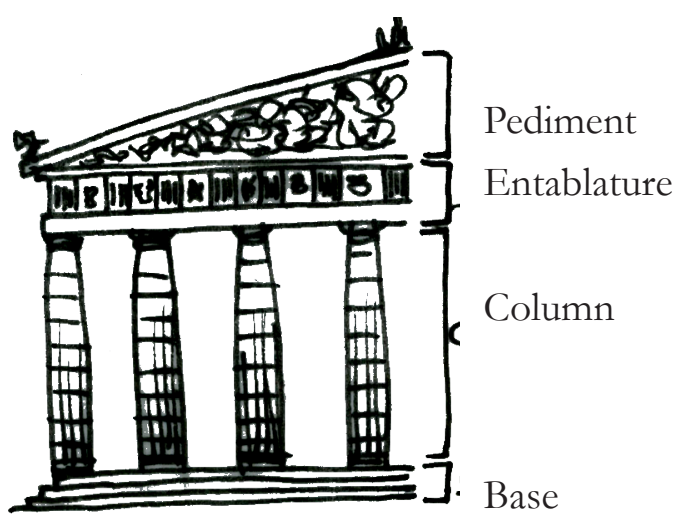

Fig. 3.03: Decoration features of a arcbitectural styles.

\section{Pediment}

The pediment is an architectural element found particularly in classical, neoclassical and baroque architecture, and its derivatives. Consisting of a gable, usually of a triangular shape, placed above the horizontal structure of the entablature, typically supported by columns. 


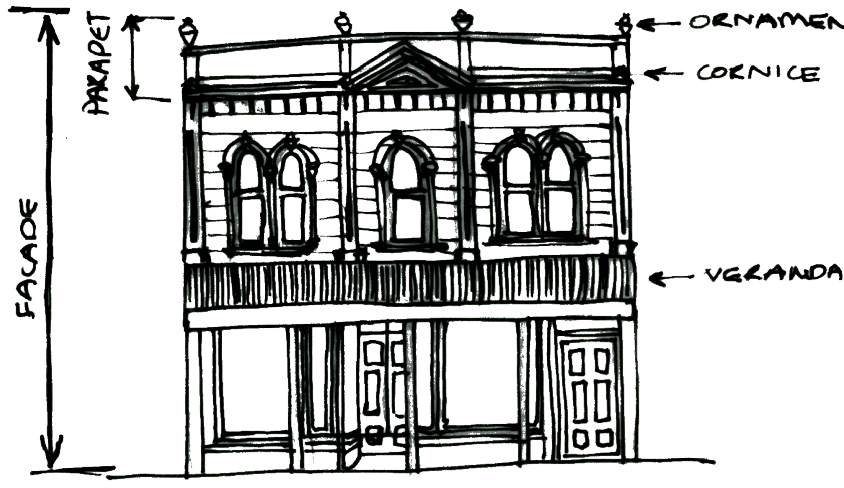

Fig. 3.04: Street facade and its terminology.

\section{Parapet}

A parapet is a low wall projecting from the edge of a platform, terrace, or roof. Parapets may rise above the cornice of a building or form the upper portion of the wall.

\section{Verandah}

In architecture, most frequently, an openwalled, roofed porch attached to the exterior of a domestic structure and usually surrounded by a railing.

\section{Windows}

Translucent view points from the building interior through the facade. Often placed symmetrically creating the facade with detailing surrounding them to accentuate the windows.

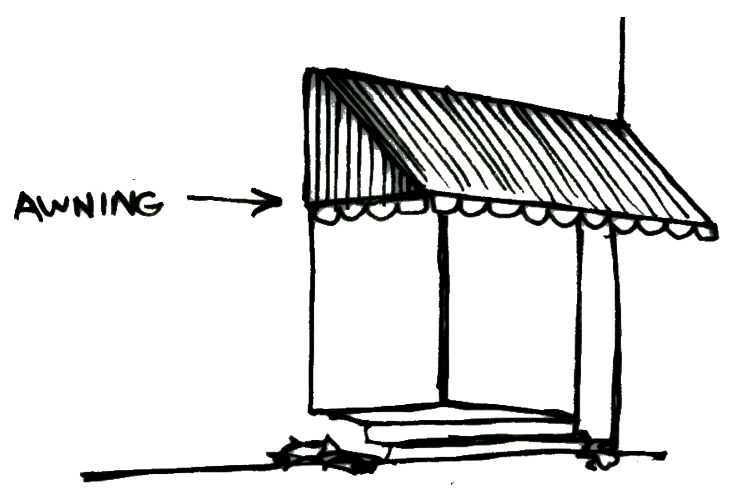

Fig. 3.05: A canopy creating shelter for the building users.

\section{Awning}

An architectural projection that provides weather protection, identity or decoration.

Having a better understanding of heritage decoration and terminology around facade design helps to recognise the architectural detail. These are commonly stripped over the buildings lifetime. By adding or removing certain elements from a buildings facade, the building's form can become disproportionate.

In reflection of understanding elements of the architectural decoration on the building facade, it illustrates the elements which are often first to be removed. 


\subsection{CORNER BUILDING ANALYSIS}

Figure 3.06 shows an analysis of the existing corner buildings located up Victoria Avenue in Whanganui's early days. They illustrate the proportion, placement of windows and also the architectural detail making them prominent buildings.

Figure 3.06 uses the colours and lines to graphically show the buildings form and scale. The glazing, floor levels, extrusions and decorations have been overlaid to create the imagery on top of an old photograph. This demonstrates the extent of detail, character and prominence the buildings had previously exhibited. The visual importance of these corner buildings are heightened as it takes up more footpath's footprint than a regular building. 


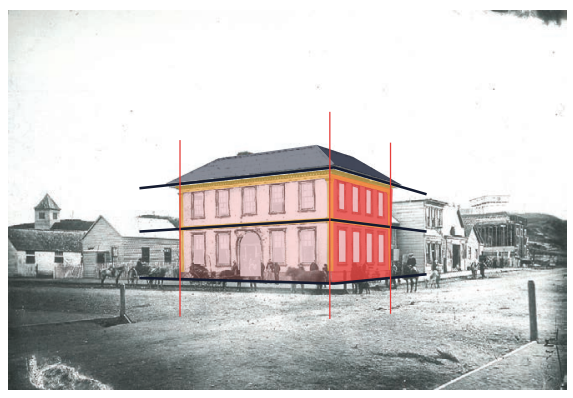

Victoria Avenue / Ridgeway Street

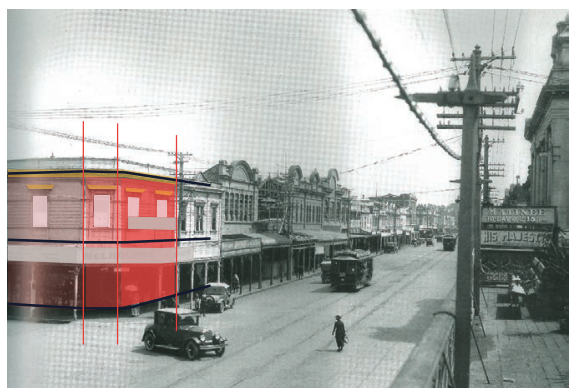

Victoria Avenue / Maria Place

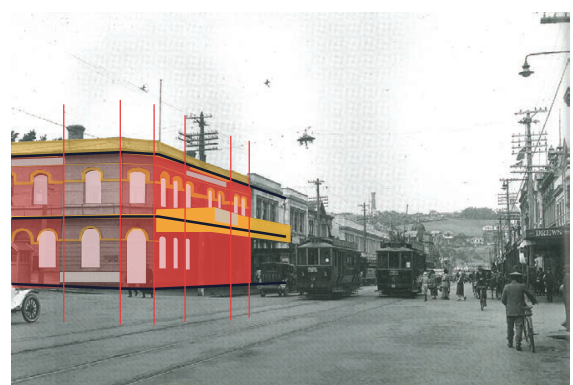

Victoria Avenue / Maria Place

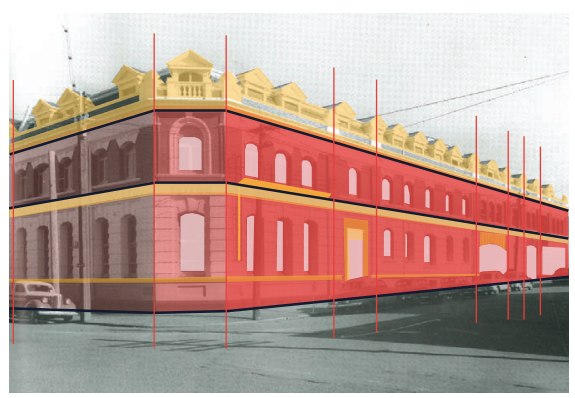

Taupo Quay / Hill Steet

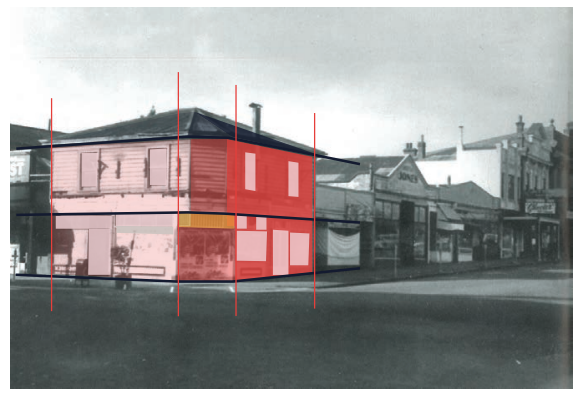

Victoria Avenue / Guyton Street

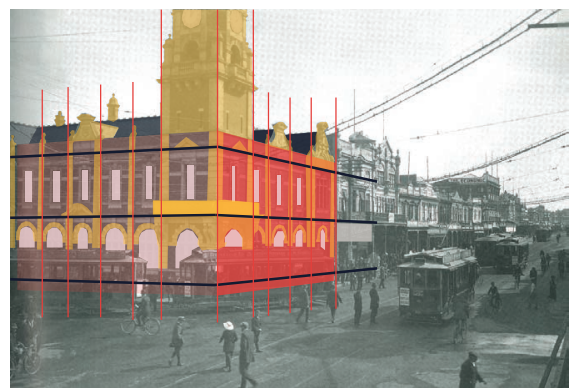

Victoria Avenue / Ridgway street

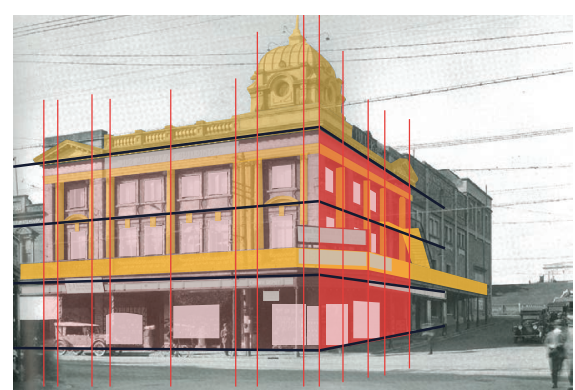

Victoria Avenue / Majestic square

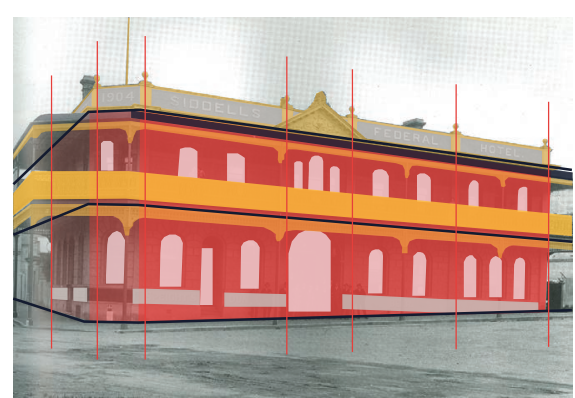

Taupo Quay / Market Place

Fig. 3.06: Corner building facade analysis shown through lines and colours. 


\subsection{COMPARISON IMAGES}

These comparison photos of Whanganui's past and present, better illustrate how architectural detail has been lost over time.

Elements of the buildings in Figure 3.07 which were removed include the parapet, pediment, turrets, verandahs, awnings and cornice detailing. This was due to the need for earthquake strengthening after the Napier earthquake in 1931, therefore reducing the risk if collapsing.

The main reasons for these buildings appearances to change is due to structural stability but also a buildings change in use with little consideration of aesthetic style.

Figure 3.07 also emphasizes how the car has taken over the street. In the future a more pedestrianized design again in the future will create a better community development.

The structural elements have not been lost over the buildings lifecycle but the facade detail has been lost.

Fig. 3.07: Historic and current images of Victoria Avenue illustrating the heritage detail lost. 

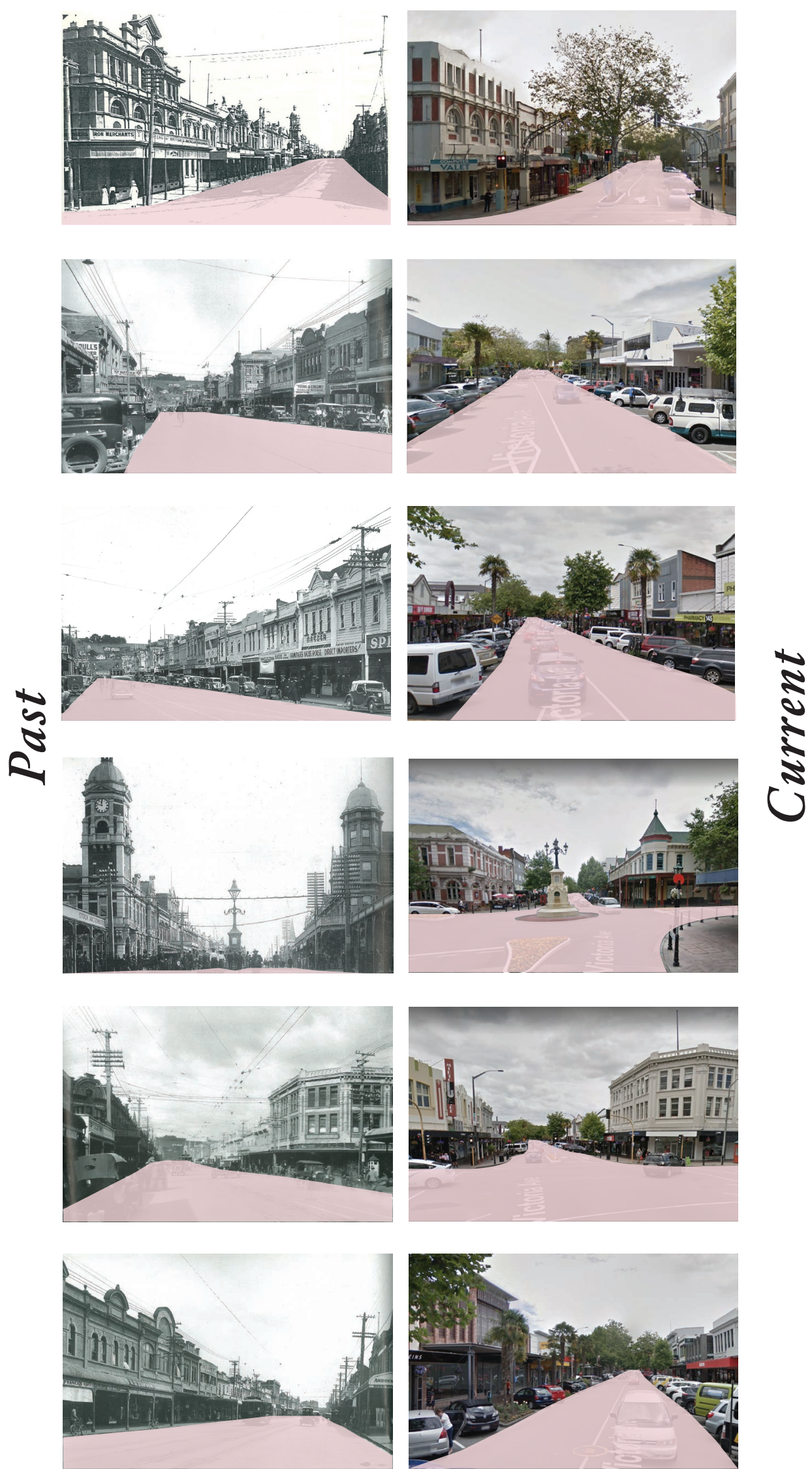


\subsection{VICTORIA AVENUE HERITAGE ANALYSIS}

In order to understand the total context of heritage buildings in Whanganui, analysis is done on what existing heritage buildings are and where they are located as well as the context between them.

Figure 3.08 is an analysis map of Whanganui indicating the different periods of which these buildings were built, showcasing the large range of building periods all located in close proximity up Victoria Avenue. Building heights are typically $2-3$ stories.

While sometimes the facades are still in contact with the adaptive reuse term of Facadism. The buildings behind them are often corrugated iron tin sheds, which are cheep to construct making the buildings feel fake.

Many of the buildings still have their façades, many in a some what in a reversible state. The large variety makes Whanganui unique and its especially evident looking down Victoria $1911-1915$ Avenue.

Fig. 3.08: Diagram illustrating heritage buildings and their period on the main street. 


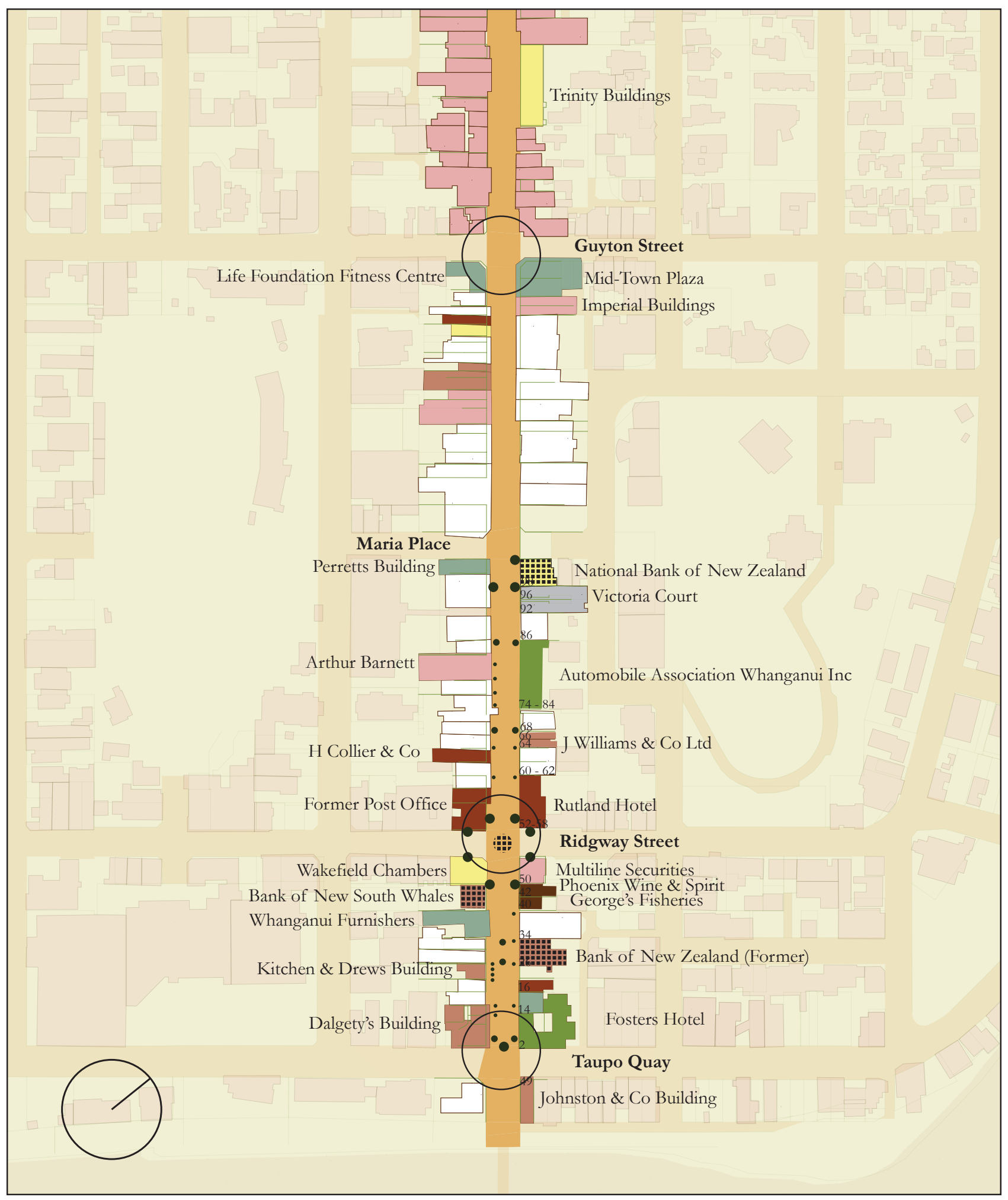


Figure 3.09 illustrates the street elevations. These have been sketched to exhibit the variety of architectural styles within one cross road. As can be seen in Figure 3.09, Moutoa Quay, the waterfront, has little architectural style compared to the building front facades on Taupo Quay.

Fig. 3.09: Elevation sketches of the street scape. 


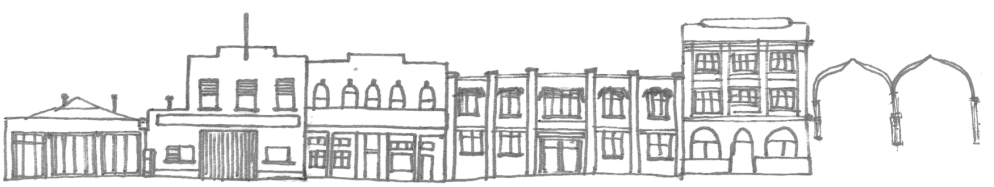

Taupo Quay

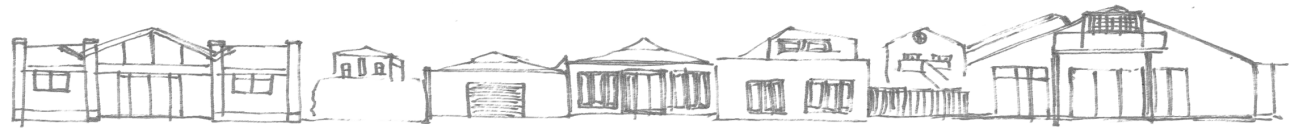

Moutoa Quay

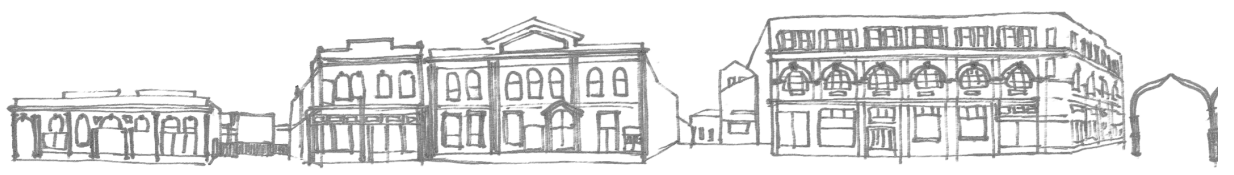

Taupo Quay

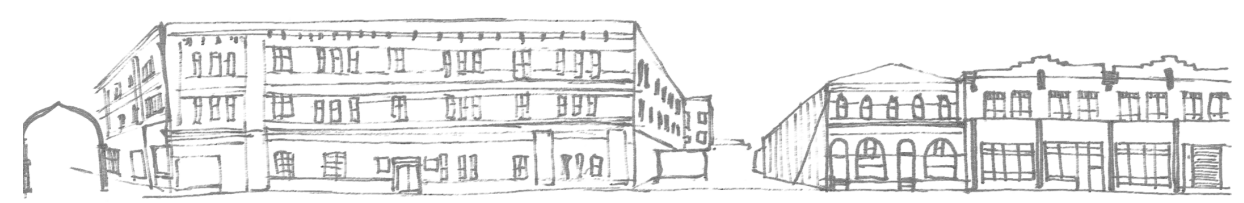

Taupo Quay

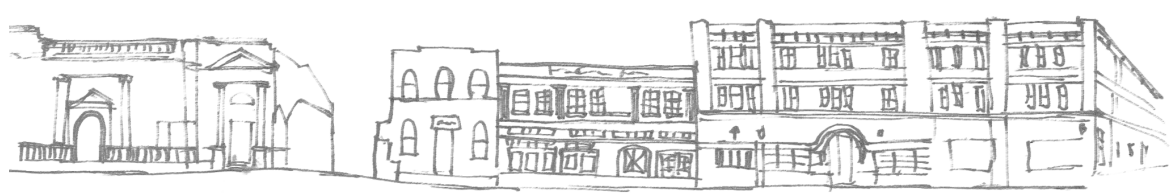

Victoria Avenue

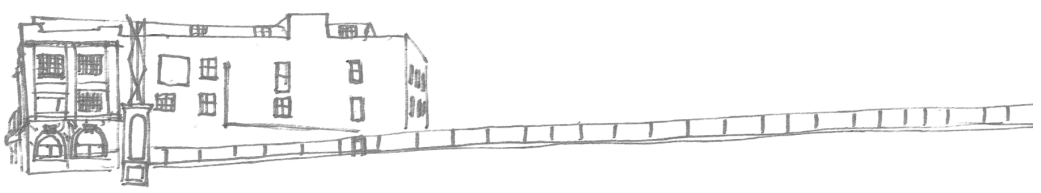

Whanganui city Bridge 


\subsection{HISTORIC CROSS ROADS SKETCH ANALYSIS}

These sketches were done of the main cross roads up the street when analysing the main street of Whanganui, Victoria Avenue. The main finding of these sketches was that the Ridgeway / Victoria Avenue intersection was a lot better kept in terms of heritage integrity. Whereas the Taupo Quay / Victoria Avenue intersection had not only largely lost its connection to the river but also the decorative features making these buildings iconic.

The Taupo Quay sketches show these buildings need some care and attention with architectural thought to bring people into the buildings and site, as well as integrate a better connection with the river.
Figures 3.11 - 3.14 illustrates the current corner façades on Victoria Avenue. They are showing context of the existing character of the site but also represents façades which have had both their style and architectural detail looked after and stripped.

The use of the sketches to draw what is seen has given a different perception on the detail of the Victoria Avenue street facades. You begin to understand the depth of the detail within each of the building facades. 


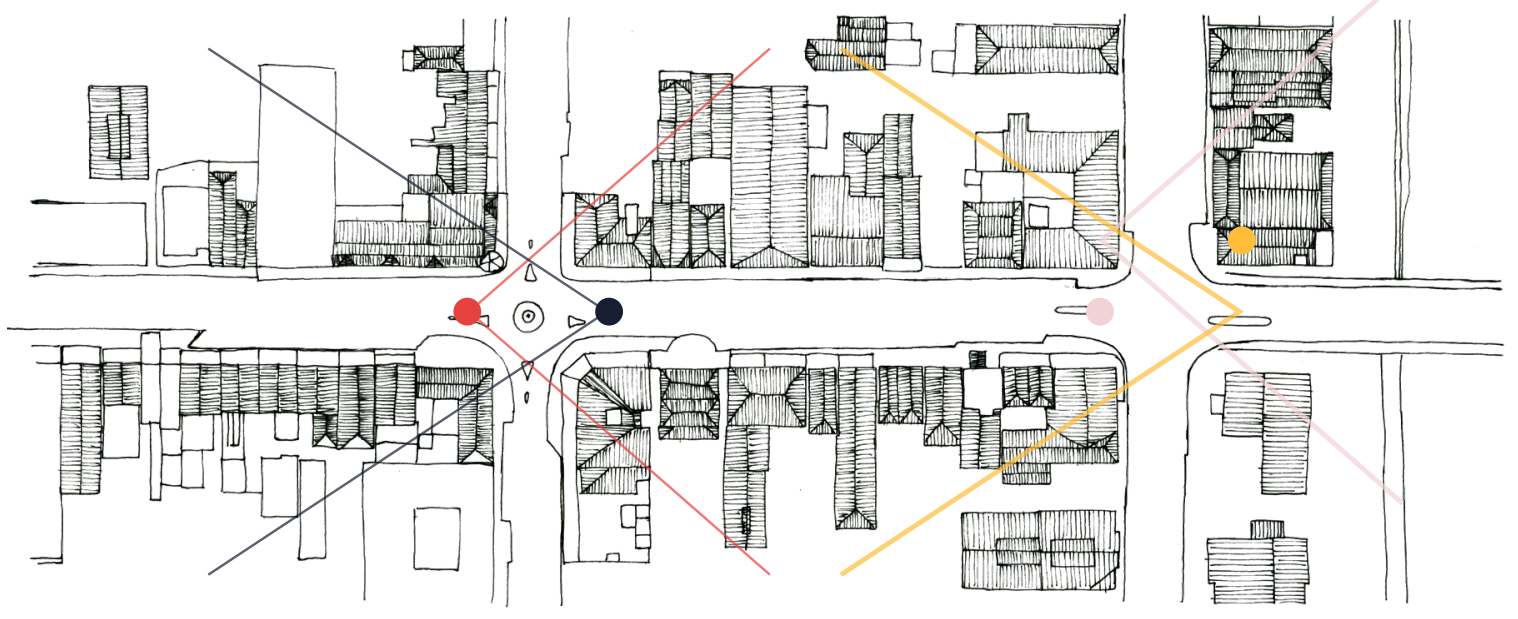

\section{Ridgway Street / Victoria Avenue}

South East Cross-Roads Persepctive

North West Cross-Roads Perspective
Taupo Quay / Victoria Avenue

South East Cross-Roads Persepctive

North West Cross-Roads Perspective

Fig. 3.10: Victoria Ave plan sketch. 


\section{Ridgway Street / Victoria Avenue}

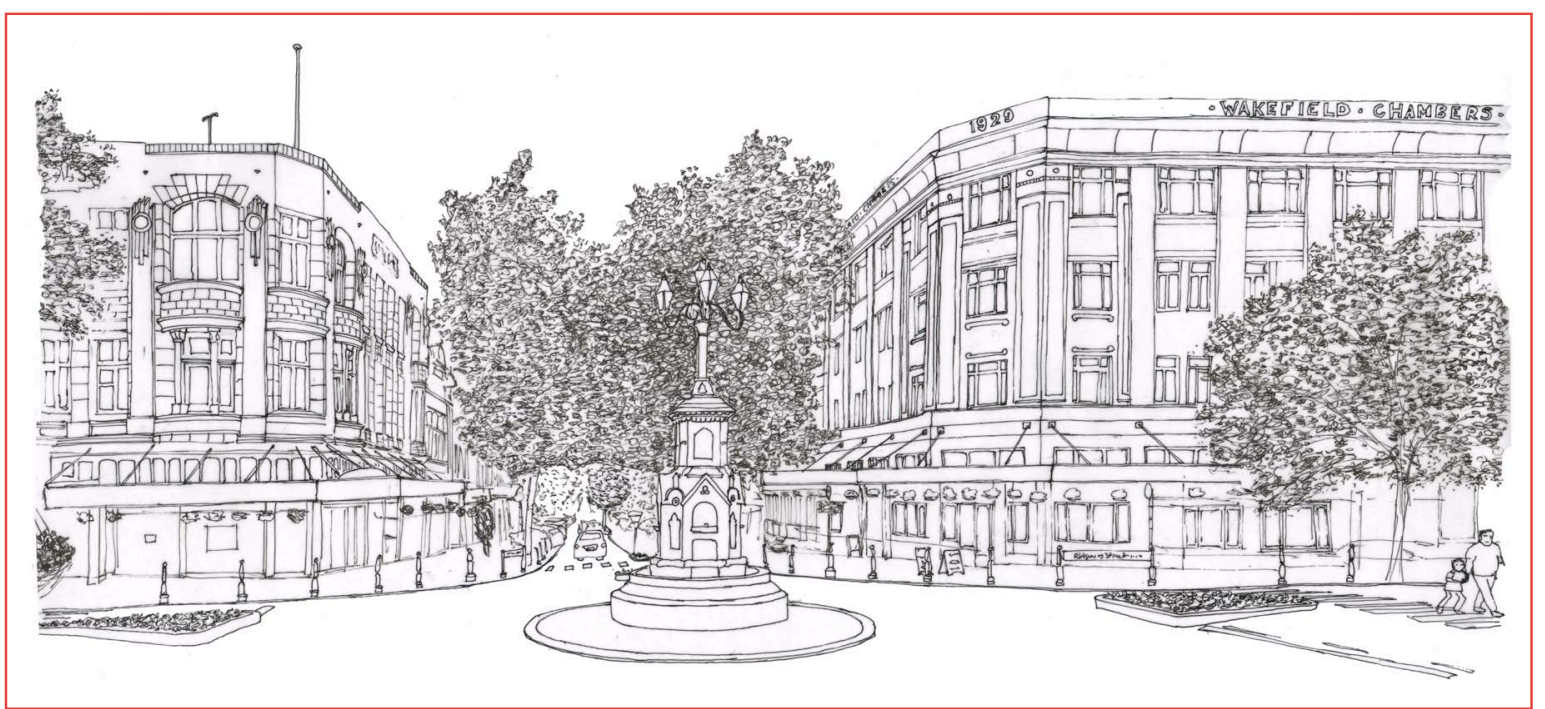

Fig. 3.11: South East Cross-Roads Perspective

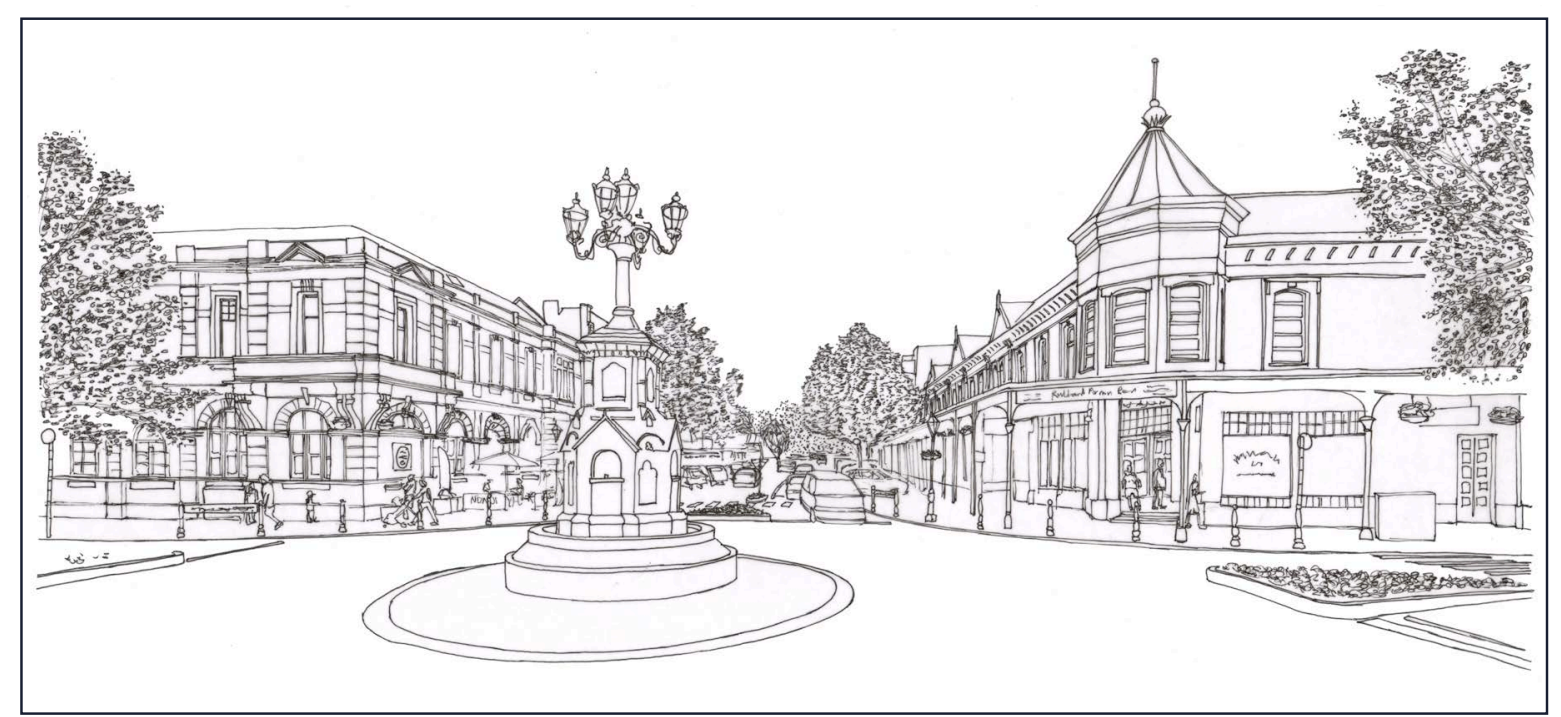

Fig. 3.12: $\quad$ North West Cross-Roads Perspective 


\section{Taupo Quay / Victoria Avenue}

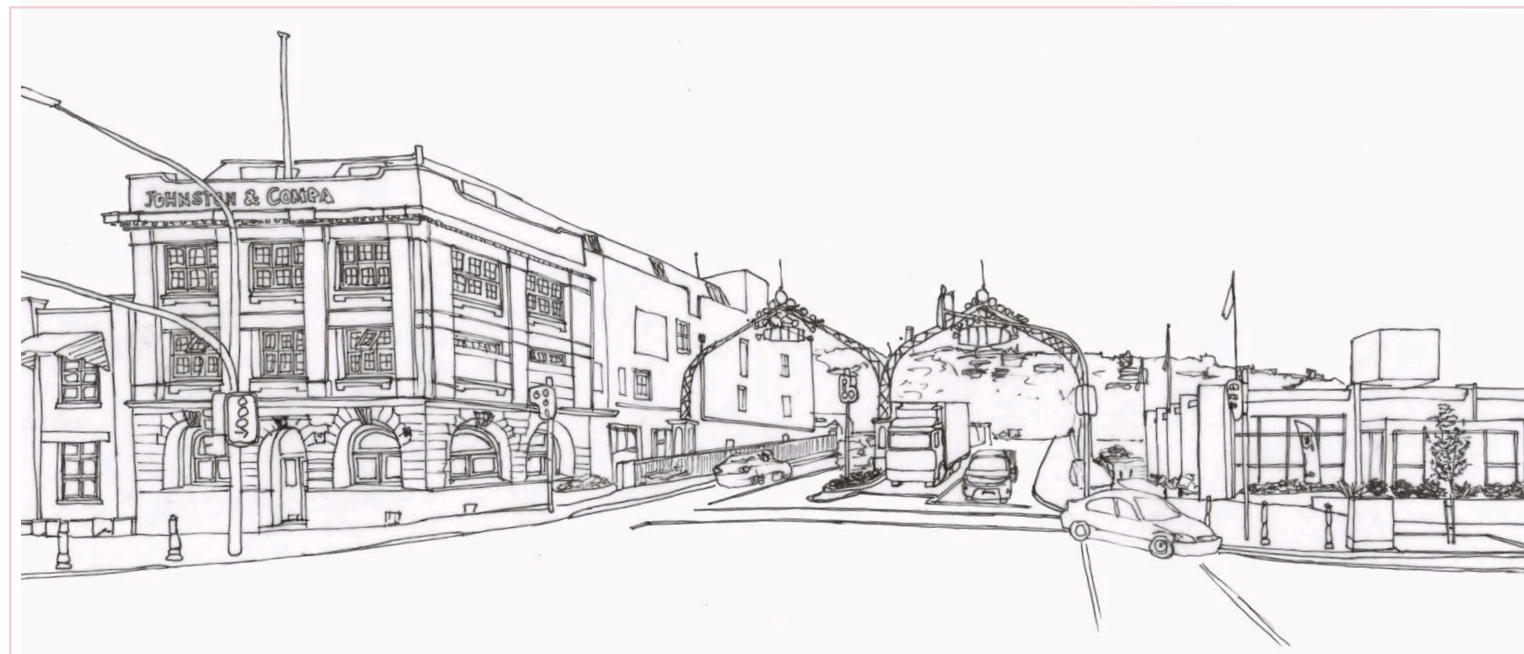

Fig. 3.13: South East Cross-Roads Perspective

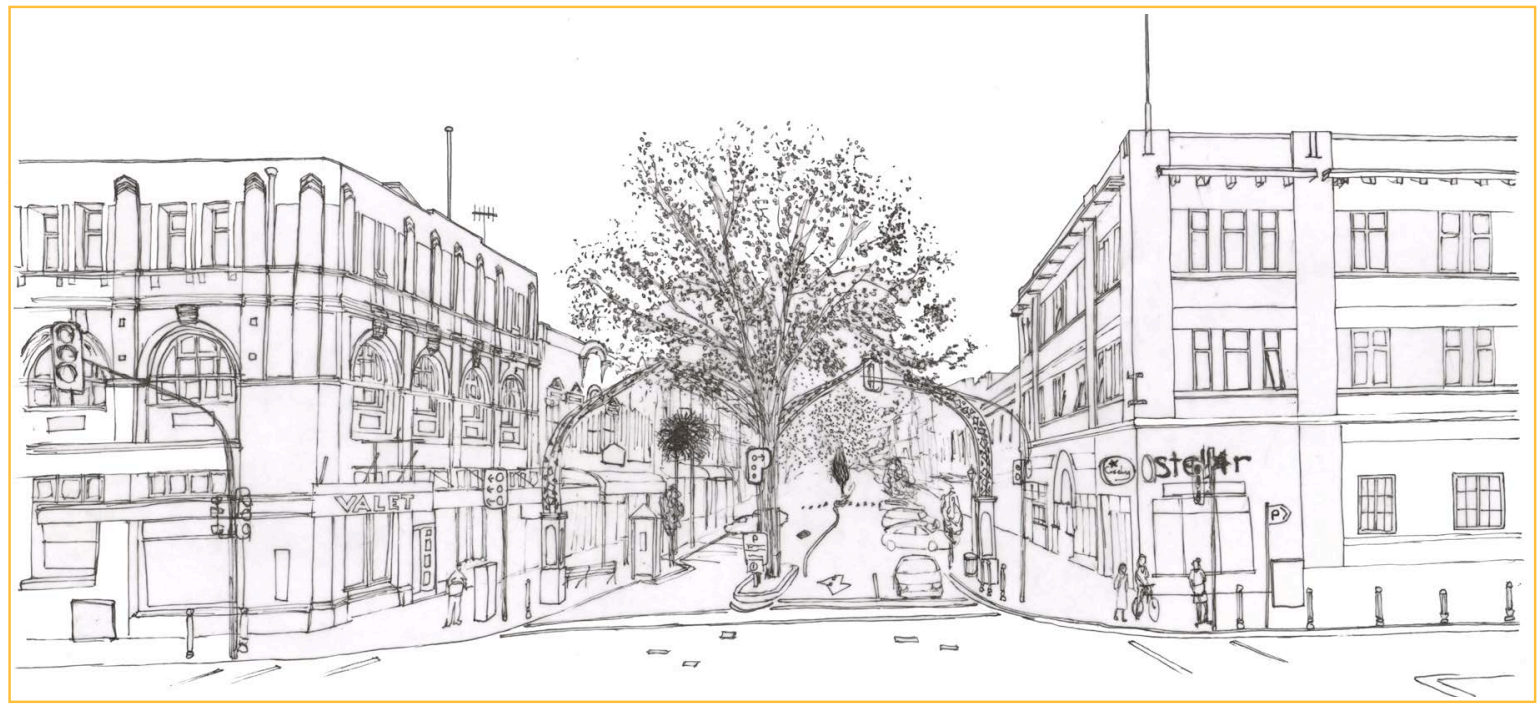

Fig. 3.14: $\quad$ North West Cross-Roads Perspective 


\subsection{POTENTIAL SITE ADAPTATIONS}

Subtraction of corner of building to create larger walkway entrance to river walkway.
Additional buildings alongside the existing of victoria ace, as well as more temporary buildings located on the corner.
Have no building creating a park in the centre city.

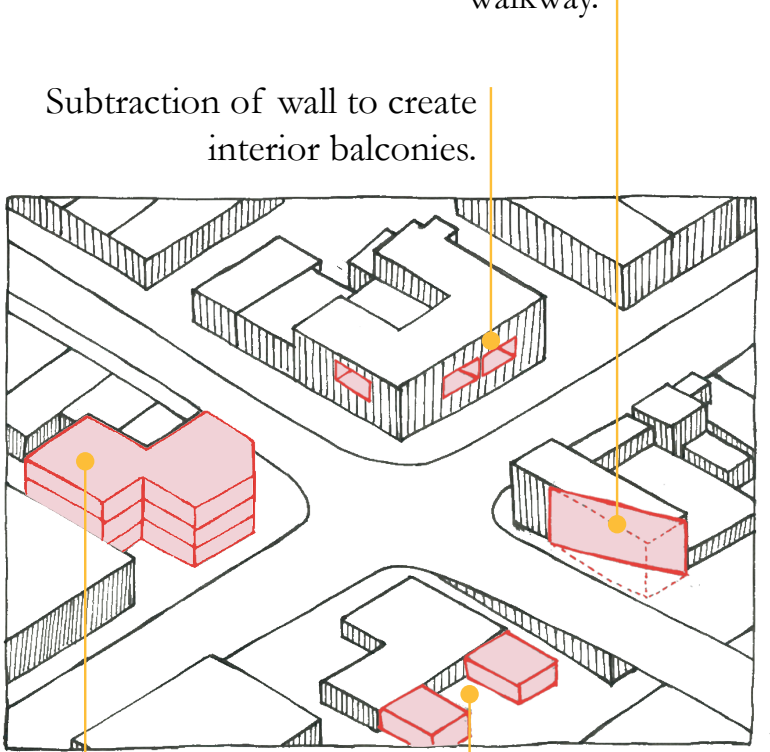

Addtion of buildings towards river on prime realestate connecting to river.
Addition of a three story building providing a building which fits in with surrounding context.
Subraction to creat light wells within building and the opportunity to plant in wells.
Addtion of cubes added to the facade for larger apartments and sunlight.

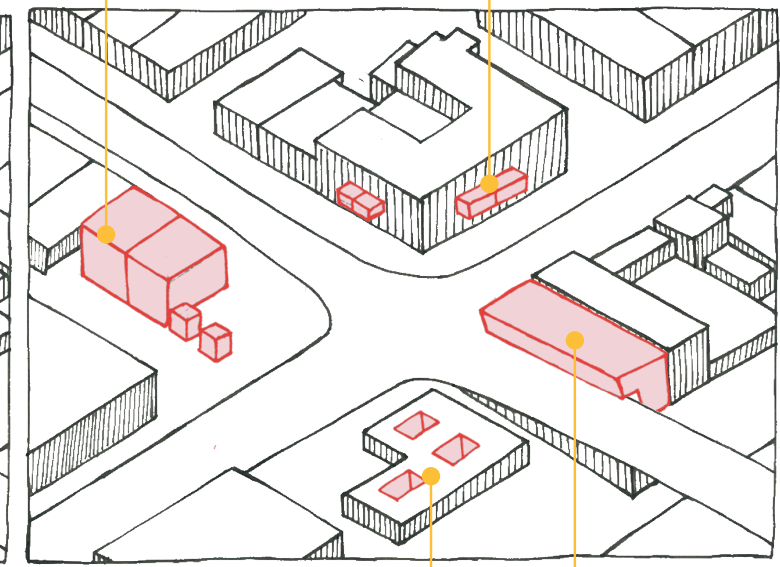

Addition to create building connection to the bridge and create entrance to river.

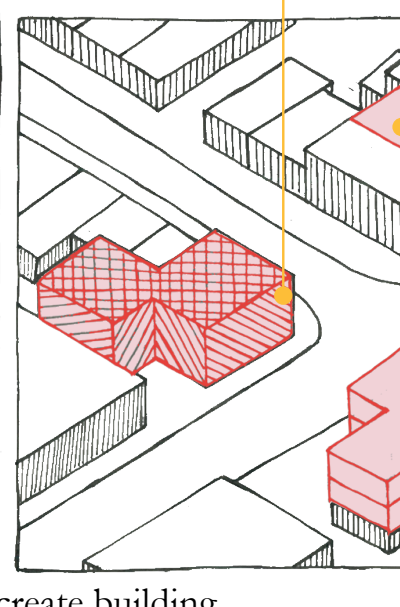

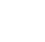


Addition of floor area, although less light into lower levels. Green roof opportunity.

Additional floor and more encroachment towards the river for greater connection.

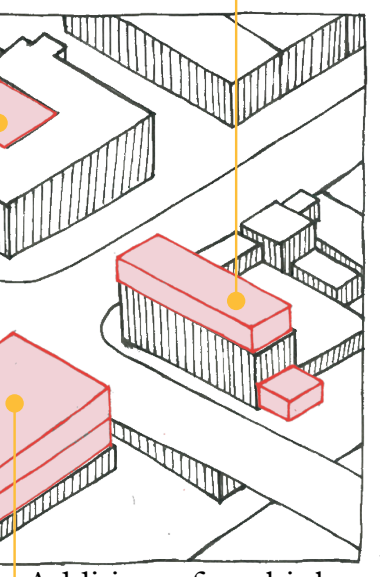

Addition of multiple stories in prime real estate as well as fitting building with its surrounding context.

Connection of buildings either side of city brige creating entrance to city.
Subtraction on southern face to add aditional light and larger entrance / walkway to river.

Shelter provided at street level.

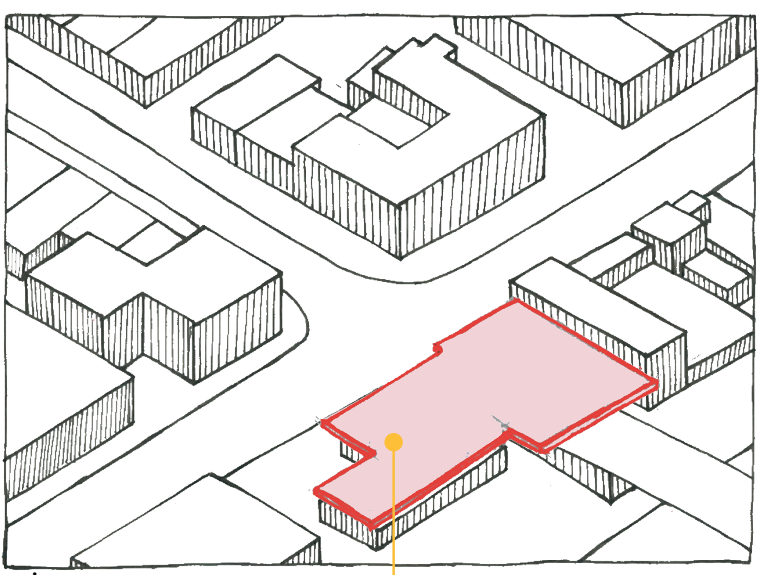

Additional buildings as well as purposely left space for green area.

Demolishing of this buildin to create park in city centre and greater connection to river. 


\section{POTENTIAL SITE ADAPTATIONS}

This series of adaptations in Figure 3.15, of the cross roads illustrate several potential adaptive reuse solutions. All of which were created to fit the site and create better use of the existing buildings, enhancing connection with the river and having community based design.

The intention was to explore a wide range of potential adaptations which could suit the site and achieve the objective of better connection to place.

The drawings were done in an iterative fashion through sketching over top of the existing buildings with translucent paper. These design explorations were created from ideas taken from the literature.

From this iterative process, this showed multiple design options quickly and allowed the decision making process of multiple solutions to manifest quicker. 


\section{CONCLUSIONS}

Conclusions that are starting to position my design include; when working with or around heritage buildings, building form in terms of proportion and architectural style is important and can be often lost through multiple renovations within a buildings lifetime.

Creating a design which fits within the building's surrounding context will achieve a better connection to place. Therefore intervening on four buildings rather than one is a decision going forward due to the importance of the context which was identified in section 3.5.

Due to the cohesion and the way the façades interact with each other it is important to interact with more than one building at the same time.

Having a more subtle intervention could be beneficial for this thesis so it can intern, fit with an existing context as well as recognise the potential of urban space which each building effects.
Having a strong understanding of heritage building terminology can greatly benefit the adaptive reuse outcome due to sometimes a more sympathetic response to the buildings history.

Pedestrianising the streets making them better designed for people rather than cars can also be used as a design tool to revitalise the street scape.

Having a large range of adaptive reuse potential site adaptations gives opportunity to discover possibilities and create connection more quickly. 


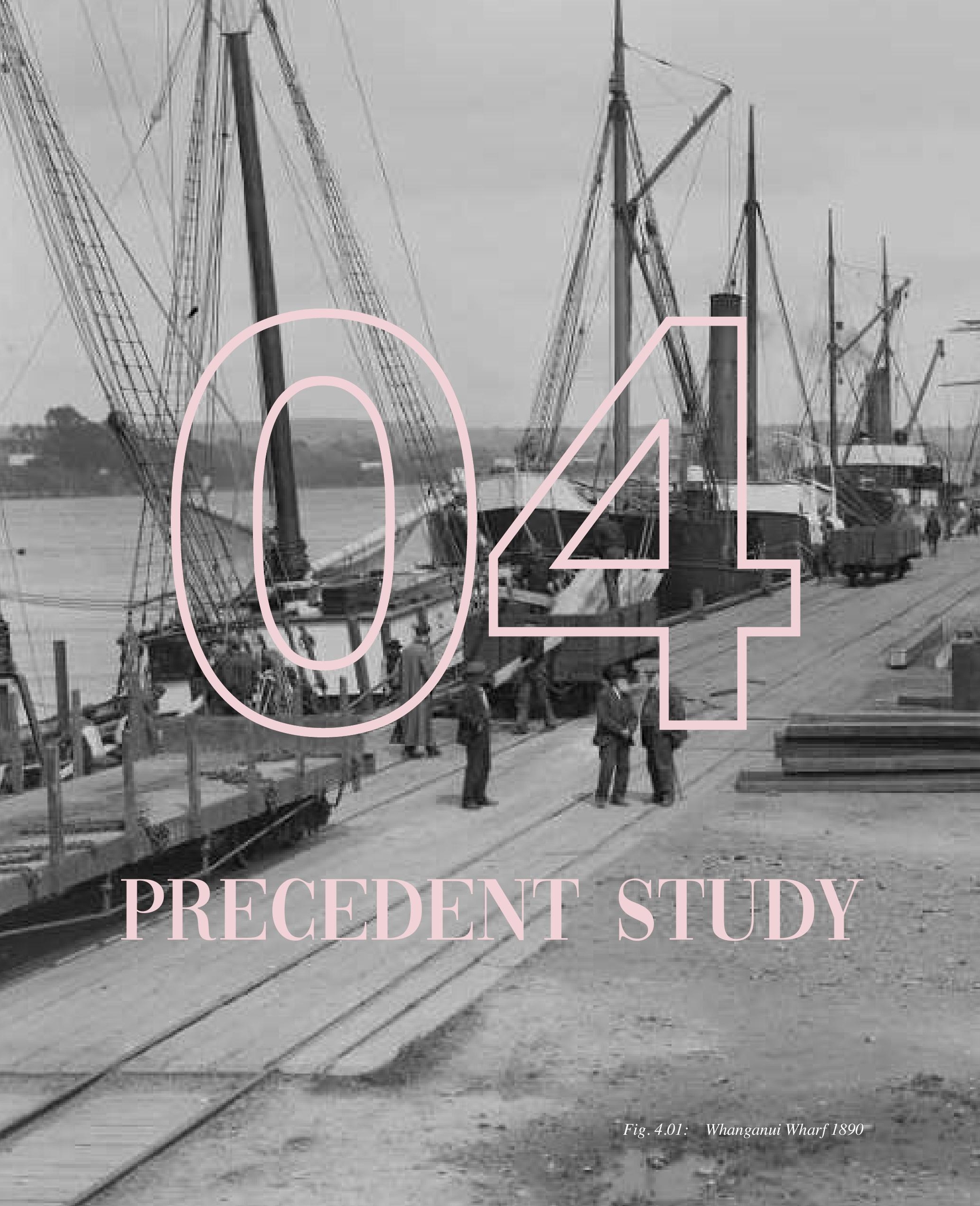



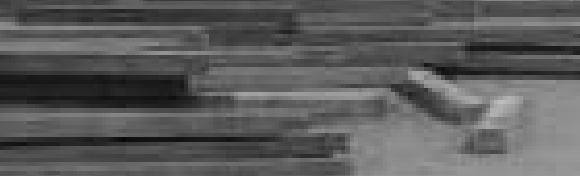

The precedent study was conducted to gather inspiration and analyse the existing adaptive reuse projects to learn from their successes and failures. 흐는

These case studies were chosen as they all had elements or attributes that best showcase strategies of adaptive reuse. These are made up of mainly intentional examples as many nations around the world have been successfully adapting and reusing buildings for many decades longer than New Zealand.
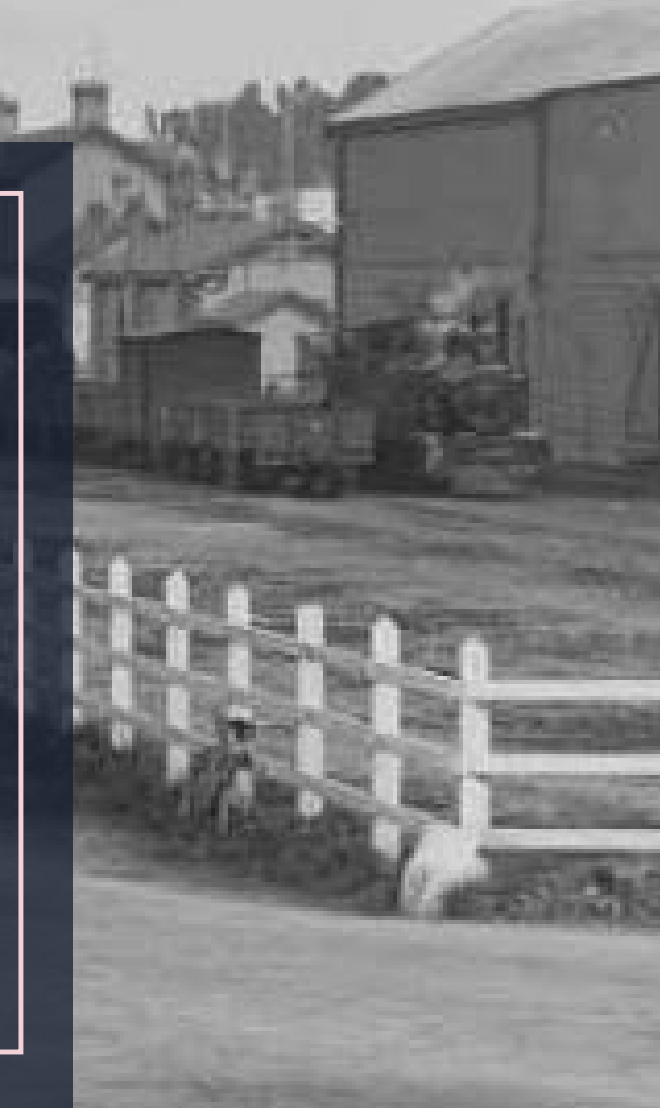


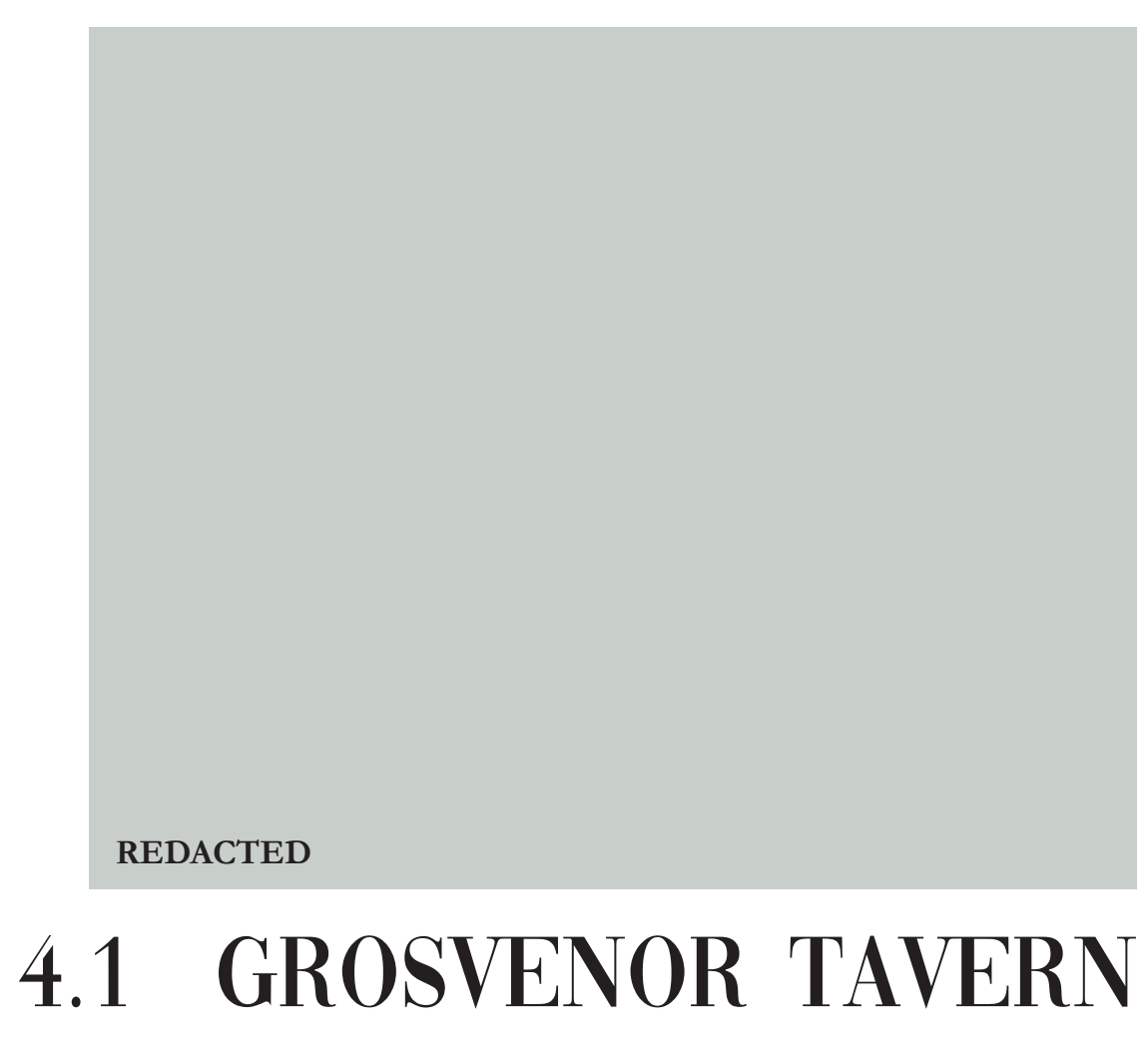

367 Moorhouse Avenue, Christchurch

Type: Formerly Grosvenor Hotel converted mixed commercial and hospitality.

Year of construction: 1877

Adaptive reuse: 2010 - 2012 
REDACTED

REDACTED

Fig. 4.02: (Left) Exterior

Fig. 4.03: (Above) Interior

Fig. 4.04: (Below) Night exterior 
The commercial classical building was designed by pioneering Canterbury architect Samuel Farr. The masonry building had many common features of Farr's commercial buildings including segmental-arched windows with prominent architraves, and a heavily corbelled parapet incorporating his favourite circular motif. The large segmental pediments above the door cases on the corner and Moorhouse Avenue frontages are particular to this building however.(Vair-Piova, n.d.)

The fate of Grosvenor's was questioned in the early 2000's due to loss of traditional industries and change in New Zealand drinking culture which saw its closure. The hotel became vacant for some time and was at risk of demolition. Before it underwent extensive renovations in 2010, which secured the building's future and ensured that it survived the 2010/2011 Canterbury Earthquakes. (Vair-Piova, n.d.)

Earthquake strengthening was crucial to the life of the building being prolonged. The concrete roof was replaced with a lightweight corrugated iron roof, structural steel reinforcing was added to exterior masonry brick walls and new interior concrete block and timber walls were constructed. (VairPiova, n.d.) The addition of structural steel frames allowed the interior to have a stripped back aesthetic and the open plan layout which was designed to maximise collaboration and create a welcoming environment for clients. (Strategy circa 1877, n.d.)

The building has new internal steel framing and concrete foundations, yet retains its 1877 facade. Farr's unique heritage details within the facade have been highlighted by the use of a well chosen paint palette. In particular the segmental-arched window surrounds were highlighted as they have been painted white. The Grosvenor hotel's facade restoration is one in which takes the building back to its heyday. The chosen colour palette and details work well in today's environment and bring it into the 21 st century.

That being said, there has been no boundaries pushed with the external appearance of the building. This case study has used the adaptive 
reuse type of Facadism, with a large influence of restoration which is common when dealing with heritage buildings. As discussed in chapter two, a common issue is a town being stuck in its past with old facades or the creation of 'fake' heritage when the building becomes a replica. This building, in terms of adaptive reuse has been successful due to its facade. However due to the internal layout of the building being unrecognisable it could be seen as having lost connection and identity.

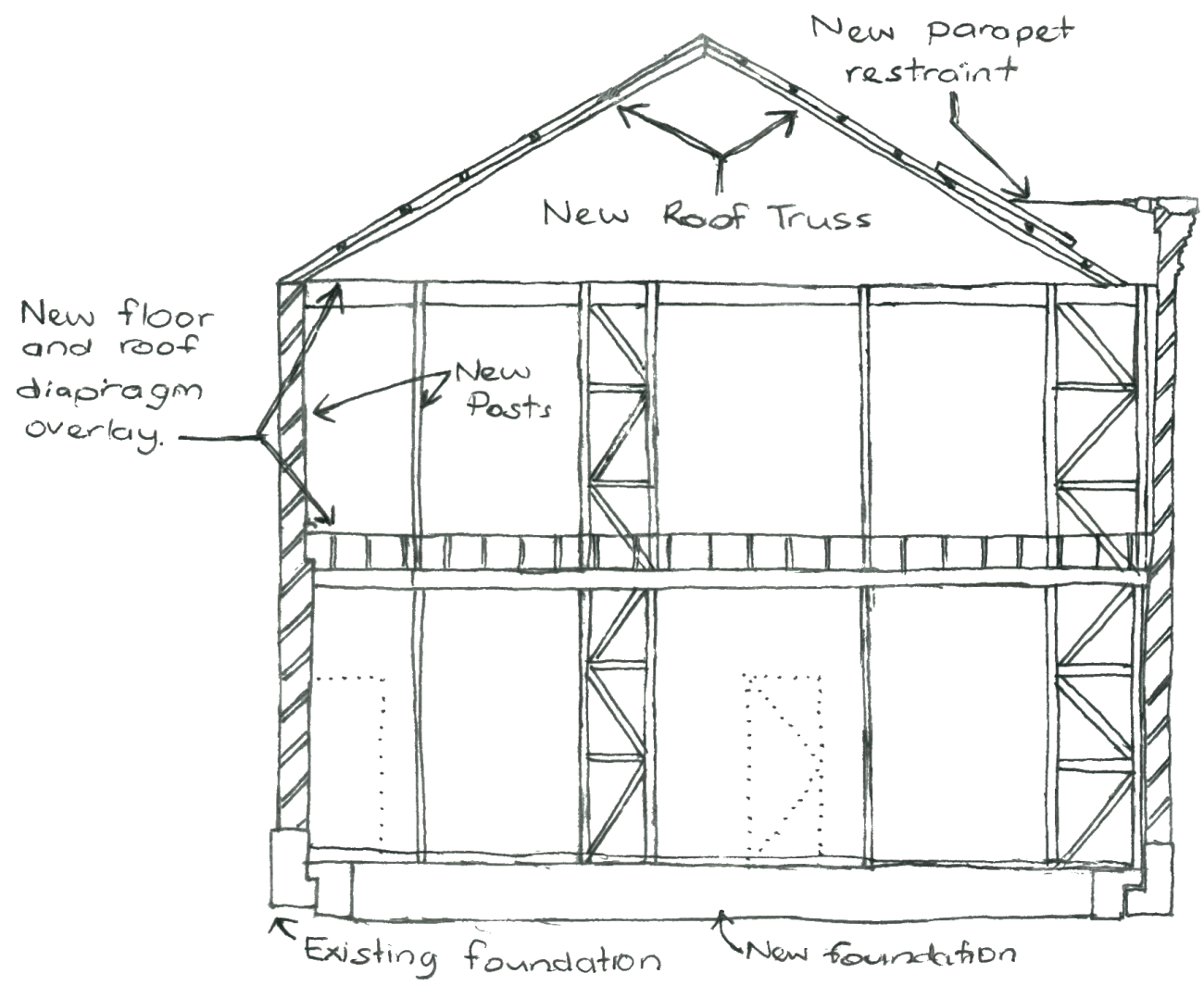

Fig. 4.05: Sketch illustrating the addition of structural support and foundations to the heritage building. 


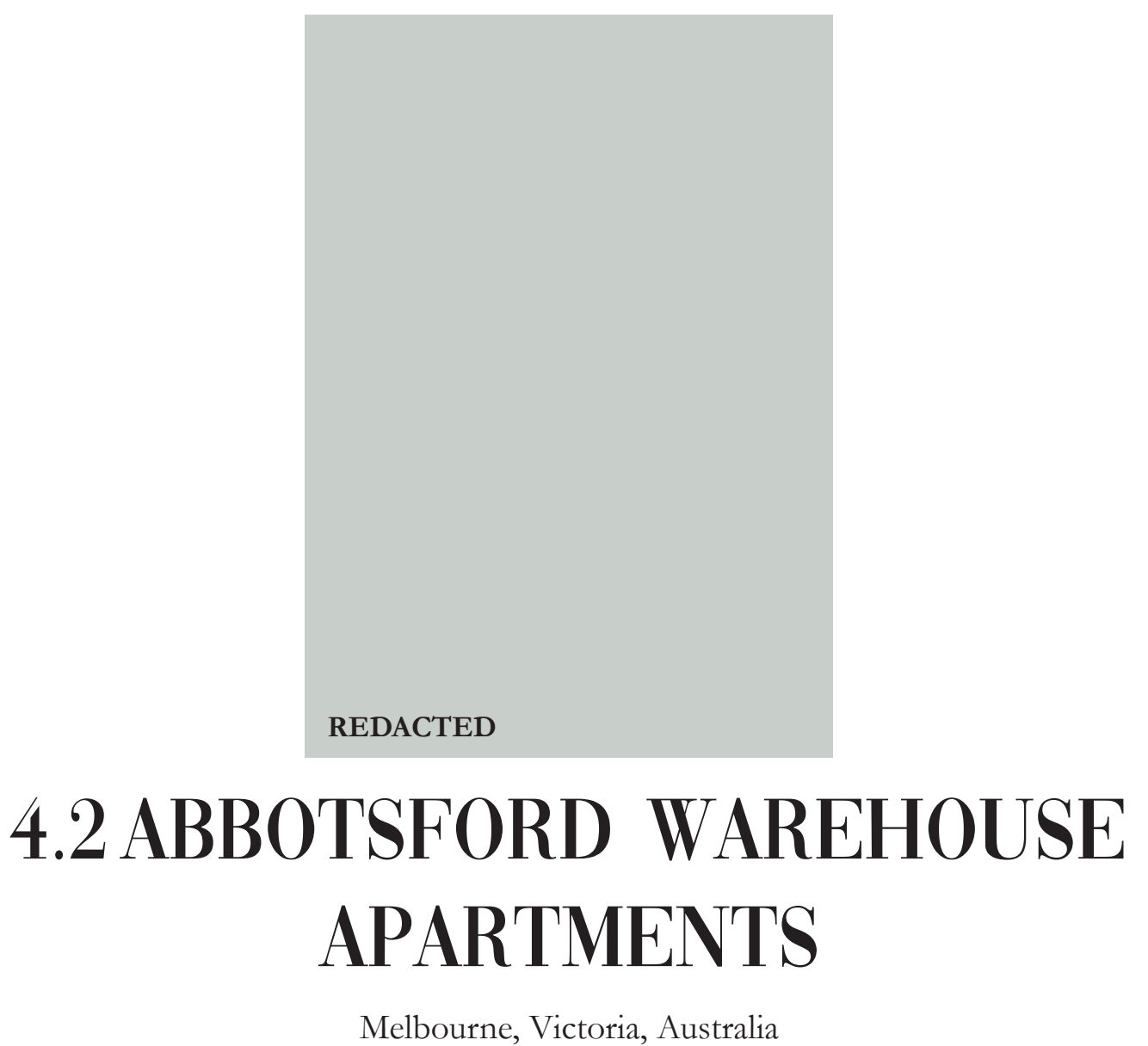

Who/Architect: ITN Architects

Type: Formerly a Catholic Technical College converted into residential apartments.

Area: $590 \mathrm{~m} 2$

Adaptive reuse: 2012 


\section{REDACTED}

Fig. 4.06: Left-Abbotsford Warehouse Facade.

Fig.4.07: Above-Interior living room.

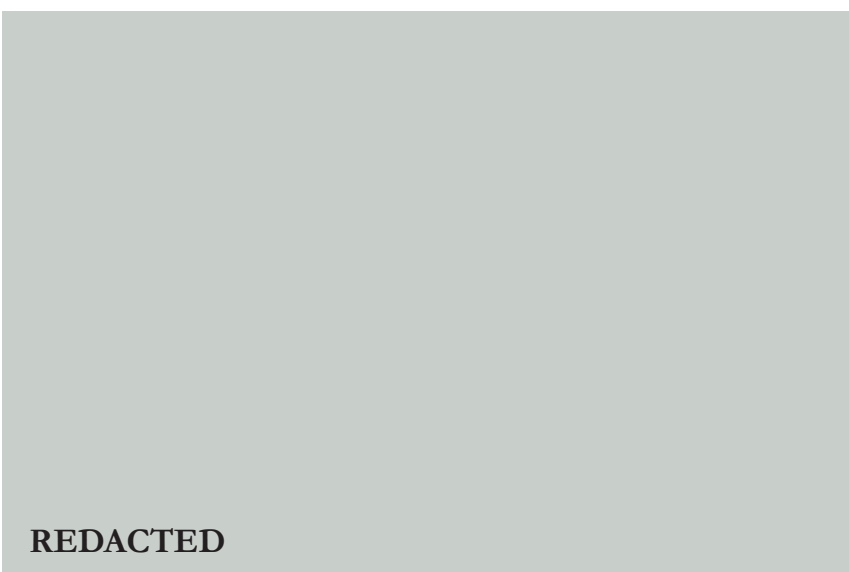

Fig. 4.08: Bottom left-Upper floor apartment.

Fig. 4.09: Bottom right-Balcony bebind existing facade. 
REDACTED

Fig. 4.10: Second Floor Plan.

REDACTED

Fig. 4.11: First Floor Plan.

REDACTED

Fig. 4.12: Ground Floor Plan. 
This former Catholic Technical College has been converted into two, three storey warehouse apartments by removing the roof, retaining the lower floors and constructing a new upper floor which has been set back on all sides to create upper decks and balconies (ITN Architects, n.d).

Many of the former industrial buildings simple details were retained as well as the external walls and lower floors. New elements and materials sit side by side with the old to create contemporary apartments with some old world charm. (ITN Architects, n.d).

Four metre high windows were converted into the steel and glass front doors and electric garage doors to create an overwhelming effect upon entry, and match the scale of the four metre high ceilings. Old timber columns were removed, repaired and reinstated with concealed steel columns within for strength (ITN Architects, n.d). Hiding these structure can be diminishing although in this case, this did allow the building style to be the same.

A large roof terrace was obtained by removing the roof structure which compensates the lack of back yard space and gained the same housing quality as a conventional family dwelling. It needs to be highlighted that this intervention was done without any influence and disturbance of the visual historical identity of the building from ground level (PetkovićGrozdanovića et al., 2016).

The buildings stepped back floors from the facade creates a unique design feature bringing natural light into the building on multiple levels. This feature opens up opportunity for natural daylight to enter places in which light usually does not shine. It also does so without sacrificing any of the facade. 


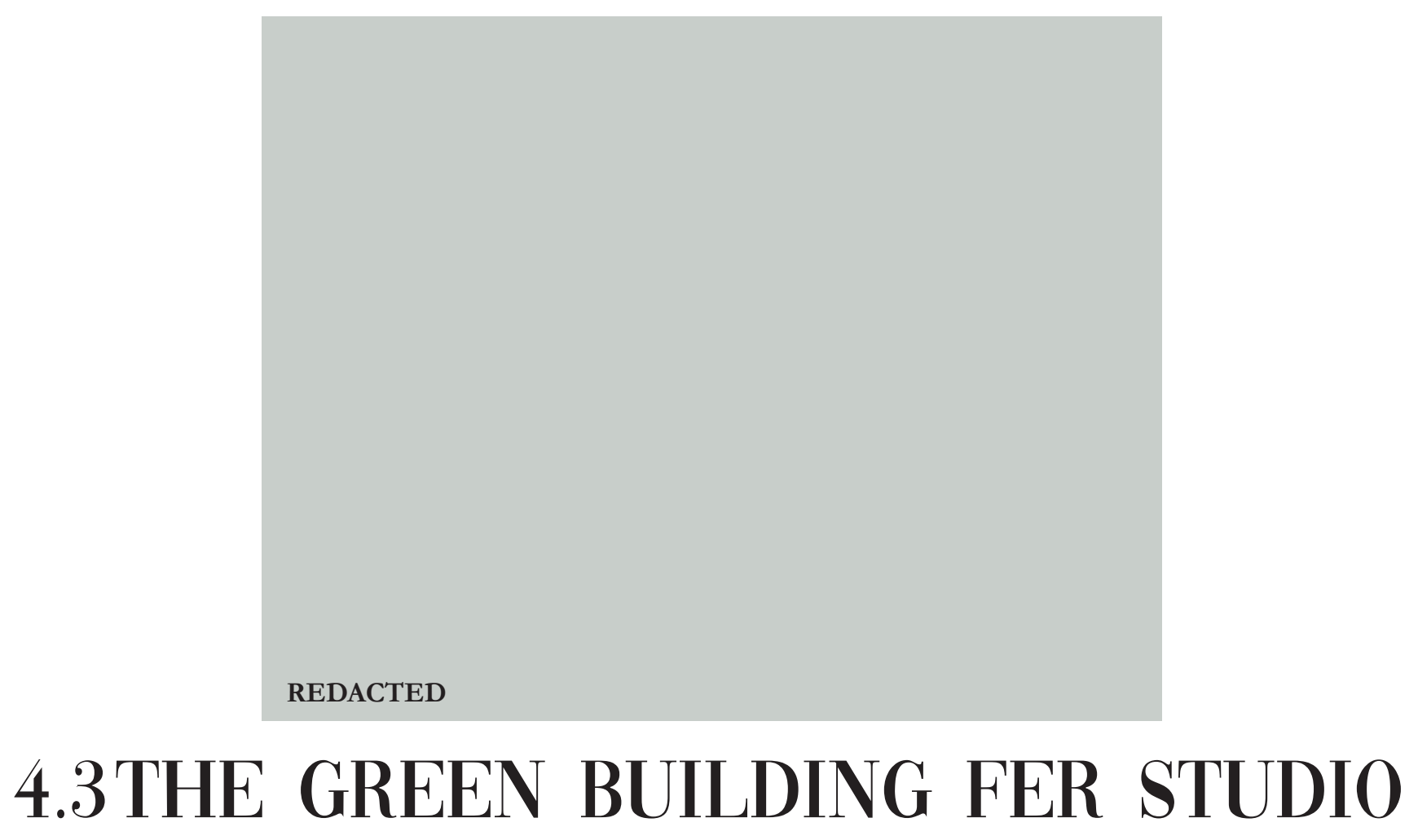

East Market district, Louisville, Kentucky, United States

Who / Architect: (fer) studio

Type: Formerly dry goods store turned into a mixed-use com-

mercial building

Area: $945 \mathrm{~m} 2$

Year of construction: 1900

Adaptive reuse: 2008 
Fig. 4.13: Left-Exterior view of The green building.

Fig. 4.14: Above Left-Ground floor gallery space.
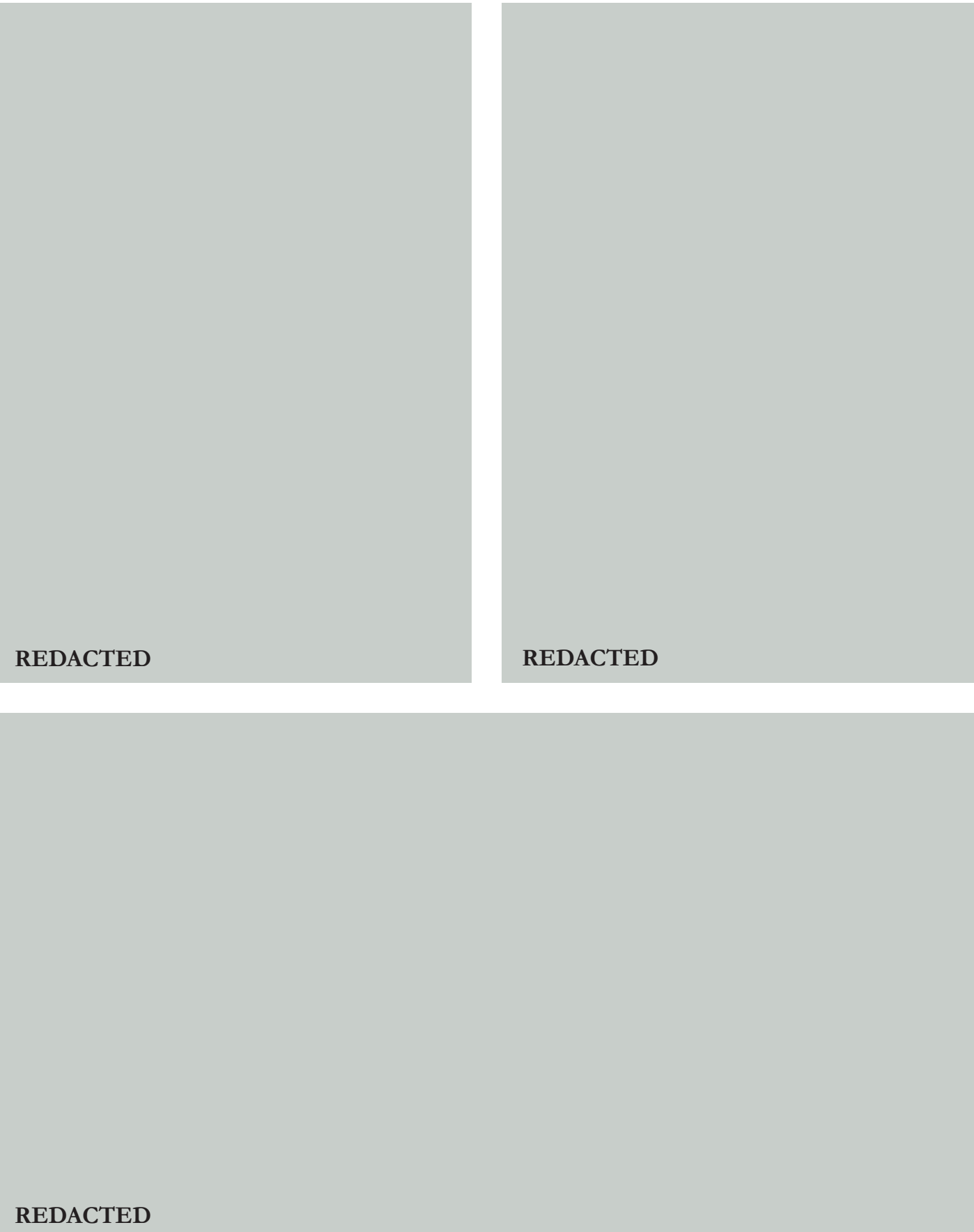

Fig.4.15: Above Right-Work space.

Fig.4.16: Bottom Right-Inverior view. 


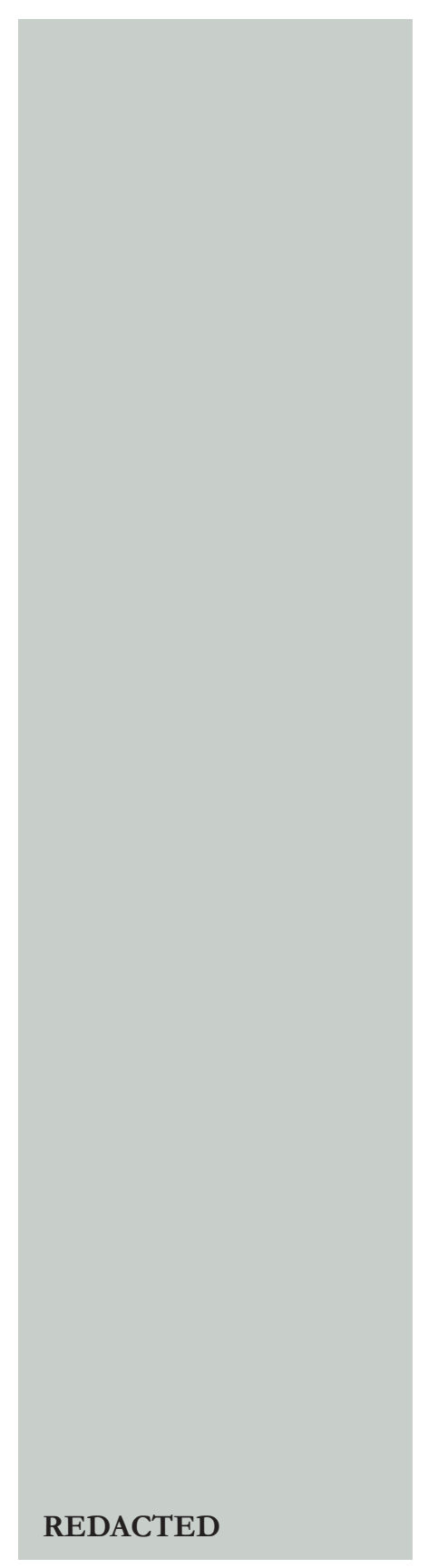

Fig. 4.17: Above Left-Ground floor.

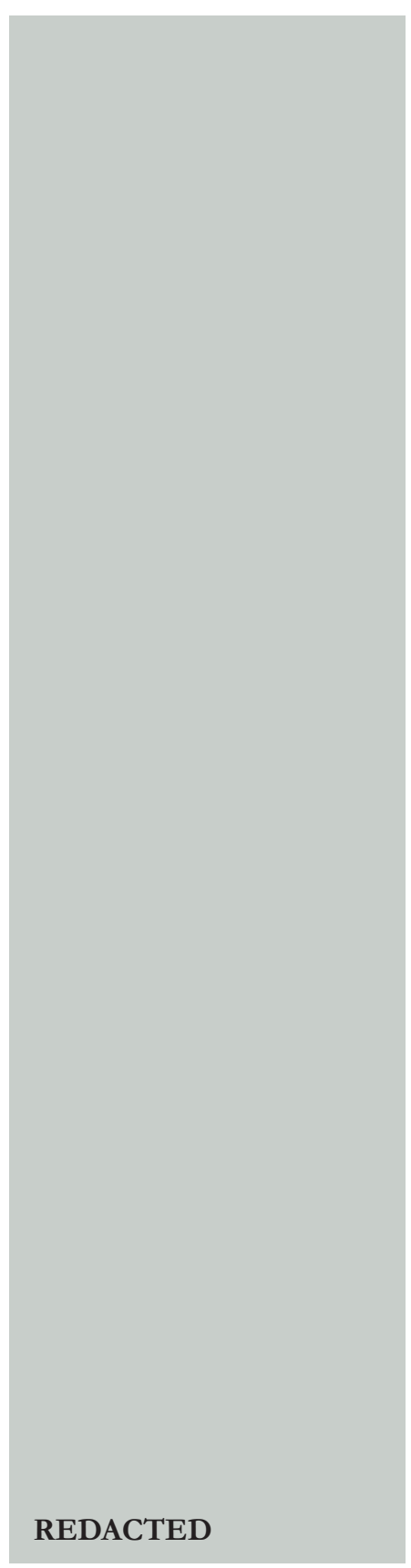

Fig. 4.18: Above Middle - First floor. 
(Fer) Studio wanted a design which created an experience of place within the buildings surrounding environment. Having an understanding of the building and its context to determine its weak points was key. Through the design of triple height spaces adjacent to single height creating contrast to have a sense of openness then more intimate spaces for the buildings many different uses. (The Green Building / (fer) studio).

In addition to reusing the buildings original shell, a lot of the materials were reused also. Recycled materials, including 100\% of the flooring, $70 \%$ of the windows, and $80 \%$ of the insulation, were also made from recycled blue jeans (The Green Building / (fer) studio).

This precedent was chosen for its clever design of multi height spaces with the incorporation of a mixed use programme. The long narrow site of the former dry goods store needed light and fer studio did a good job of bringing light into the buildings core. This was done with the large modern curtain wall addition through the middle of the building. This large structure bought a modern feel to the building

\section{REDACTED}

Fig. 4.19: Above Right-Second floor. going away from the heritage of a dry goods store. This dramatic change has resulted in the 
interior of the building no longer feeling like a historic building, disproportionate to the heritage facade.

One of the strongest features of this design are the sustainable features. These were architecturally designed to complement the buildings history. The reuse of the original materials grounds the new design within the buildings history. This makes it stand out as a case study exemplifying its sustainable success.

\section{REDACTED}

Fig. 4.20: Bottom - Long section. 

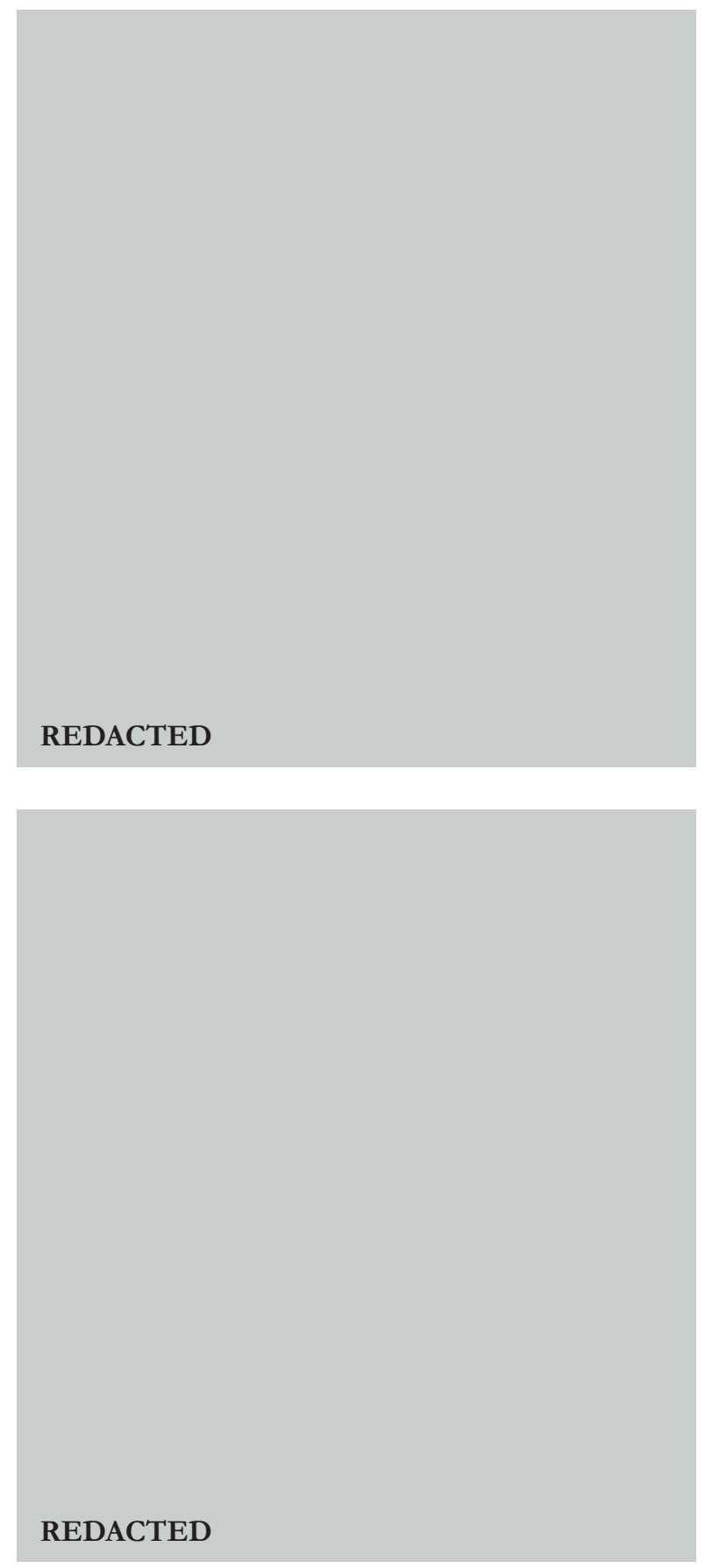

Fig. 4.21: Above-Original Facade before the adaptive reuse.

Fig. 4.22: Bottom - Original facade of the 115 year old former dry goods store. 


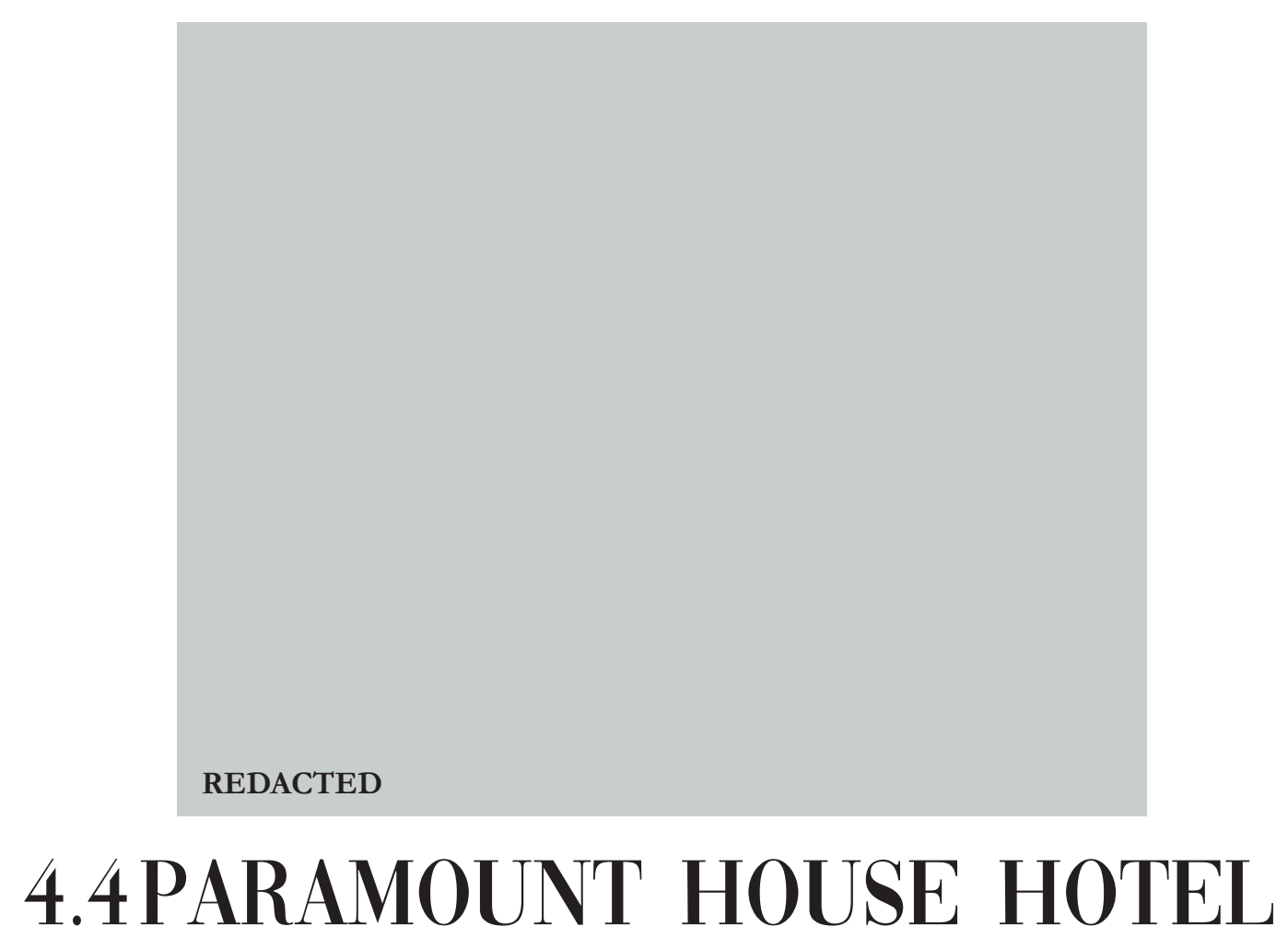

80 Commonwealth St, Surry Hills NSW, Australia

Who / Architect: Breathe Architecture

Type: Formerly warehouse associated with film pioneers

Paramount Pictures into a boutique hotel

Year of construction: 1930

Adaptive reuse: 2018 

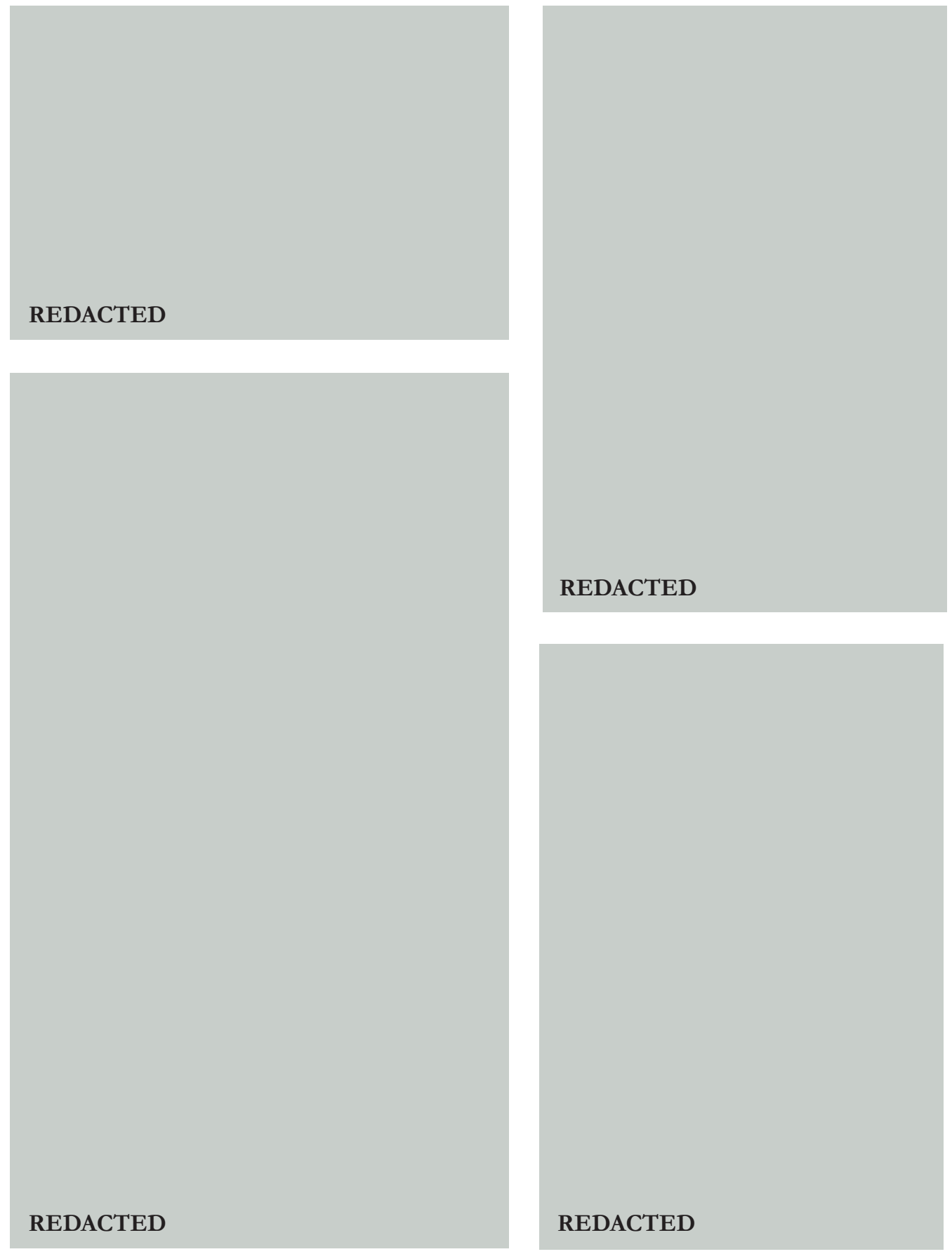

Fig. 4.24: Above Left-View from bathroom through to bedroom in room.

Fig. 4.26: Bottom Left - Contrast of facade of old and modern.
Fig.4.25: Above Right-Textured existing wall and modern furnishings.

Fig. 4.27: Bottom Right-Varying textures through the wall. 


\section{REDACTED}

\section{REDACTED}

\section{REDACTED}

The paramount hotel is a three story 1930's brick warehouse located in Sydney. Its surrounded by other heritage buildings in the inner city located on an irregular block corner. Its adaptive reuse takes inspiration from its past life and historic context as Paramount Pictures Studio.

\section{The idea behind the design was about marrying the past and present in a way that captures "the spirit and excitement of the golden era of film," explains Jeremy McLeod, the director of Breathe Architecture (Breathe Architecture).}

There is a clear contrast between old and new as the old is exposed with existing brickwork stripped and expressed (Breathe Architecture). Breathe Architecture have successfully bought forward the historic nature of this building in through its adaptive reuse. They have done this through expressing the imperfections of decay and years of layers of wear. They have celebrated the character of the historic building by making them a feature within the modern retrofit. This design principle aligns with the literature on reusing the ruins, which they have done with great effect.

Fig. 4.28: Above - First Floor Plan.

Fig. 4.29: Middle-Ground Floor Plan.

Fig. 4.30: Bottom - Section through Hotel. 


\section{REDACTED}

The facade creates a subtle extension to the building as it contrasts the existing brick exterior below. The detail of the panels allow for it to be seen as one from a distance while looking out from the interior of the facade, it acts as a barrier. The panels manage the amount of light and ventilation into each of the hotel rooms. It also creates an unique view from each of the rooms. This design's facade addition can be considered to be successful due to the choice of materiality and transparency of the design. The modern styled addition complements the historic facade below as it fits into its surrounding context.

Fig. 4.31: Left-Hotel room view of window seat and facade.

\section{REDACTED}

For Breathe Architecture sustainability was a priority for the design. While they did not reuse the old materials they did intend to reduce the amount of building waste produced. Where possible they also locally sourced materials. 


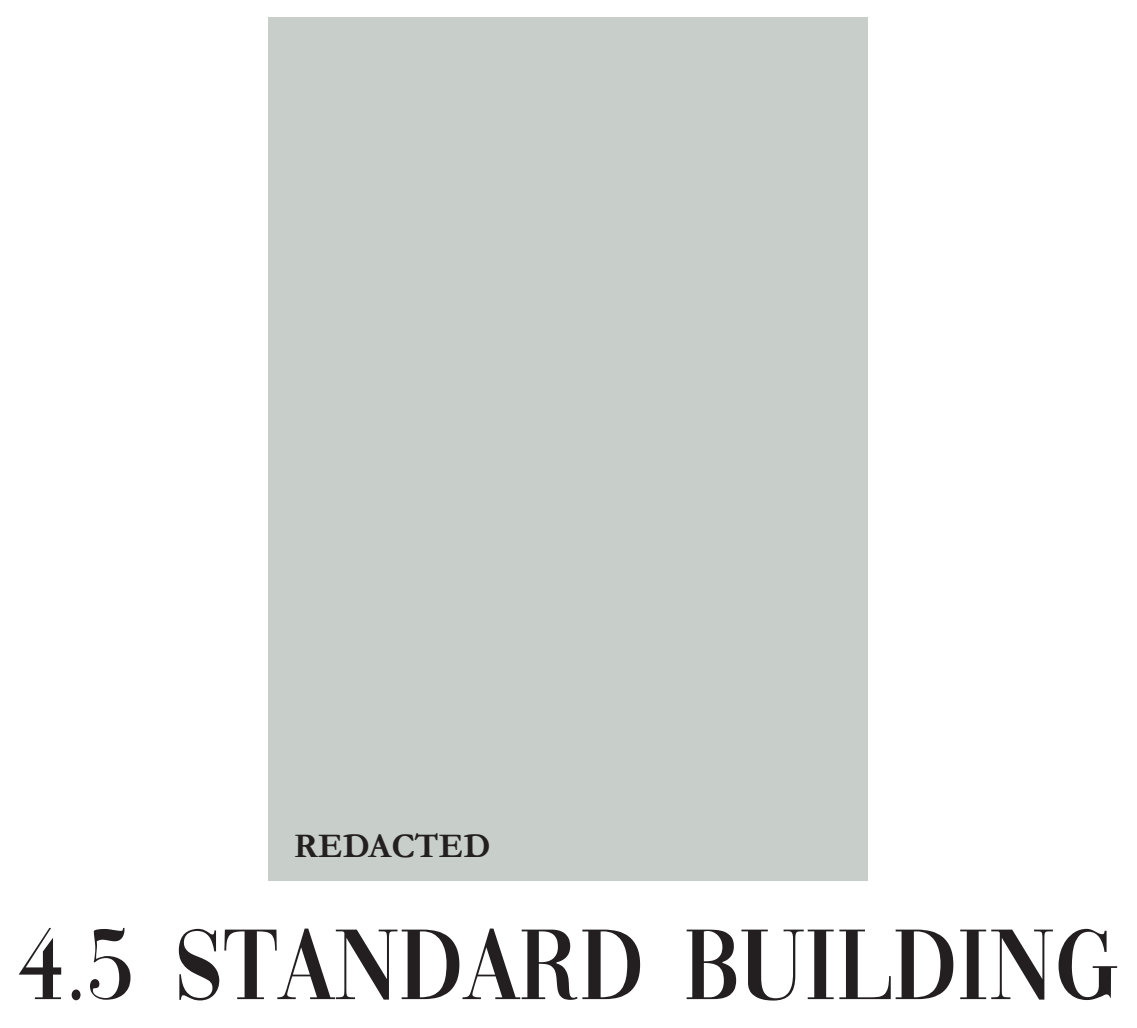

201 Princes Street, Dunedin, New Zealand

Who / Architect: Baker Garden Architects Ltd

Type: Formerly insurance company building converted cafe.

Year of construction: 1875

Adaptive reuse: 2015 


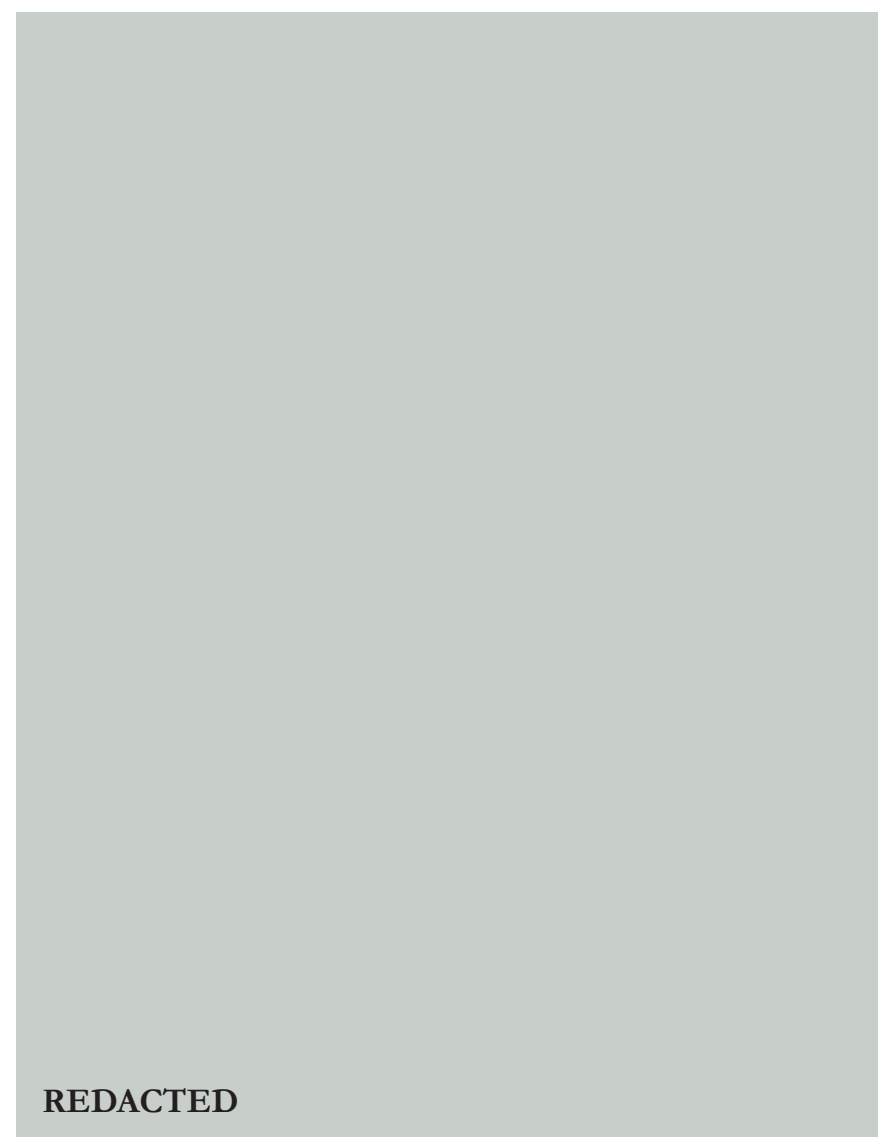

The Standard Insurance Building underwent an extensive restoration to have earthquake strengthening as momentum grew in Dunedin to revitalise it's old buildings. The facade got a face lift as well as an internal addition of an innovative light-filled multilevel atrium linking all the floors and bringing light into the lower spaces (Gibb, 2015). In the early 2000's it sat vacant until it's conservation process began in 2009.

The restoration included the reinstatement of the historical facade, it was previously stripped, therefore the original plaster details and mouldings were replicated, based on early photographs (Kerr, 2011). 

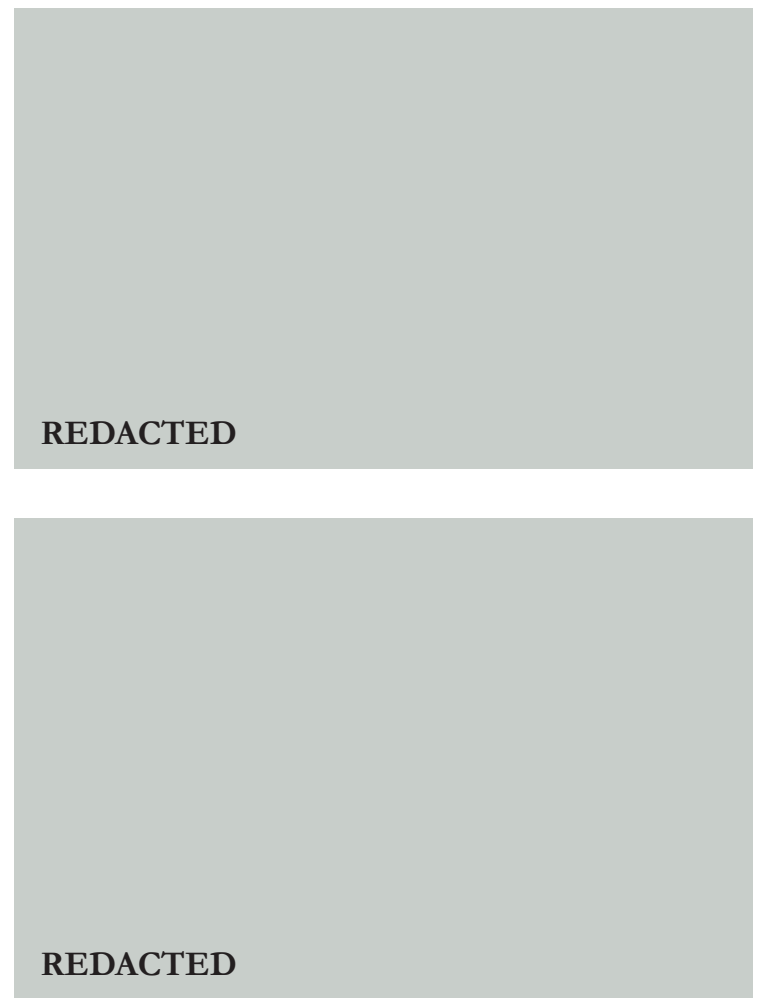

\section{REDACTED}

Fig. 4.35: Above Left-Historic image of the standard building in its early years, 1880.

Fig. 4.37: Middle Left-Standard building in 1920's.

Fig. 4.36: Bottom Left - Addition of staircase and light well.
"Its an "absolutely incredible" conservation and adaptive reuse project. It's a real big leap forward in terms of what people are doing with beritage buildings."

- Dr Hazelton

This precedent shows a successful restoration of the buildings original facade, with replicated plaster detail and mouldings. Knowing which period and style of facade to redesign is interesting as over its lifetime, there would of been many alterations in colour and depth. The addition of fire exits and plumbing would also create a very altered building facade. Today it can be seen as a replica of its historic state which is doing itself justice through proportion, colour palette and decorative detail.

While this is seen as a replica or 'fake' heritage, the attention to detail in recreating the original facade can be applauded. The recreation of the facade has reinstated the life and history of this building. 


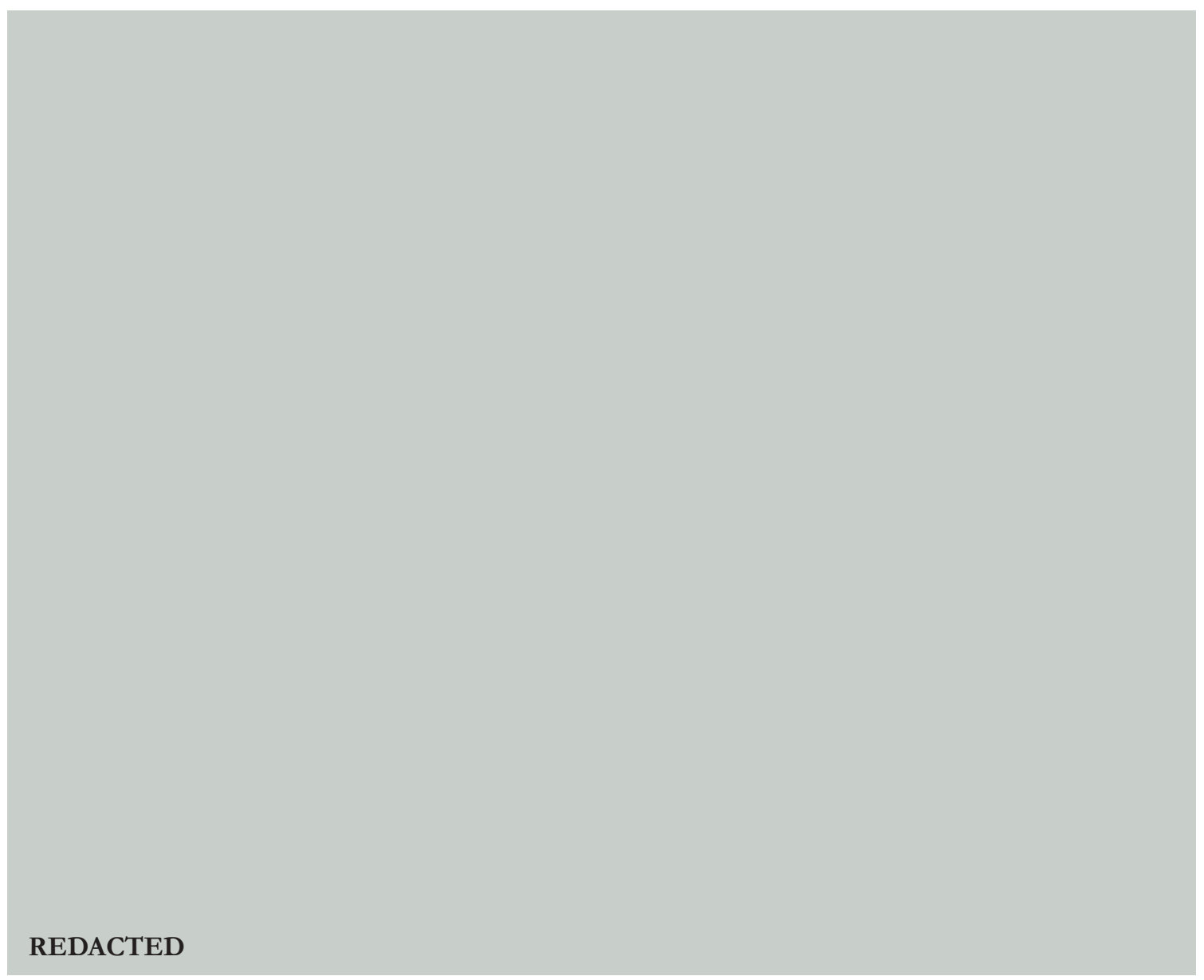

Fig. 4.38: Right-Standard building during the restoration. 



\section{CONCLUSION}

These case studies have been used to initiate design strategies and ideas which could be trailed in my design experiments. The case studies allow for critical design analysis of both successful and failed design strategies. These strategies can then be joined or added to the strategies established in the literature review chapter.

To draw people back into a site, the building needs to be brought back to its heyday. With the design being of high quality, it then has the opportunity of empowering the occupants and therefore can create better connection to place. This in turn is designing for the users and the future generations.

Inclusion of expression of the buildings past can bring the design to life, while also allowing the idea of memory to create design. Designing at multiple scales allows the design to be read uniquely to each occupant who uses the building therefore creating an unique relationship with the area.
Natural light, proportions of areas and circulation are crucial to creating an adaptation that should succeed, as well as having a cohesive design style which is authentic or compliments the modern addition. This can be achieved through a well-chosen heritage colour palette and wise materiality choices.

Above all, these case studies show that these projects needed first of all someone to believe in the buildings potential, they all show high quality well thought out designs which in turn give the opportunity for the revitalization of the building's surrounding area. Therefore the design need to reflect the surrounding community and be adaptable to change in the future. An aspect that was beyond my scope of this research was talking to local community groups, the council and enthusiasts. This is a common theme of these adaptive reuse projects and one of the main factors that help them succeed as a design. 


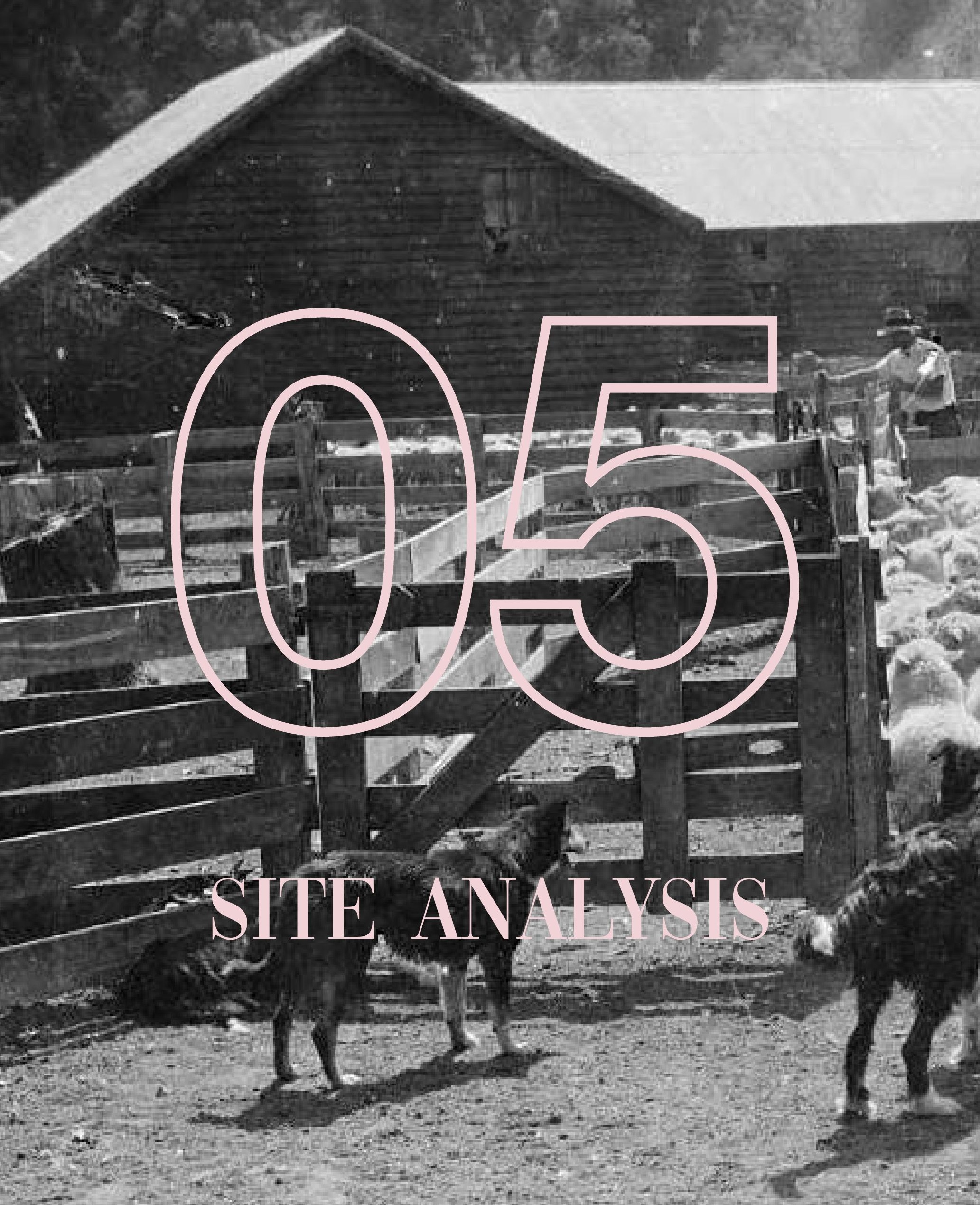




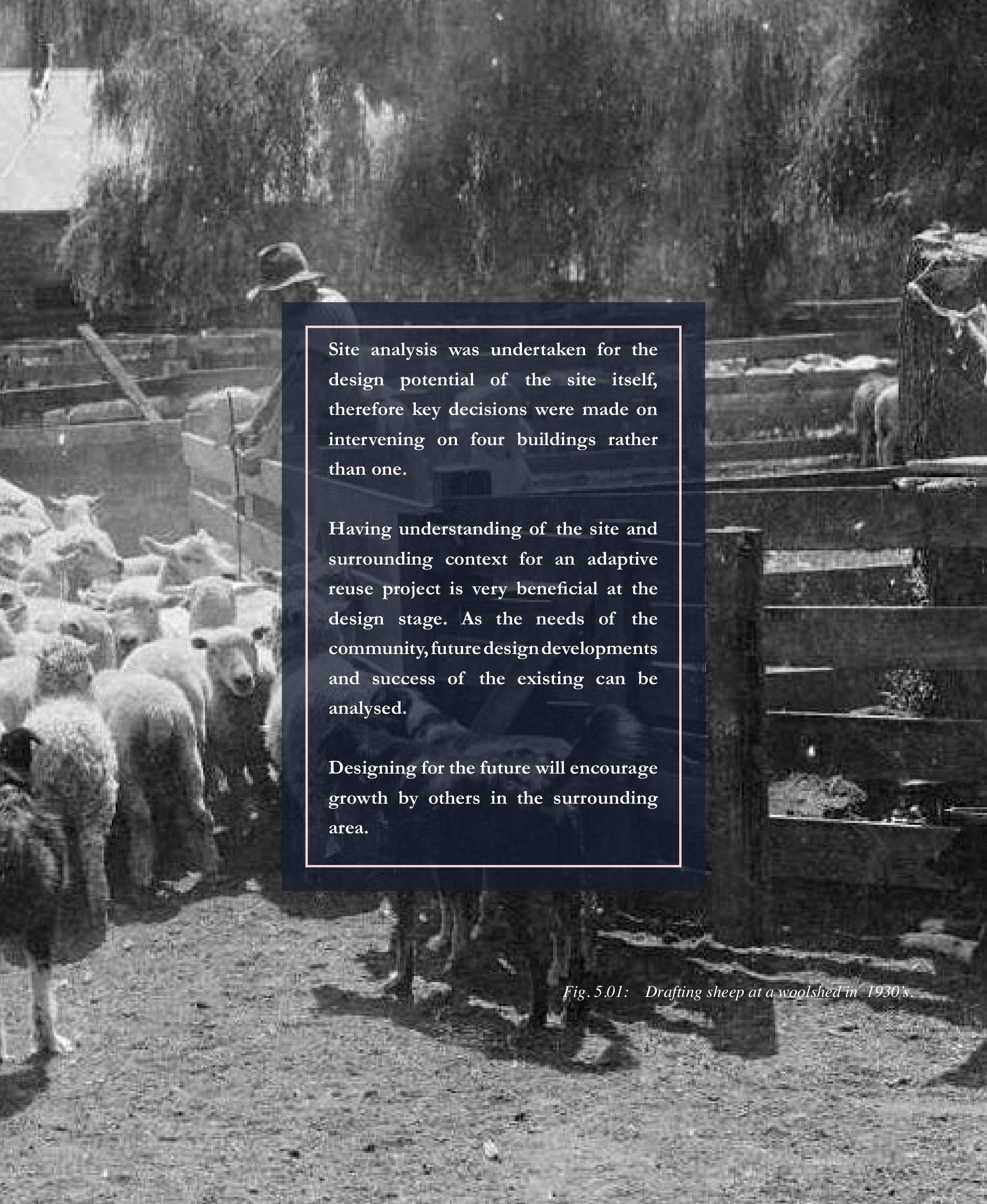




\subsection{WHANGANUI}

Whanganui was chosen as an example in this thesis due to it being a rural town of New Zealand with a rich cultural heritage with both Maori and European. This distinct character of early settlement in Whanganui its irreplaceable and needs to be recognised and protected for both the present and future generations of Whanganui (Wanganui Town Planning Dept, 1978).

Having the river in the heart of the project makes it relevant to many other New Zealand towns which also have strong identities to rivers. This adaptive reuse project should also benefit any revitalisation of old towns in New Zealand with connection to place.

A key design driver of the site is the connection between the town centre and river as well as the existing heritage of Whanganui. A coherent collection of architecture from many eras makes it a feature. Victorian and Edwardian styles co-exist with mid-twentieth century modern architecture. This creates a strong sense of place and identity especially due to the concentration of significant heritage buildings (Cochran, 1990). Making sure the town doesn't get stuck in its past is also a key driver.
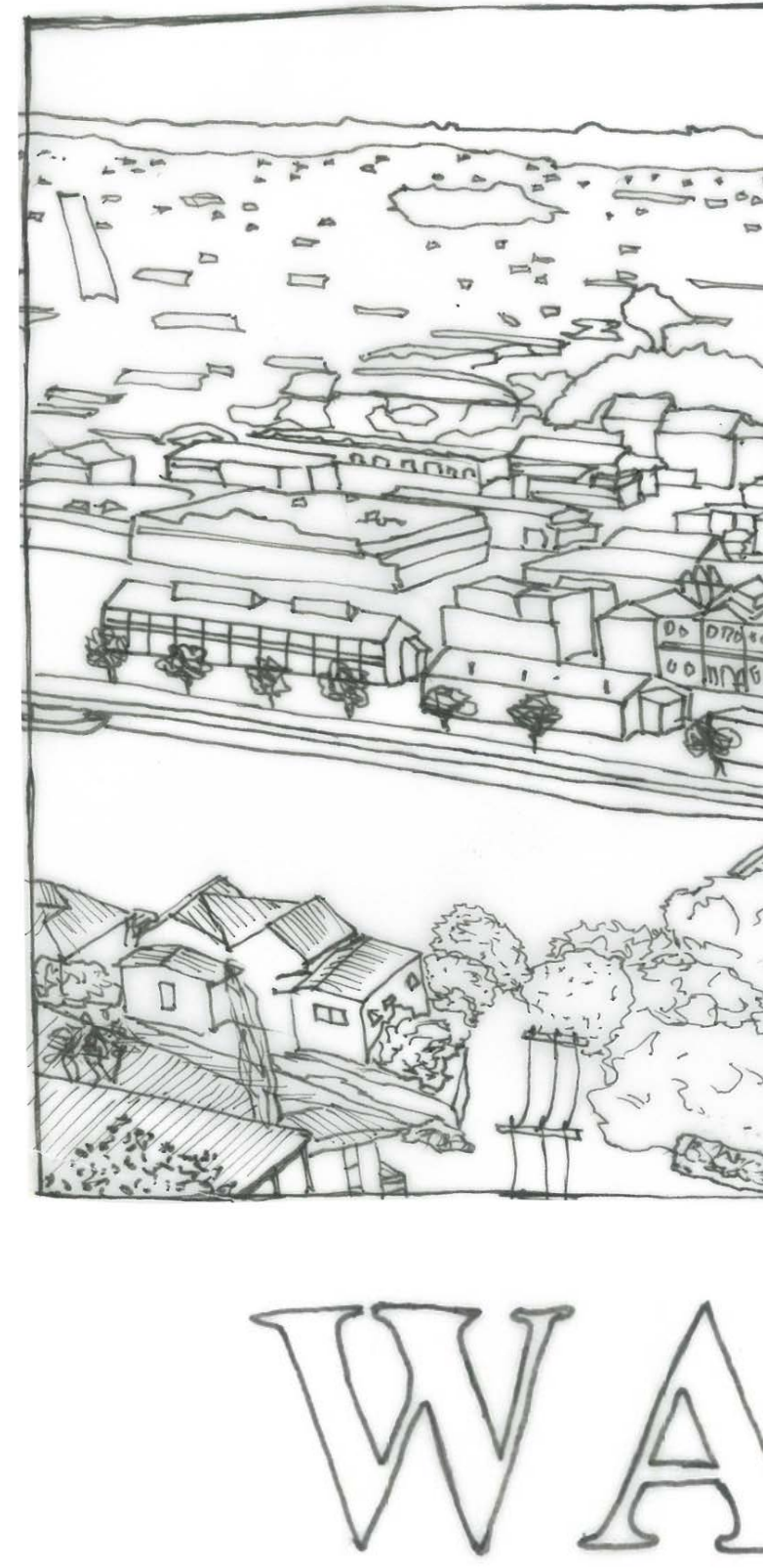

"Here one can liv - A lett 


\subsection{EUROPEAN SETTLEMENT}

Whanganui is an area of early European settlement due to being the Second New Zealand Company settlement in New Zealand (Cochran, 1990). The ships arrived in the area in 1814 from London.

The possible agricultural potential of the area was then seen. The first real European settlers were the whalers and traders, which led to the falling out between Maori and European due to unfair trade leading to the local Maori selling the heads of visitors in the 1830's.

The New Zealand Company sold a lot of land from London, all unseen, un-surveyed and land in which they did not own. In May 1840, the local land was sold by the native chiefs to the New Zealand Company however the fact that the Maori chiefs returned gifts was a clear indication they had not understood the nature of the land transaction. This lead to the beginning of many land troubles.

In February 1841, the first settlers arrived in Whanganui from Wellington by boat. But many made the five day walk from Wellington along the beach. The area of Whanganui continued to be attractive to settlers for its flat land which could easily be cleared cheaply, while the river also provided excellent communications.

By 1860 , Whanganui had grown to 1,500 inhabitants and the next period of conflict began between Maori and settlers. It had become a thriving rural servicing centre and port as well as still being a military centre.

Whanganui like many early New Zealand towns was very much a town of timber and tin resulting in fire being an ever-present danger. Flooding too was a danger with serious flooding of the town centre in 1858, 1891 and 1904 and this is still a problem today. The boom years in Whanganui were considered to be the 1910's and 1920's where the port was busy, farming was prosperous, and many new buildings were built. Many of these buildings are those standing today.

In 1900 the population of 8,524 then grew to 
27,000 by 1940 . The main industry was rural produce, it was Whanganui largest income and was once regarded as New Zealand's largest cattle shipping centre. Wool sales were also a big income earner with the wool being shipped directly from Whanganui all around the world.

There has been little thought gone into the heritage value of industrial and commercial buildings, which makes up Whanganui's heritage due to the river bringing in a large amount of trade via ships to New Zealand. When the industrial buildings use was no longer required, they were often left vacant and can only be seen as an eye sore to the general public while deteriorating. Lack of respect to heritage, the buildings are often demolished. Therefore denying the buildings potential to have another life cycle. 


\subsection{WHANGANUI DEMOGRAPHICS}

Whanganui is a city located on the west coast of the north island of New Zealand.

After many years of population decline the city population has grown in the last year by 700 people. (Waters 2018)

The test census figures show the population now stands at 44,500 people.

"The population increase reflects what people are experiencing - a lot of Whanga-newbies, rising bouse prices, and a growing economy". - The mayor Hamish McDouall

It has now become an attractive place to live with more jobs available and cheaper rent than other cities. There has also been a growth in international migration.

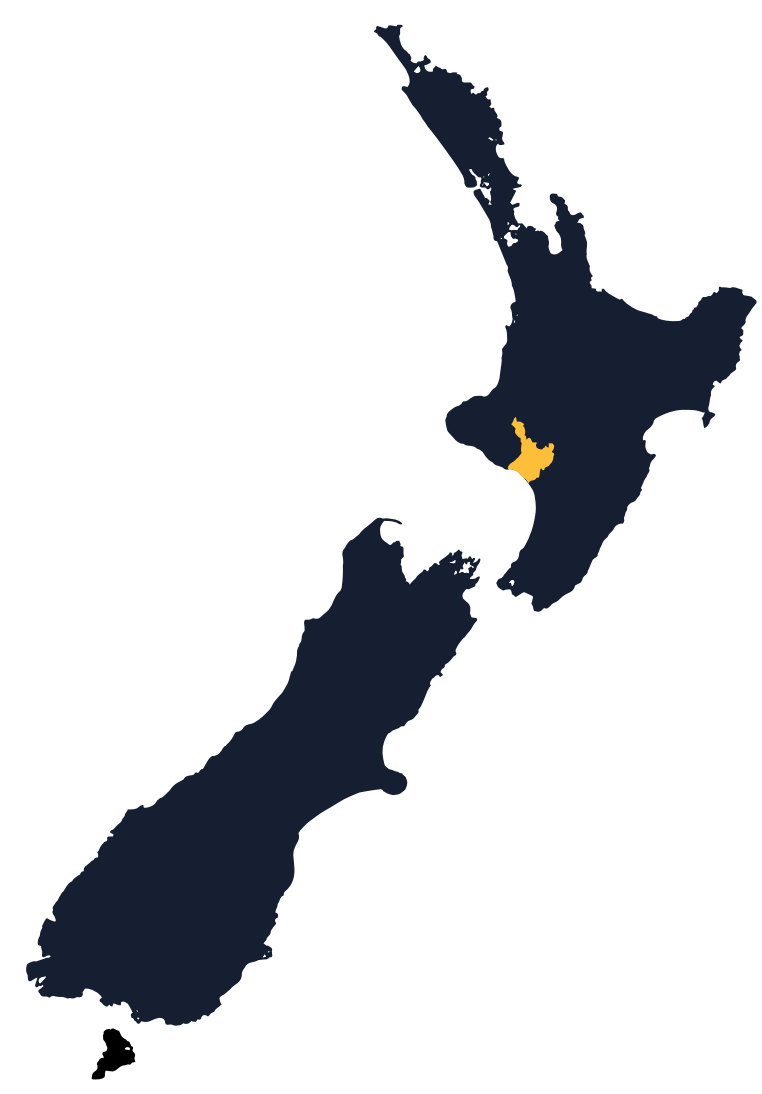

Fig. 5.03: Map of New Zealand indicating the region of Whanganui. 


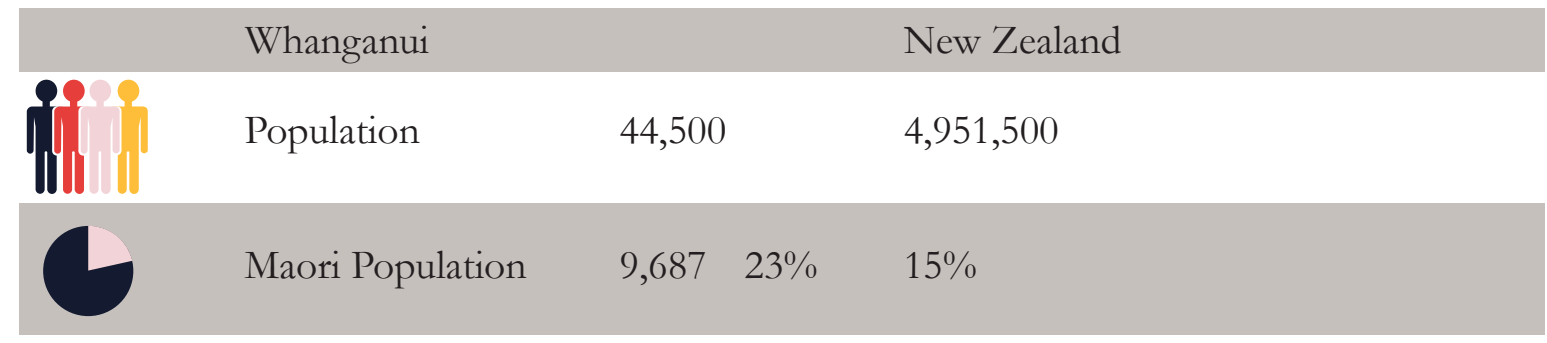

$\begin{array}{lll}\text { Speaks Maori } \quad 2,202 & 5.2 \% & 3.1 \%\end{array}$

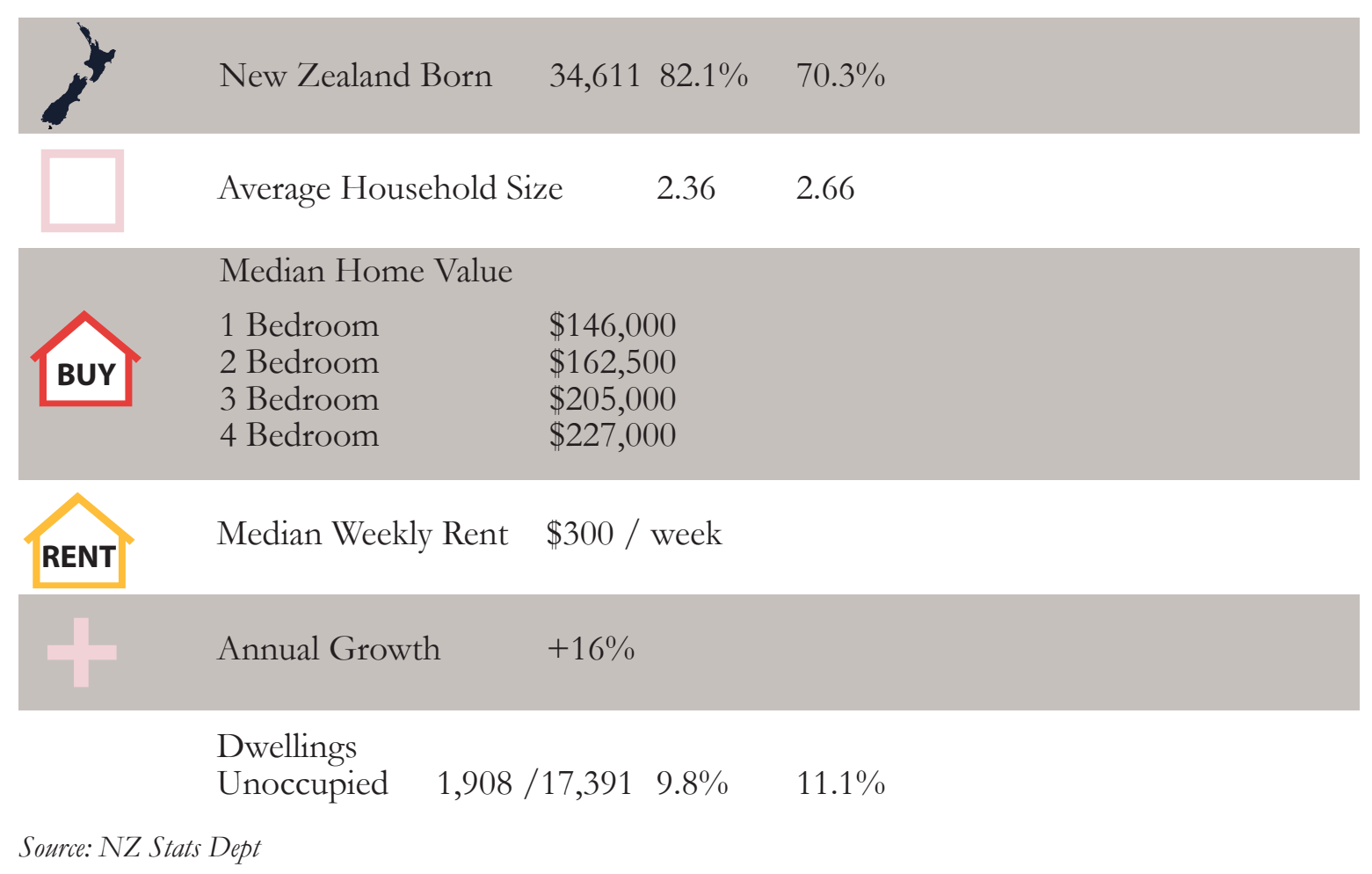




\subsection{WHANGANUI CURRENTLY}

Currently there are recommendations on the guidelines for the conservation, restoration and enhancement of heritage buildings within the conservation areas in Whanganui.

The most cost effective and dramatic method of improving individual heritage buildings and the street scape is the heritage paint colours.

Signage on the heritage buildings is a major problem in Whanganui, traditional signage was always painted on and was usually located on the parapet of the building, on the verandah fascia or painted on the window glass.

Verandahs should be of suspended or cantilevered style and posts occur they should be non-structural. There is encouragement for the replacement of traditional verandahs and architectural detail.

The historic architectural features are often altered on the shop fronts of commercial buildings and with sensitive rehabilitation the revitalisation is possible. In Whanganui many of the heritage buildings suffered from a loss of significant towers and very commonly decorative ornaments and pediments are missing. A large amount of the detail seemed to have been removed after the 1931 Napier earthquake. They could have been replaced with lightweight materials although due to cost it was believed not necessary. 


\subsection{MAKING WHANGANUI VISIBLE}

'Making Wanganui Visible' by Urbanismplus ltd, is a key document due to it recognising the needs for Whanganui's future. It discusses the opportunities and challenges the town faces in Whanganui's town centre. The potential sustainable urban solutions and a vision for the upgrade of the town centre. All while taking into account retail, arts and culture, tourism, employment, community, built form, river connection, transport and nature.

There is a significant level of oversupply of town centre retail and office floor-space with low levels of occupancy above ground floor level. Some early interest in the conversion of retail property to residential use is evident although low capital and rental values together with Building Act requirements make such proposals marginal at best.

Whanganui has an attractive town centre environment with a lot of potential but some tough decisions around land use and floor space in the town centre are necessary if Whanganui is to be strongly and positively positioned to serve its community, attract additional residents and investors and those who may wish to do business, live or play here in the future. 


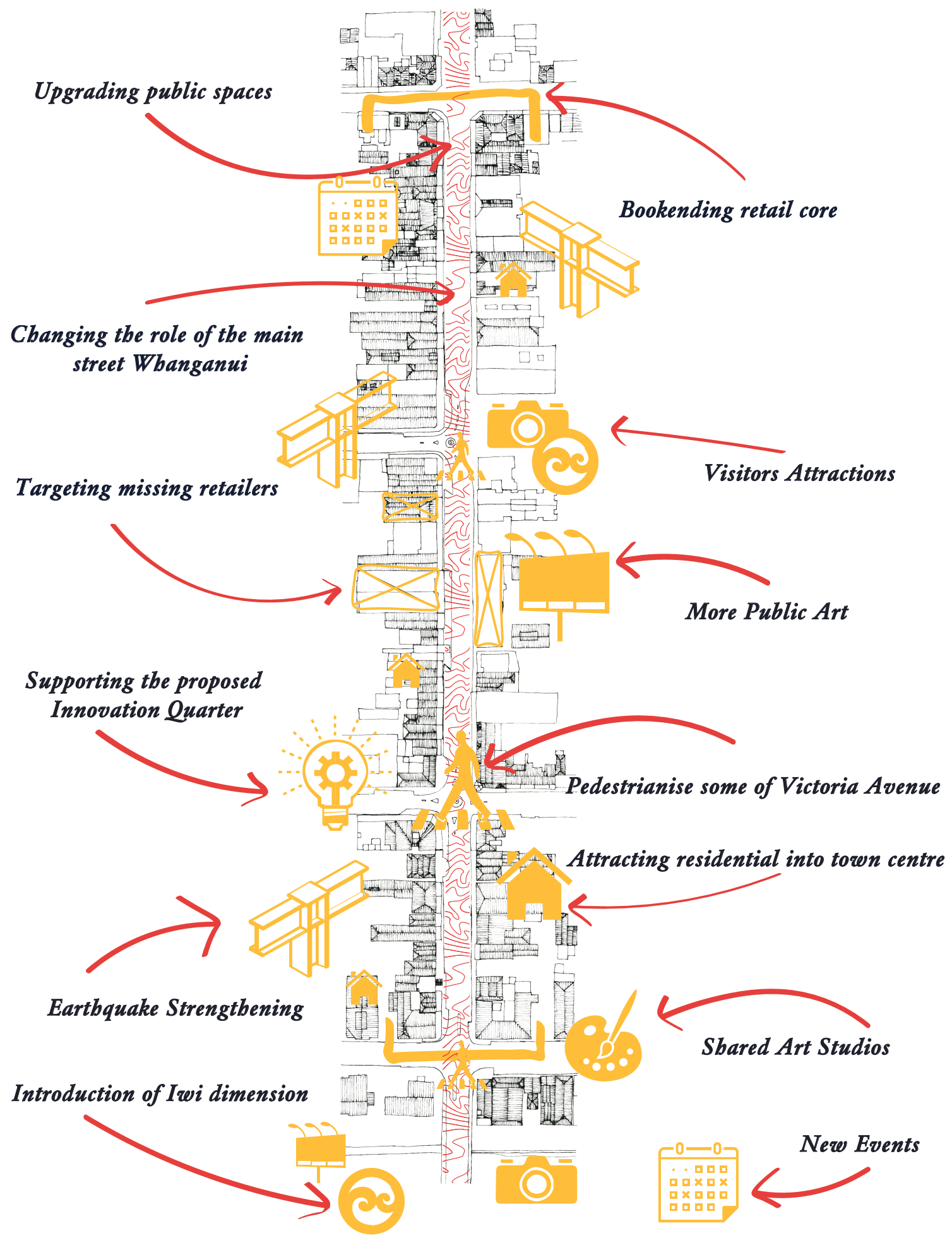

Fig. 5.04: Strategies taken from 'Making Whanganui visible' to regenerate Whanganui's town centre. 
Within the regeneration strategy issues which could be accomplished through the chosen site include;

- Significance of the river and river-front linkage

- Physical shift of town centre retail towards the river in the last decade.

- Reflection of multi-cultural community in the physical urban environment.

- Enhancement of the built heritage resource, recognition of earthquake prone building and design guideline issues and opportunities.

- Technology, government policy and earthquake prone building implications for the existing town centre.

- The potential for new technology to significantly impact the built environment through reducing demand for retail premises and demand for flexible, mixed use developments.

- Implications of the trend for commercial activities to establish in locations beyond the existing commercial area on the residential fringes or adjacent to key transport routes.

- Integration and enhancement of transportation facilities consistent with objectives of the Whanganui Urban Transportation Strategy 2011.

- Commercial and residential location and development trends. Impediments to potential demand for future residential development within the town centre area.

- Creating an attractive shopping experience

Whanganui's stock of preserved historic buildings defines the town's character for a large part. However, many of these buildings are underutilised or vacant or even under threat of demolition. For the well-being of the centre, these buildings generally deserve revitalisation, supported by public space enhancements. 


\section{WHANGANUI DISTRICT PLAN.}

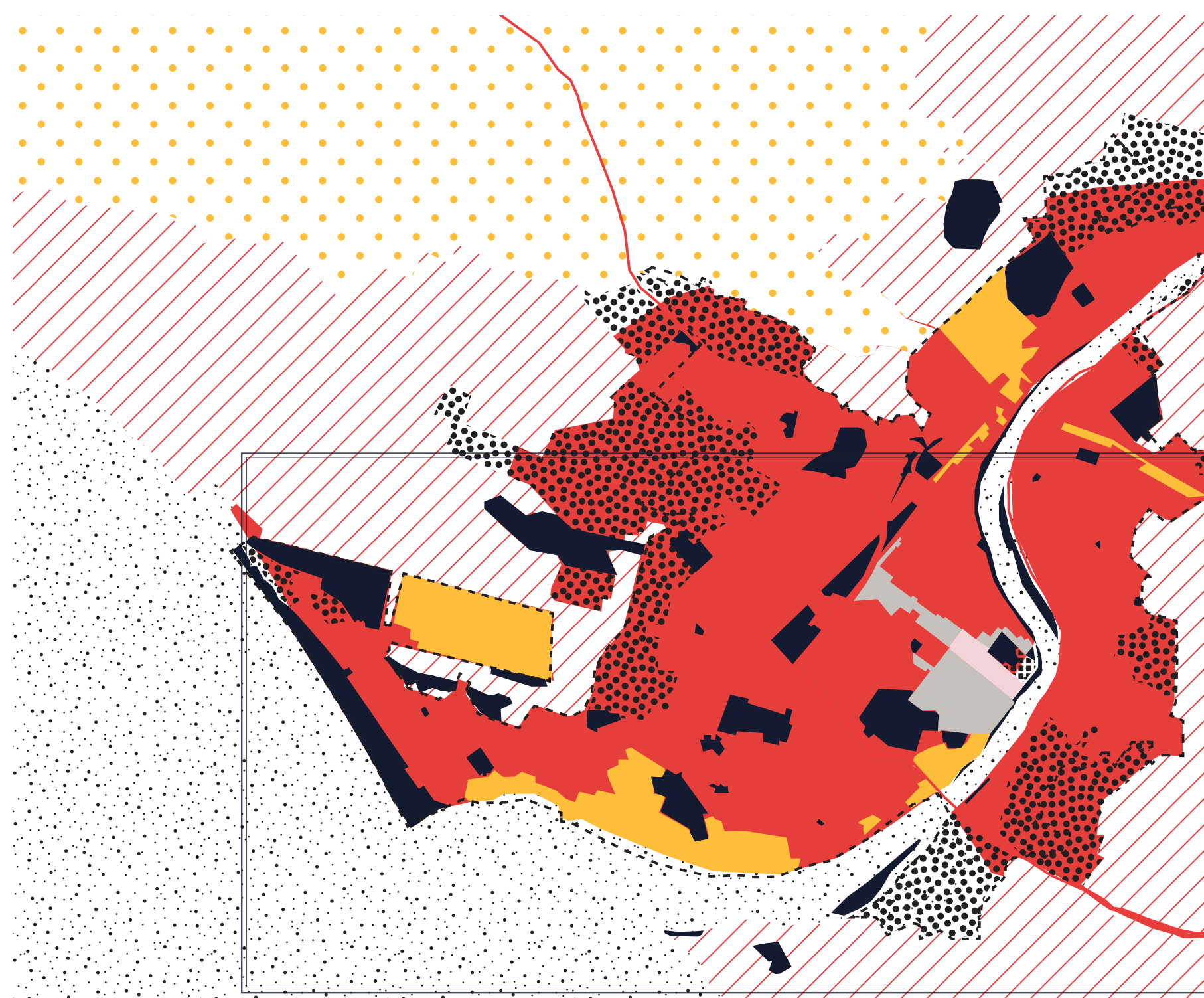

Fig. 5.05: District plan map indicating the land use. 


\section{WHANGANUI CITY PLAN}

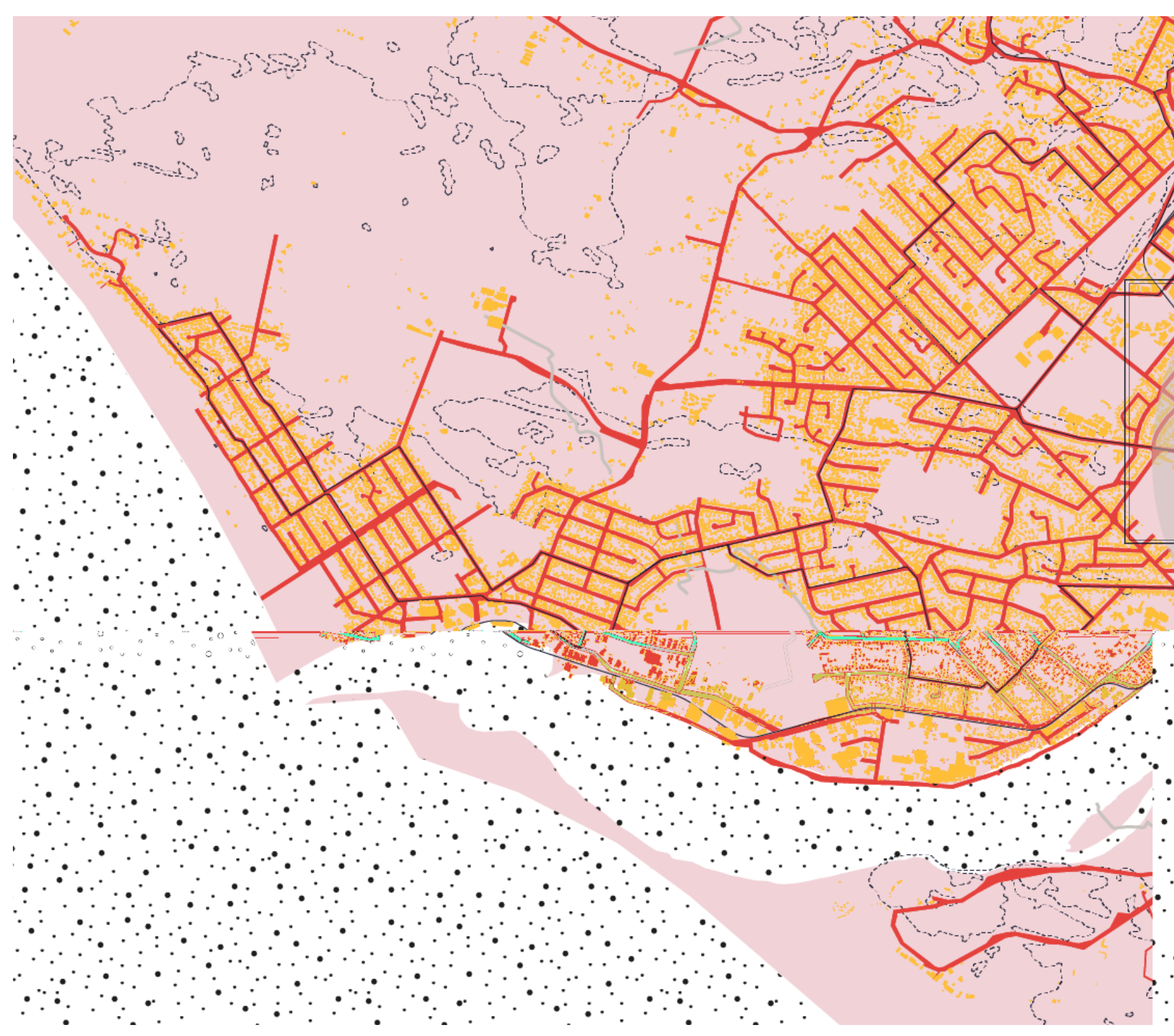

Fig. 5.06: City plan show the citys sprawl along the river. 


\section{CITY CENTRE PLAN}

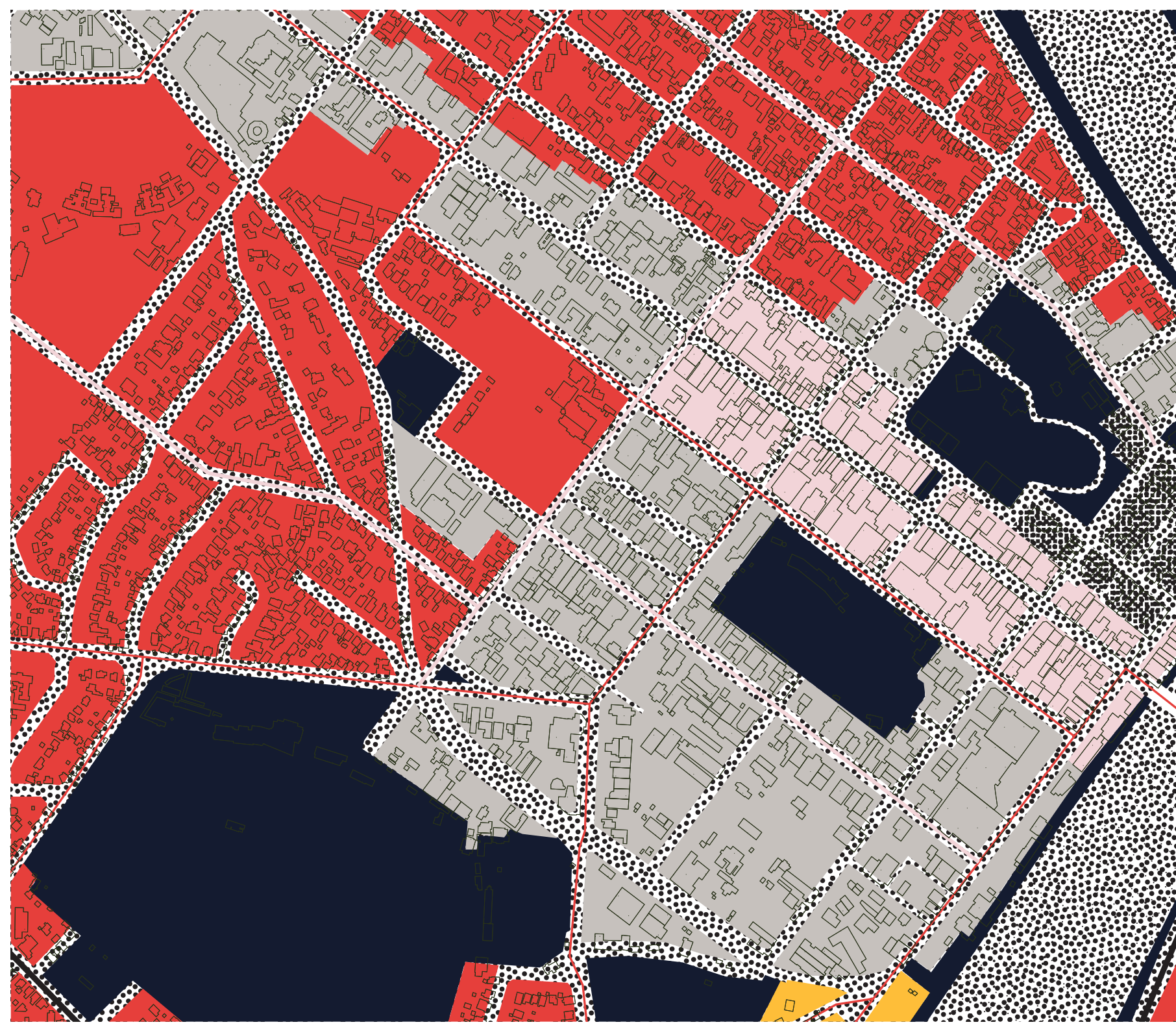

Fig. 5.07: City centre plan representing zones and roading. 


\section{PANORAMIC VIEW OF WHANGANUI}

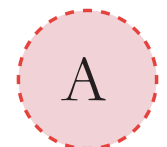

River bank walkway running the length of Taupo Quay.

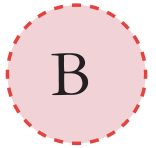

Whanganui river upstream from site, often used for rowing and waka ama and boating activities.

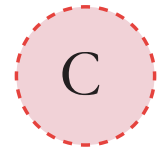

No connection to river with harsh concrete retaining wall. Road to kowhai park and Whanganui East.

D City to sea bridge, looking towards Durie Hill, which is mostly residential.

E Main road entry into Whanganui city centre. Again harsh concrete with no connection to river.

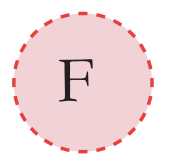

River looking south, $6 \mathrm{~km}$ to the sea.

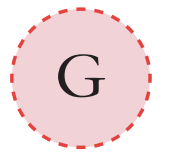

Industrial area of Whanganui with the board walk wharf.
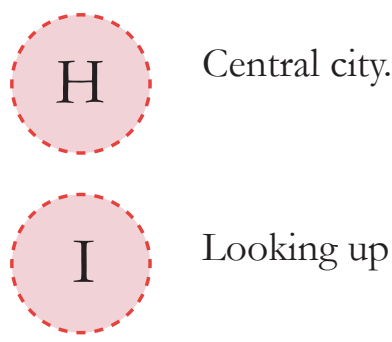

Looking up Victoria Avenue.

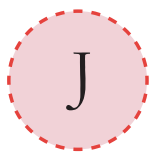

Chosen building.

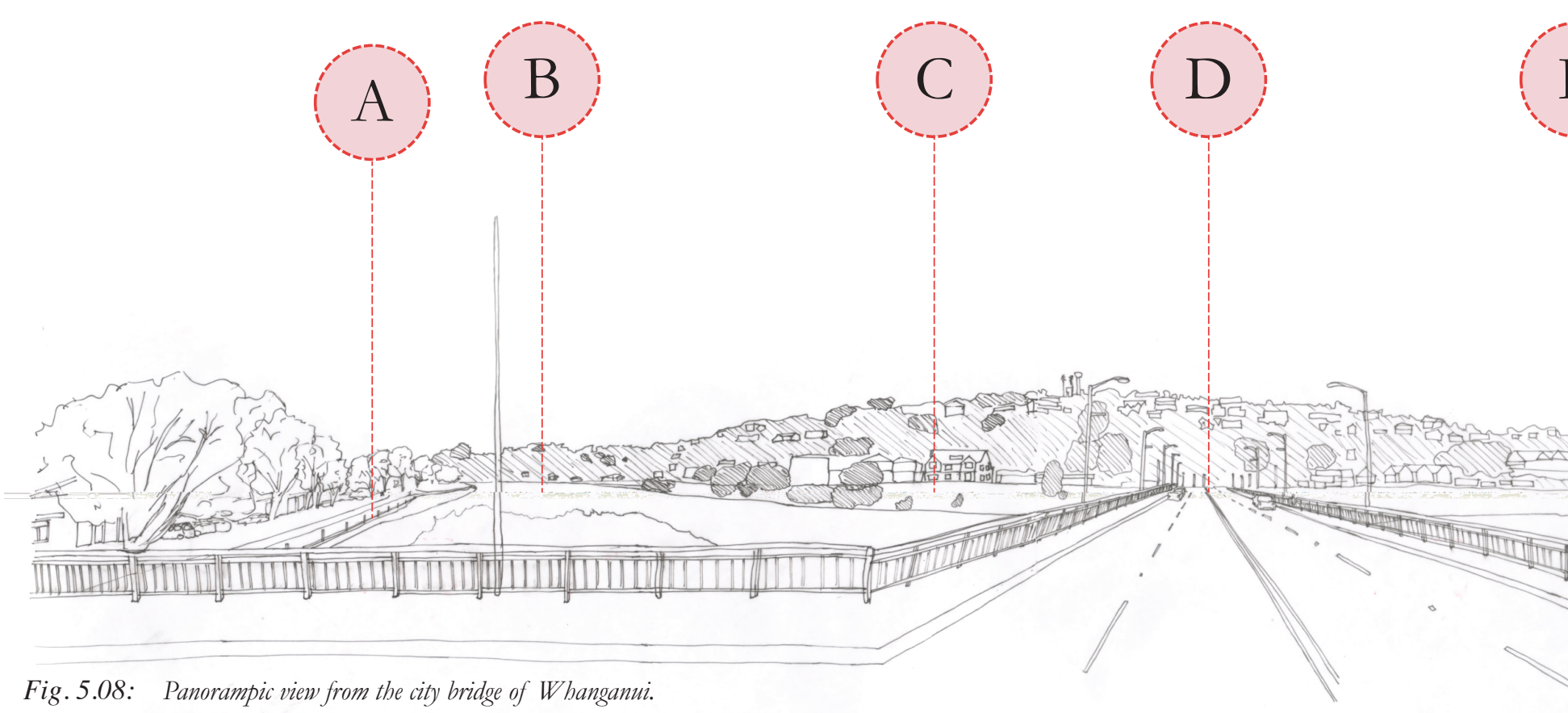

Fig. 5.08: Panorampic view from the city bridge of Whanganui. 


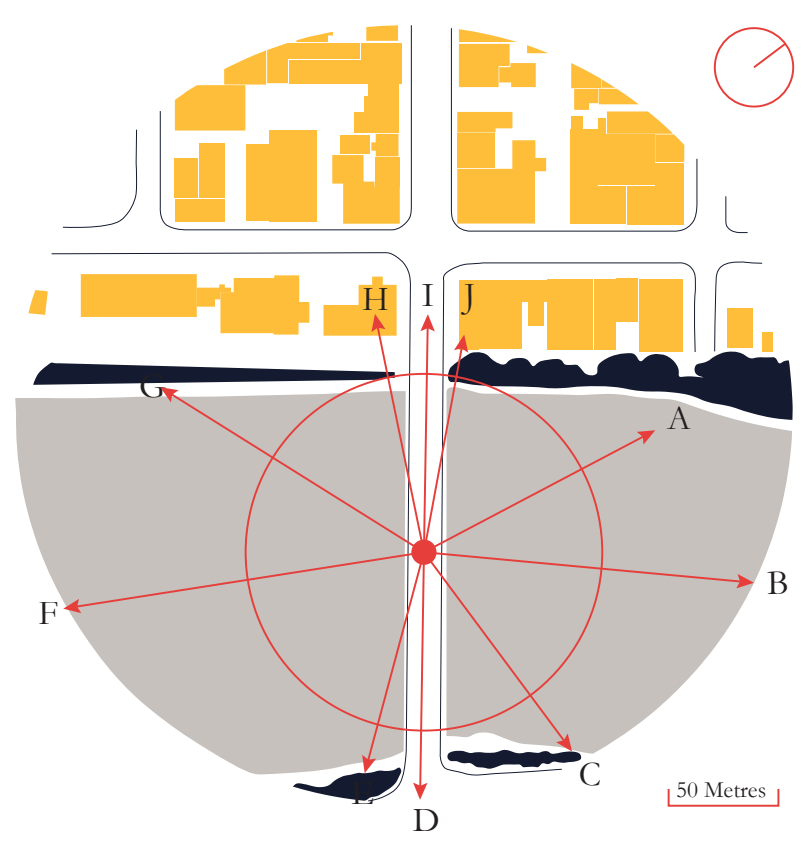

E)

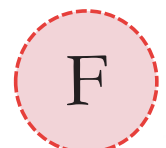

\section{ta}




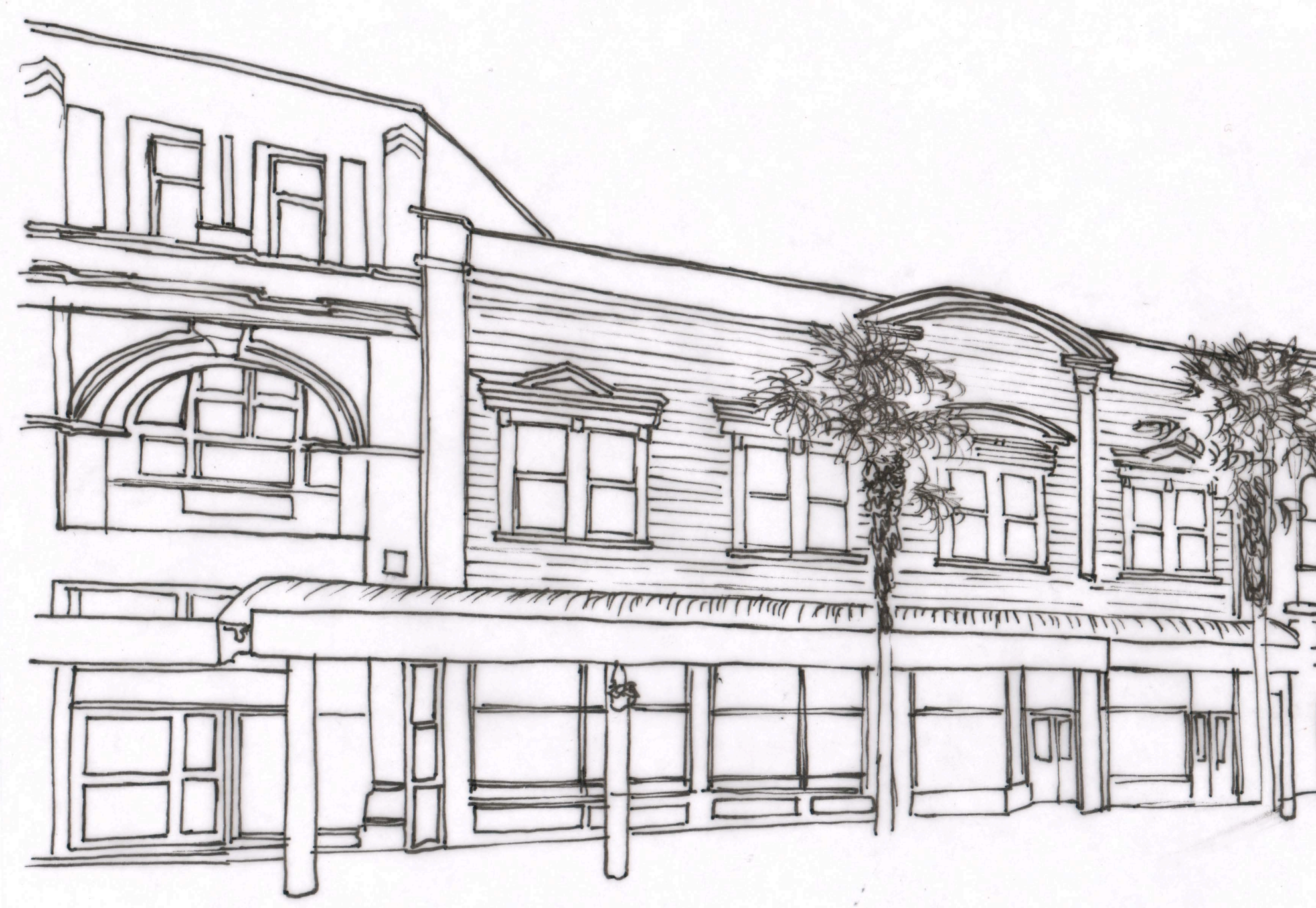

Fig. 5.09: Sketch of Whanganui's main street. 


\section{VICTORIA AVENUE}

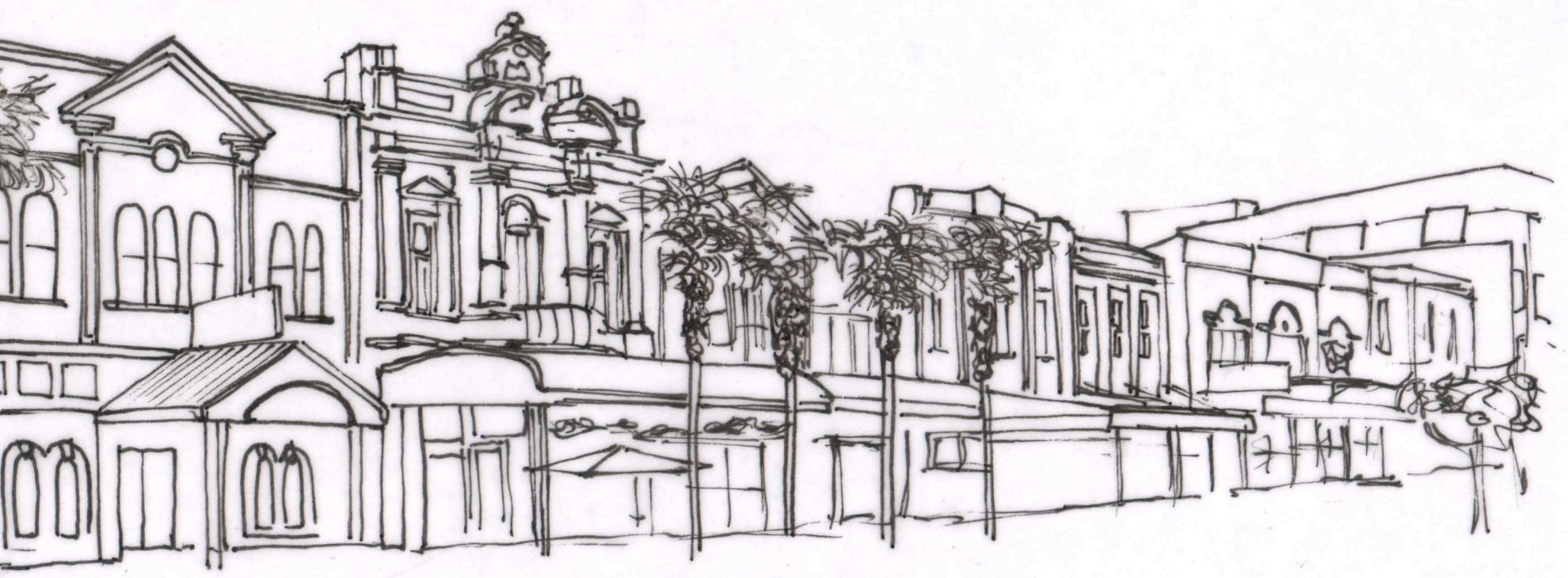




\subsection{RIVER IDENTITY}

In New Zealand the Whanganui River is the longest navigable river running from Mount Tongariro to the Tasman Sea. The river has provided both physical and spiritual support to the local iwi and their hapu. It also provided for the Maori population until the arrival of Europeans.

New Zealand's longest standing legal battle ended in March 2017 with the Whanganui river becoming the first river in the world to gain its own legal rights as a human entity. Just five days after the same legal person-hood was given to the river Ganges in India. This shows the potential of how influential and innovative New Zealand is to the rest of the world. (Innovative bill protects Whanganui River with legal personhood)

"The new status of the river means if someone abused or harmed it the law now sees no differentiation between harming the tribe or harming the river because they are one and the same." Eleanor Ainge Roy
(After 140 years of negotiation, Maori tribe wins recognition for Whanganui river, meaning it must be treated as a living entity.)

In May 1940, the crown got involved with the Whanganui iwi and eight years later it purchased its first large block of land and started to claim authority over the river. The following 100 years lead to a steam service being introduced, forest cleared from the river banks, gravel and sand extracted from the river bed and water diverted into a power scheme all damaging the health and wellbeing of the river. (Change-maker-The Whanganui River, n.d.)

The Whanganui, then, was a river without beauty, in a region without a sense of place, in a community without a developed sense of belonging. In the name of progress, the post war town turned its face away from the river.

- (Young, 1998) 

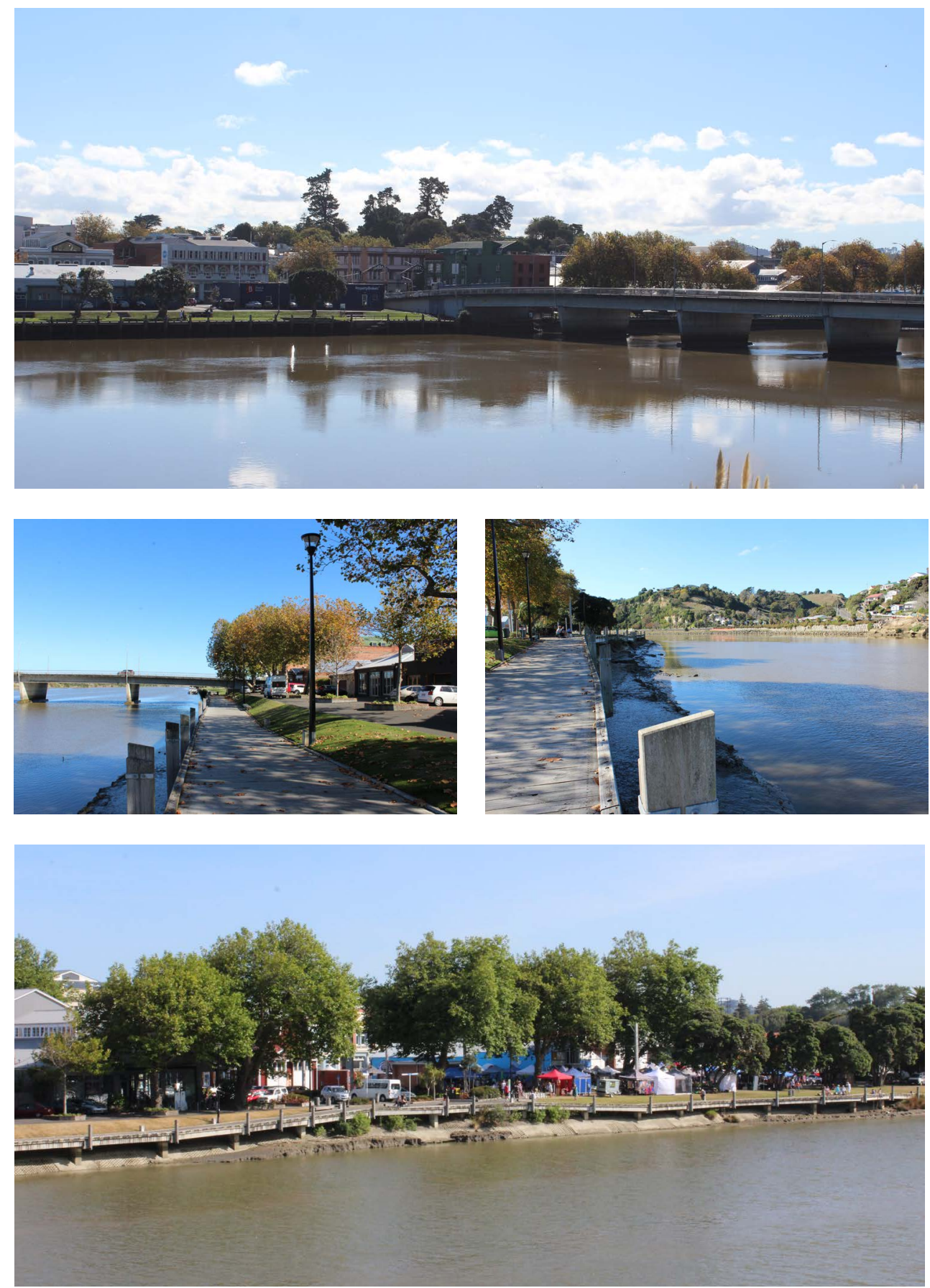

Fig. 5.10: Above - River view looking towards the cross roads.

Fig. 5.11: Left middle - Walkway looking south towards the sea.
Fig. 5.12: Right middle - Looking up river to the location of the Saturday markets.

Fig. 5.13: Bottom - Looking across the river to the Saturday markets. 
The river played an important role for the social life of the Whanganui township with picnics, swimming, boating and rowing being popular. The tribes of Whanganui river travelled by waka, caught tuna (eels), built pa (villages) on its banks and fought for it for centuries. The river includes the whole river system, its spirit, and the people related to it.

Today due the river now being respected, changes are being made. The river banks are being replanted to prevent erosion and the use of the river is monitored. There is currently not enough widespread knowledge about how the river has gained its own identity. The move reflects Whanganui's unique relationship with the river and better understanding of its deep spiritual connection.

Turangawaewae as foundation.

One of the most well known and powerful Maori concepts.

Turanga - standing place

Waewae - feet

Often translated to 'a place to stand' Where we feel especially empowered and connected.

Inner sense of security and foundation.

(Taonga, n.d.)
REDACTED

Fig. 5.14: Left above - Looking up river towards the mountains.

Fig. 5.15: Left middle - The Waimarie paddle steamer.

Fig. 5.16: Left middle-River flooding diagram of the 100 year flood.

Fig. 5.17: Left bottom - 2015 flood in the town's centre.

Fig.5.18: Middle top - Whanganui flood 1940 from Taylorville.

Fig. 5.19: Middle middle - 1904 flood eroding the bank opposite the city centre.

Fig. 5.20: Bottom middle - 1940 flood on the corner of Taupo Quay and Victoria Ave.

Fig. 5.21: Above right-Tourism on the Whanganui river.

Fig. 5.22: Bottom right - The multiple Maori settlements up the Whanganui river.
REDACTED

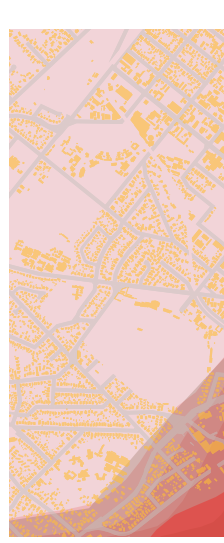

REDACTED 
REDACTED

REDACTED

\section{REDACTED}

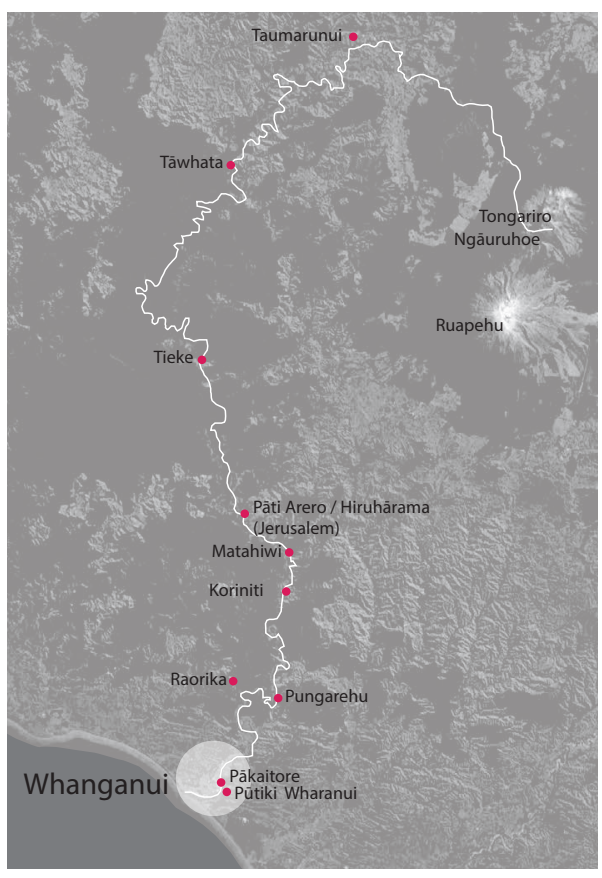




\section{WHANGANUI CITY BRIDGE}

The city bridge originally opened to allow for ships and cargo to pass through it, although in the 60's this aspect changed due to the need to run water mains and electricity across the bridge. In 1970 the new large bridge was formed to allow for the town's growth in population and as vehicles became the main mode of transport.

Due to the widening of the bridge this also changed the connection pedestrians had with the river from Victoria Avenue. The bridge now passes close by the Johnston and Co building creating a small alleyway often cold and shaded due to being either side of the bridge and the three story building. A small water feature at child's height was installed to bring some friendliness to the space but the space needs to be better designed.
Fig. 5.23: Original Arches of the bridge 1919.

Fig. 5.24: The old bridge and Johnston and Co .

Fig. 5.25: Todays view from the City bridge to the town centre.

Fig. 5.26: Whanganui viewed from Durie Hill.

Fig. 5.27: Whanganui 1872, The barque "Malay" which sailed direct from England to Whanganui.

Fig. 5.28: The old town bridge with open span. It last opened in 1902. 


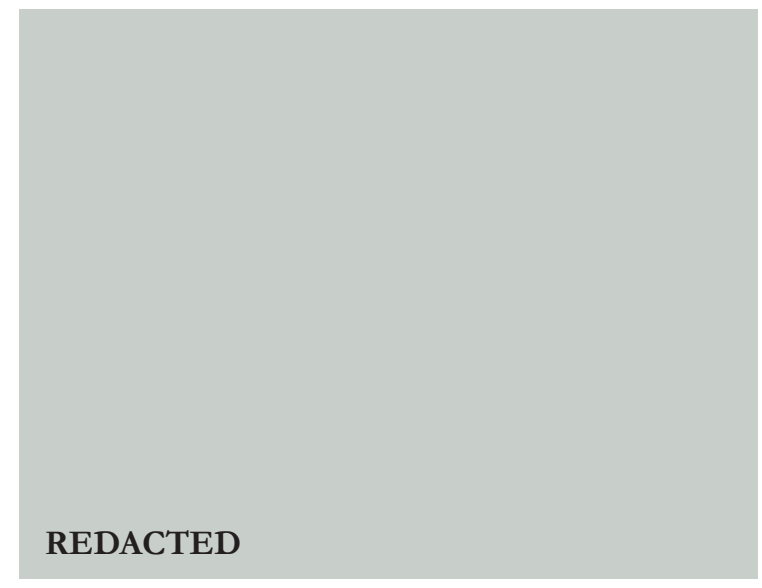

REDACTED

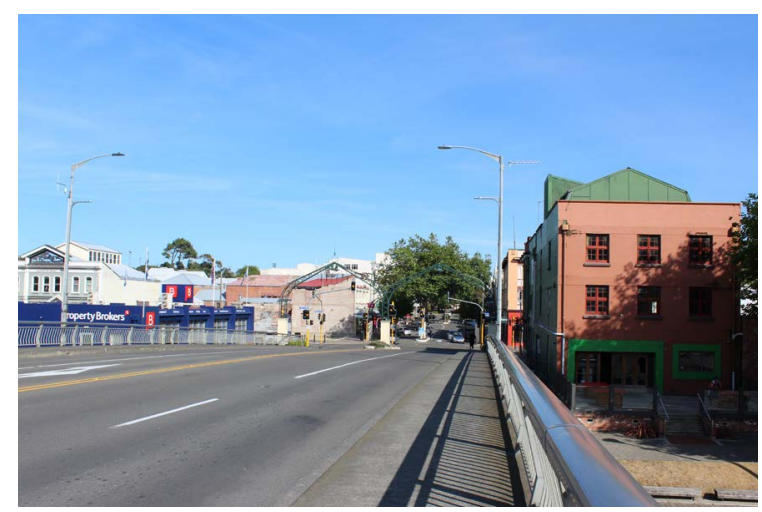

REDACTED

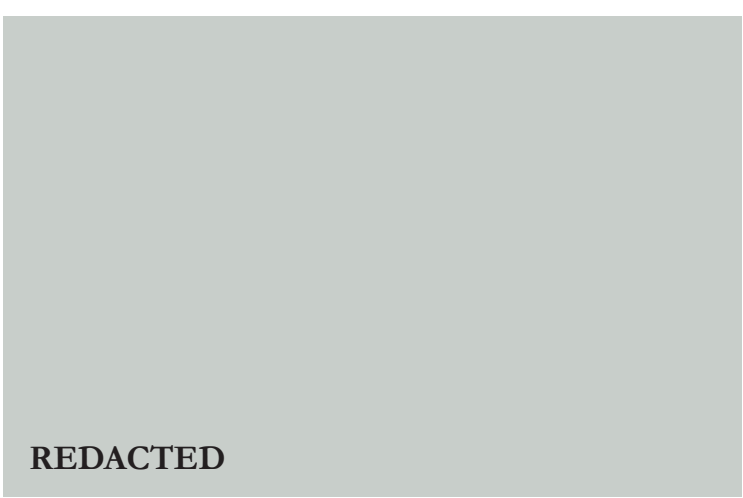

REDACTED 

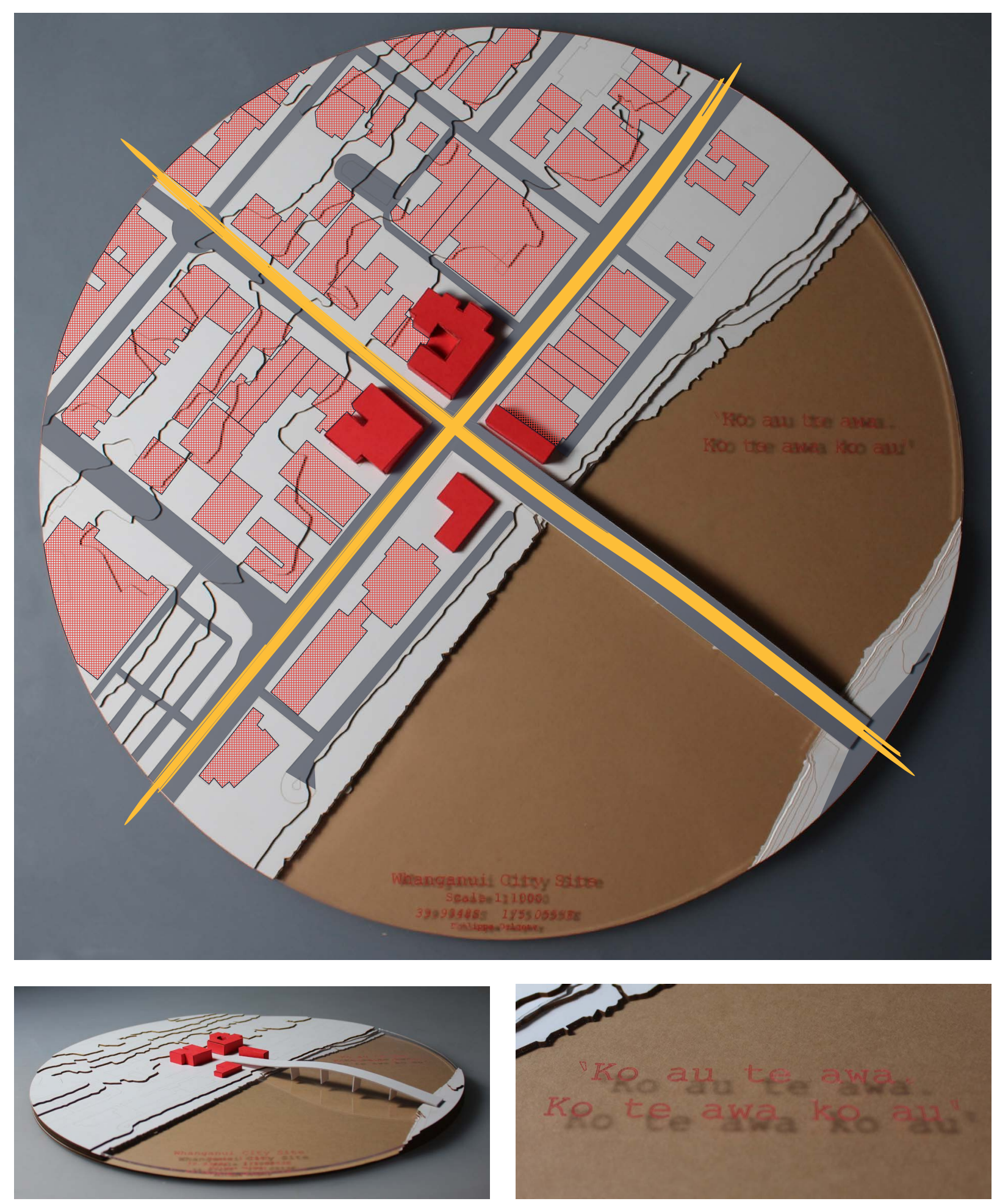


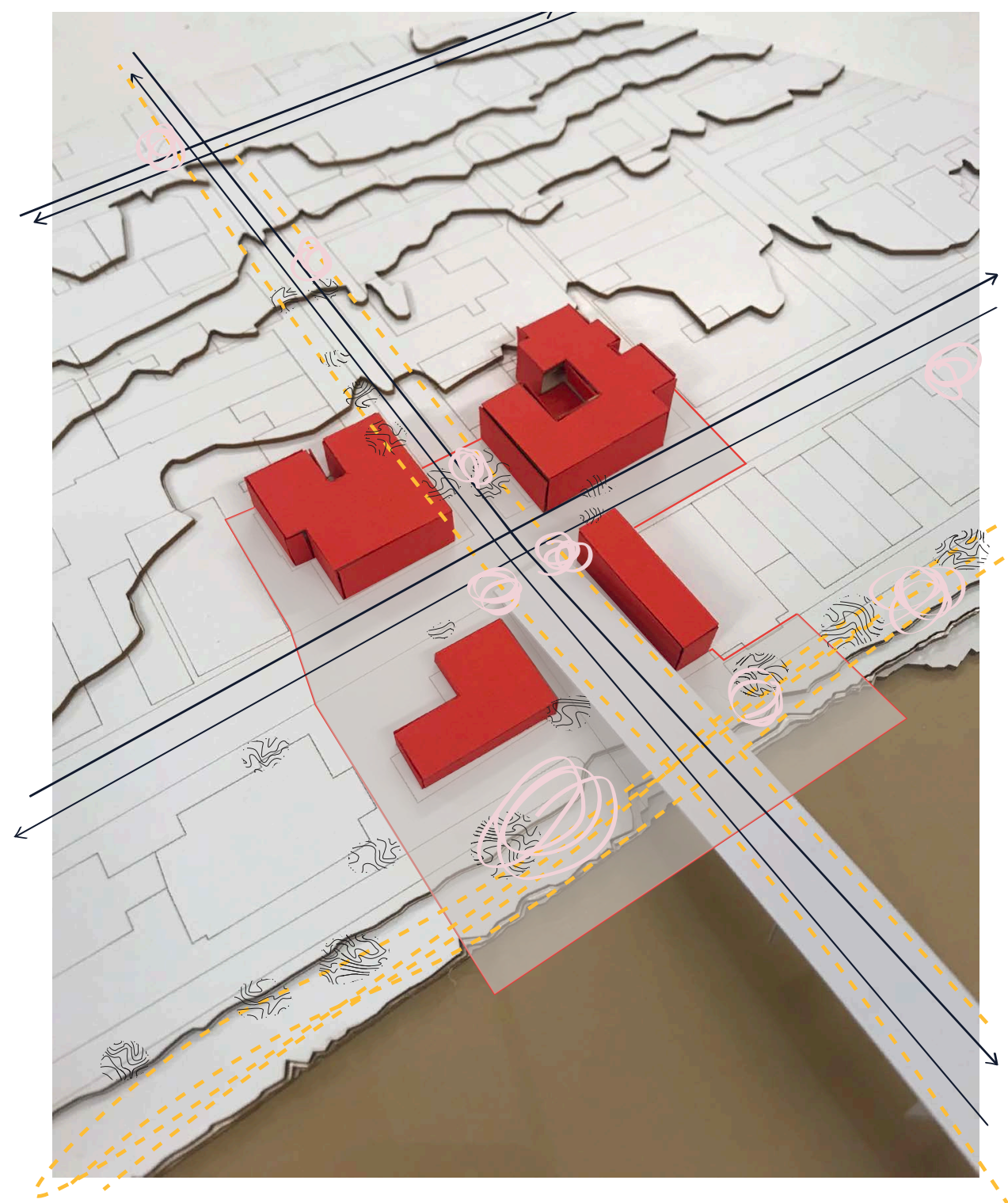

This model shows the landscape of the river in relation to the chosen site. The blue lines indicate the transportation routes of cars, while the yellow indicates pedestrian flow through the site. The pink illustrates the most common meeting points or clusters of people.

Fig. 5.29: Left - Plan view of physical model with digital analysis.

Fig. 5.30: Bottom left-Physical model photo.
Fig. 5.31: Quote meaning 'I am the river, The river is me.'

Fig. 5.32: Close up of physical model showing shadding, traffic and pedestrian flow. 


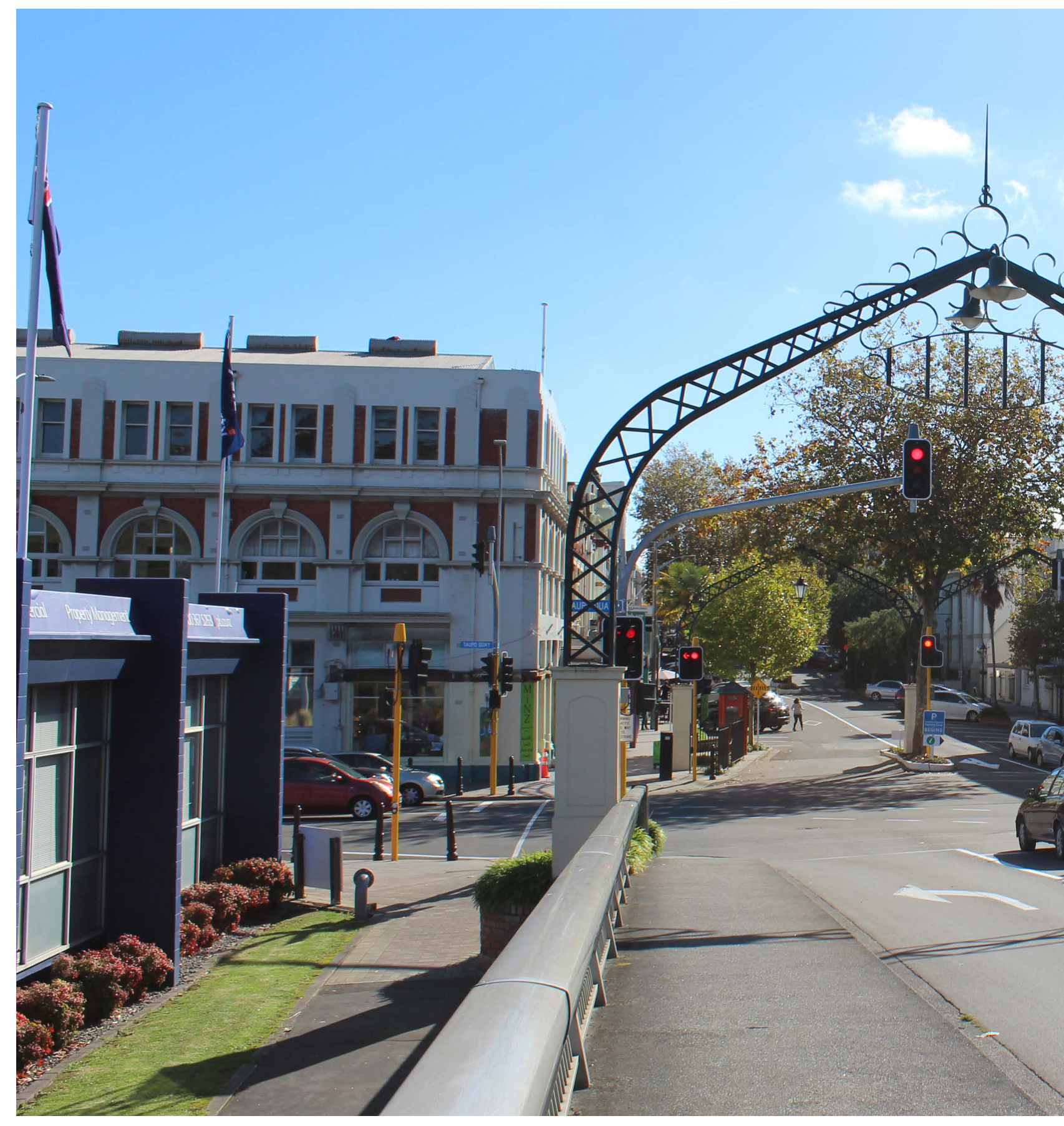

Fig. 5.33: The cross roads of Whanganui. 


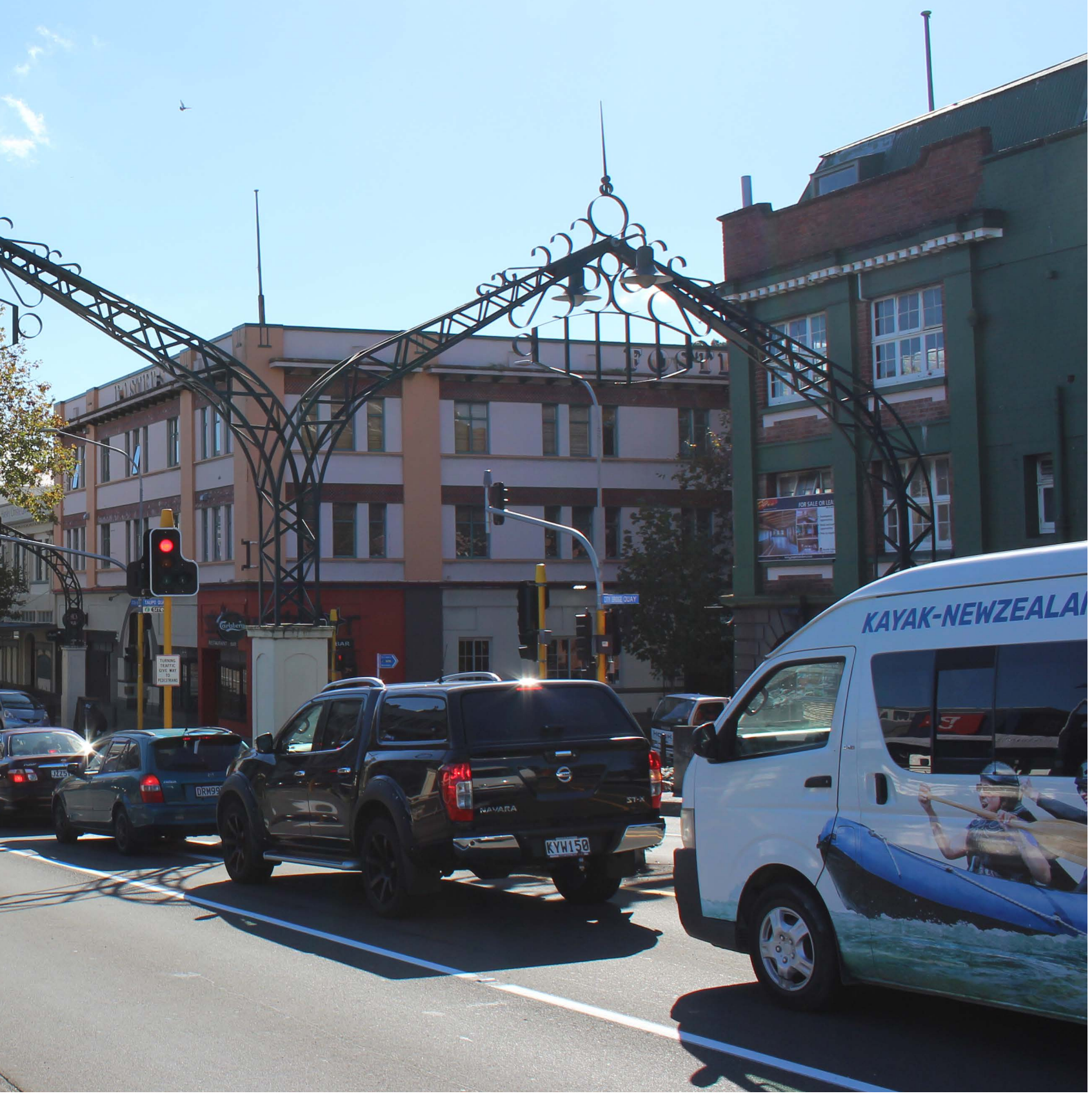




\section{CONCLUSION}

The site analysis gives an opportunity understand all aspects of Whanganui's history and context. Having this information and understanding how it may affect the design decisions later in the design stage is greatly beneficial.

Having the council's future development plans from 'Making Whanganui Visable" allowed for a strong source of projected futures and a view of what they believed Whanganui needs in its future.

The analysis of the existing regional and city plans illustrated the large amount of rural / agricultural areas which make up a lot of Whanganui's population.

The surprising demographics were the population growth of Whanganui as well as its percentage of Maori and Pacifica population is also considered larger than other regions.

Reflecting on these findings will give the design a better grounding within its context as well as reasoning behind the design choices. It also provides an example of the process undertaken to gain a strong understanding of the site. 


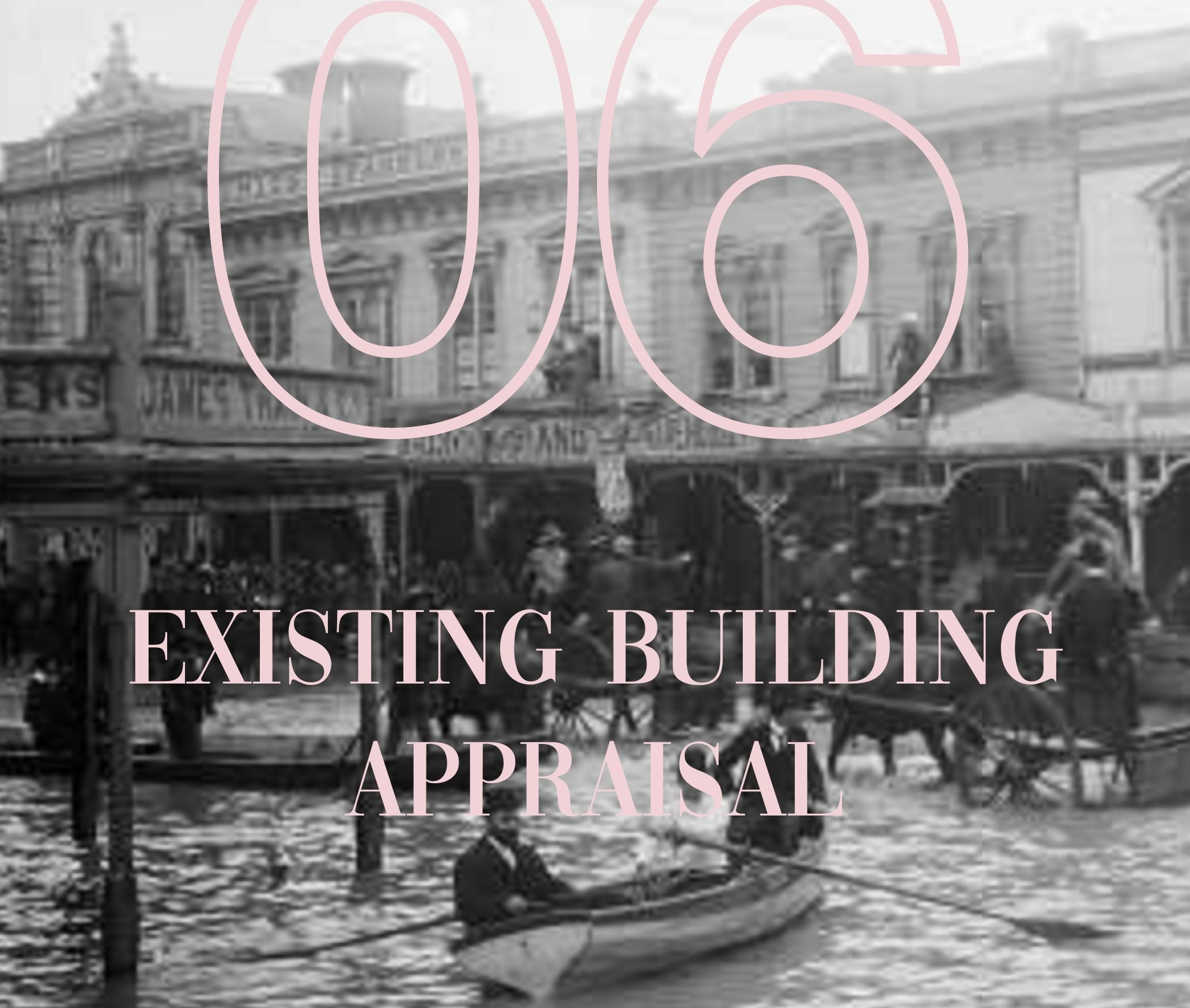


This chapter looks closely into each of the chosen buildings and their history's to therefore be able to revitalize them, through design while respecting their heritage.

A time line and collage of images has been used to gain a snapshot of the changes made to the building over its life cycle and give understanding of the buildings past. As many of the buildings have undertaken many small alterations to suit the changes in building use and can be seen visually.
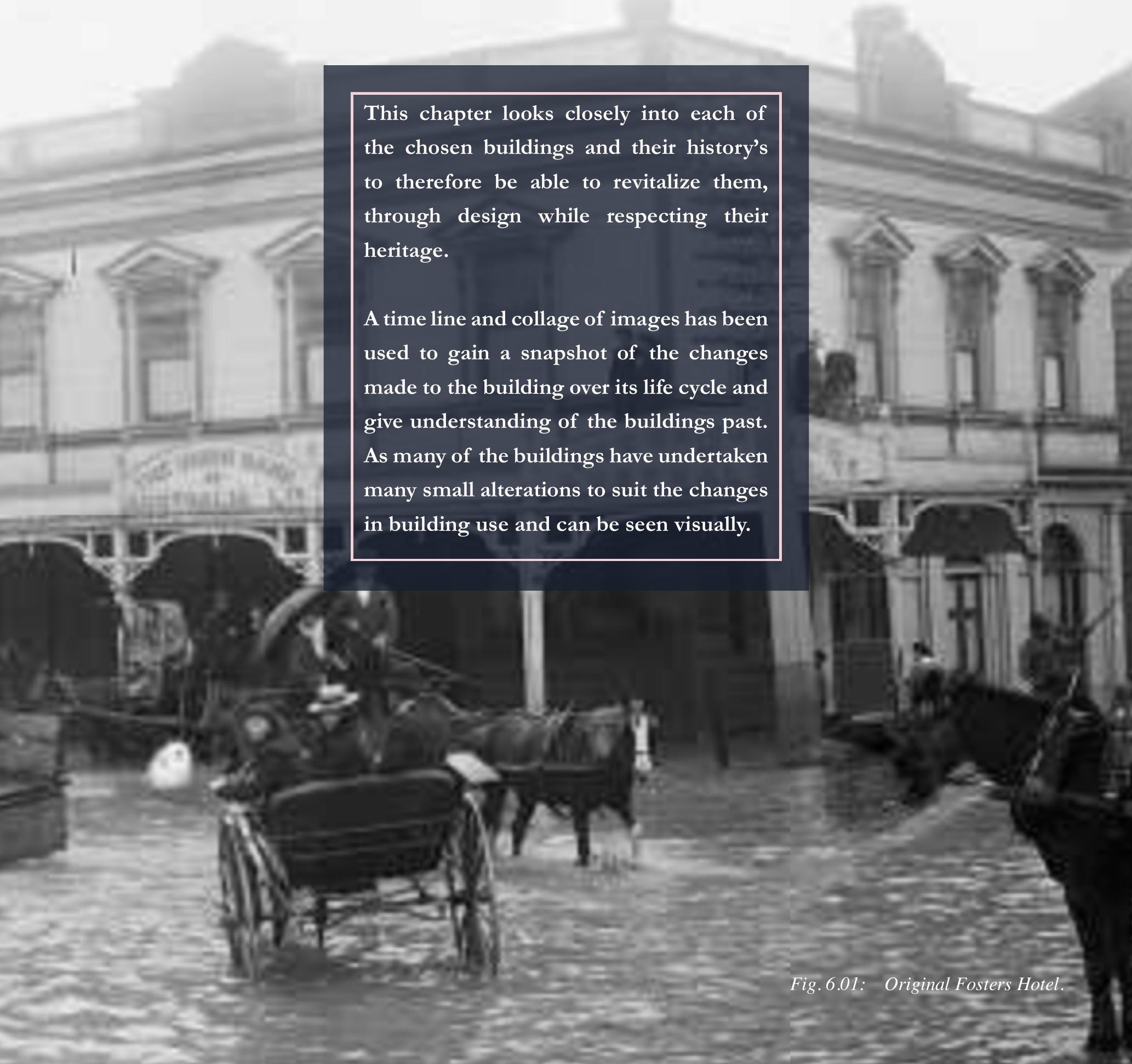


\section{CHOSEN BUILDINGS}

The reason for doing four buildings is to have the opportunity to deal with different issues and create multiple uses within the area establishing a revitalised town centre. Choosing to do Johnston and Co building more in depth allows the amount of detail necessary to be explored to express a successful adaptive reuse. 


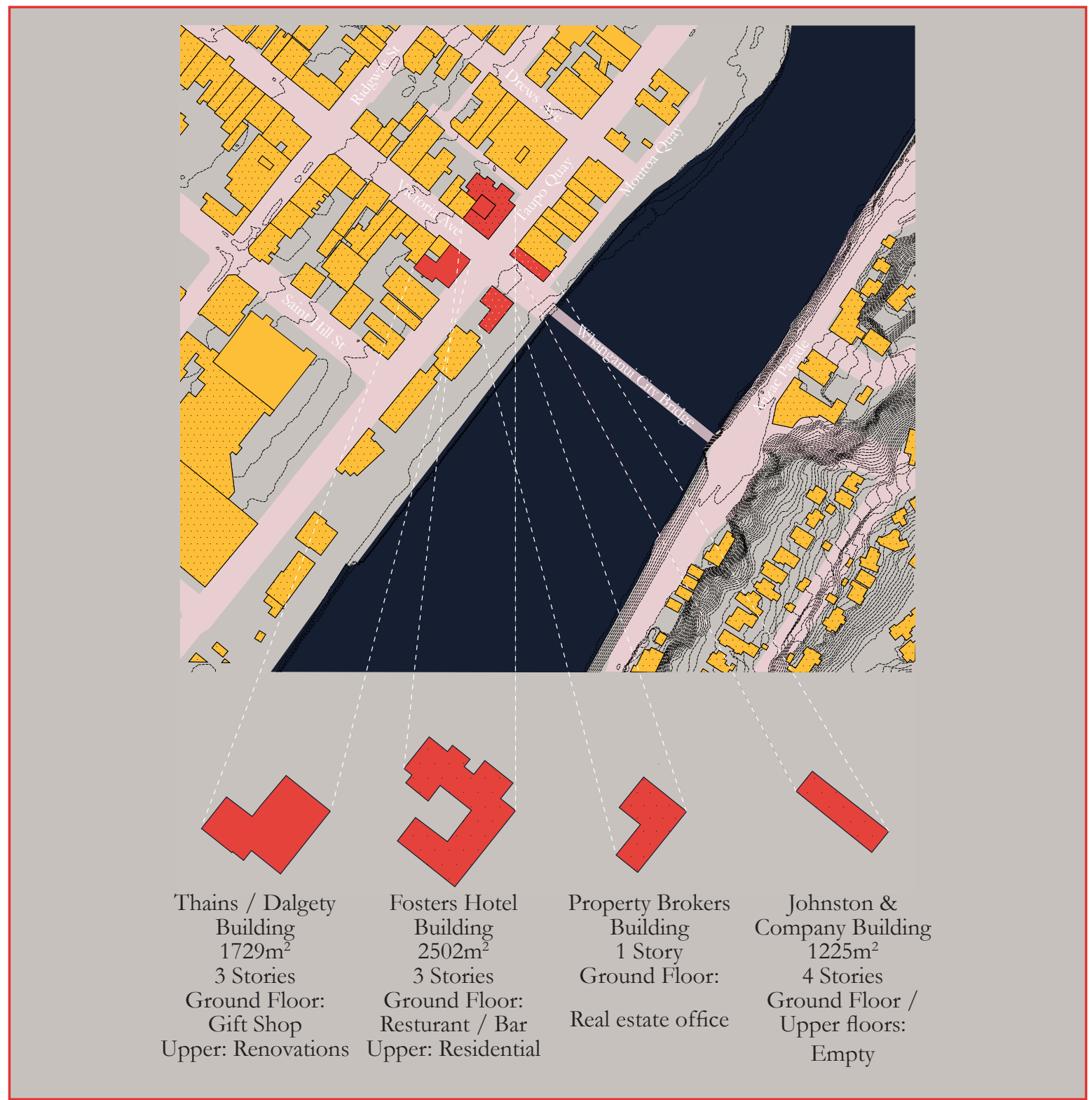

Fig. 6.03: Illustration showing the four chosen buildings. 


\subsection{JOHNSTON AND COMPANY BUILDING}

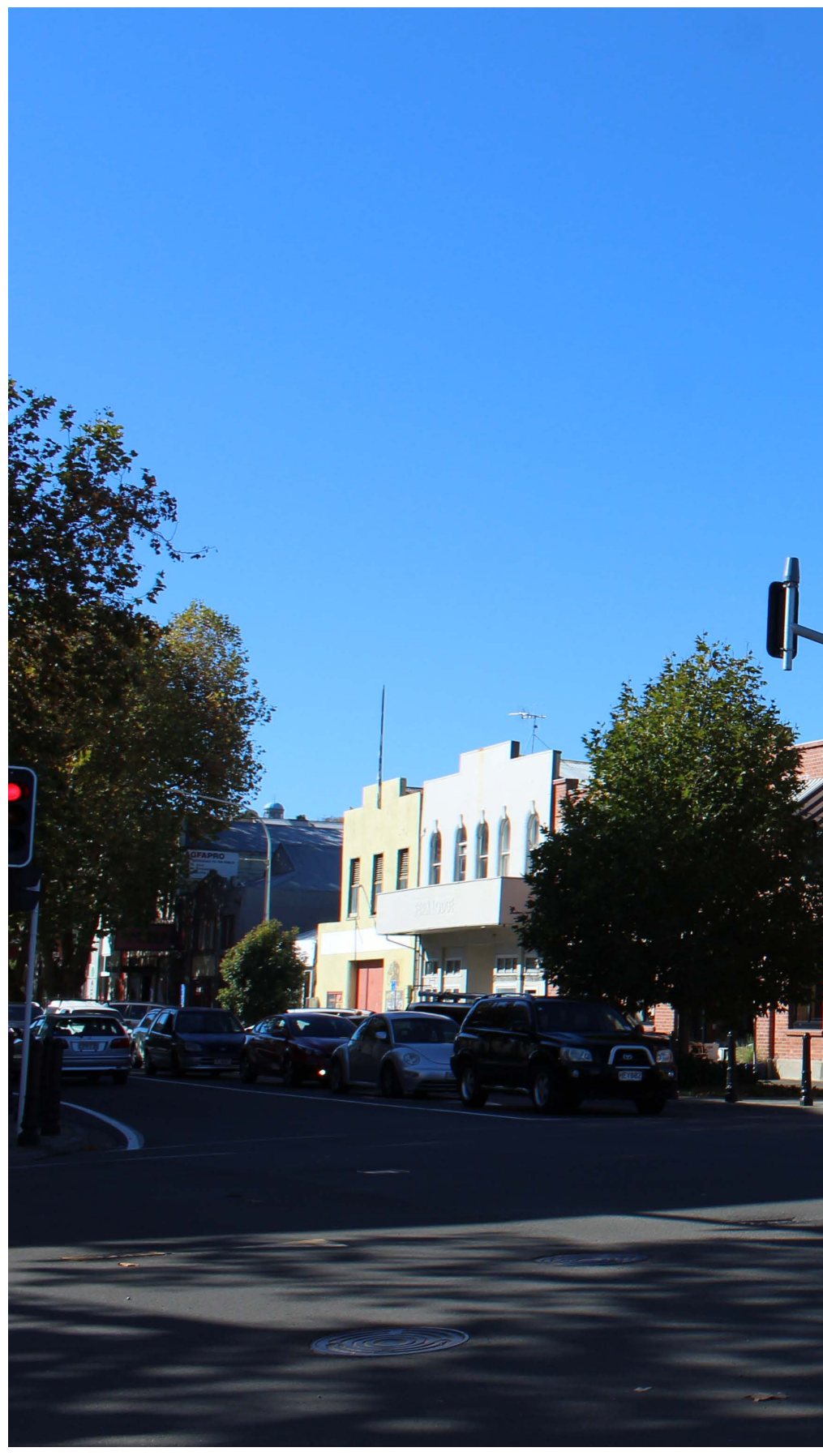

Fig. 6.04: Location plan of the building.

Fig. 6.05: Street view of Johnston and Co Company. 


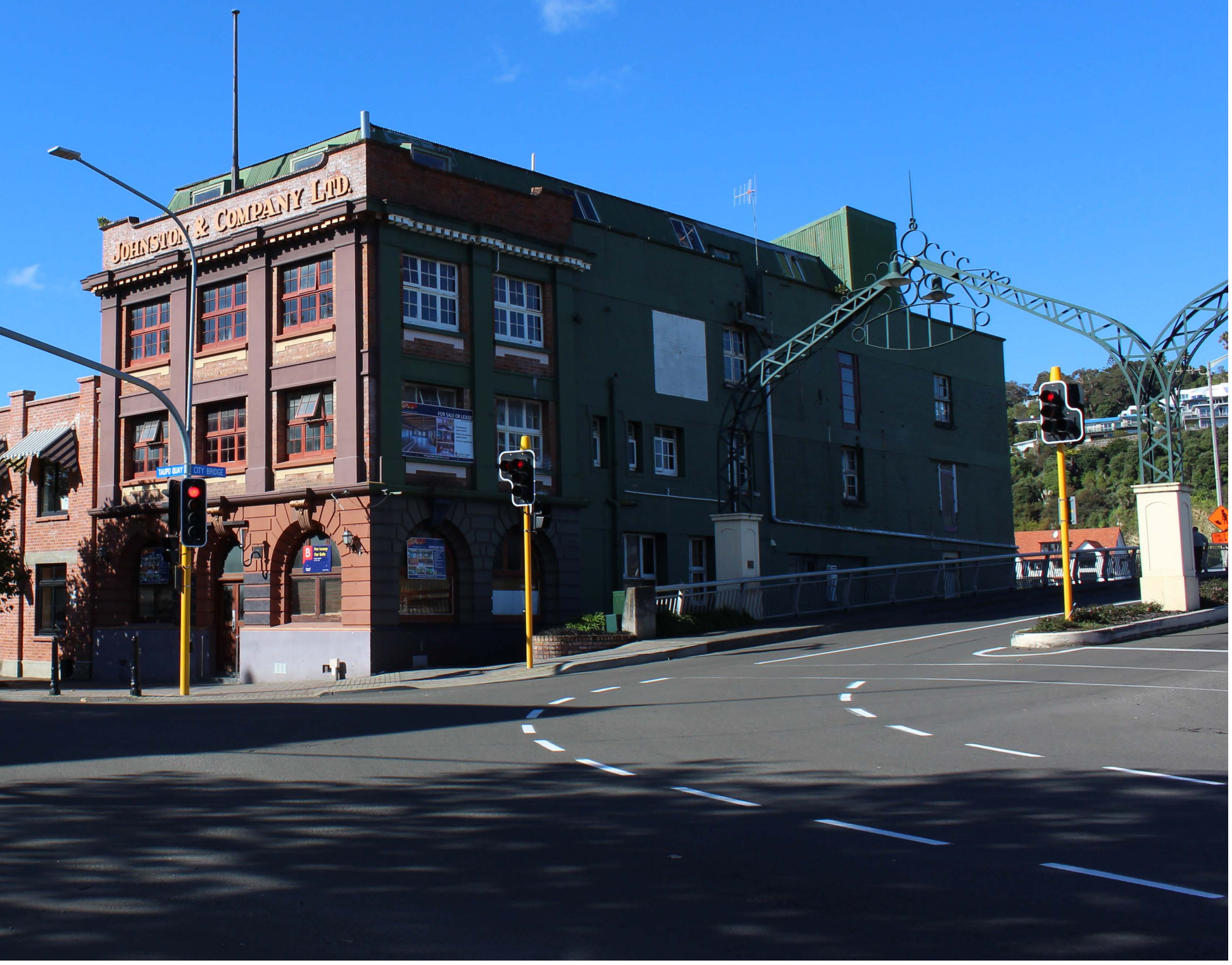




\section{Taupo Quay, Wanganui}

Architect / Designer: L J Atkinson

Architectural Style: Edwardian Baroque

Built: 1923

Thematic Context: Rural Servicing, Industry, Transport \& Trade

Significance: Historic, Architectural, Technological, Townscape. Class B Heritage item in the Whanganui District Plan meaning it has high heritage values at a regional or local level.

History: The building was built by Johnston and Company General Merchants who occupied the site until at least 1955. Johnston and Co were merchants, woolbrokers, shipping insurance providers, land stock and station agents for various shipping and air companies Between 1831 - 1912 Johnston and Co ships usually travelled between Whanganui, London, Liverpool and Westport.

It was later taken over by Toop and Co and was used by various tenants after they left the building. In 1990 it was owned by R.G Trott who used the building as part of an indoor rowing centre.

It is currently for sale.

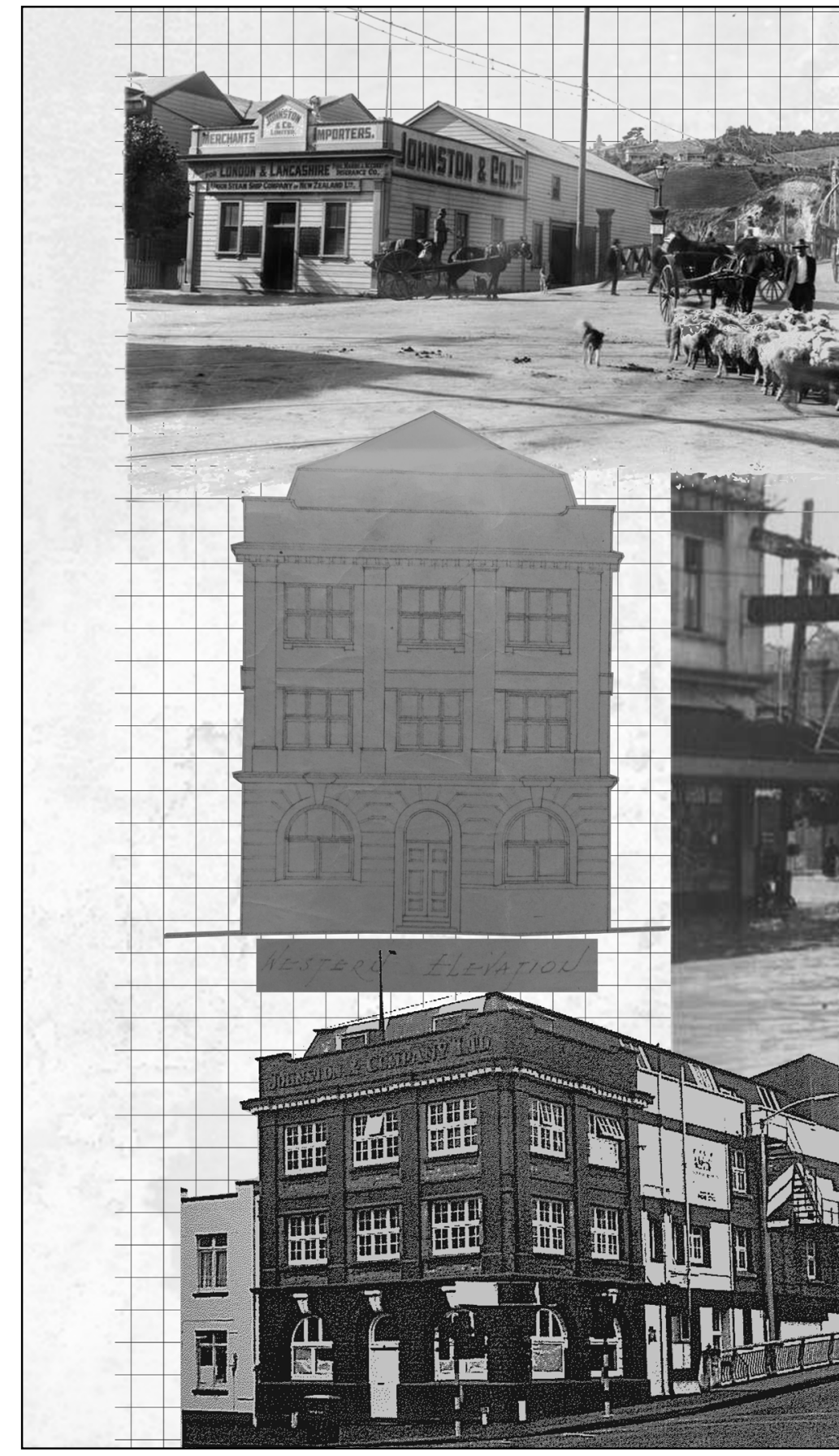

Fig. 6.06: Collage of images of Johnston and Company building. 


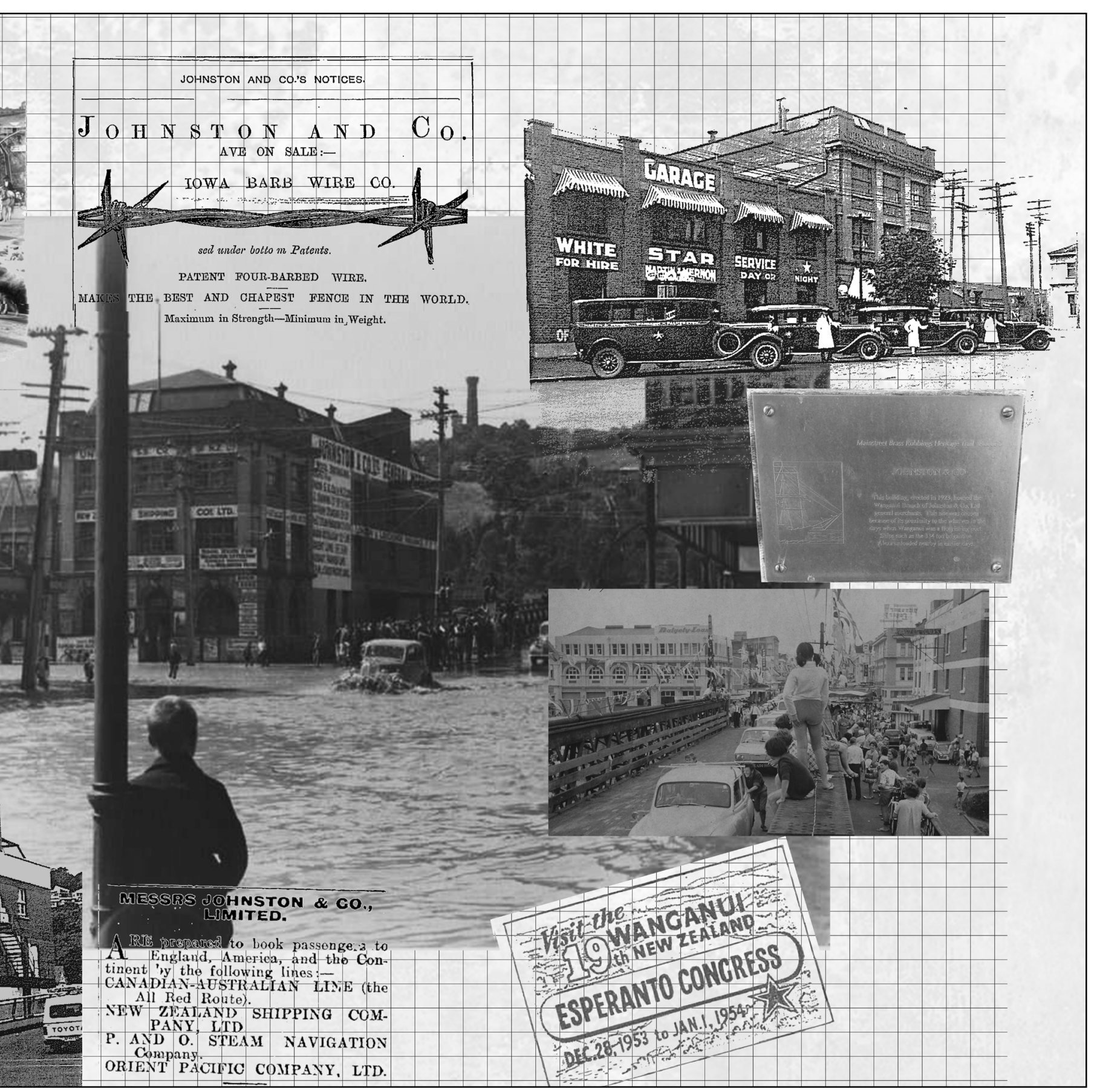




\section{TIME LINE}

Description: Three story brick building with corrugated iron mansard roof containing an attic story.

Cast iron columns support timber floors. At the time of construction the architecture was described as "Georgian renaissance" Today the building is more of an Edwardian Baroque style, an good representative example with round headed windows, exaggerate keystones, rusticated base, decorative cornice and parapet, pilasters at corners expressed in the parapet and aprons under windows.

The Johnston and Company building was chosen because of its location to the river. Its non-existent facade on the southern city bridge face is poorly designed and has had little upkeep although it is the most visible. The colour palette of the exterior could be more sympathetic.

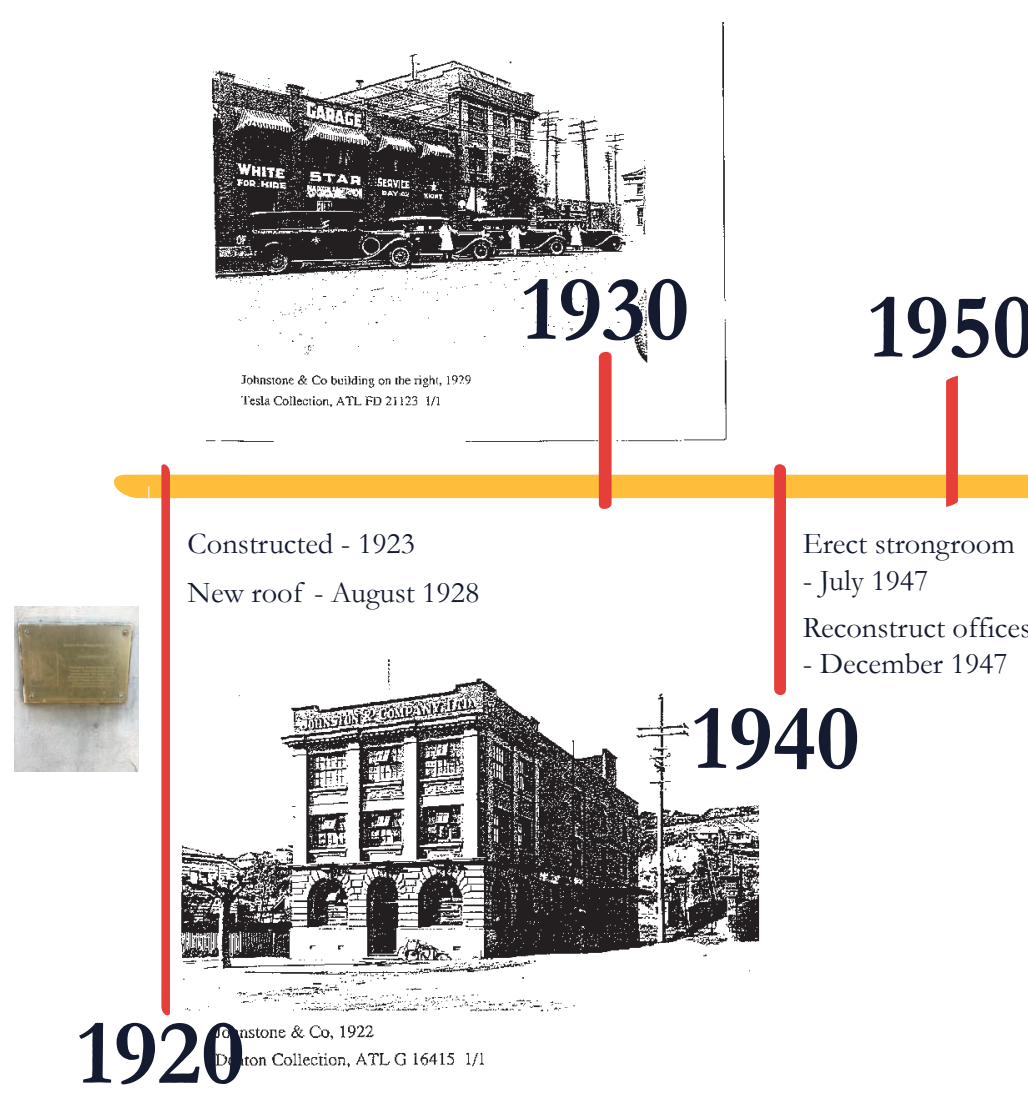

Fig. 6.07: Johnston and Company building time line of events associated with the building. 


\section{0}

\section{0}

Addition of fire escapes - October 1970

Addition of entrance way and toilet to commercial building
Removal of section of

roof and build of new wall

- Feburary 1990

Addition of windows into rowing centre

- Januarary 1991

Conversion into licensed cafe/bar Erection of service area (toilets, fire exit and kitchen)

Repairs to north facing wall - Feburary 1994

Alteration of toilet and kitchen area - June 1997
Removal of Parapet and replaced with new motar - December 1980

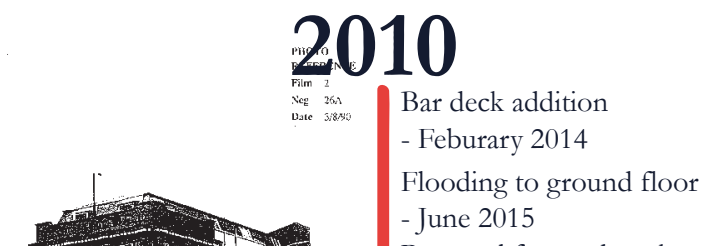

Proposal for earthquake

strengthening - September 2016

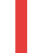

Internal wall modified for new entrance way

- August 2002

Addition to resturant - May 2003

Alterations to ground

floor lobby

- May 2004

Flooding of ground

floor - June 2005

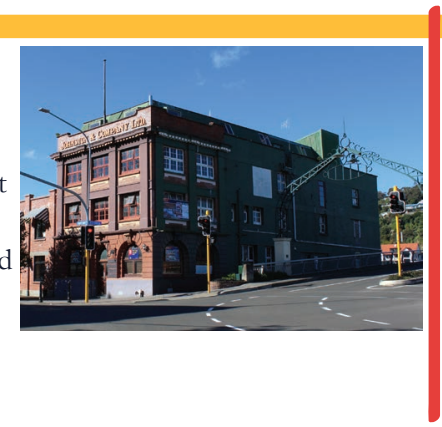




\section{EXISTING FLOOR PLANS}

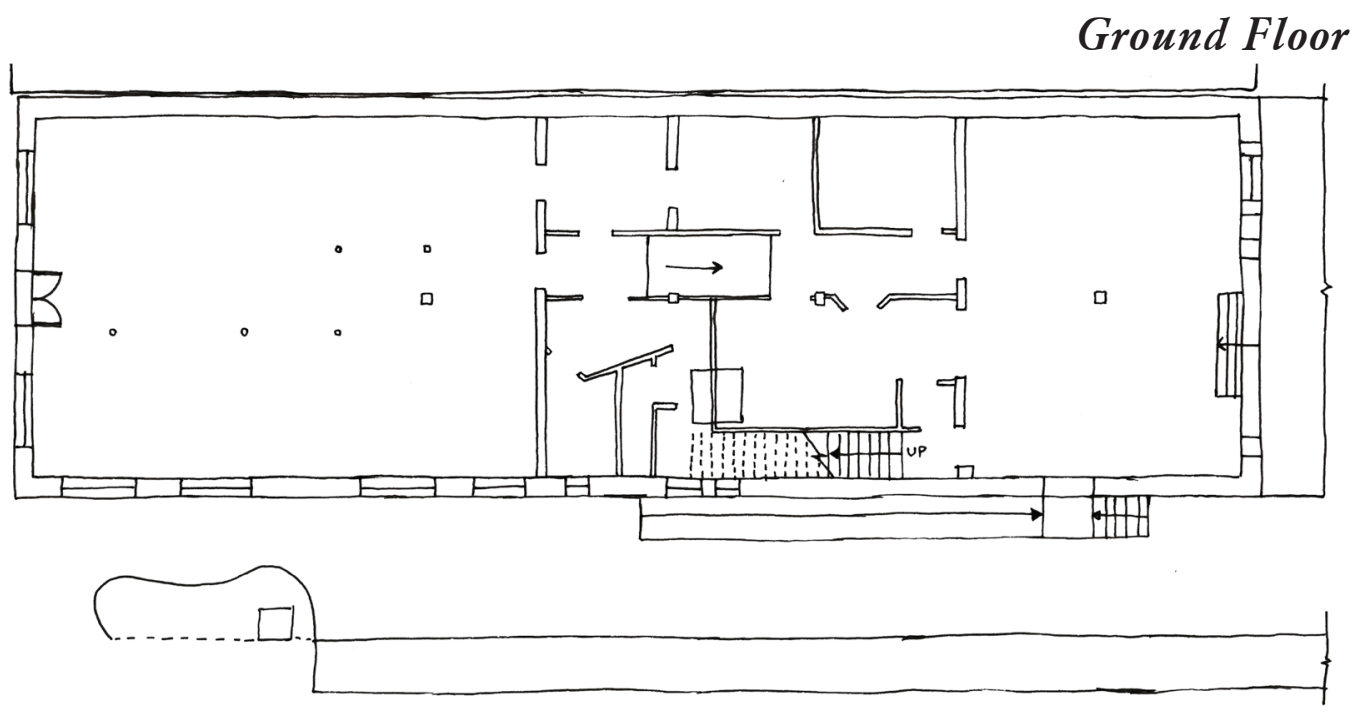

\section{REDACTED}

Fig. 6.08: Above-Ground floor plan

Fig. 6.09: Bottom left - Bar at the river end of the ground floor.
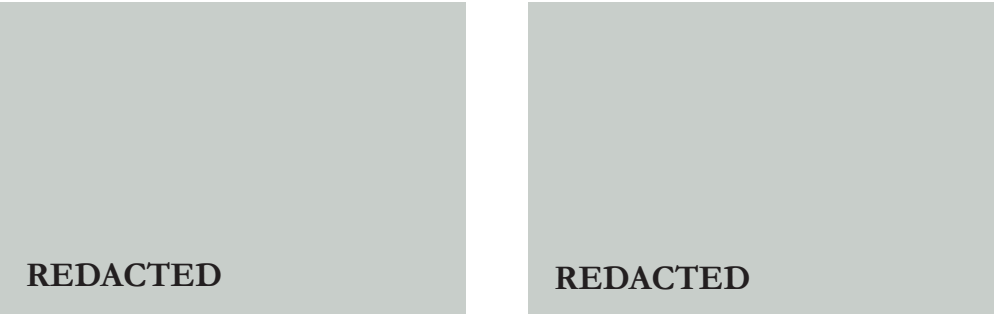

Fig. 6.10: Middle - Kitchen area.

Fig. 6.11: Bottom right-Street side bar. 
First Floor

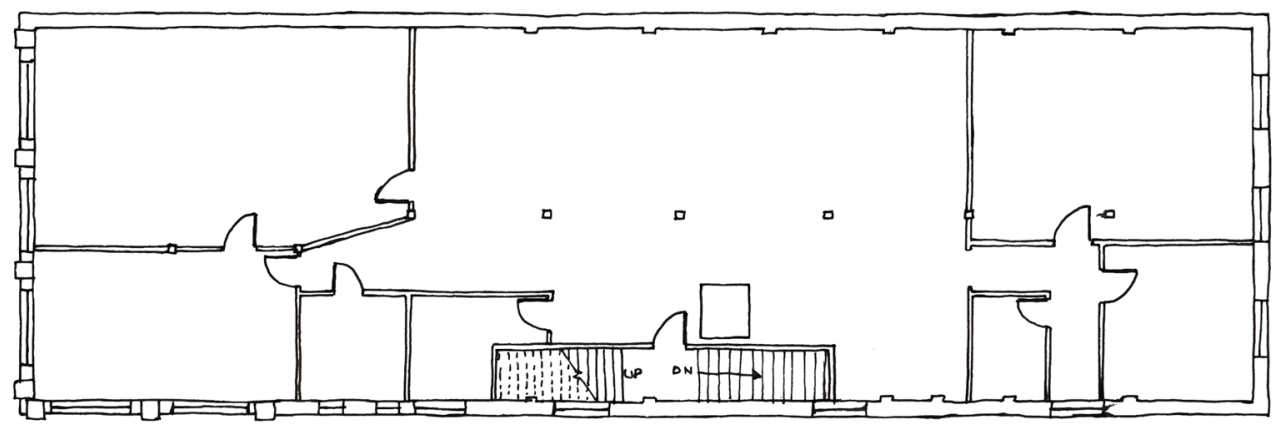

\section{REDACTED}

Fig. 6.12: Above - First floor plan

Fig. 6.14: Bottom left - Open area.
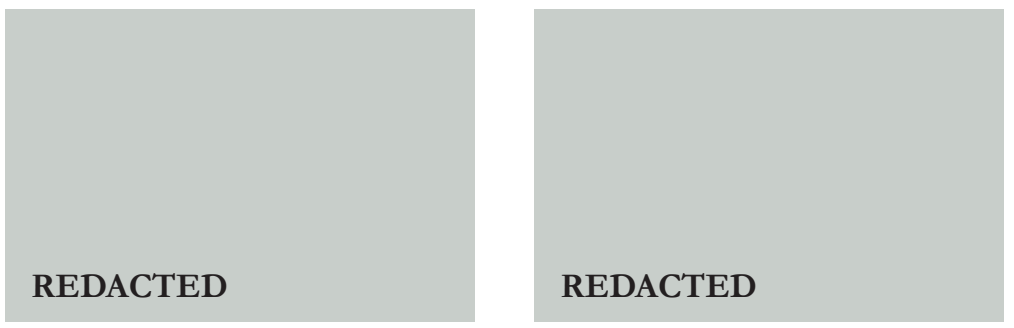

Fig. 6.13: Middle - Looking through to street side of the building.

Fig. 6.15: Bottom right-River side of the building. 
Second Floor

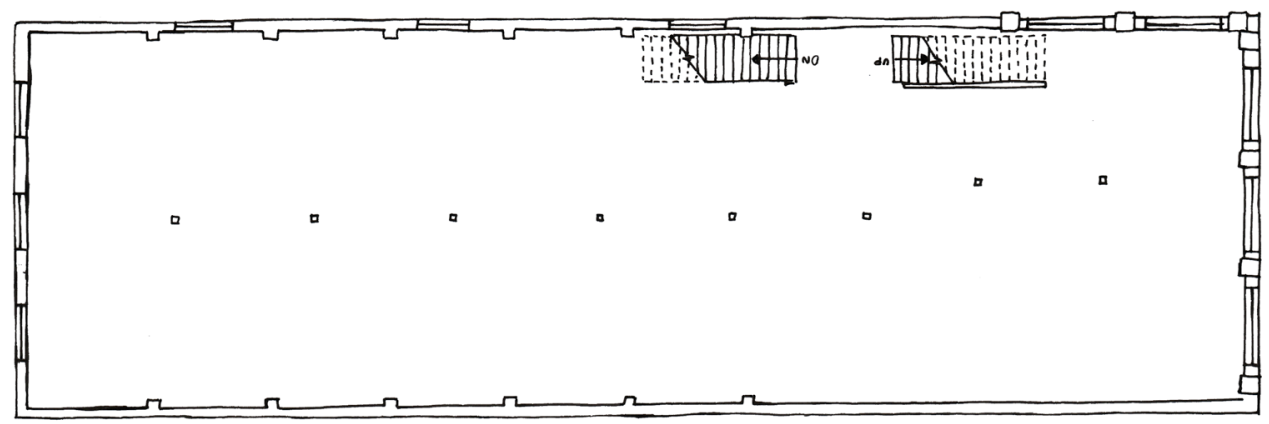

\section{REDACTED}

Fig. 6.16: Above - Second floor plan.

Fig. 6.17: Bottom left - Floor area looking towards street.
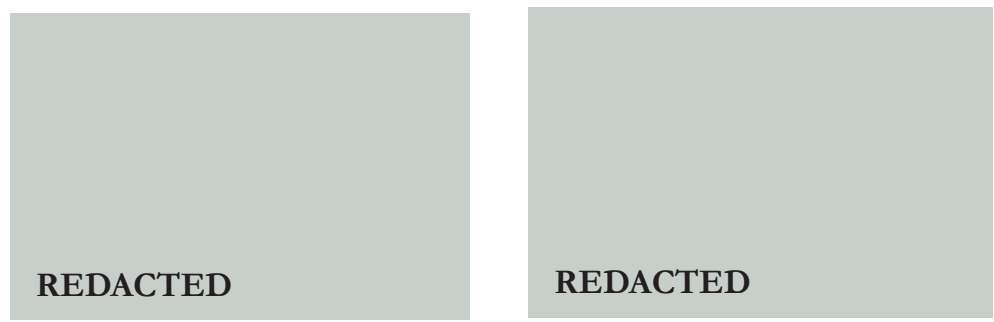

Fig. 6.18: Middle - Floor area looking towards river.

Fig. 6.19: Bottom right-Stairs between floors. 


\section{Third Floor}

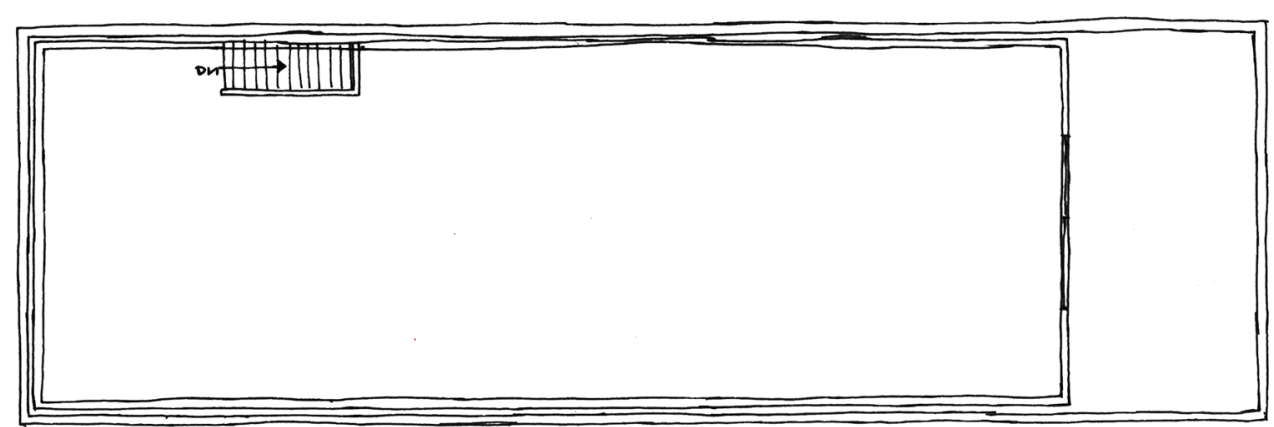

\section{REDACTED}

Fig. 6.20: Above - Third floor plan.

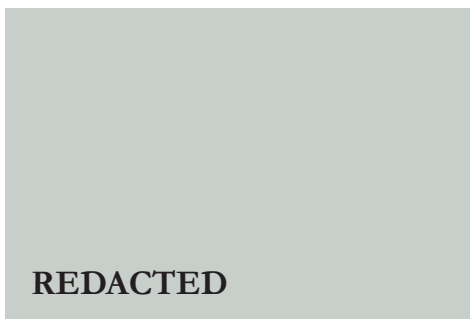

Fig. 6.21: Right-Looking through to river side balcony.

Fig. 6.22: Bottom left-roof truss looking towards the street. 


\section{IMAGES OF BUILDING AND SURROUNIND SITE}

Fig. 6.23: Left-Alleyway connecting river board-walk to Victoria Avenue.

Fig. 6.24: Above middle - Signage on the Johnston and Co building parapet.

Fig. 6.25: Below middle - Decoration around the windows of ground floor.

Fig. 6.26: Right above - Street Facade detail.

Fig. 6.27: Below right--River facade.
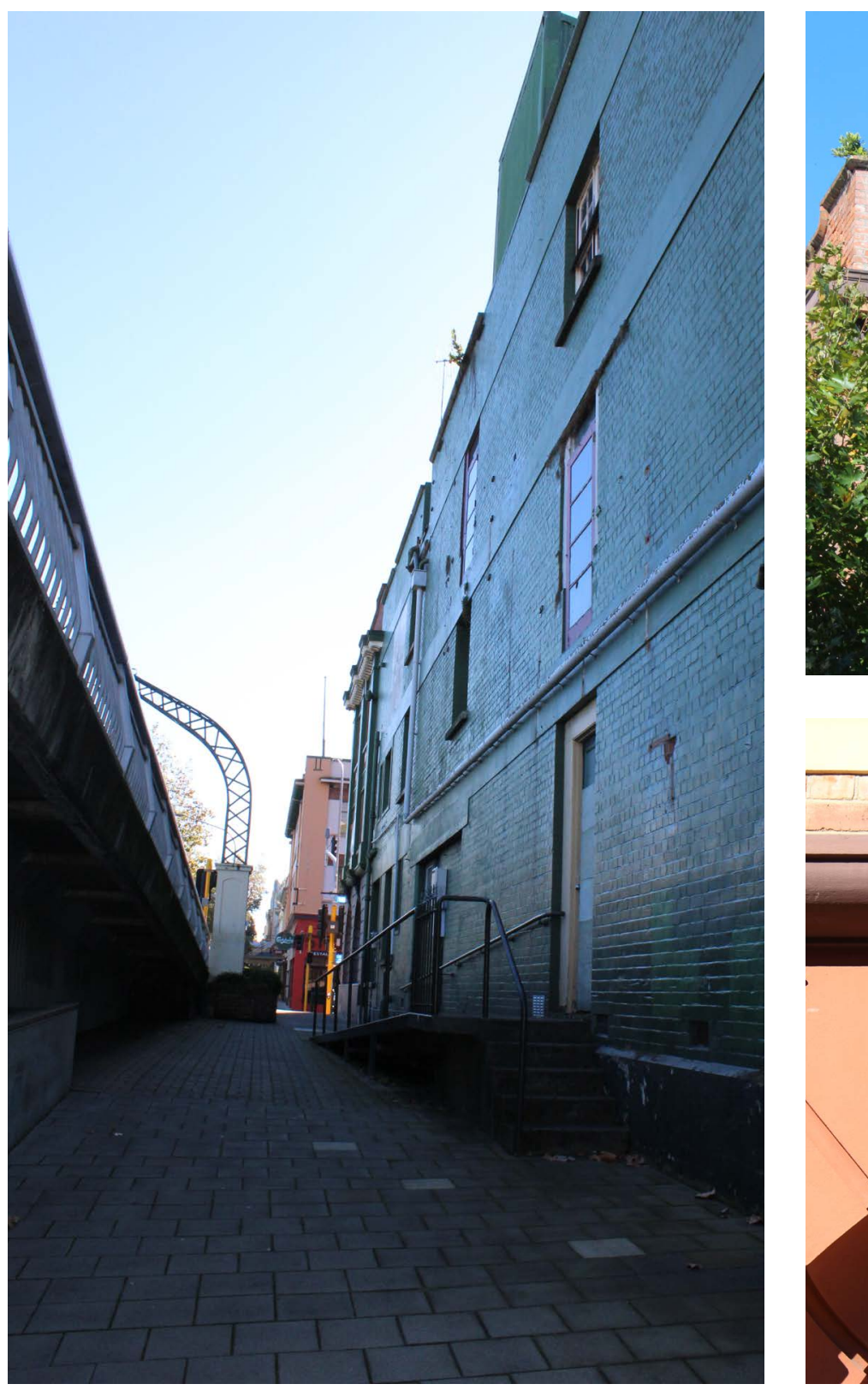


\subsection{FOSTERS HOTEL BUILDING}

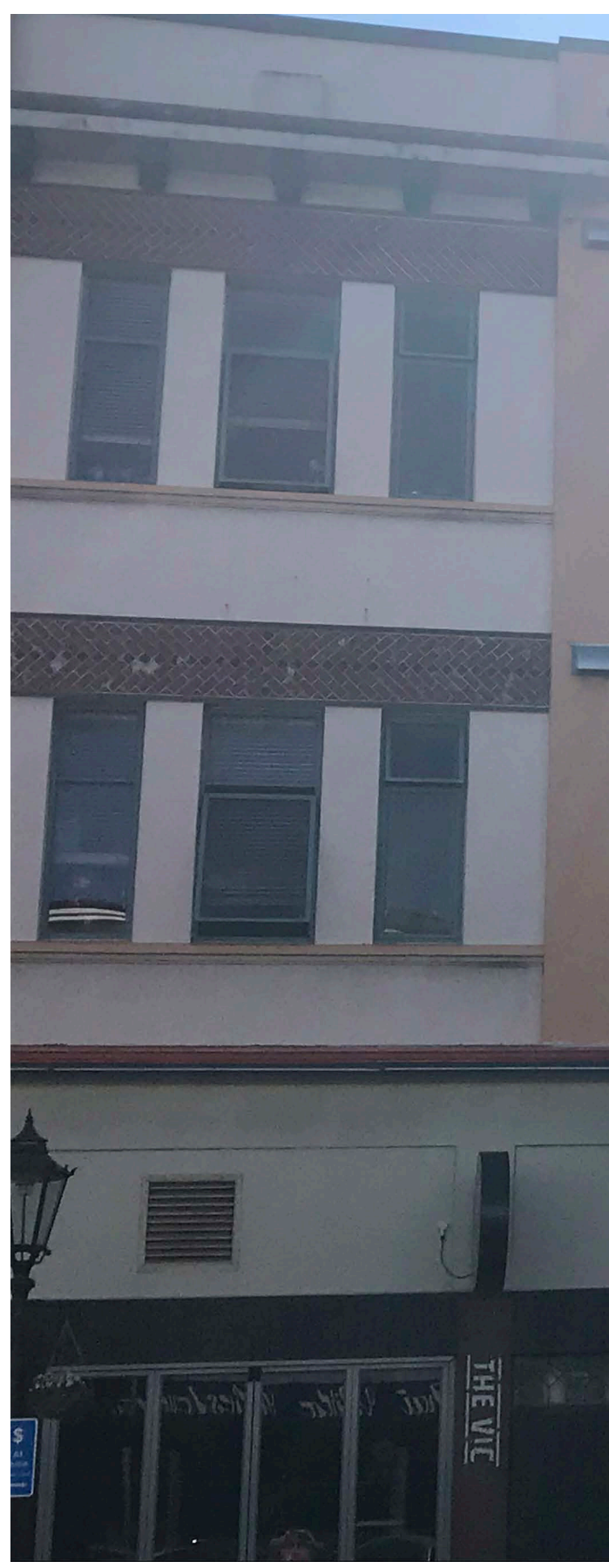

Fig. 6.28: Location plan of the building.

Fig. 6.29: Street view of Johnston and Co Company. 

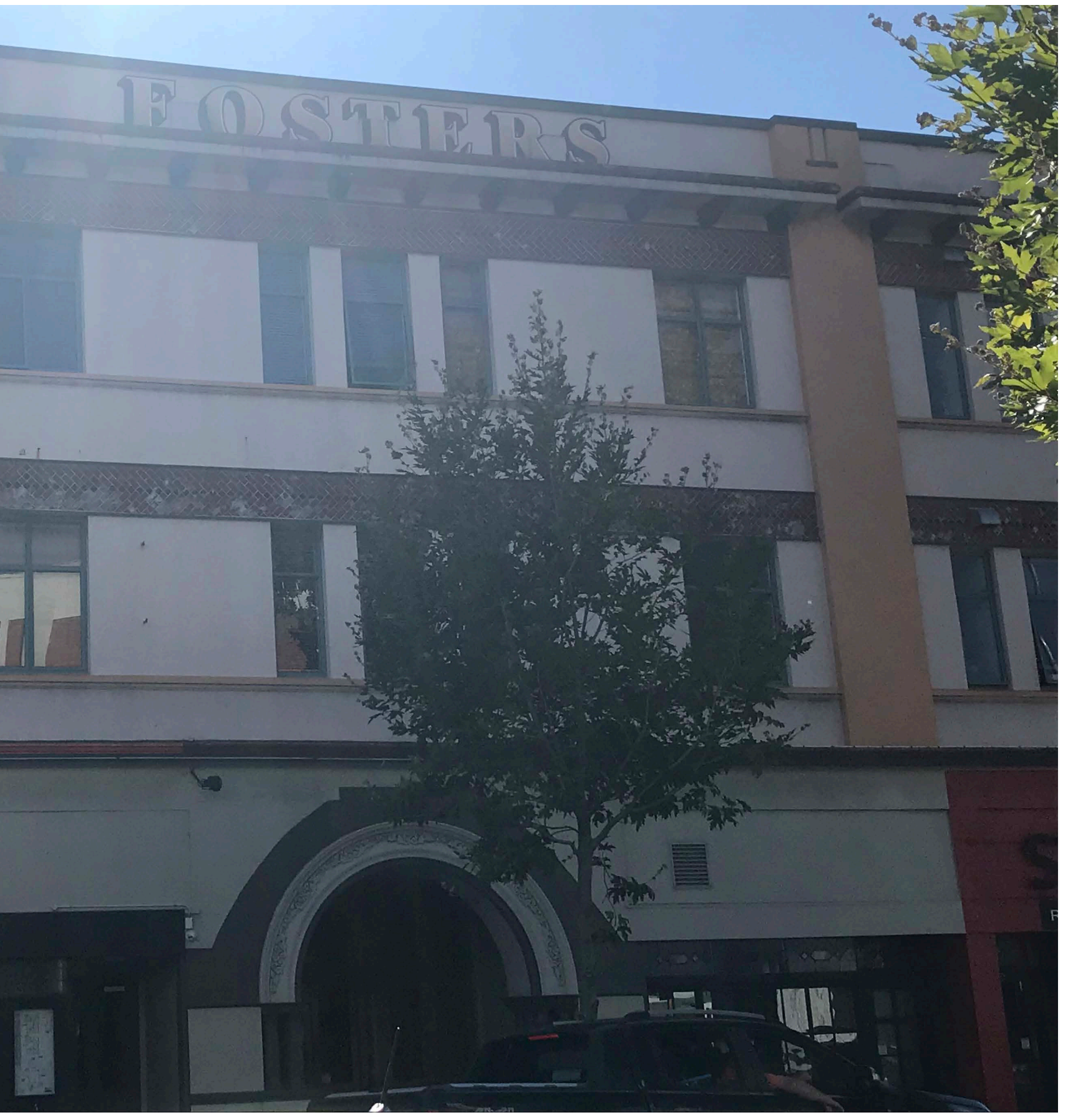


\section{Victoria Avenue (corner Taupo Quay) Whanganui}

Architect / Designer: Atkins \& Bacon

Built: 1925

Thematic Context: Rural Servicing, Transport and Trade, Civic

Significance: Historic, Architectural, Technological, Townscape

History: The totally reinforced concrete building was designed to be earthquake and fire proof after the original burnt down 1857 - 1918. The tiled friezes above the upper windows are an unusual feature in Whanganui buildings of this era. Alterations were made over time, primarily to the bars and the upper floors turning into the apartments. The building compliments the Edwardian buildings in the neighborhood.

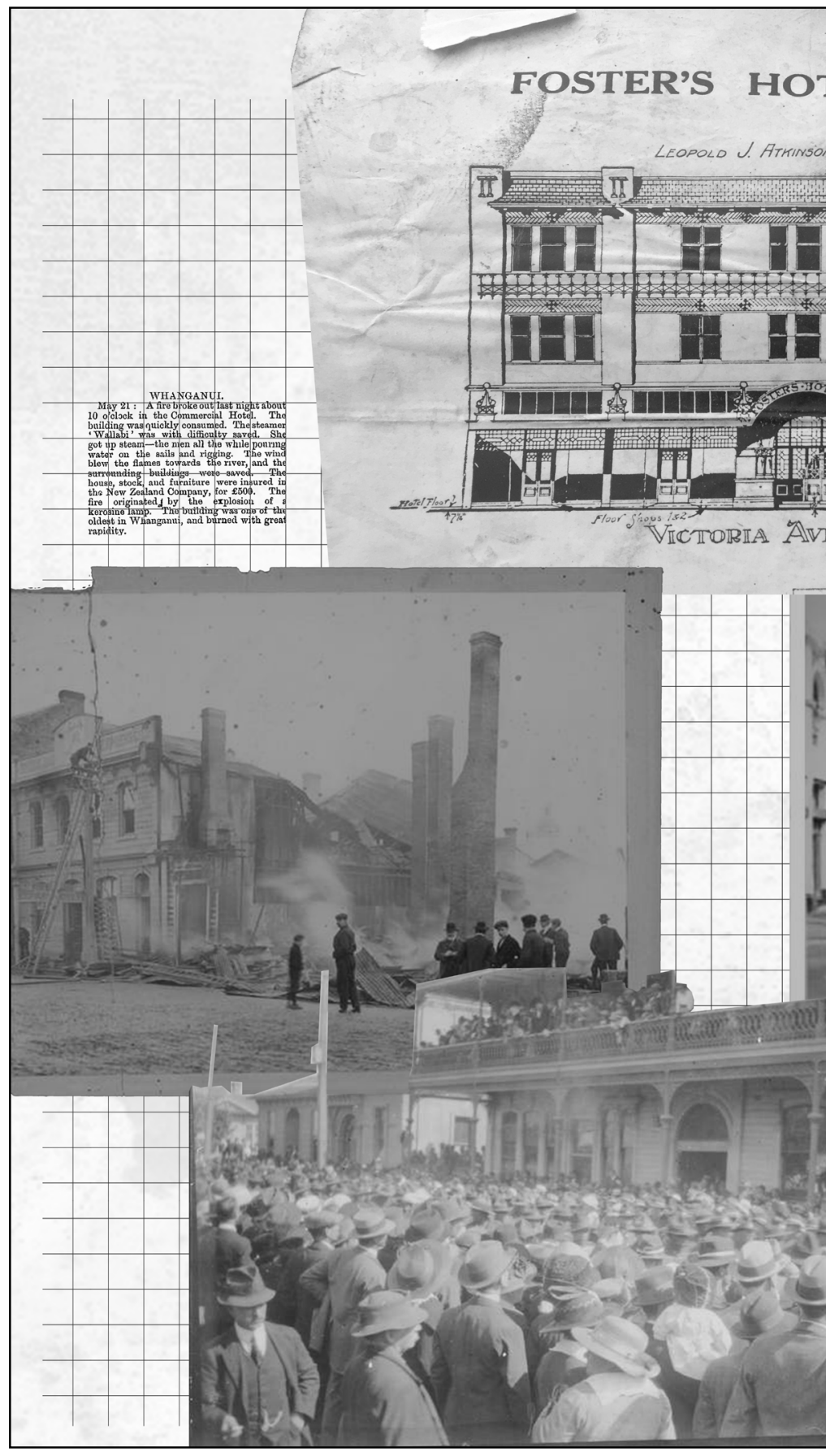

Fig. 6.30: Collage of images of Fosters Hotel. 


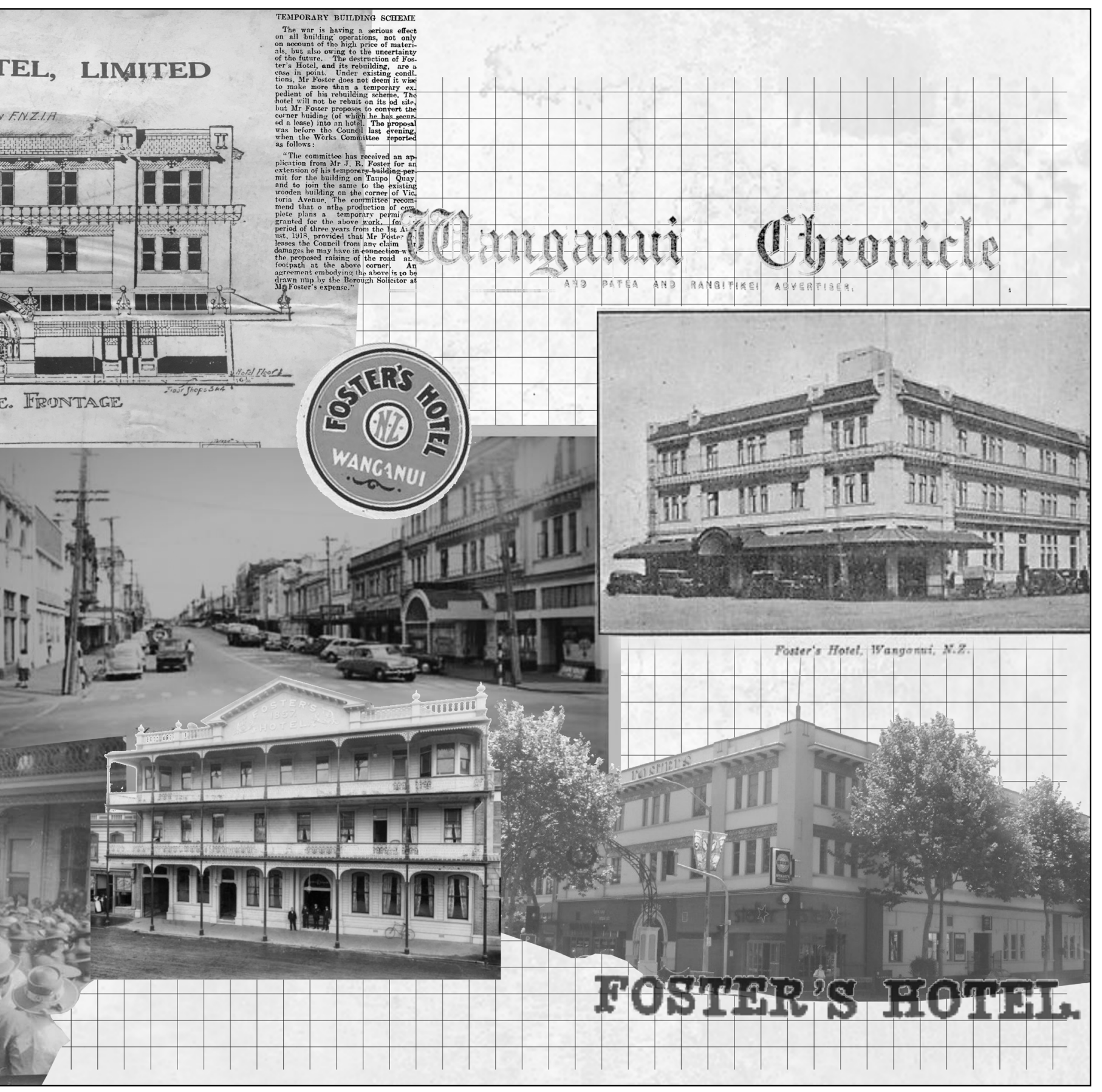



PROPOSED PRIVATE BAR

FOR
FOSTERS HOTEL

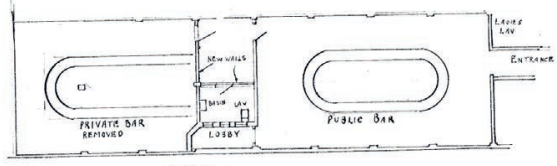

Alterations to priver bar

for lavy - July 1954

. APPlication for Building Permit

No 867,199 wanganu,

to THE CTTY ENover

2nd deptember 1955

CITY ENOINEER,

eneat finceraras

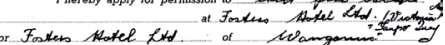

Additions of fire escapes

- September 1955

\section{0}

Internal alterations to convert hotel bedrooms into rental spaces with hand basins and shared bath facilities on upper floors - April 1970.

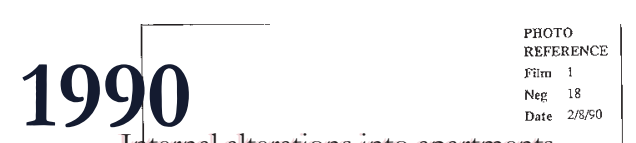

Internal alterations into apartments on upper floors - April 1995

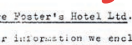

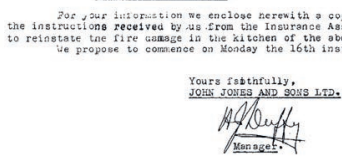

Reinstate the fire damage in kitchen - Janurary 1961

Alterations to ground

floor bar - August 1962

\section{0}

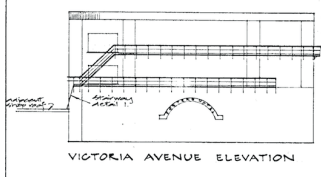

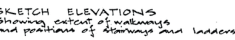

Erection of fire escapes - September 1967

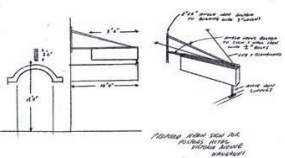

Replacement of Neon Light - April 1968

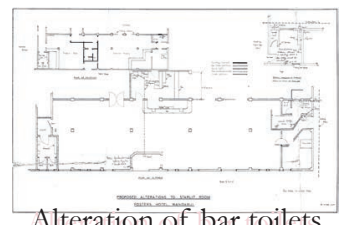

- Feburary 1969
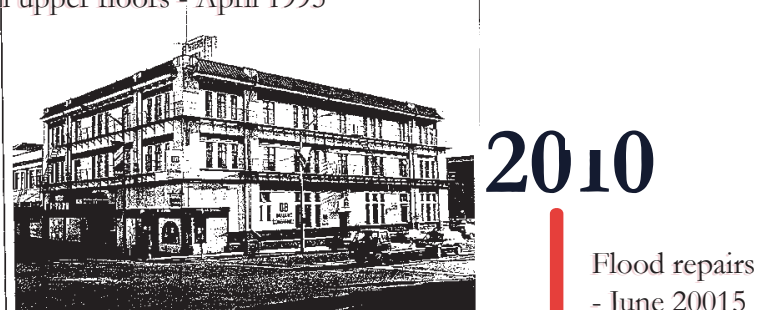

- June 20015
1980

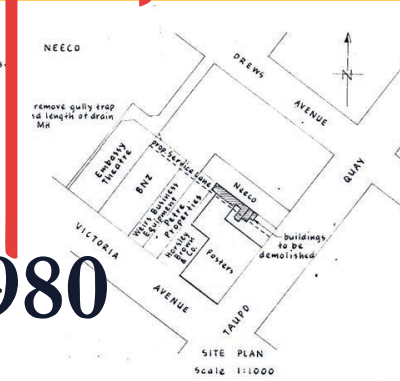

Demolition of outbuildings

for proposed lane - November 1980
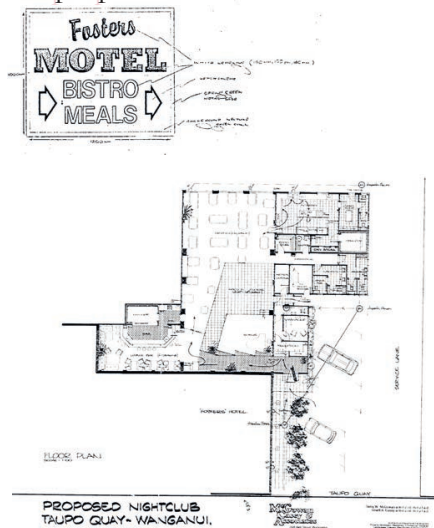

Internal alterations into night club - October 1987

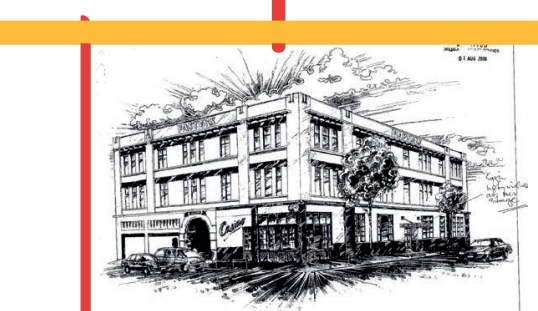

Redevelopment of Tavern

- December 2000

Structural redevelopment

- Feburary 2001
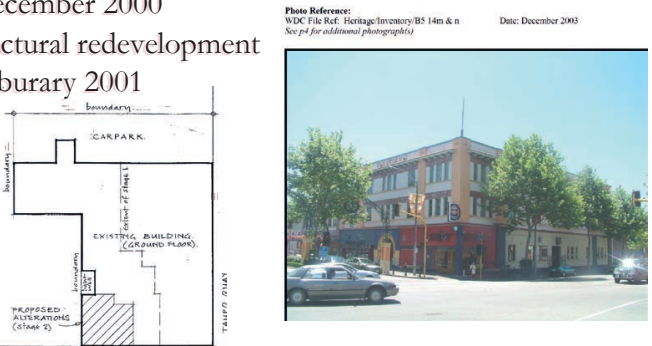

Internal alteraxationns to create cafe - June 2001

Renovation of existing apartment spaces - August 2004

2000

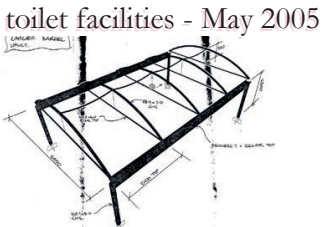

Rain shelter installed over outdoor seating at the rear of stella bar

- October 2008 


\section{EXISTING FLOOR PLANS}

Ground Floor

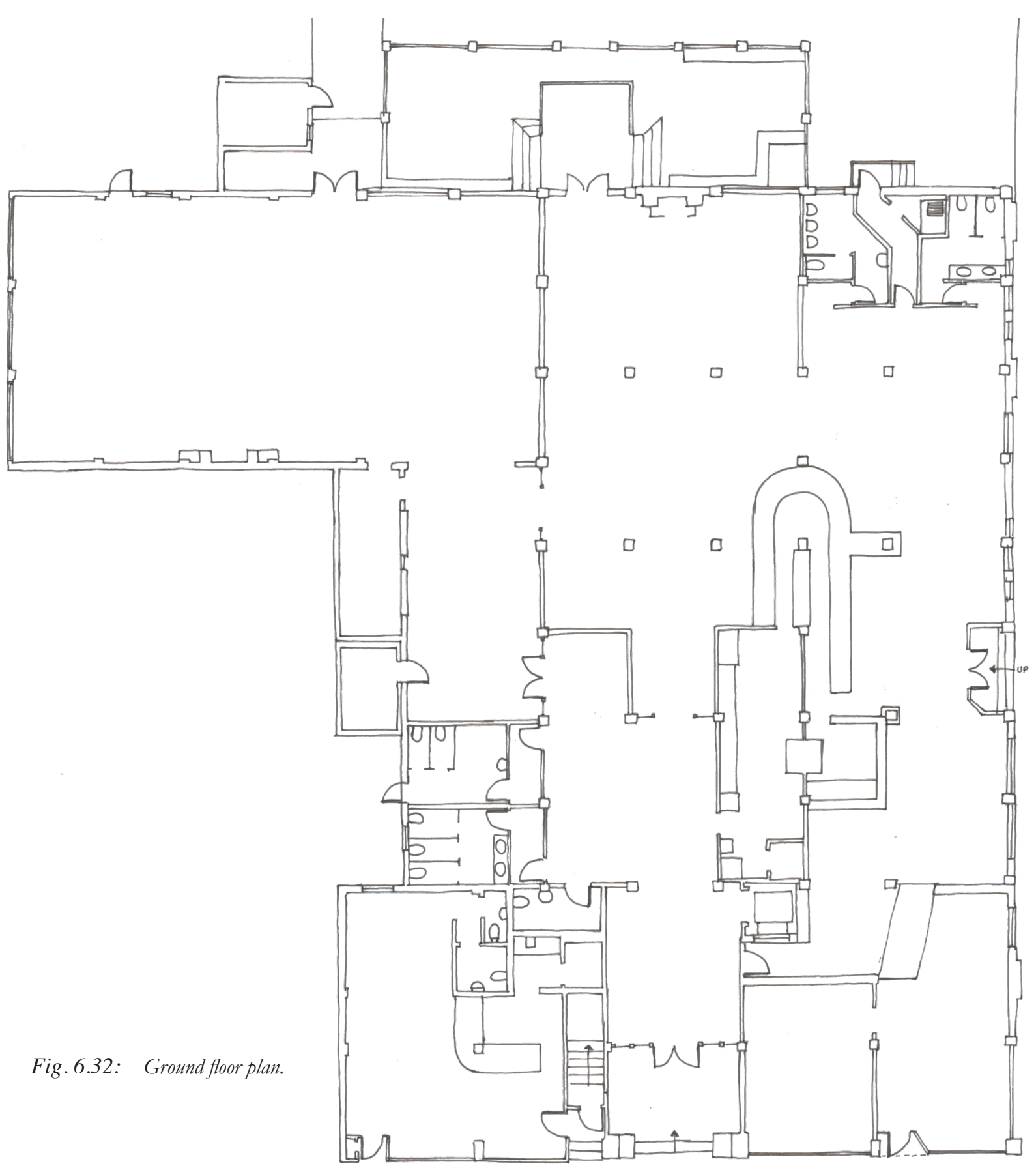


First Floor

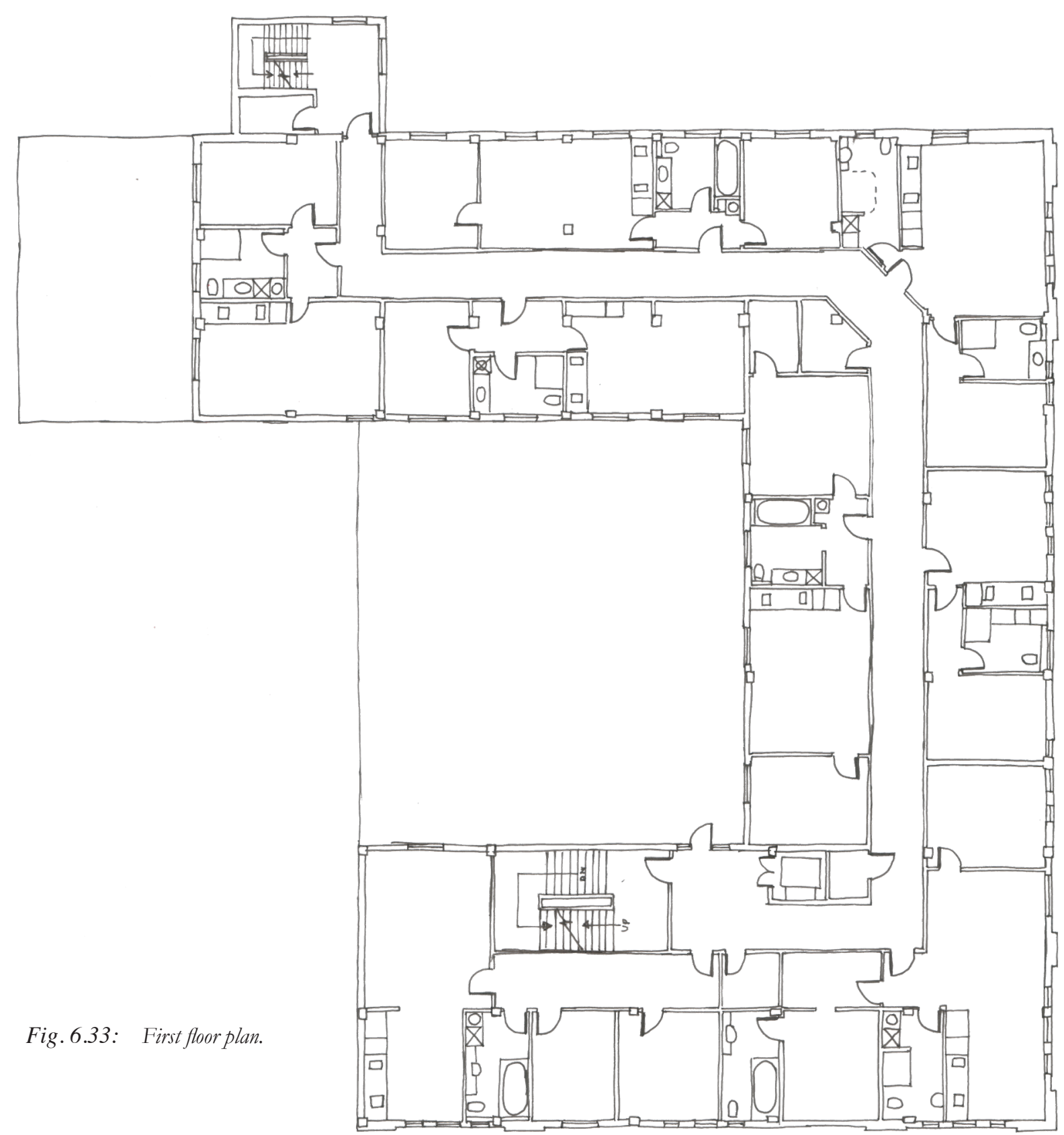


Second Floor

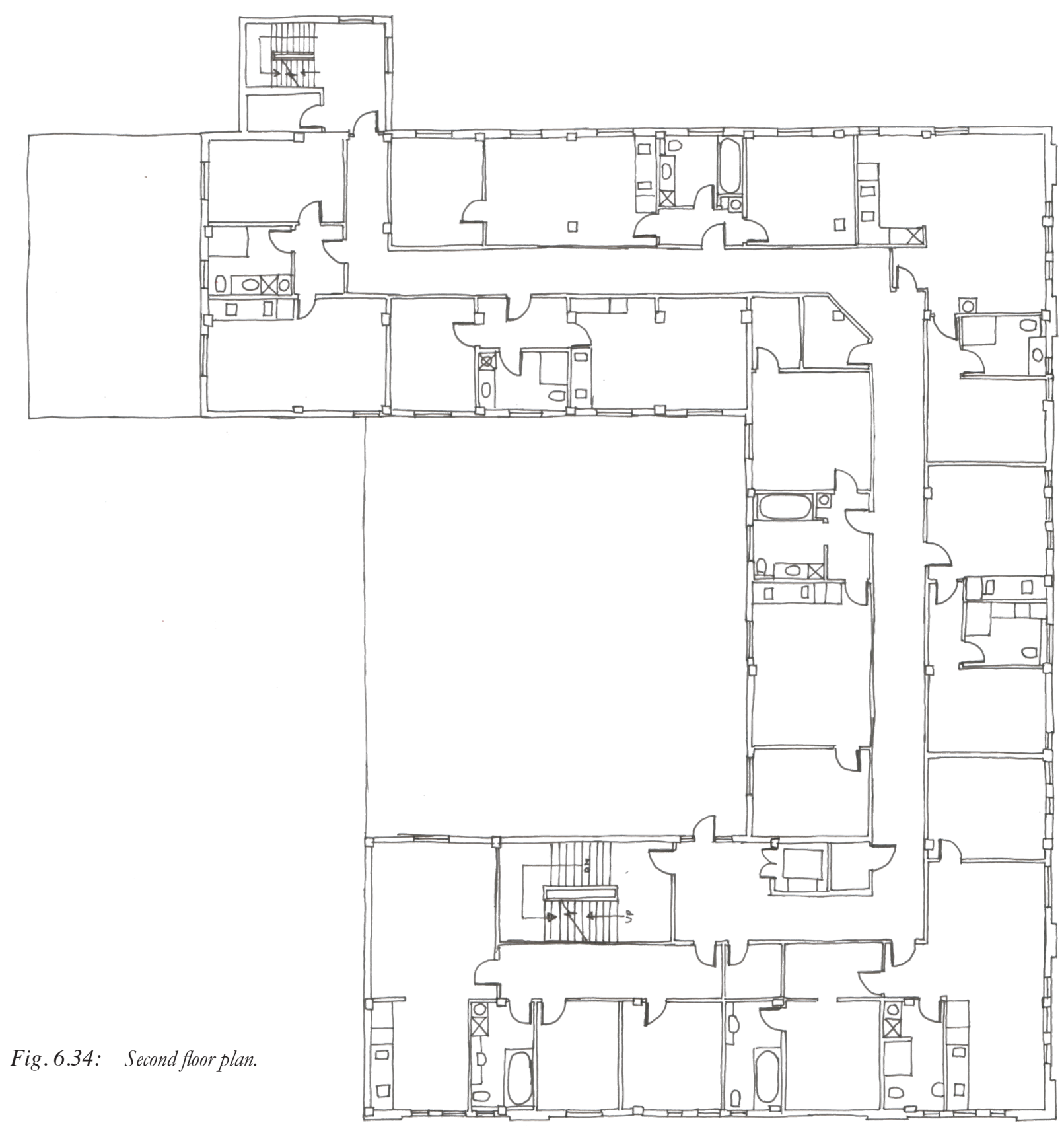




\section{IMAGES OF BUILDING AND SURROUNDING SITE}

Fig. 6.35: Above left-Original grand entrance to Fosters hotel.

Fig. 6.36: Below left-Stella Bar on corner.

Fig. 6.37: Above right-Taupo Quay facade from street.

Fig. 6.38: Back alley way of Fosters Hotel.

Fig. 6.39: Bottom right-Vic bar on Victoria Avenue.
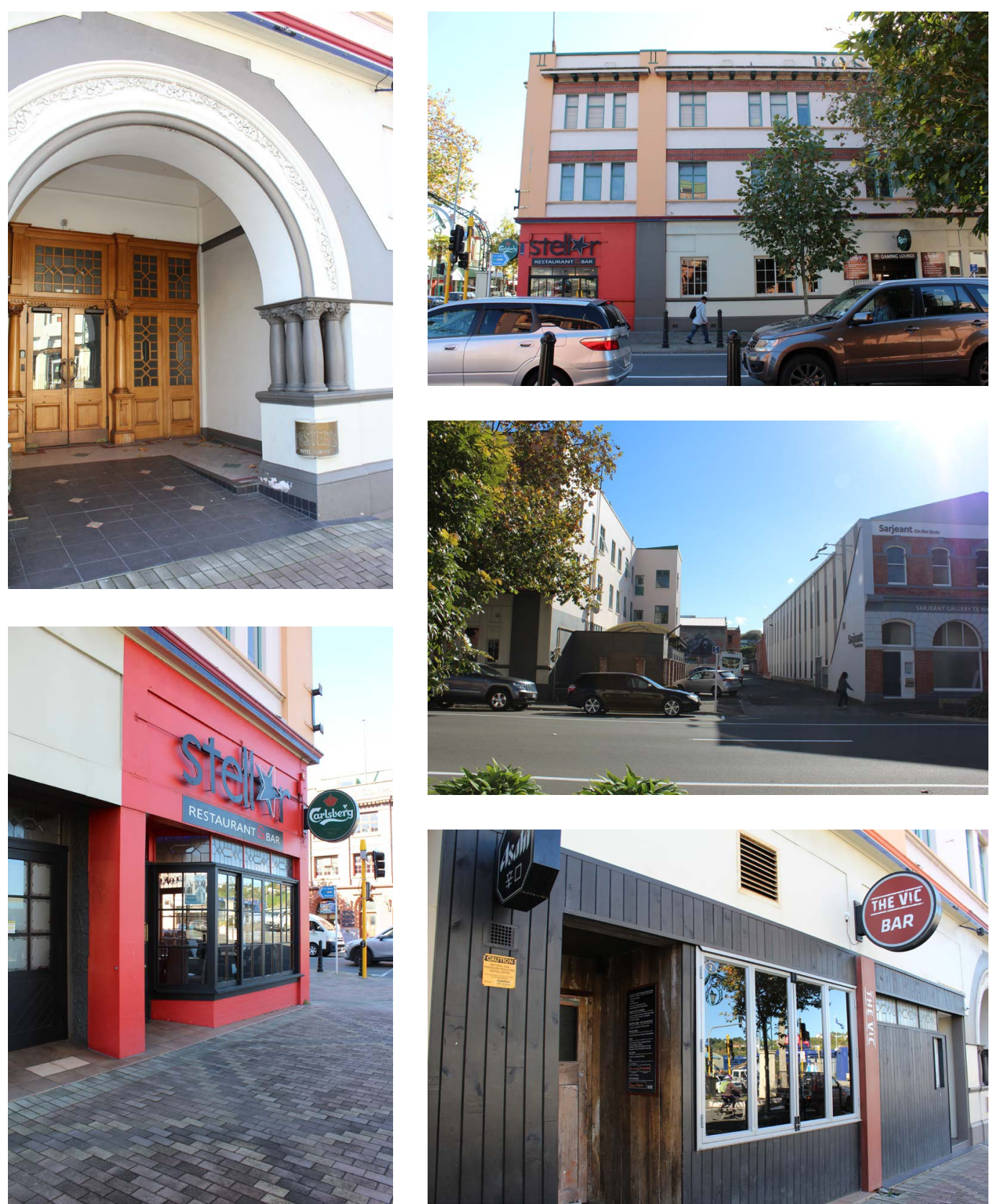


\subsection{THAINS AND COMPANY BUILDING}

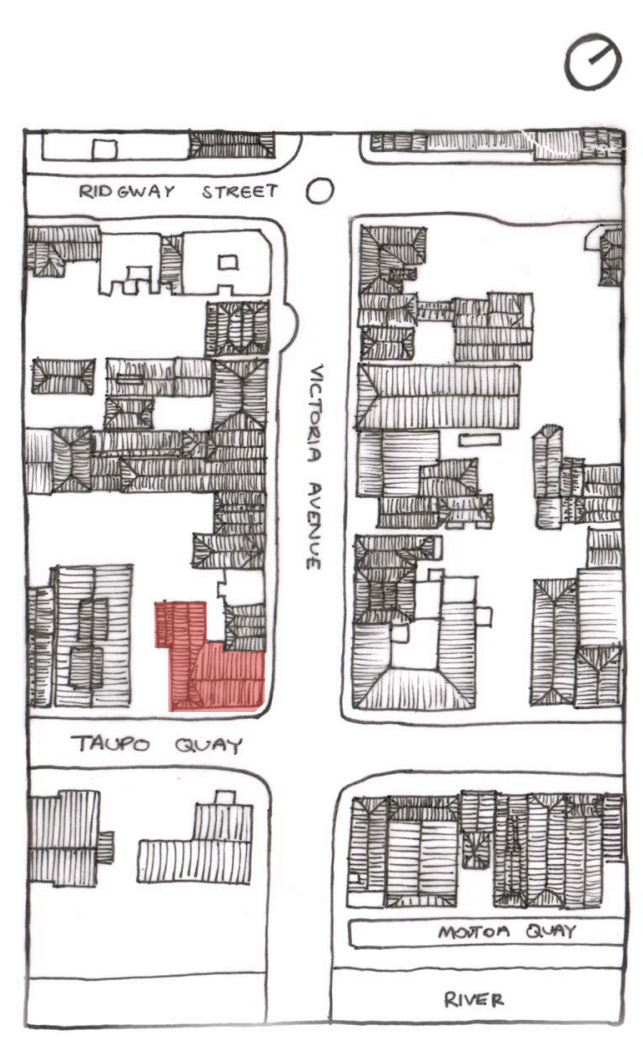

Fig. 6.40: Location plan of the building.

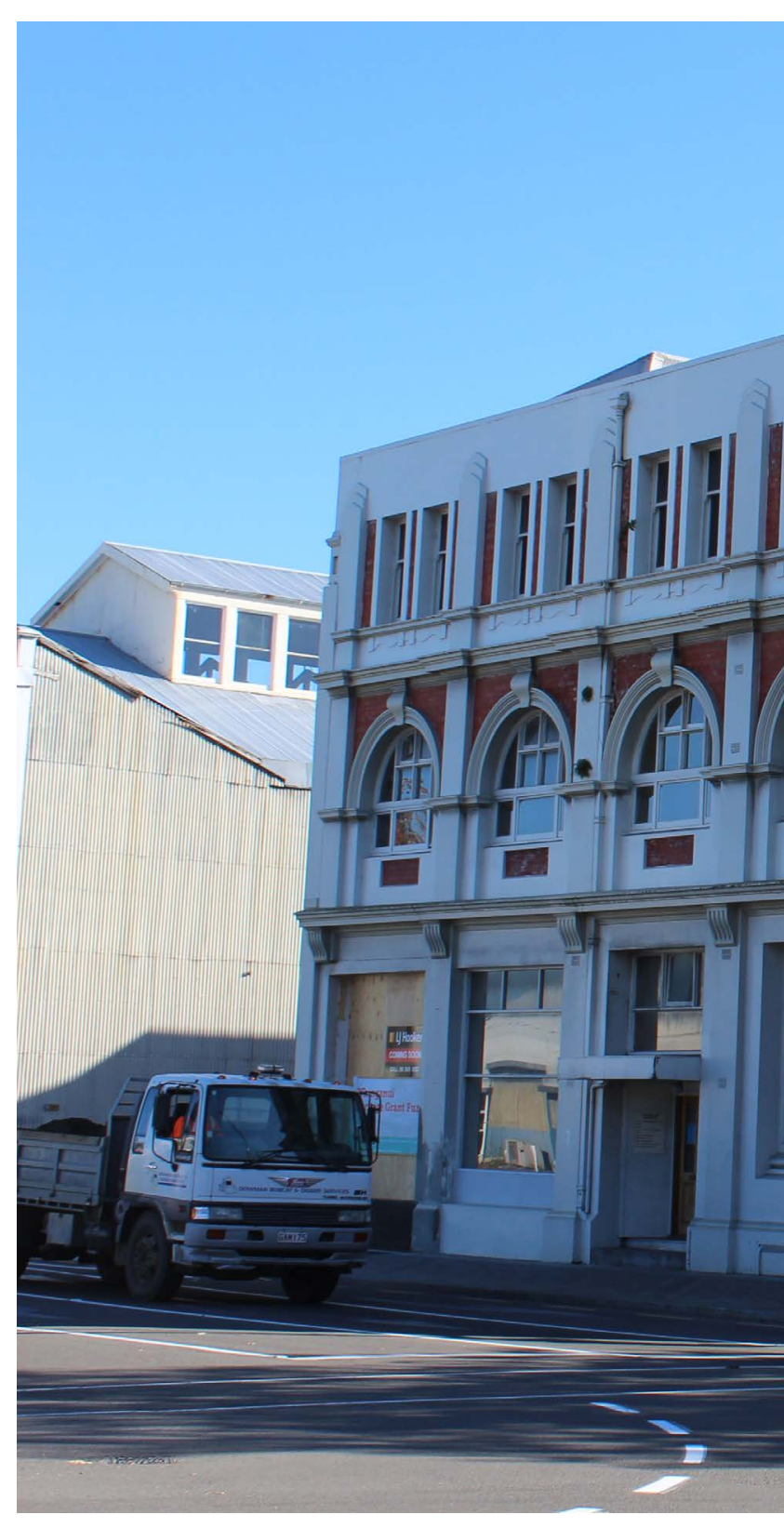

Fig. 6.41: Street view of Dalgety / Thains Building. 


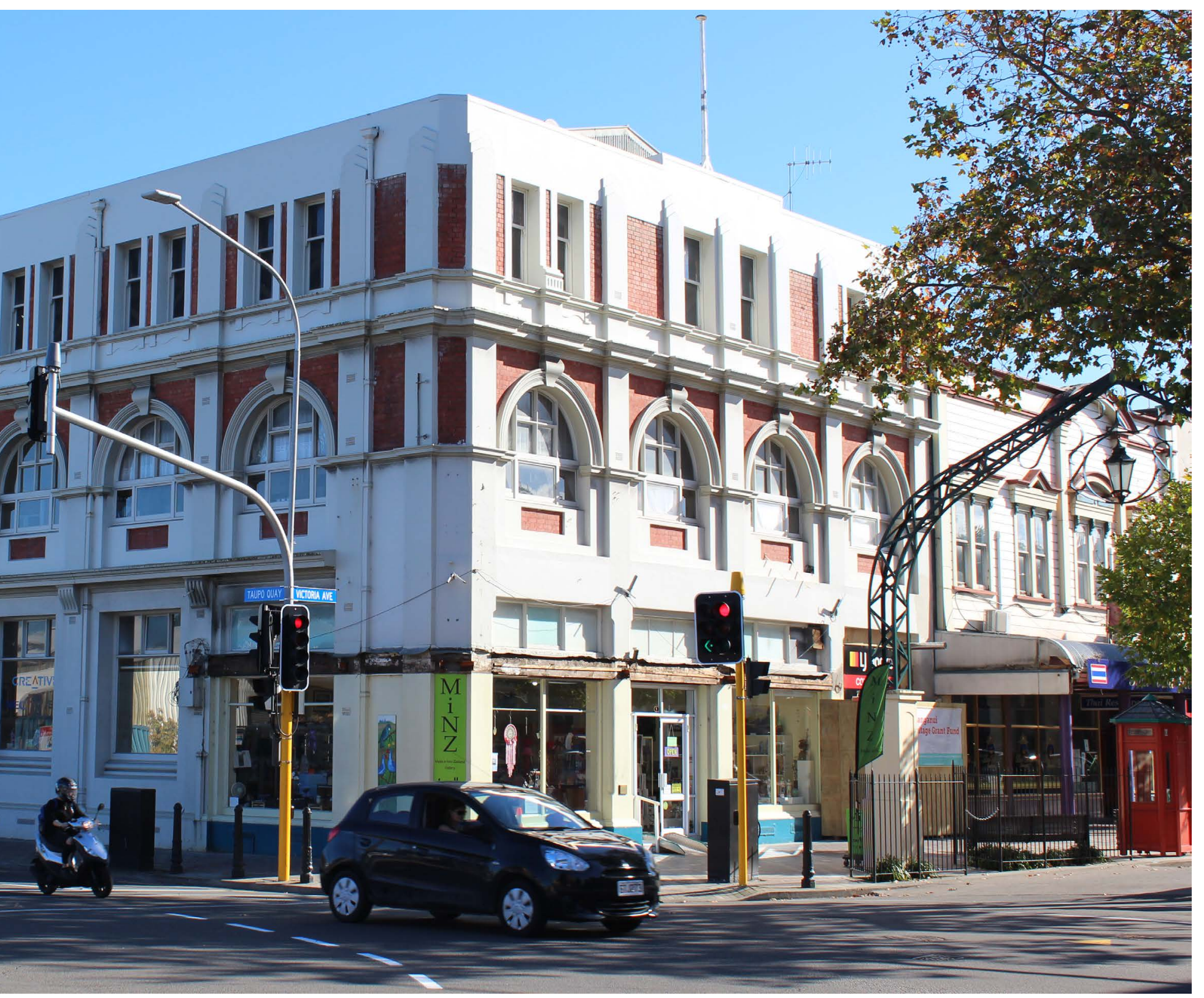


1 Victoria Avenue (corner Taupo Quay), Whanganui

Architect / Designer: T H James Built: 1908

Construction: By Nicholas Meuli

Thematic Context: Rural Servicing,

Transport and Trade

Significance: Historic, Architectural, Technonlogical, Townscape

Class B Heritage item in the

Whanganui District Plan meaning it has high heritage values at a regional or local level.

\section{Land area: $1247 \mathrm{~m}^{2}$}

Floor area: $1850 \mathrm{~m}^{2}$

Description: Three storey building, concrete frame with brick infill.

Ornate parapet with high central pediment to Victoria Avenue has been removed and replaced with a fascia with art deco motifs.

History: Site of John Duthies small hardware store which opened in 1868. In about 1888 the business was brought by James Thain and W.H.

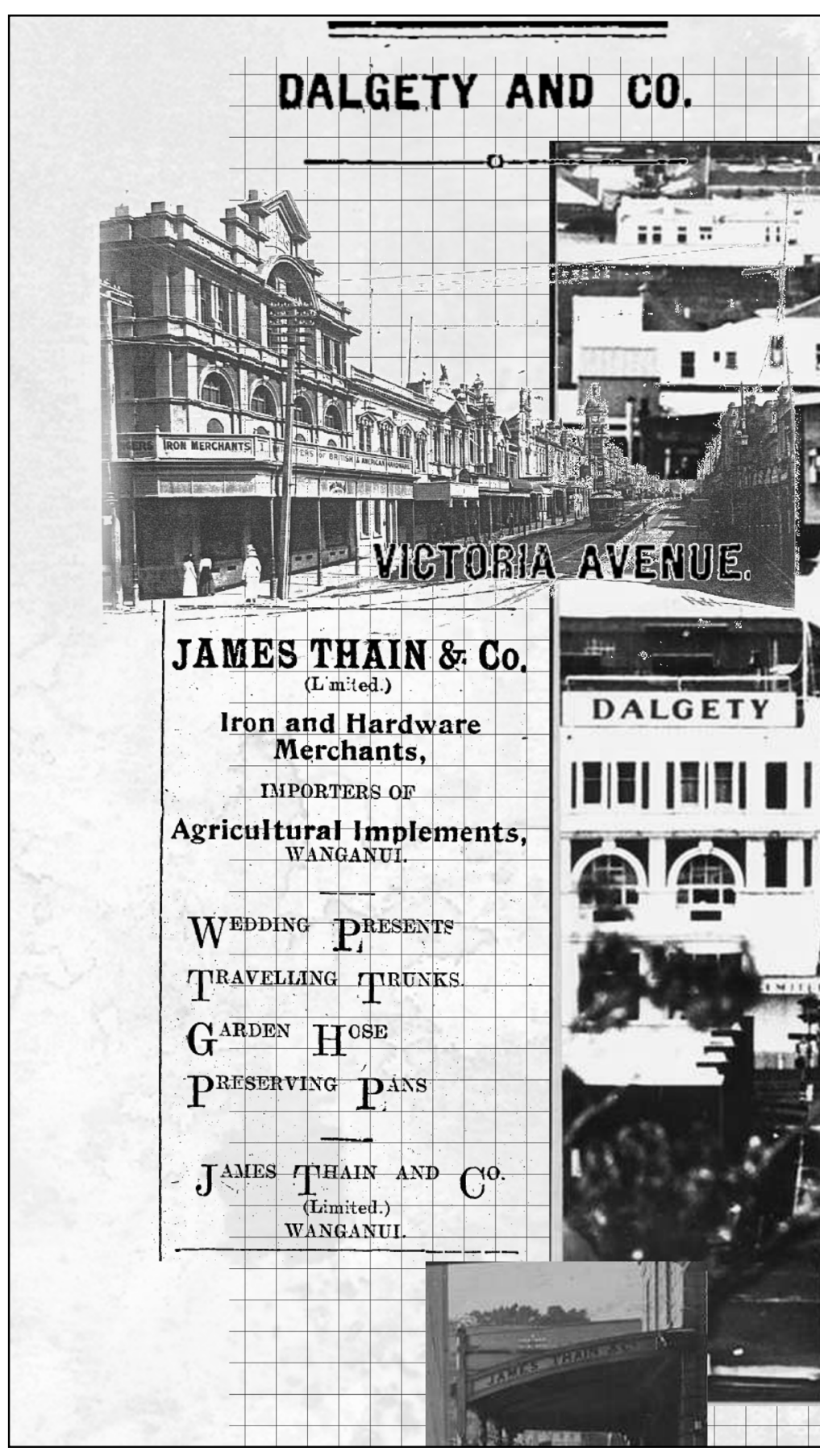

Fig. 6.42: Street view of Dalgety / Thains Building. 


\section{UNCERTAIN FUTURE: The}

Thain's building owner is applying for consent to demolish it.
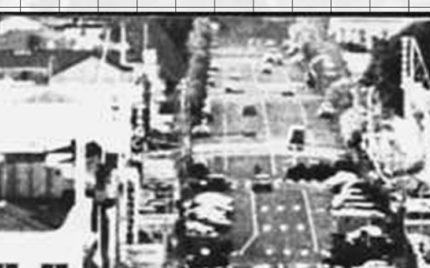

45
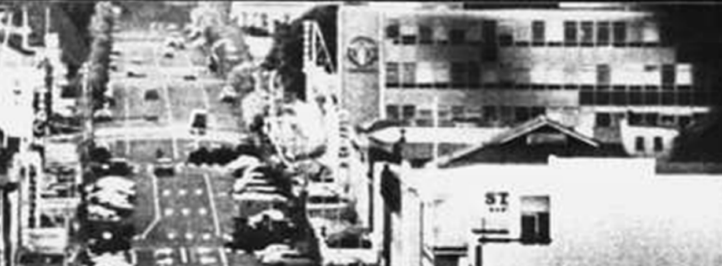

$\int_{i=1}^{2}=1$
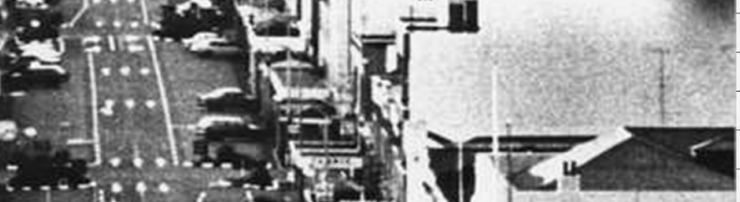

5.

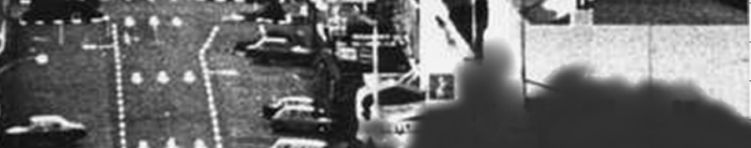

ai

8
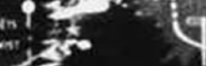

$\geq 2 F$

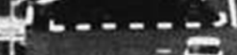

굴

$-6$ $\left.25\right|^{2}$

$$
4
$$

$9: \infty$ decrese $H \equiv$

1.

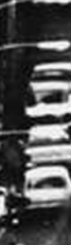

.

4

2.
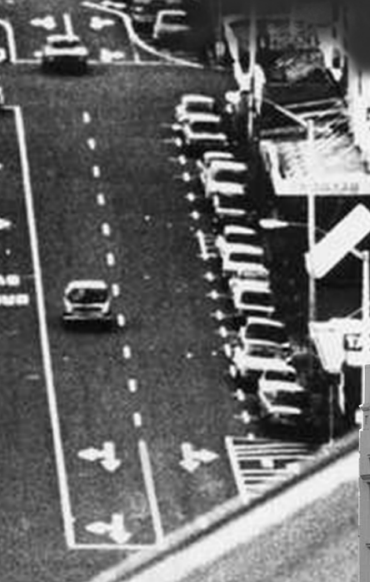

SHEARING. EASON, 1892

We have just landed our First shipment

SHEEP SHEARS,

We have every reason to beliove the

demand will be greater than the supply

this season, so buyers should order early

to prevent disappointment.

to our A diten write.. "Wo shall hav

makers being unablo to aupply in time."

Marking Oil, Hone's assorted Needles

Twine, Stencils, Stencll Ink, Ruddlo

JAS. THAIN \& CO.,

IRON \& HARDWARE MERCHANTS

Victoria Avenue, Taupo Quby, and

St. Hill Street.

W A N G A N U I.

\begin{tabular}{lll} 
Whangantritheritage building beyond repair after & \\
\hline & & blaze
\end{tabular}

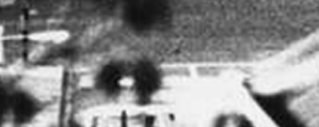

1. Eita

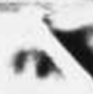

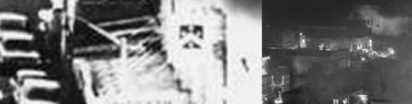

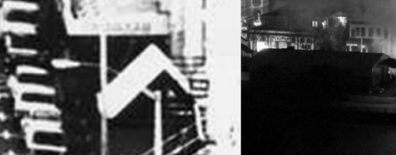

if

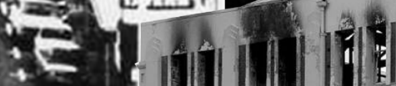
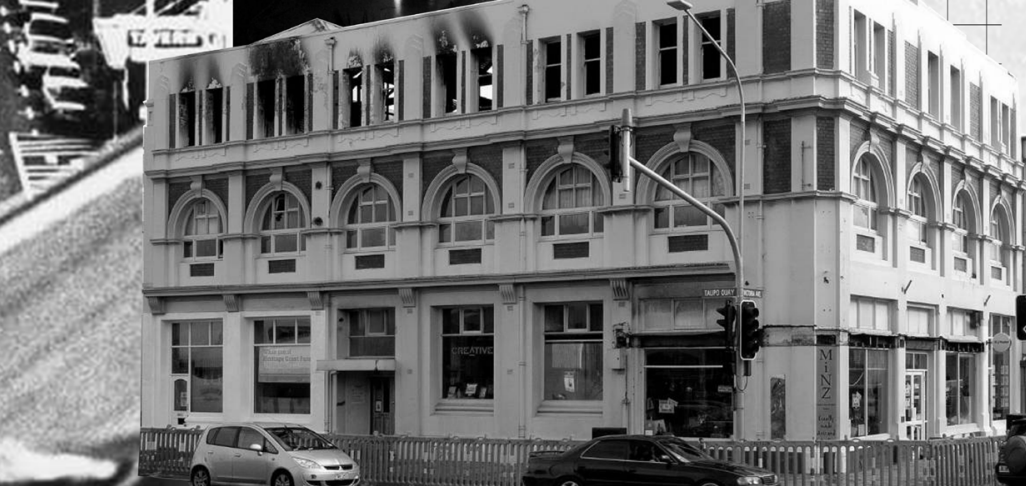

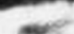

\&.

$0=0=$

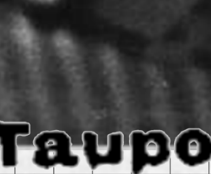

8 
Chapham who built it up to become one of the largest hardware shops in New Zealand. It was later bought by Dalgety \& Company, the stock and station agents. James Thain \& Co - The sale of household goods and agricultural supplies. Since 1980 the building has been leased for retail and office space. In July 2019 the building suffered a large fire resulting in demolition mid August.

Fire broke out in a building, on the corner of Taupō Quay and Victoria Ave, about $8.45 \mathrm{pm}$ on Saturday, 20th July engulfing the top two floors, which was finally extinguished by $12.55 \mathrm{am}$. Fire and Emergency New Zealand shift manager Gill Webley said the building - a mix of office and residential flats - had received "extensive damage".

The Thain's building is a Class B heritage building in the Whanganui District Plan but has no national heritage status. The three-storey unreinforced masonry building is severely earthquake-prone at 5 percent of new building standard (NBS) and the ground floor was flooded in the June 2015 floods.
https://paperspast.natlib.govt.nz/newspapers/WC18921025.2.4.2

Page 1 Advertisements Column 2 (Wanganui Chronicle, 25 October 1892)

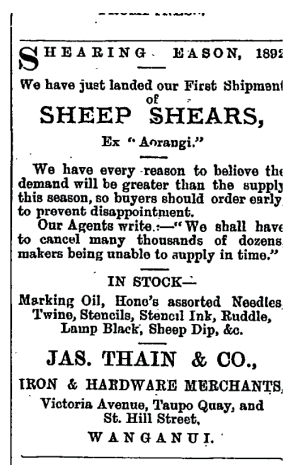

1890

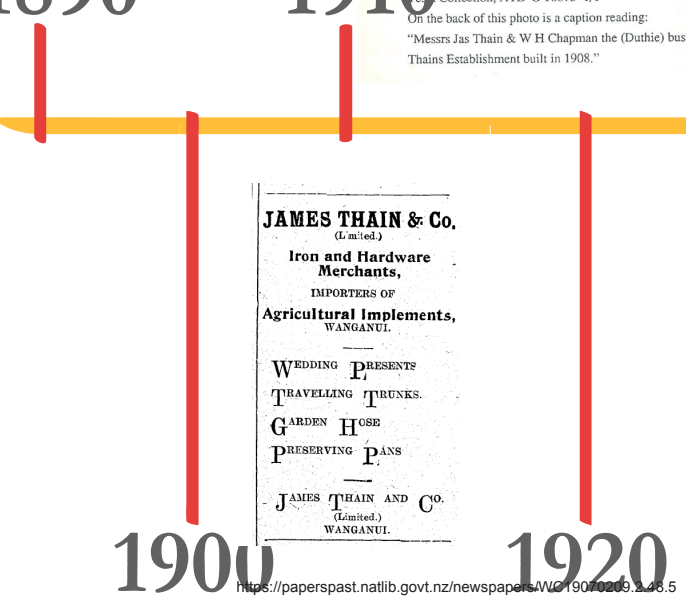

Page 7 Advertisements Column 5 (Wanganui Chronicle, 09 February 1907)

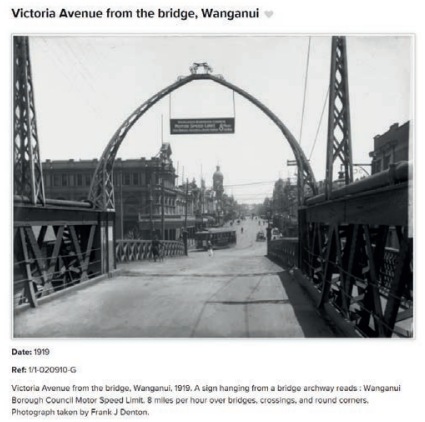

Fig. 6.43: Time line of events associated with the building. 

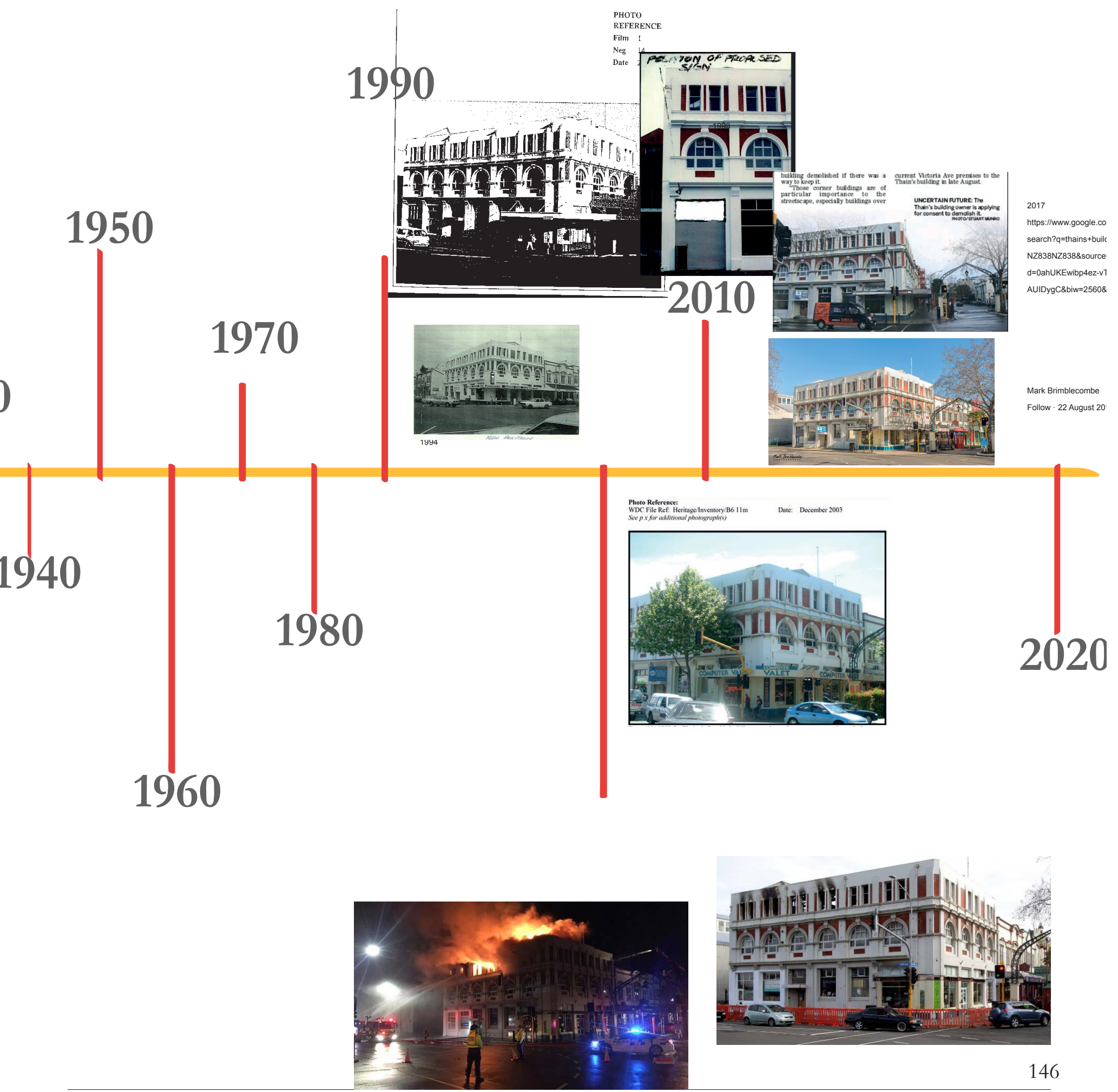


\subsection{PROPERTY BROKERS BUILDING}

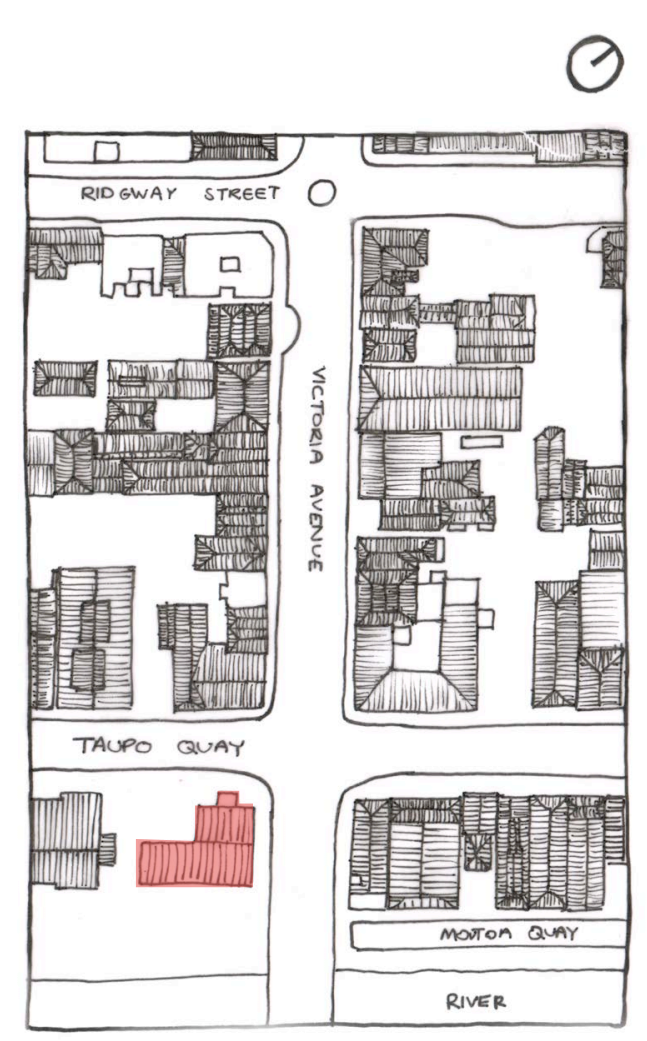

Fig. 6.44: Location plan of the building.

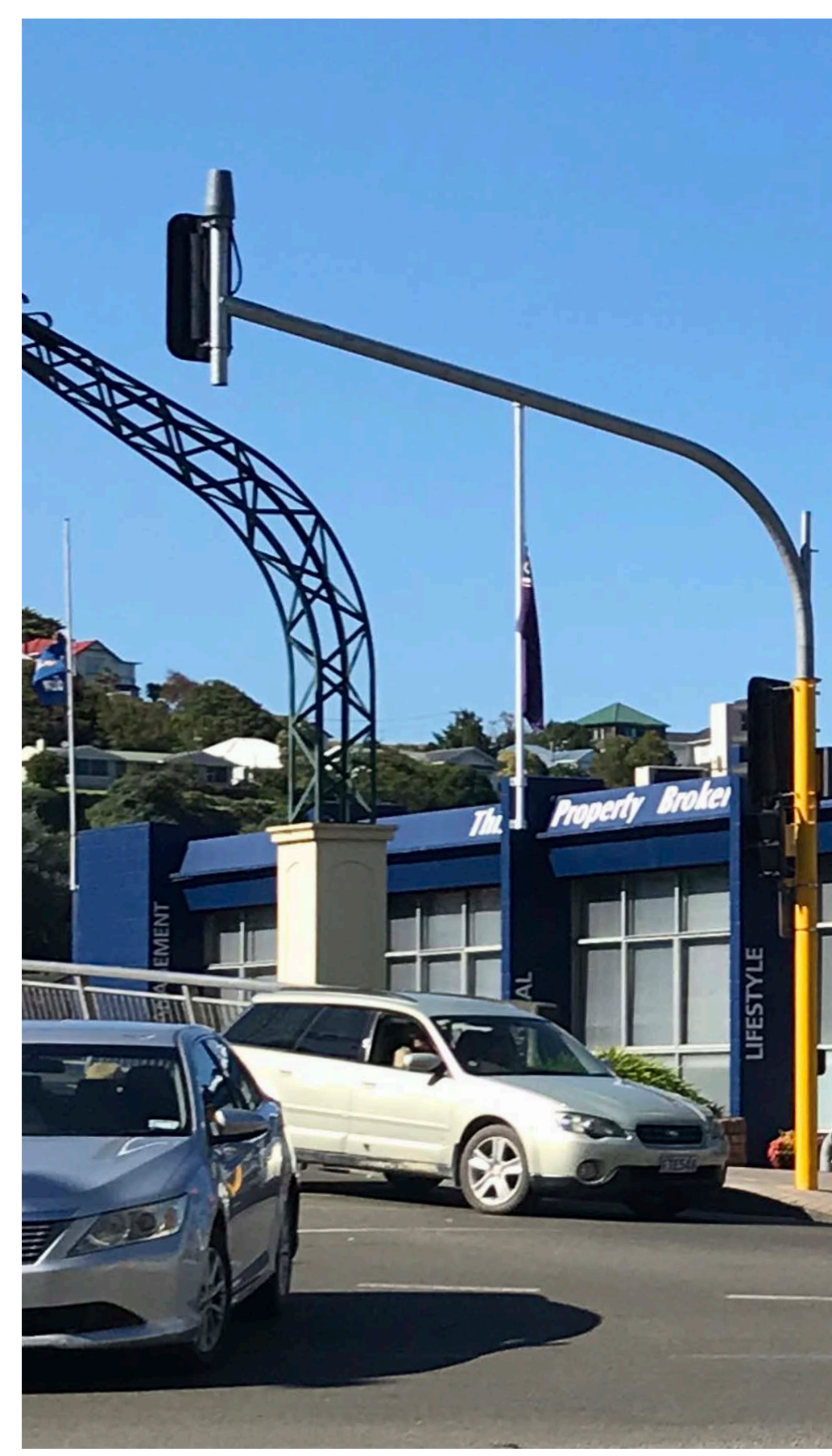

Fig. 6.45: Street view of the Property Brokers building. 


\section{PROPERTY BROKERS BUILDING}

51 Taupo Quay, Whanganui

$\$ 314$ / rent per week

Rental Yeild 6.86\%

Land Area - 1242m2

Floor Area - 540m2

Construction 1970's

Construction - Concrete external walls, Iron roof

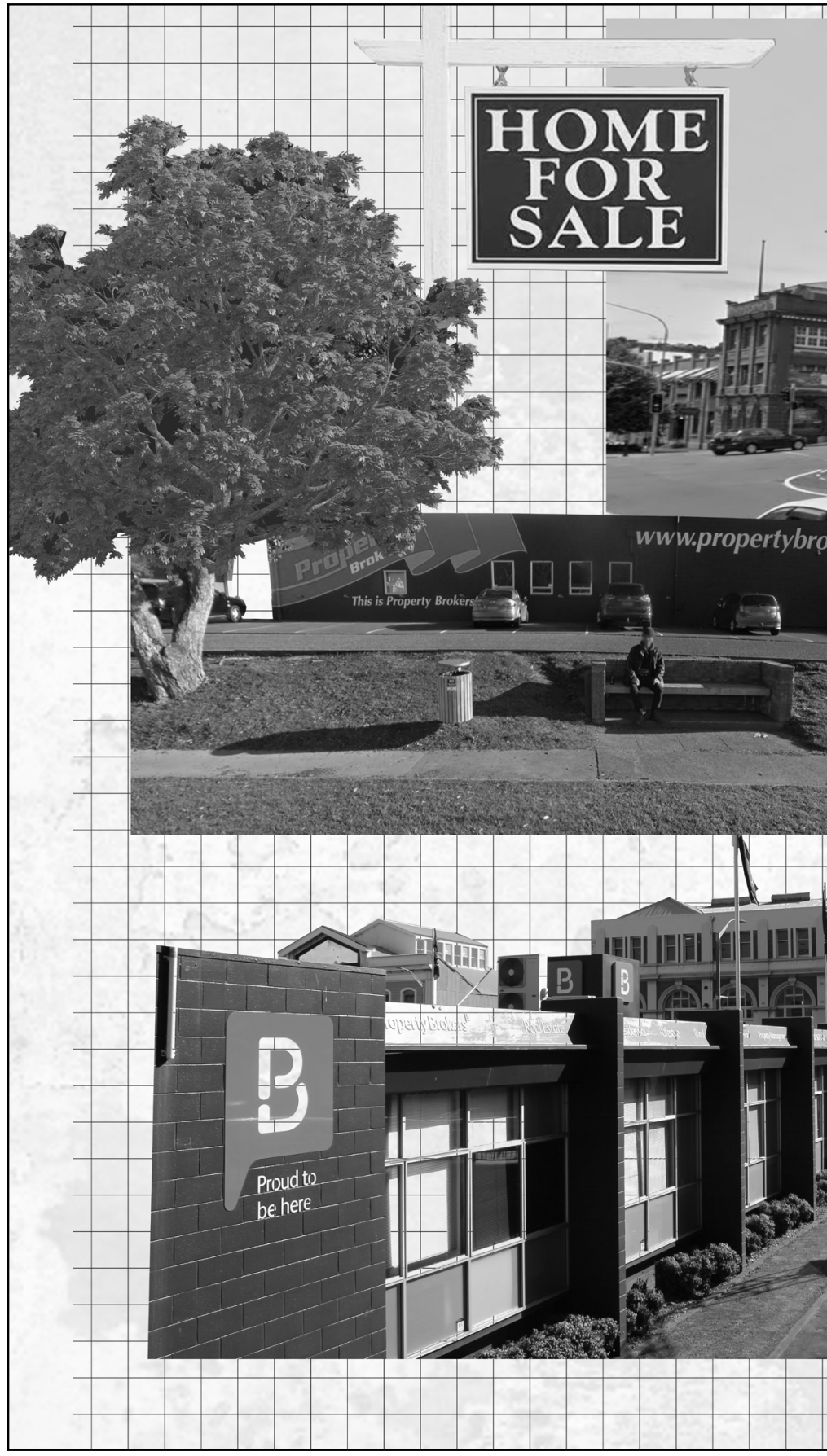

Fig. 6.46: Collage of Property Brokers Building. 


\section{Property Brokers}

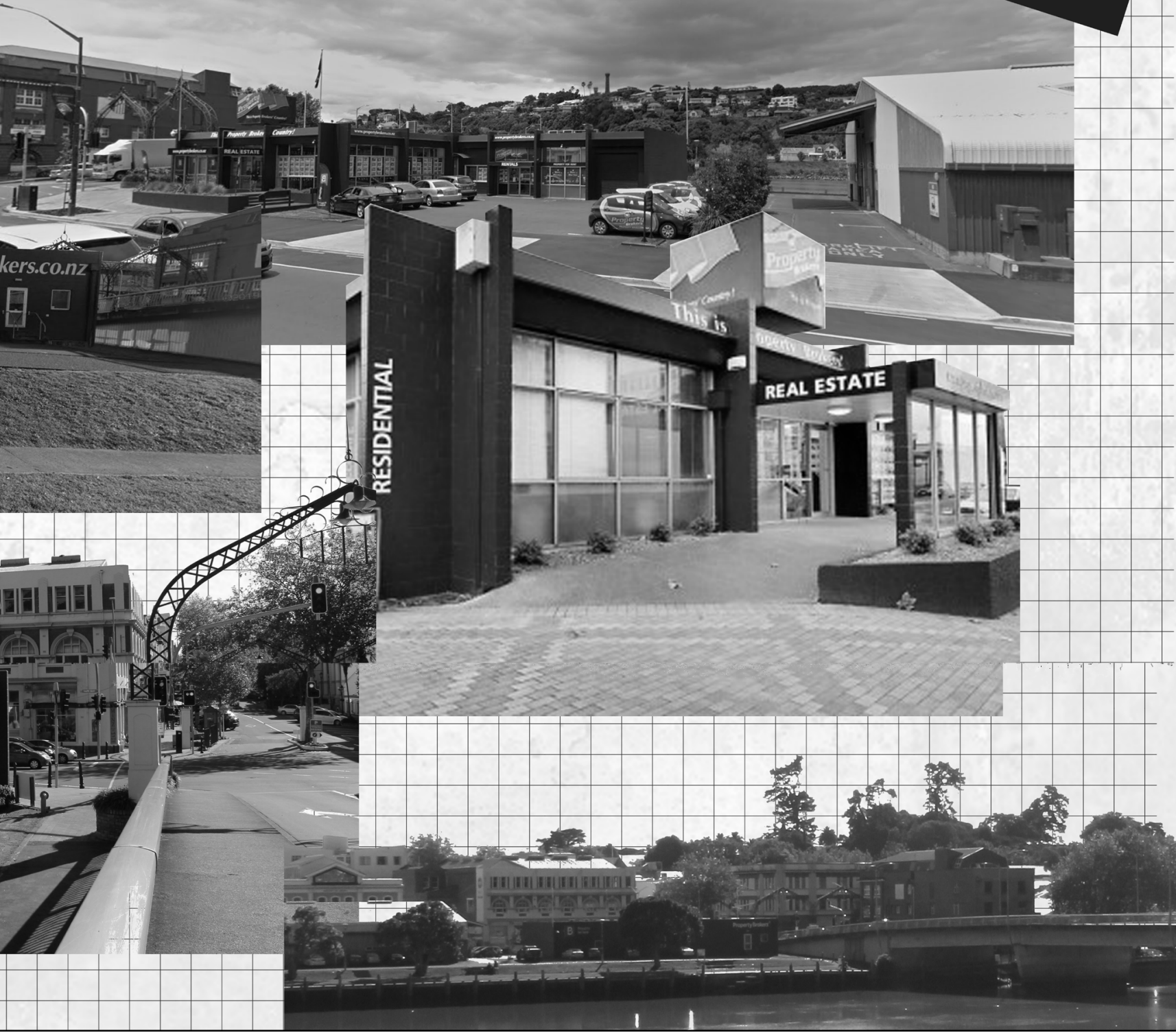




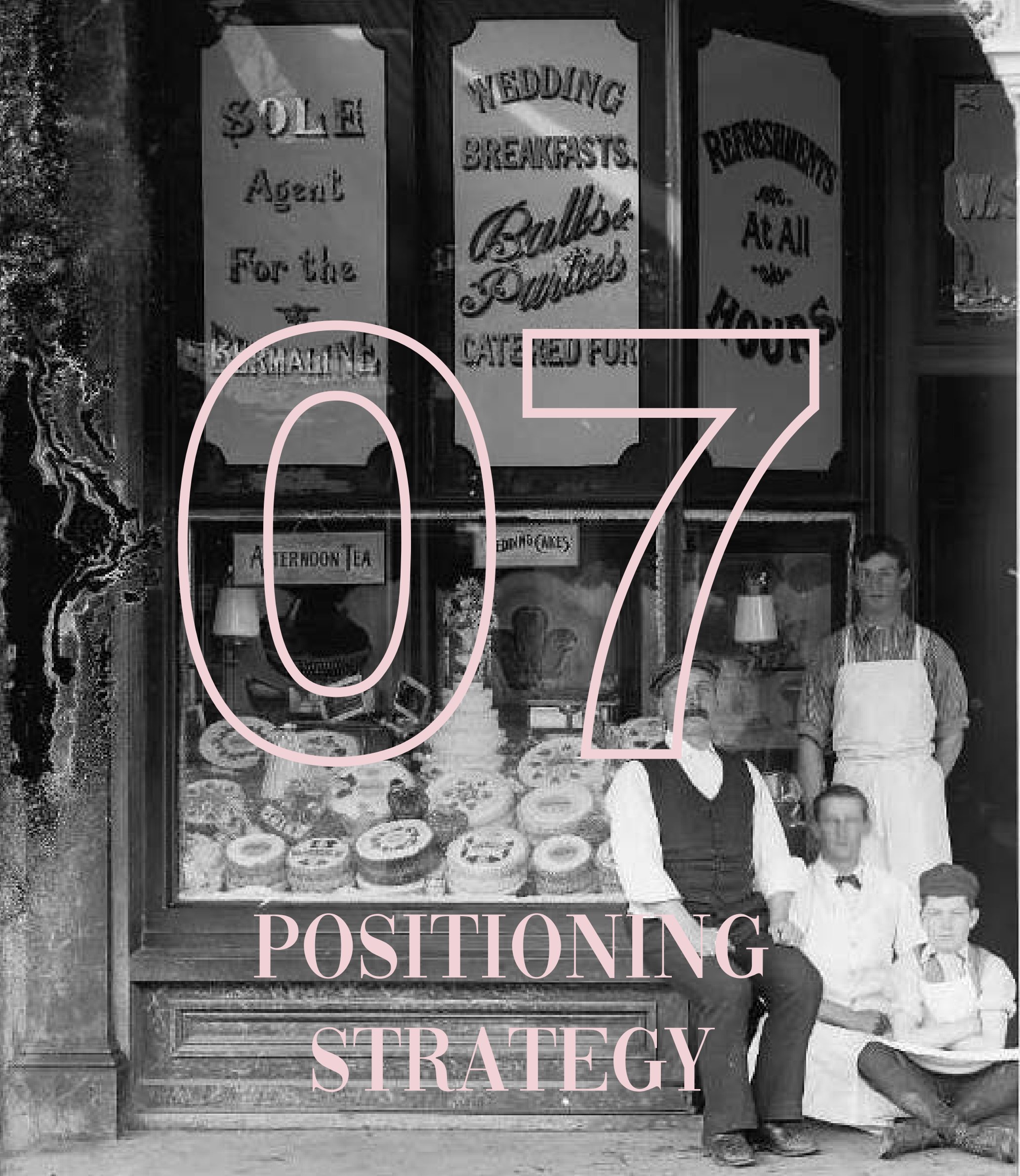




\subsection{POTENTIAL CIVIC DEVELOPMENTS}

\section{HERITAGE}

When developing a strategy to revitalise a town centre, you first need to understand the urban context. Which buildings have heritage value and or need earthquake strengthening and prioritise these.

Recent changes to the national earthquake upgrade incentive programme has enabled a more affordable option for building owners in the regions. The programme offers up to $67 \%$ of the cost of the seismic upgrade work to be paid by the Heritage EQUIP fund if one of the buildings is heritage or a listed property (Heritage Equip , 2020). These modifications provide better support to building owners in medium or high seismic risk areas like Whanganui. (Maslin, 2019).

Figure 7.02 is an image of Whanganui's Central Business District and the shaded buildings indicate the heritage buildings listed by New Zealand Heritage. Victoria Avenue has a strong sense of identity due to its variety of outstanding architectural features from multiple periods in close proximity to each other.

Figure 7.03 illustrates the high number of buildings that need earthquake strengthening in the town centre. First priority buildings are located adjacent to the chosen site along Victoria Avenue. 


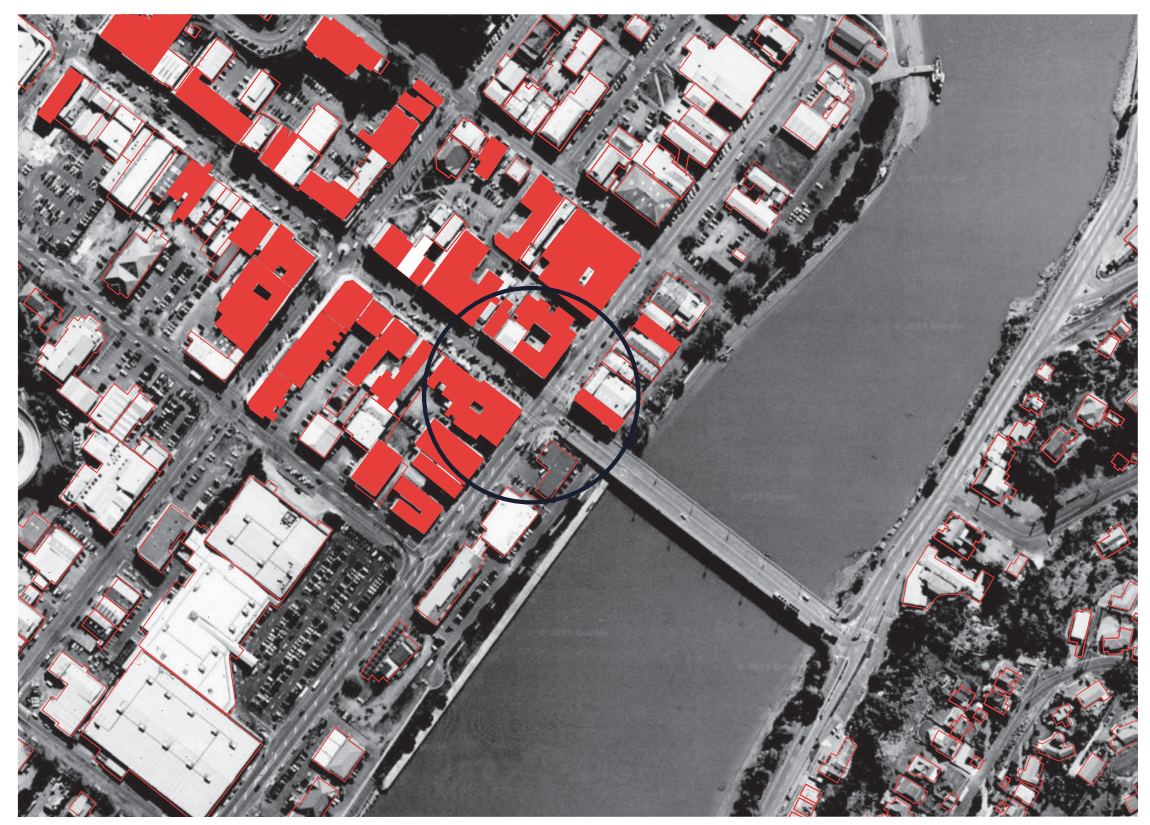

Fig. 7.02: Heritage buildings.

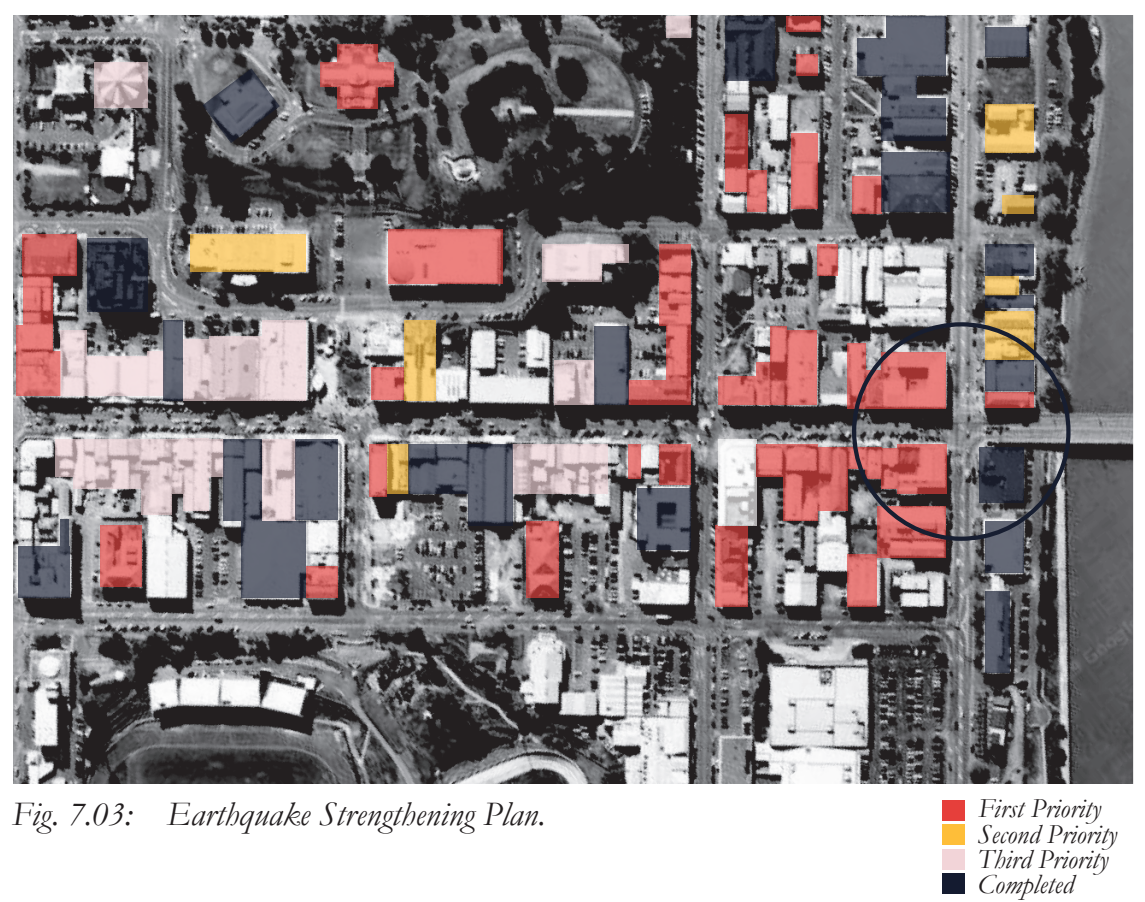




\section{ARTS AND CULTURE}

Whanganui has a strong arts and culture sector which is visible in many parts of the town centre. Amplifying the arts will give Whanganui a stronger identity. Council led initiatives include an artist led shared studio, introduction of an iwi dimension, introduction and enhancement of arts events and activation of public art spaces.

Figure 7.04 illustrates Whanganui's two greatest assets which are the Whanganui River and the Sarjeant Gallery which creates an axis to Cooks Gardens. Although the linkage between the two is poor. The linkage is also the relationship between the mountains of the central plateau and the Whanganui river mouth. The enhancement of this should bring social cohesiveness.

Local street art illustrated in Figure 7.05, painted on old buildings is also common in Whanganui as a way of bringing life back into spaces, as well as allowing locals to express their talent.

Bringing cultural connection back to Whanganui will better integrate artistic elements into the town's design and generate more opportunities for Whanganui. 

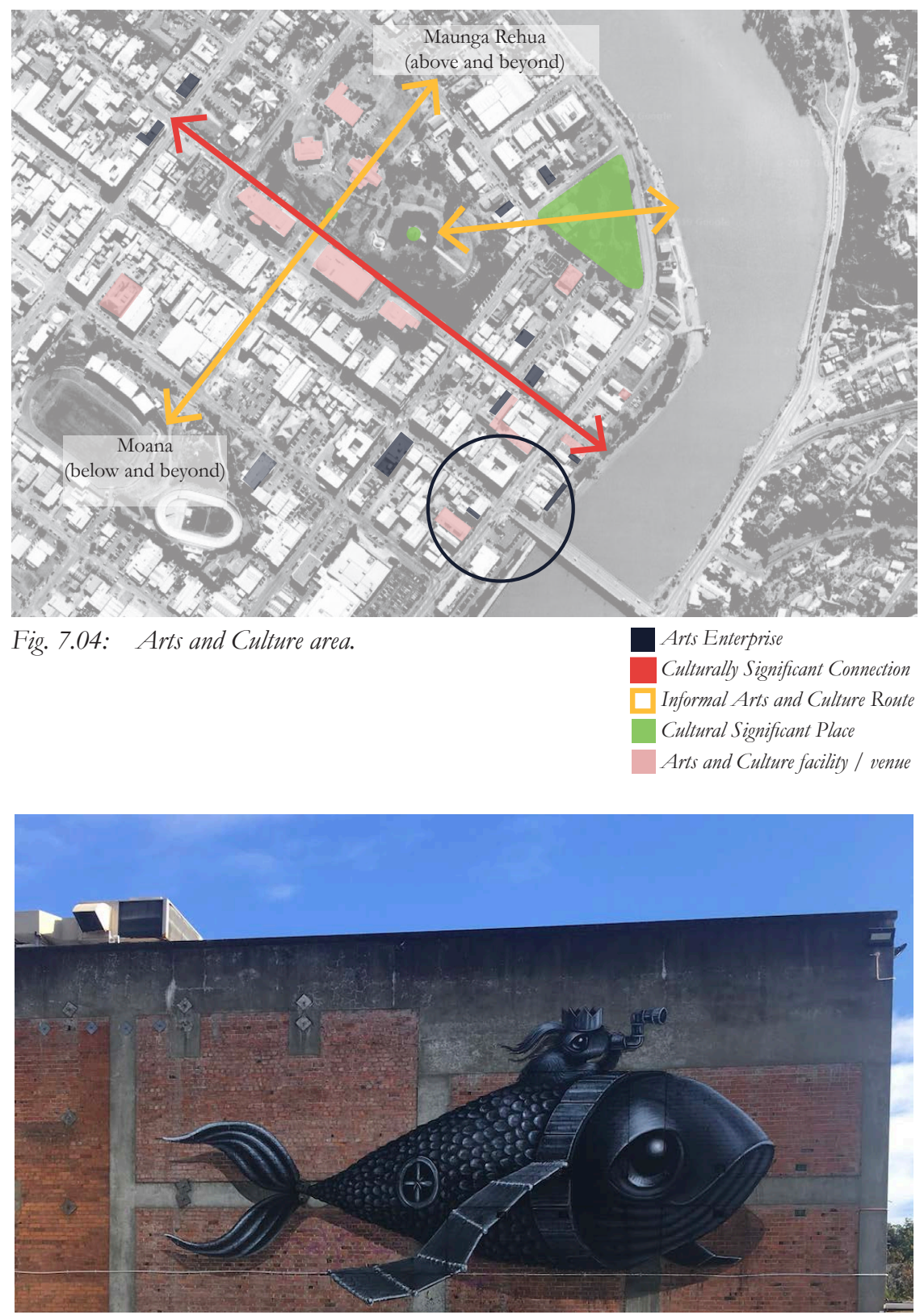

Fig. 7.05: Street art. 


\section{COMMUNITY}

An appealing and vibrant town centre needs to have good community facilities that are accessible by all. They need to be connected and designed with the whole community in mind.

"Whanganui is an attractive city with a strong local sense of identity and a commitment to improvement." In Whanganui there is a need to focus on community and civic amenities especially those along the waterfront (Making Whanganui Visible).

Like many provincial towns the region lacks accommodation, conveniently located adjacent to town centre amenities. This lifestyle is enjoyed in New Zealand's larger cities within apartments in mixed use buildings and brings life back into the city centre.

There is opportunity in Whanganui to create affordable accommodation for the continuing care of older people from retirement through to advance care. This is necessary due to New Zealand's growing ageing population and the increasing demand for affordable housing.

Community care approaches such as 'ageing in place' appeal because the idea of segregating the older people into rest homes will become less desired. More intermediate care such as home care, supported living and similar arrangements are becoming more desired.

Care related accommodation needs support services in close proximity like a doctors general practice, pharmacy and supermarkets. Figure 7.06 illustrates the common community facilities in close proximity to the chosen site.

It is desirable for older people to live close to these facilities as they are convenient and less expensive to access. Also being well integrated in the surrounding community means they can stay longer in this 'supported care' type accommodation thereby avoiding loneliness and enabling passive surveillance and interaction with different age groups. 


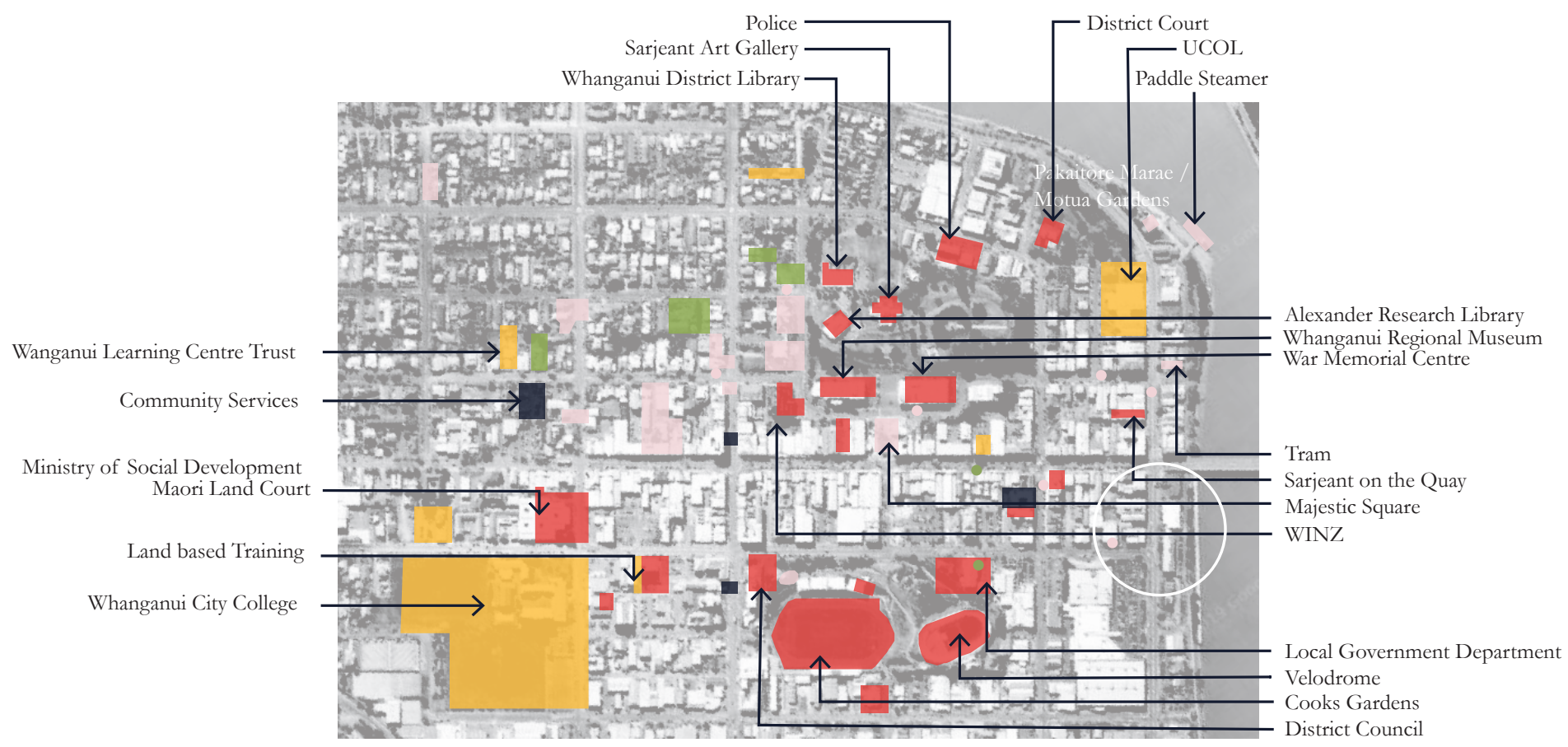

Fig. 7.06: Community areas.

This approach is likely to lead to significant heal benefits and a more vibrant community.

Community spaces should be designed with all ages in mind and when all amenities are in easy access a more vibrant community with strong connections is created.
However if any additional essential amenities are still required in the immediate facility. For example a library and its development would suit the chosen site and the existing building structure then this could be an alternative proposal in the future. 


\section{TOURISM}

There is growing opportunity for tourism in the region, as Whanganui becomes a more popular destination due to its outstanding natural and cultural features.

For centuries the Whanganui River has been considered a scenic wonder - "The Rhine of New Zealand", yet it remains relatively 'untouched' so outdoor tourism is a significant draw card to both international and domestic visitors. They can enjoy the river on an historic river boat, by jet boat or self propelled canoe. Alternatively visitors can hike or cycle including two 'Great Rides' which are part of the national cycle trail network. Nga Haerenga (The Journey) formerly the 'Timber Trail' and 'Mountains to Sea.

Cycling's popularity is now a world wide phenomenon as most ages can ride a bike and now with the surge of electric bikes, cycling is like to result in significant tourism growth in the region.

Mt Ruapehu is two hours north and offers many attractions including the Sky Waka gondola and snow skiing in the winter.
There is an opportunity to tell the "Whanganui River Story'. The mountains and river have a unique spiritual character and the many marae settlements along the river banks mean visitors can have an authentic hands on experience showcasing Maori history, architecture, traditions and values.

\section{"Growing cultural tourism experiences which connect marae of the Whanganui River to the growing interest in the tourism, educational and recreational experiences to be hand in Whanganui National Park." Unlocking Maori cultural and spiritual dimensions.}

(Manawatu-Whanganui Growth Study 2015)

Visitors get to understand the Te awa Tupua legislation passed in 2017, giving person hood to the river and the concept of the river being a treasure, a food basket, medicine cabinet, highway and defensive moat; teacher, priest and parent; source of prestige and core of their being (Kennedy, 2019).

Domestic tourism also offers visitors a unique experience, strip retail shopping amidst character architecture in an attractive vibrant setting. Whanganui can be a recognised 
destination, celebrating its revitalised using colour and through design by uplifting appearance, acknowledging its past yet valuing the existing heritage building facades.

its vital cultural connection to the river.

A strong tourism sector with vibrant tourist The growth of any region is dependant on attracting people, both domestic and attractions positively adds to Whanganui's strong sense of identity which in-turn strengthens its cultural connection to place.

The city's strong historical character would become a tourist attraction in itself. This can be done through 'telling the historic story', internationally to enjoy the space. With the hope that some of these visitor's will be tempted to relocate to the area upon discovering its value. Hence the importance of tourism in our rural provincial towns and cities. This is still considered a significant growth opportunity for the Whanganui region.

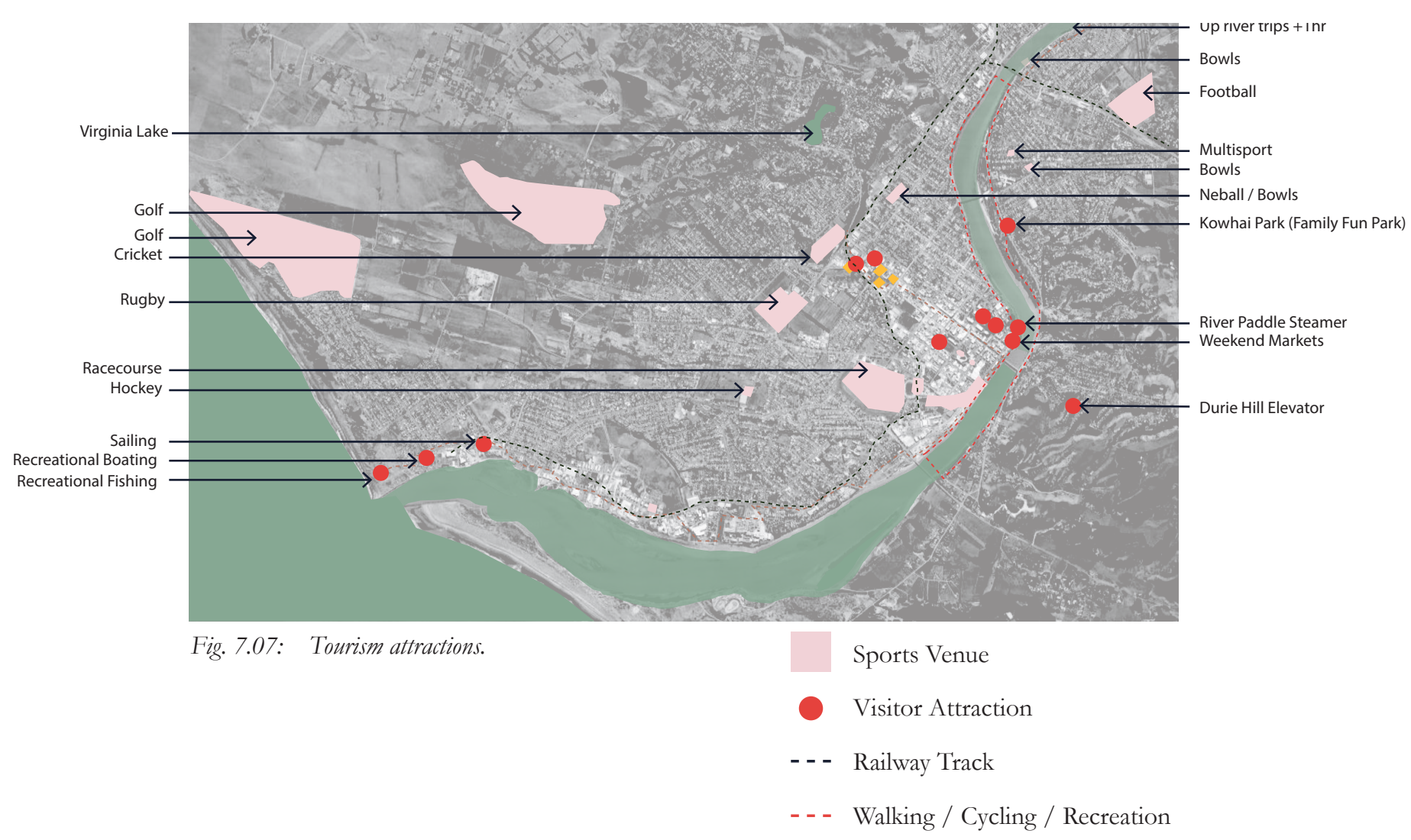




\subsection{URBAN DESIGN CHANGES}

The Whanganui City Council plans was used as a starting point for the redesign strategy for the cross-roads at an urban scale (Making Whanganui Visible,2016).

The largest change aims to reduce the levels of car traffic and create a more pedestrian friendly environment. These improvements are typical of what many cities are doing to future proof and re-pedestrianize crowded urban spaces. Further reducing the amount of parking by changing angled parks to parallel parks will encourage walking and increase levels of time on the footpath. This will also result in more room for wider footpaths to accommodate more seating, attractive urban landscaping or the potential to house temporary stalls. Finally creating a slow vehicle zone at the lower end of Victoria Avenue ensures an improved pedestrianized design strategy.

Fig. 7.08: Whanganui's current urban plan. 


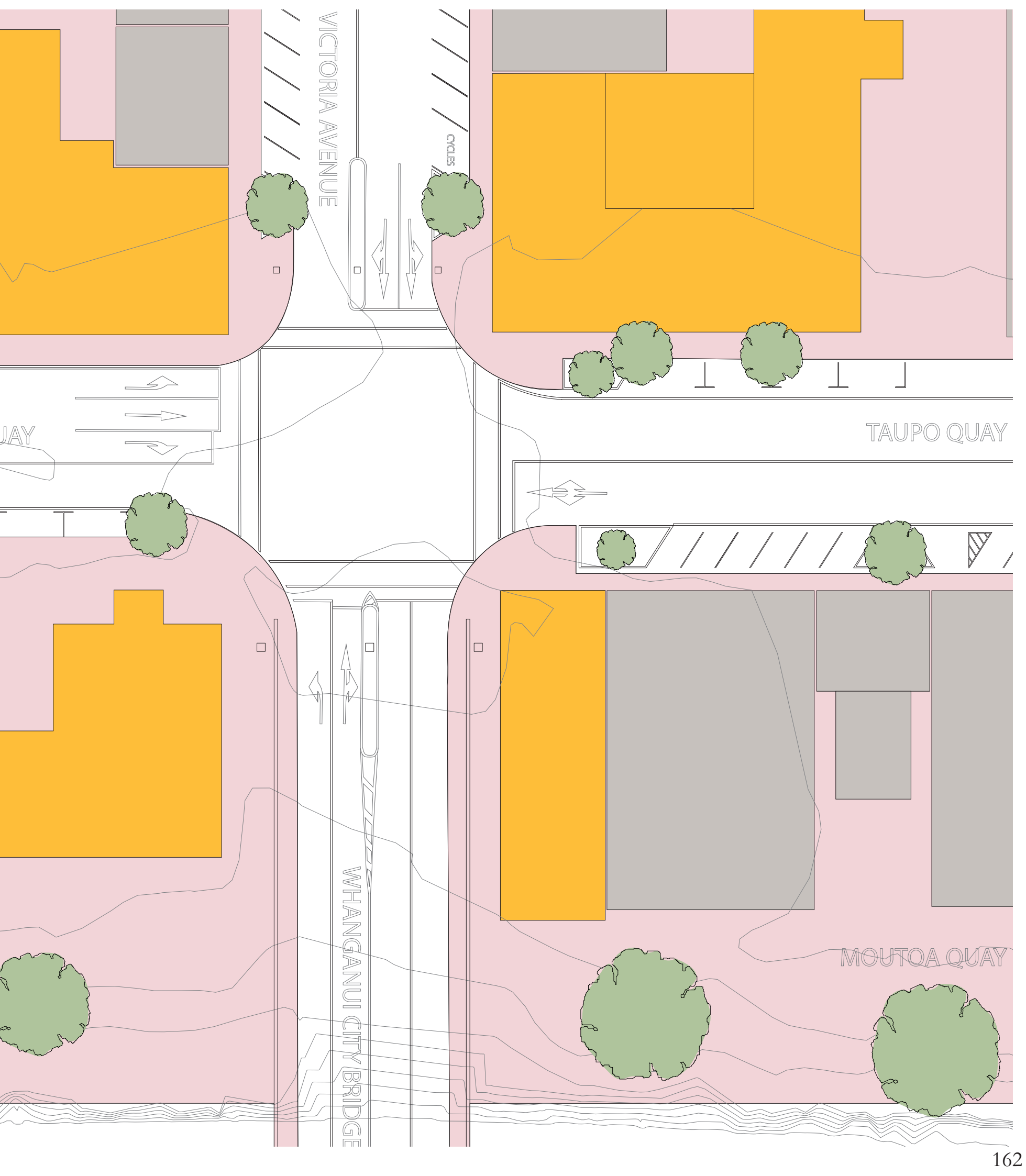




\section{MAKING WHANGANUI VISIBLE IDEAS}

Figure 7.09 illustrates the additional pavement space if the cars are parked parallel compared with angled parking. The additional pedestrian area can be used by the shops down Victoria Avenue for seating or food trucks could park up and use the pavement area.

Less parking on Victoria Avenue will encourage walking and increase levels of time spent on the street. While slowing cars down will create a more safe centre. A slower Victoria Avenue slow zone will also create a more people oriented city centre. 

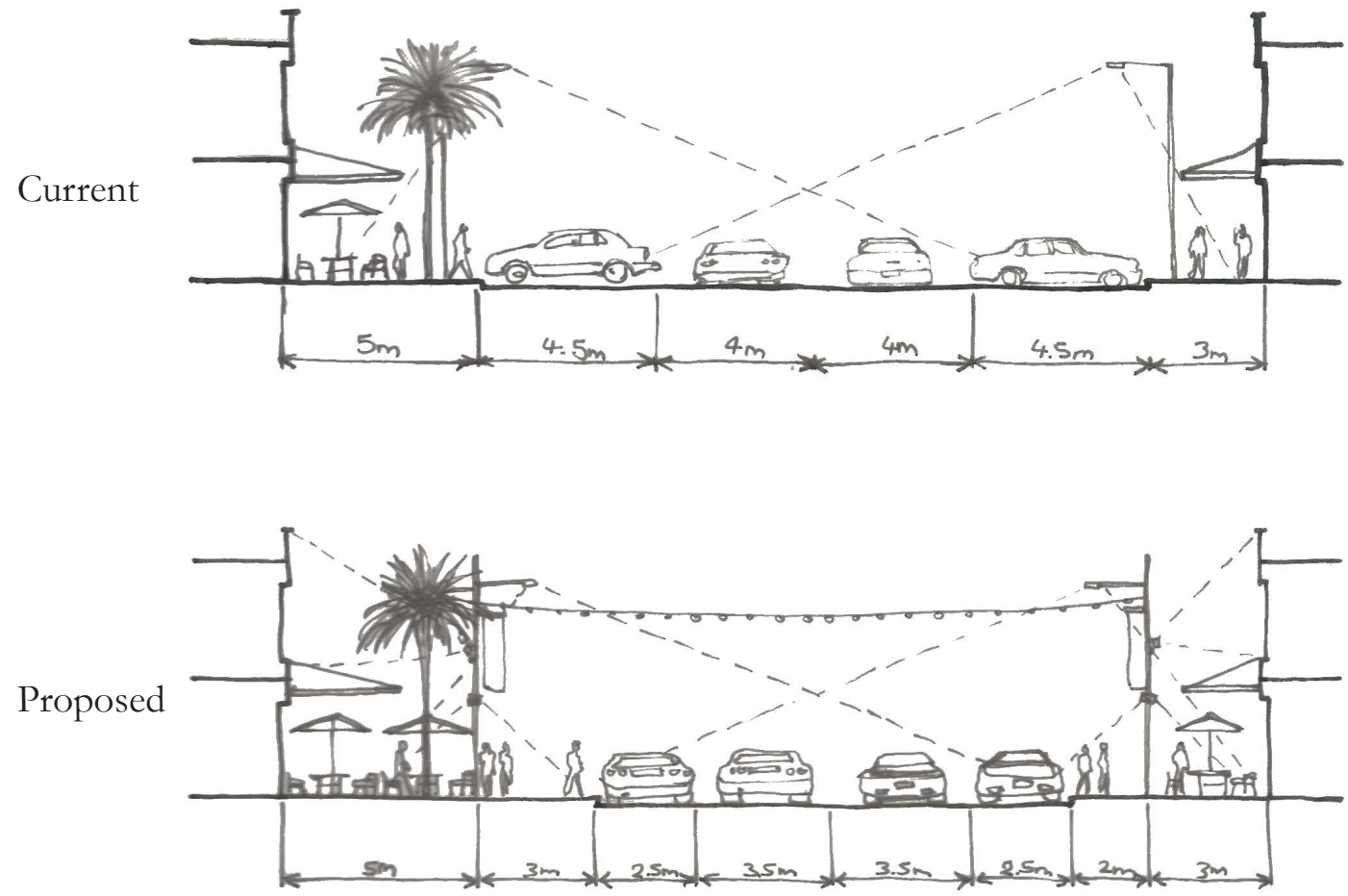

Fig. 7.09: Pedestrian orientated design .

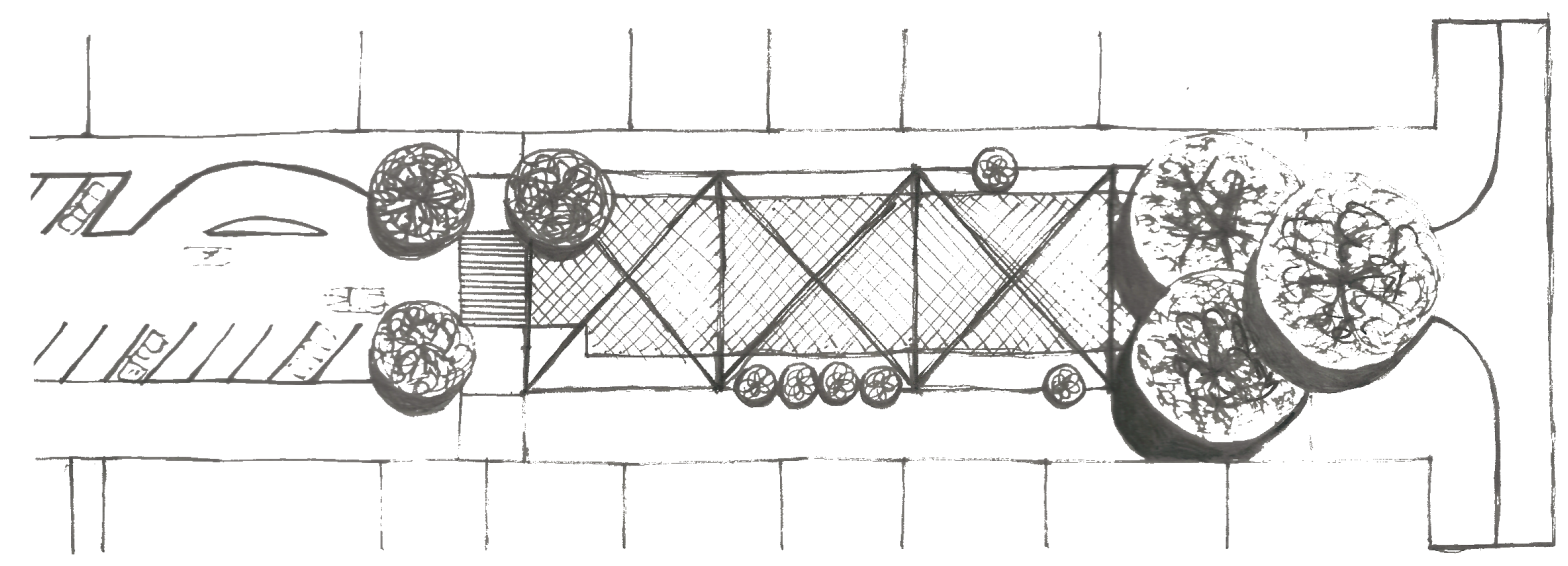

Fig. 7.10: Lower Victoria Avenue Slow Zone. 


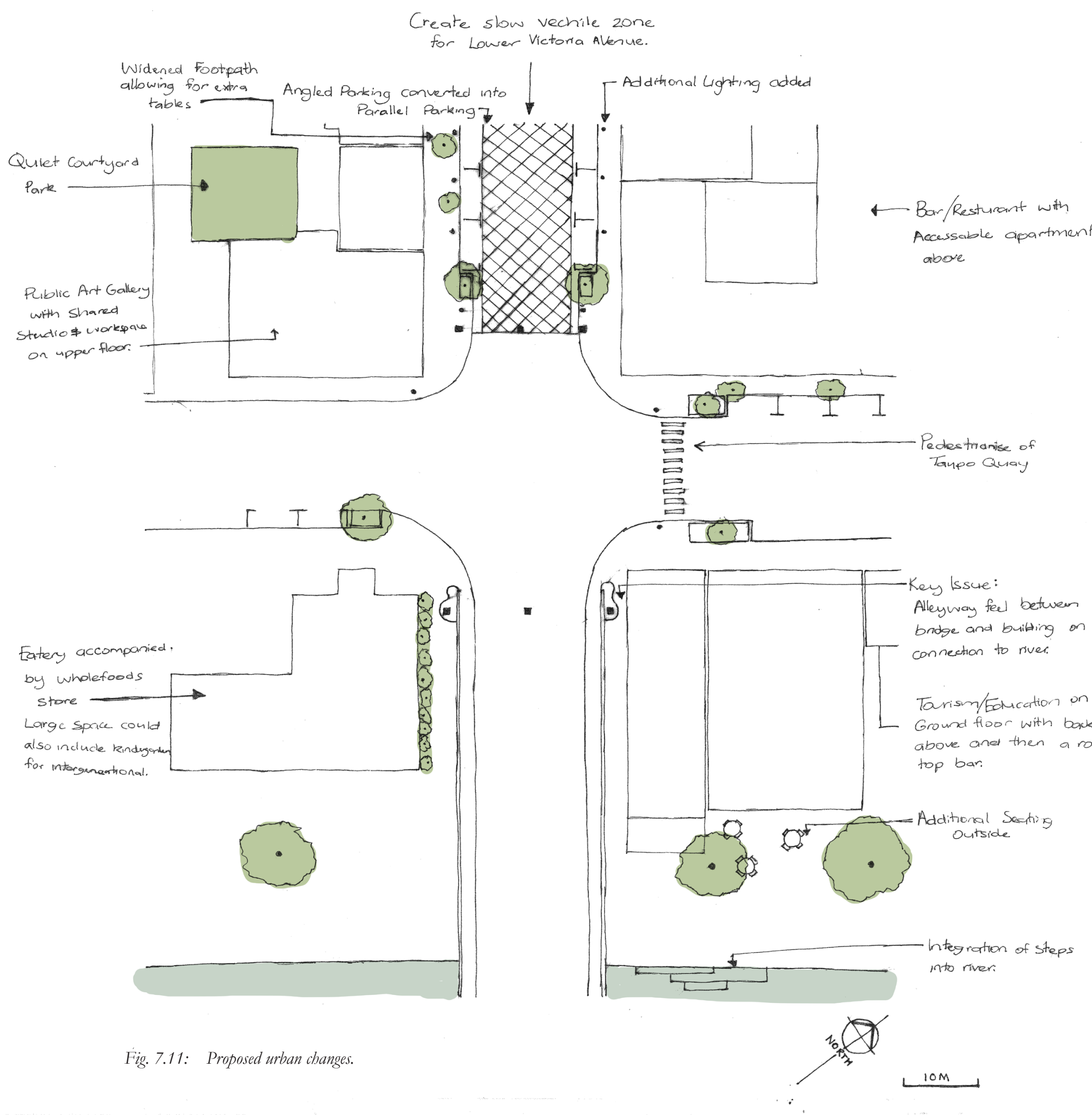




\subsection{BUILDING PROGRAMMES}

Any potential building program needs to consider a design that meets the needs of its community. That is to accommodate the needs of all ages not simply the elderly.

\section{"The Whanganui City council's goal is to make Whanganui a Family Friendly \\ City, a great place to live, that will attract visitors and new residents."}

For Whanganui to be a safe and a pleasant place to live, enhancing the quality and liveability of the central area is key.

Life is being brought back into abandoned buildings all over the world through being creatively re-purposed.

The list below was formed through acknowledgement of amenities which a successful city has within easy access.

Design programme ideas include:

Culture, leisure, sports, research, education, design, services, production, housing, agriculture, retail. Some are later being reinhabited by other stores. However, the longer a premise is empty the harder it is to overcome the perception that retail cannot succeed at that location. (Retrofitting Suburbia)

Regreening - Globally "Pocket parks and community gardens are known to increase the sale prices of surrounding homes by as much as $30 \%$ in the process." It's also low maintenance (Douglas 2006).

When choosing a program for the buildings it's important to explore all possibilities and have a good understanding of the existing market and what the community needs. Nonprofit groups often generally can't afford new construction so adaptive reuse gives an opportunity for cheap unused spaces to have alternate uses. (Retrofitting Suburbia)

When considering retrofitting or adaptively reusing an existing structure and changing the buildings use; accessibility, connections, services, neighbouring areas, visibility and views should be weighed up (Douglas, 2006).

A program which is seen as beneficial to the community and fits into its surrounding context is achieved through having a good understanding of the surround context. 


\section{PROGRAM DEVELOPMENT}

The site model including the river, bridge and cross roads, shows the surrounding site. The stacked blocks of different colours indicate the different types of building use.

Potential building programmes:

- Residential Apartments for multiple ages
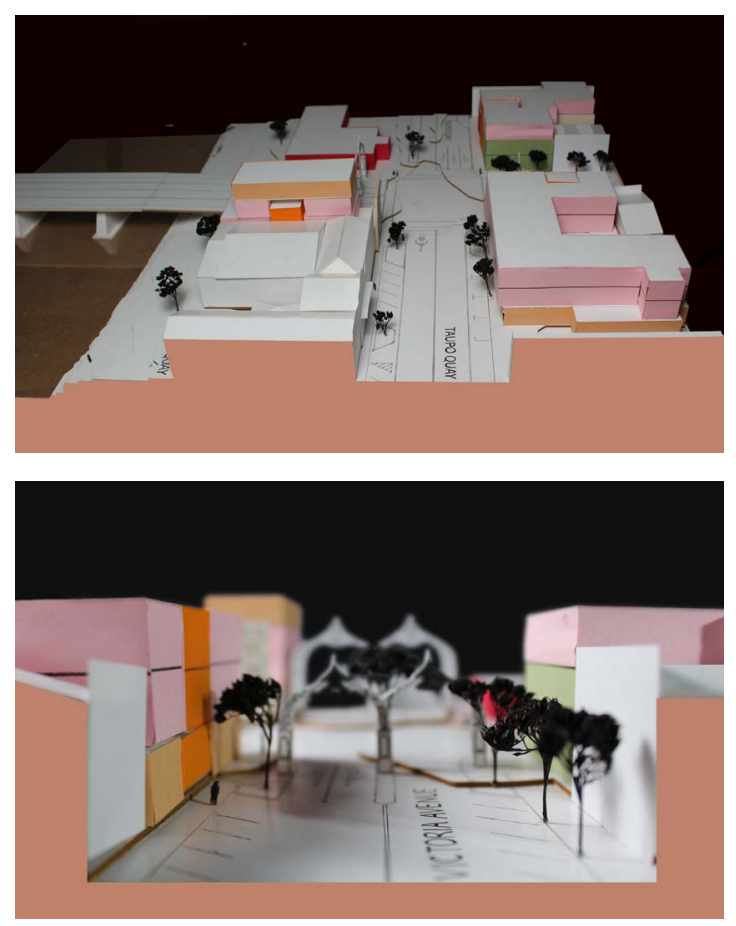

Fig. 7.12: Above left - North view of cross roads.

\section{Fig. 7.13: Below left - West view of cross roads.}

\section{Residential}

Retail

Bar / Restaurant

Shared workspace.
- Shared artist studio

- Art Gallery / Art Classroom

- Keep current existing building use

- Tourism Hub

- Back Packers

- Roof top Bar / Garden
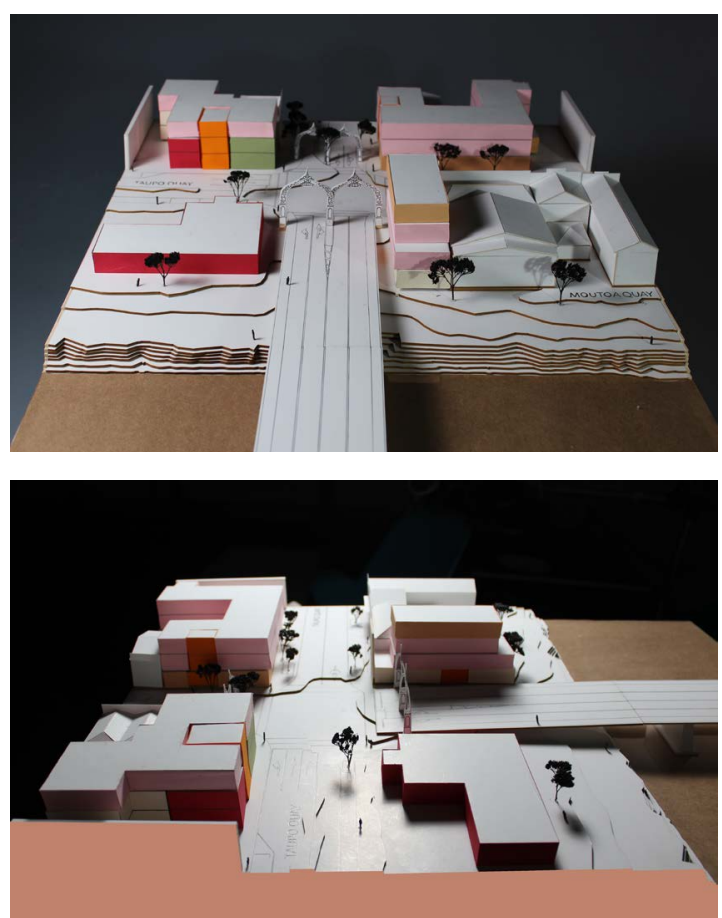

Fig. 7.14: Above right-East view of cross roads.

Fig. 7.15: Below right-South view of cross roads. 
Residential

Retail

Bar / Restaurant

Shared workspace.
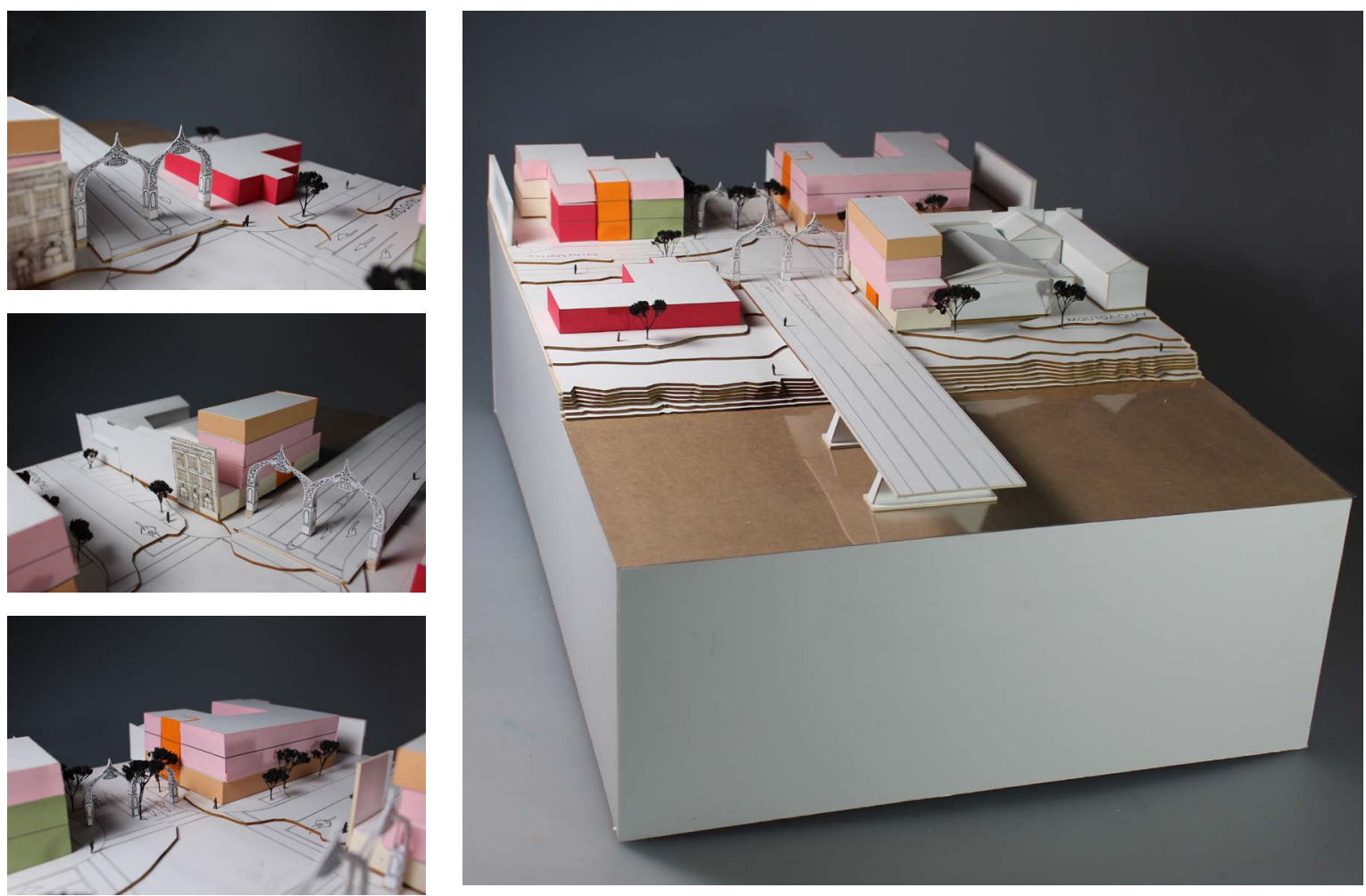

Fig. 7.16: Above left-Victoria Avenue looking towards the Property Brokers Building.

Fig. 7.18: Middle left-Looking towards the Johnston and Co building.
Fig. 7.17: Below left-Looking towards Fosters Hotel.

Fig. 7.19: Right - The physical model representing the cross roads of Victoria Avenue, Taupo Quay and the City Bridge. 


\subsection{DESIGN CONSIDERATIONS}

\section{CIRCULATION}

Quality and Comfort - Accessibility, Natural light, views and fresh air are all requirements for better living. With an adaptive reuse project, more design process is necessary to achieve these goals.

There are often significant economic advantages of building upwards. A central corridor turns a single-storey apartment into a single orientation dwelling, therefore depending on the orientation, it may receive too much or too little sun.

With a standard ceiling height, adequate natural light extends about $5 \mathrm{~m}$ from facade into a dwelling. Therefore higher ceilings allow for natural light to penetrate deeper into the dwelling.

An obvious location for a bathroom and storage is where light can't reach. A central core allows more freedom to organise the spaces around the exterior of the building.

(Leupen \& Mooij, 2012)

\section{NATURAL LIGHTING}

With a conversion to residential, natural lighting is necessary to provide a quality living space. The often large industrial buildings have big spans allowing easy transformation into new uses. This is also a disadvantage getting light into the depth of those spaces.

If a building has a much greater depth, the introduction of an atrium may be necessary. This is in order to ensure adequate quality of daylighting for residential use. It will also result in improved natural ventilation. With increased natural lighting and ventilation also comes increased heat gains and privacy issues.

The large structural systems of industrial buildings is favourable for flexible living spaces which can be customised and adapted to the different users needs. "Open plan" living solves the problem of unknown future users and makes the building more sustainable. 


\section{ADAPTIVE REUSE FOR HOUSING \\ UPPERFLOOR VACANCY}

The trend started in the 70's when the transformation of industrial buildings such as warehouses were converted into residential buildings. People enjoyed the symbolic characteristics of industrial such as large open spaces, large windows and found raw materials like exposed brick, iron and polished wooden floors, as fashionable. (Plevoets \& Cleempoel, 2019)

Grouping the fixed facilities like kitchen, toilets and building core allows for more flexibility everywhere else achieving greater spatial flexibility and adaptability of the dwelling (Petković-Grozdanovića et al., 2016).
Many provincial town centres like Whanganui face the issue of disuse or under-use of upper-floor spaces above shops and other commercial properties. Even when demand for retail space is high, this problem usually still exists.

There is a variety of reasons for upper-floor vacancy including over-stringent regulations (fire), poor physical amenity (accessibility and parking), multiple ownership (poor communication, sharing cleaning and repairs), commercial pressures (shop frontage and building management) and zoning (council laws). 


\subsection{SITE ISSUES}

\section{NARROW ALLEYWAY}

The issue with the main walkway between Victoria Avenue and the river walkway is this alleyway which is often shaded and narrow making it not inviting.

The physical model was used to better understand possible design solutions to mitigate the issue of an unwelcome entry.

The alleyway between the city bridge and the Johnston and Co building is the main connection to the river from Victoria Avenue

This model indicates the issue of the narrow corridor created, which can be problematic due to giving the feeling of being cold and damp. Within the design strategy this issue needs to be minimized as much as possible.

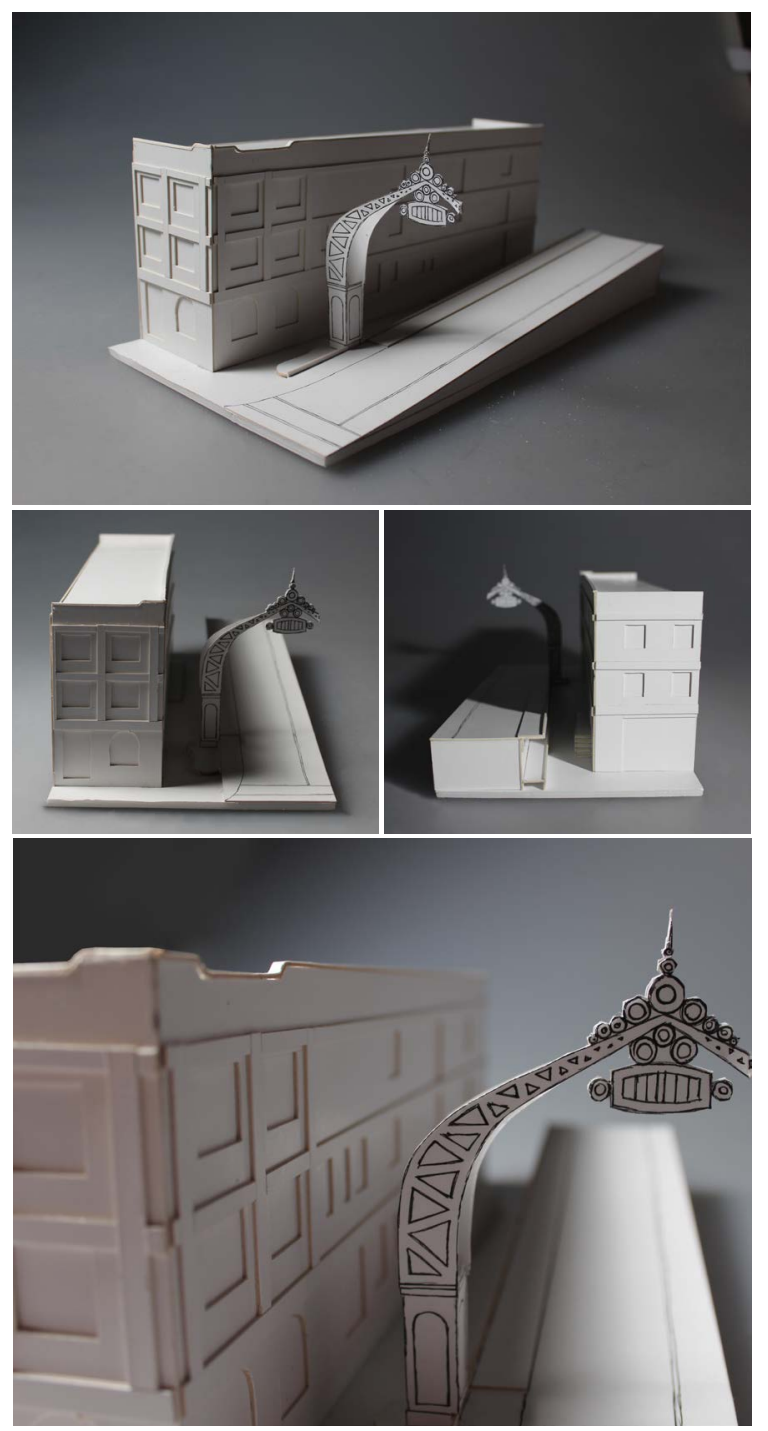

Fig. 7.22: Middle right-Sectional view through the bridge looking from the river.

Fig. 7.23: Bottom - Close up of the bridge arch and its connection to the adjacent building. 


\section{RIVER CONNECTION}

The connection with the river itself is also an issue. The board walk was an amazing addition to the area. But with a little more design consideration the connection to the river could be possible.

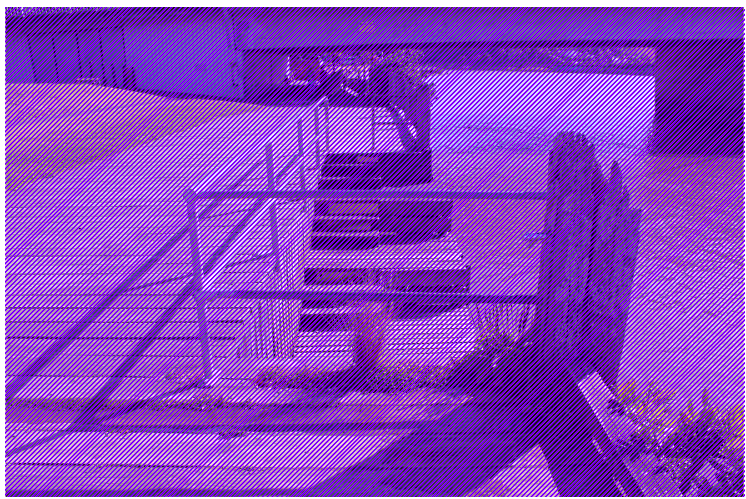

Fig. 7.24: Looking north to the city bridge.

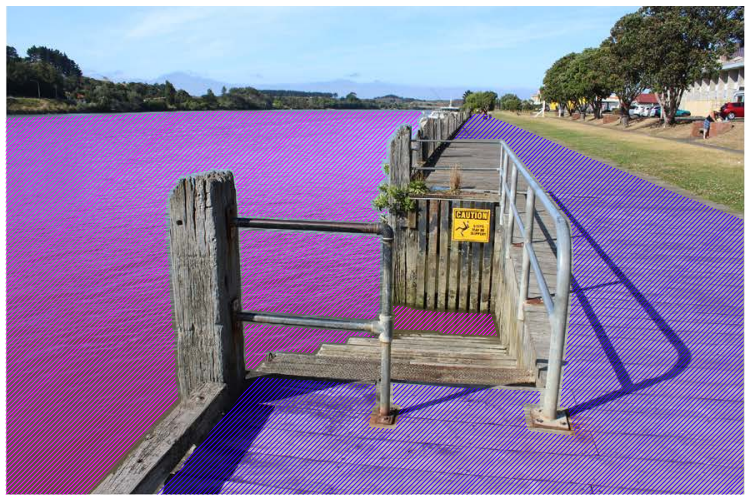

Fig. 7.25: Looking south, showing the lack of connection to the river.

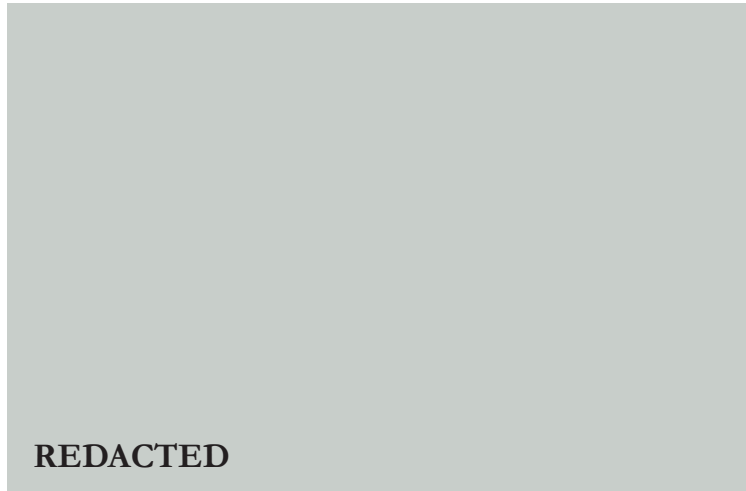

Fig. 7.26: Shipping at the town wharf adjacent to the present Whanganui town bridge.

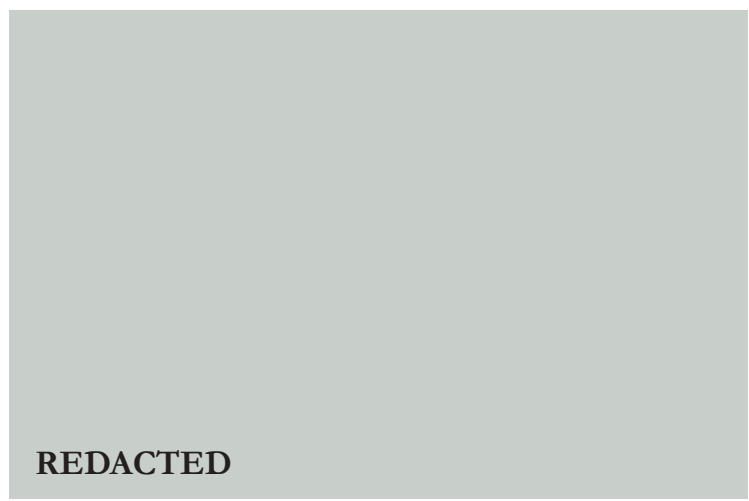

Fig. 7.27: The "River City" berths at the town wharf on her maiden voyage from UK March 3, 1952. 


\subsection{RIVER CONNECTION}

The strategic direction of Melbourne City's Pre-settlement, the Whanganui river would future development of its river corridor would have thrived with natural riparian zones alone, also benefit the Whanganui context. It was valuable to compare the Whanganui context to cities where the river connection has been successful.

From Melbourne's strategic plan, the element which connected with Whanganui the most was the reintroduction of a riparian zone to improve water habitat, biodiversity and create a healthy river ecosystem. (Appleton, 2019) both sides providing wildlife habitat and movement corridors. The vegetation would have slowed the flow of the river, therefore reducing soil erosion and flood damage. Due to more concrete infrastructure today the river is becoming channelled but the inclusion of a riparian zone would support the diversity of species and improve water quality. When designing the riparian zone active water uses like rowing and boating need to be considered as interference of the fragile area could be damaged.

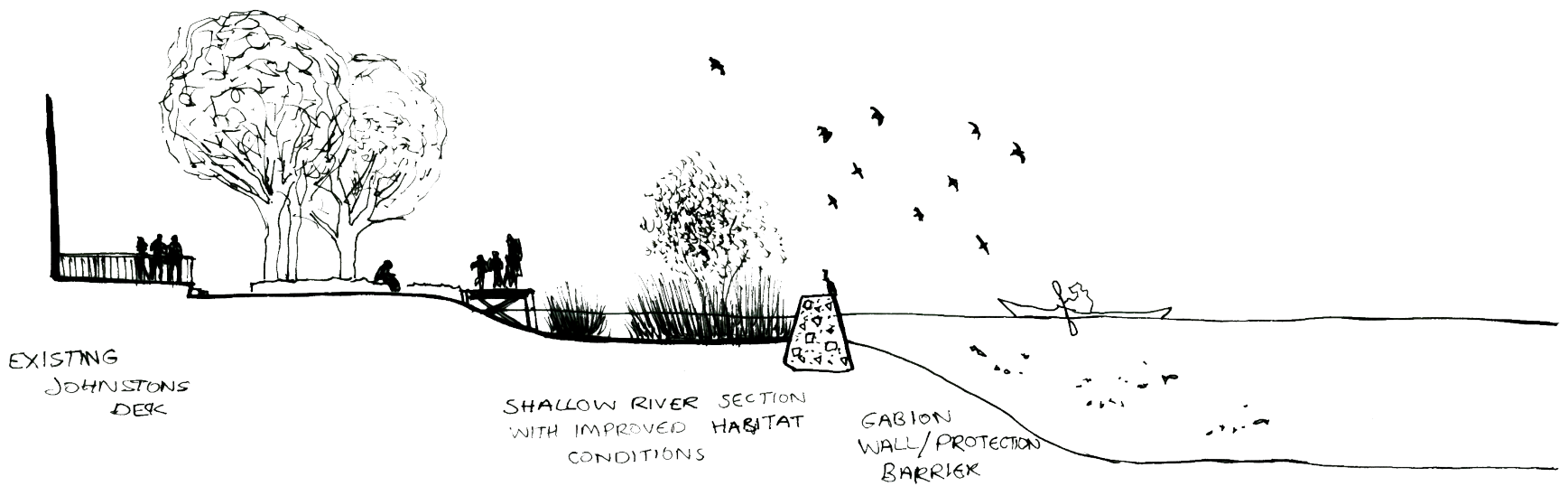

Fig. 7.28: Sectional view of a potential wetland area with retaining wall to river. 

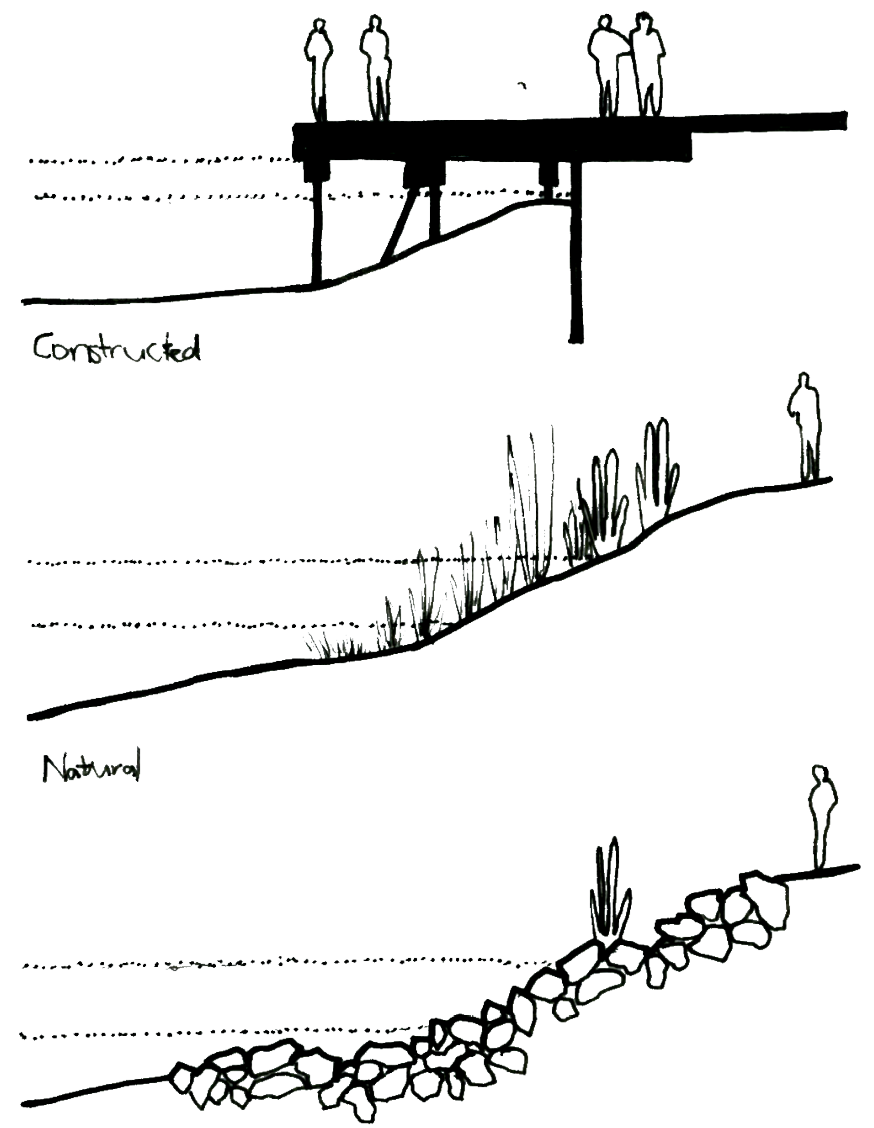

stablized

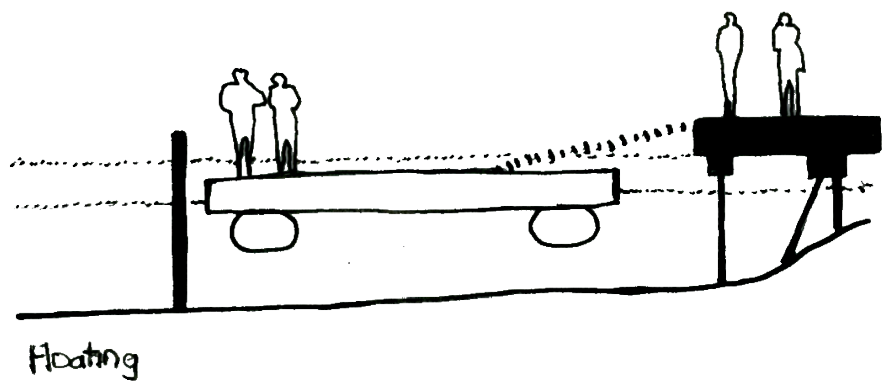

Fig. 7.29: Different relationships

between the river and land. 


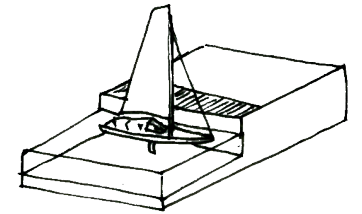

Fig. 7.30: Hard surface.

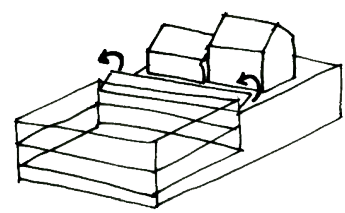

Fig. 7.34: Wall protection.

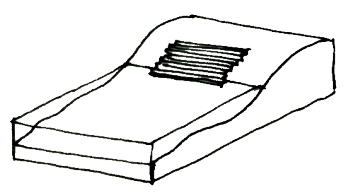

Fig. 7.31: Steps for easy accessibility.

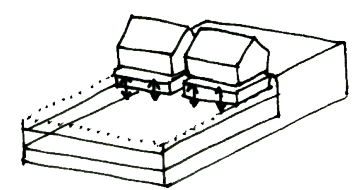

Fig. 7.35: Floating buildings.

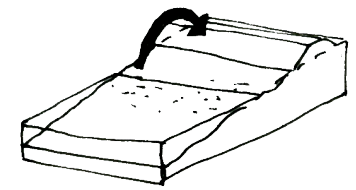

Fig. 7.32: $\quad$ Raised rivers edge to reduce flooding.

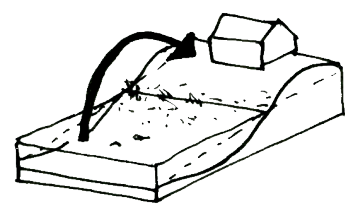

Fig. 7.36: Restored bank.

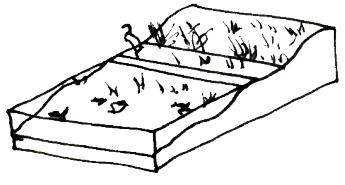

Fig. 7.33: Wetland restoration.

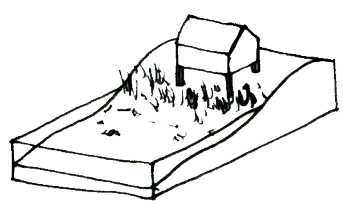

Fig. 7.37: Stilted structure reducing impact on habitat.
Landscaping and urban design are very important elements in the rehabilitation and revitalisation of Whanganui. Appropriate paving, lighting signage, street furniture and planting must be considered.
There has long been a tendency for Whanganui to turn its CBD back on the river, lining its banks with industrial backyards. There would appear to be a wonderful opportunity for Whanganui to reverse the trend and refocus on the river. (Cochran, 1990) 


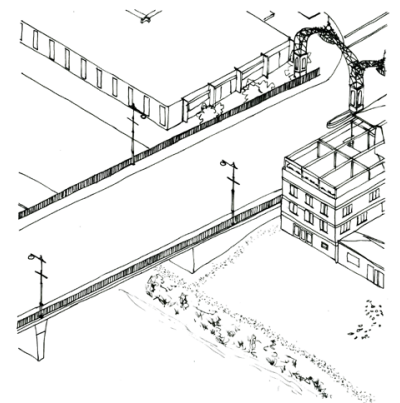

Fig. 7.38: Native riparian zone with gravel walkway.

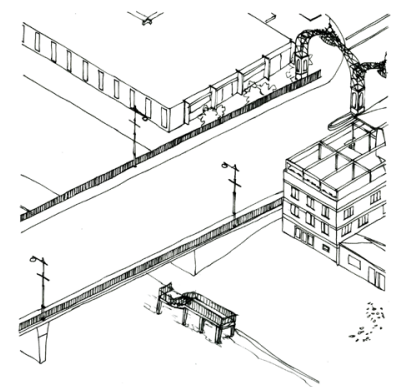

Fig. 7.41: $\quad$ Raised stilted viewing platform.

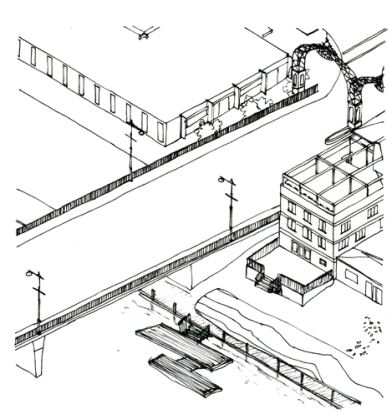

Fig. 7.44: Jetty which is floating and moves with the tide.

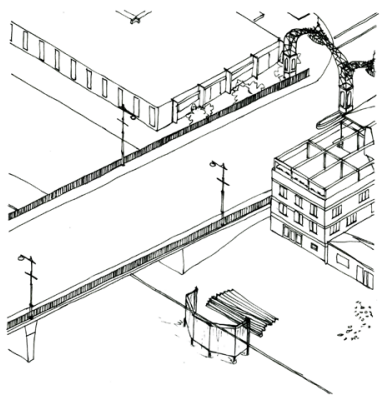

Fig. 7.39: Water curtain for digital projection and seating.

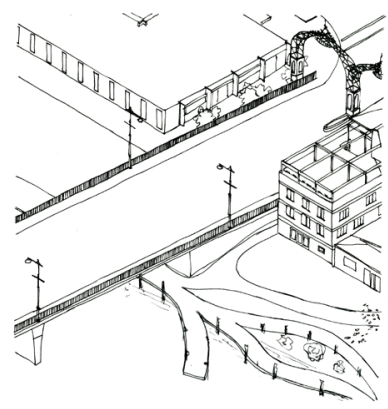

Fig. 7.42: Organic new walkways with planting.

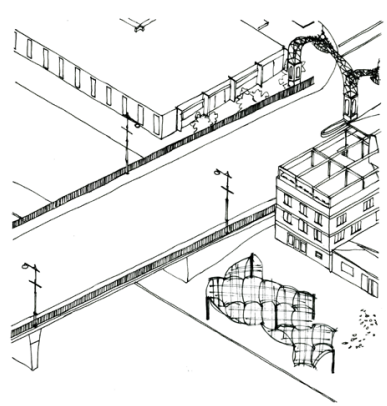

Fig. 7.45: Canopy for shelter and shading.

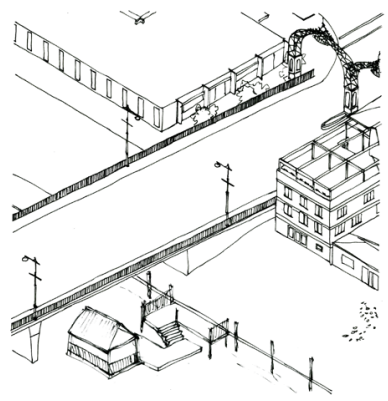

Fig. 7.40: Floating pavilion.

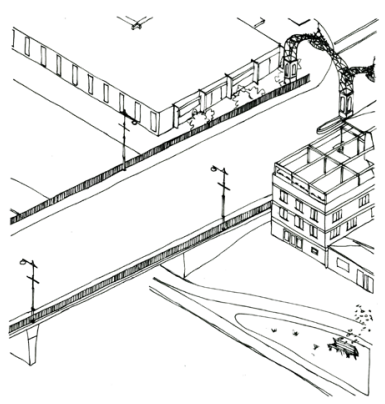

Fig. 7.43: Cycle lane and walkway with green area.

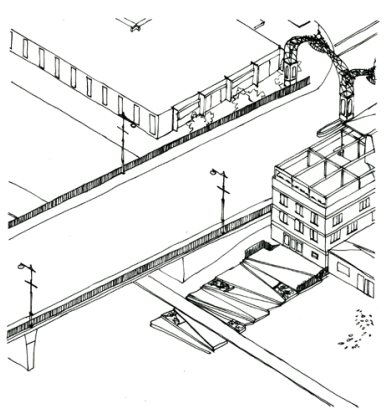

Fig. 7.46: Steps with planting and the option to use steps as seating. 


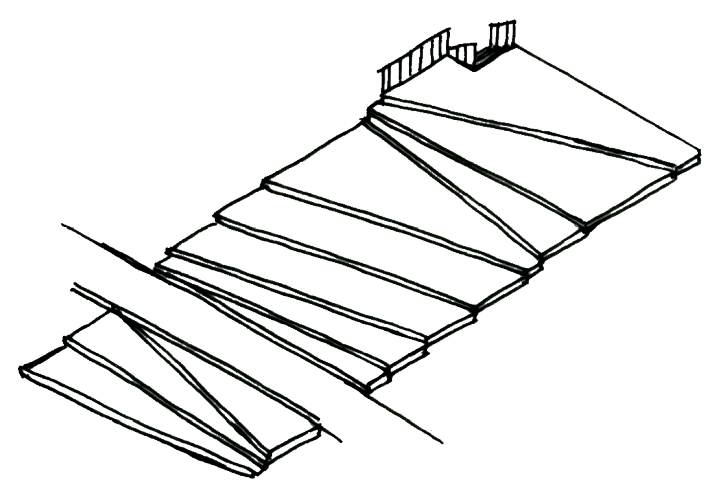

Fig. 7.47: The chosen concept to integrate connection to the river.

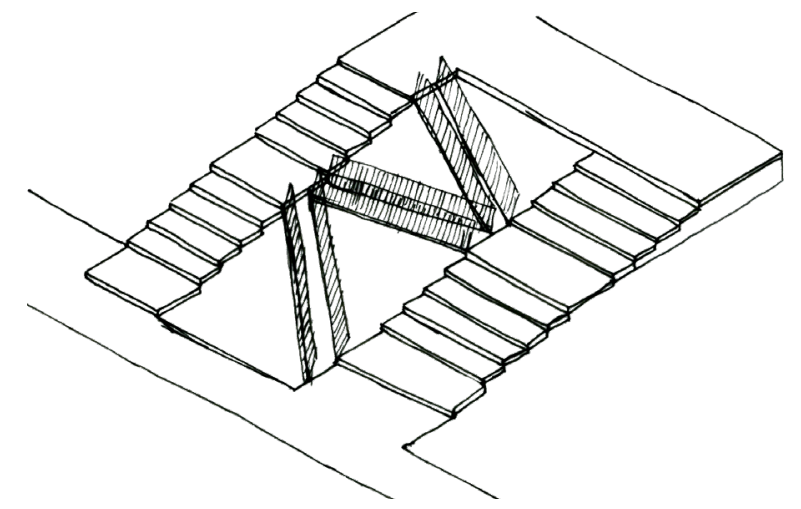

Fig. 7.48: Concept with the addition of a ramp for easy accessibility to all.

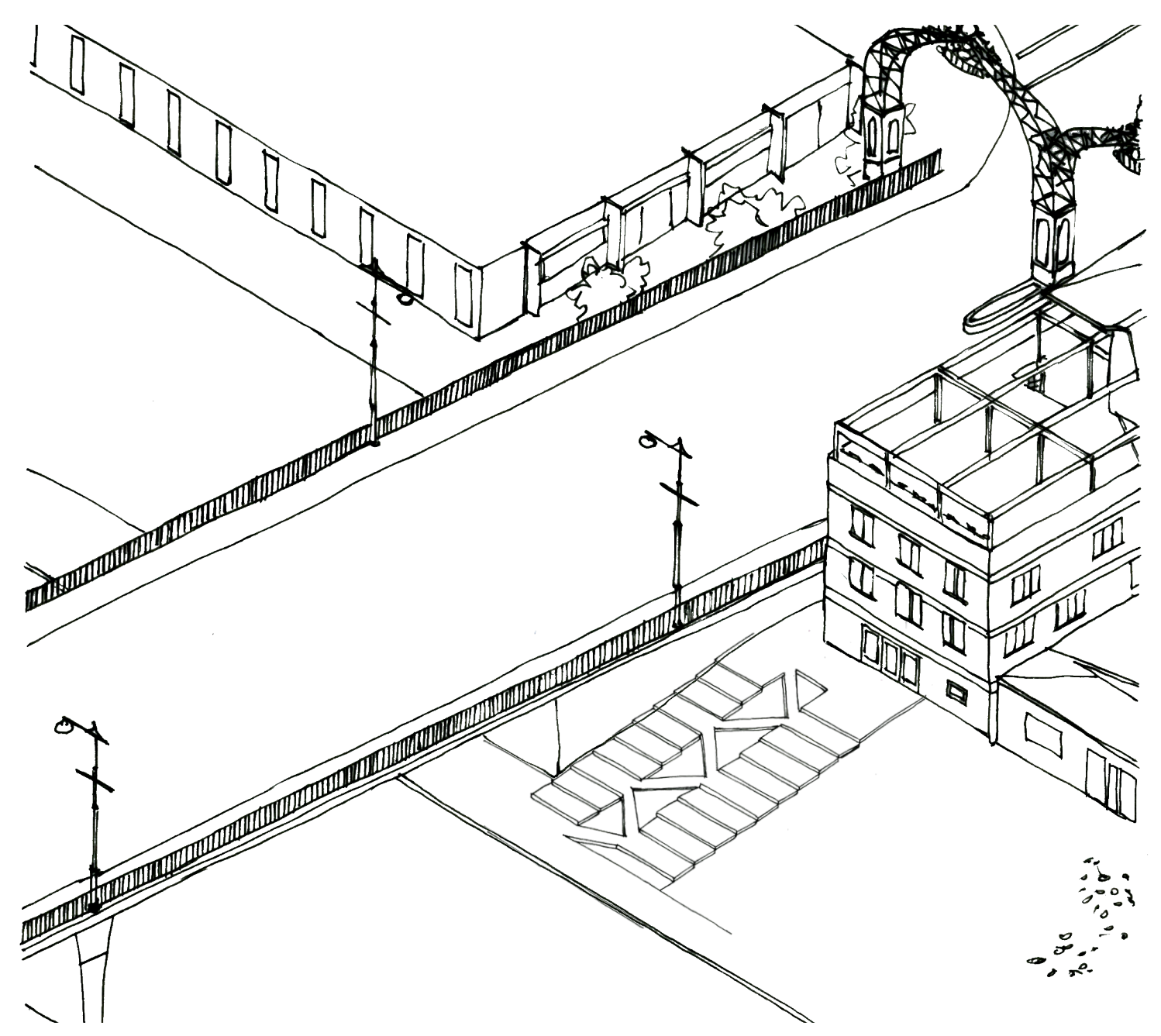

Fig. 7.49: Planted areas between ramp. 


\section{CONCLUSIONS}

This chapter allows the research to be more grounded within its context, by acknowledging the sites surrounding environment and its strategies to revitalise through design.

By identifying and upgrading the prioritized existing heritage buildings in Whanganui's town centre, this will create a strong picture of heritage architecture in a New Zealand city. This will make the town centre more attractive and therefore would attract more tourism.

Having art and culture better integrated into Whanganui, can also make the city more appealing, it will appeal to people and create growth for Whanganui.

Designing town centre urban spaces with community in mind, while intentionally designing with all ages in mind will form an mixed use, easily accessible, more vibrant, pedestrian focused town centre. While not having community engagement limits the understanding of the committee's immediate needs, having more understanding of context minimises this issue.

The river connection to Whanganui is crucial to the design strategy as its linkage to Whanganui's past, heritage, culture and growth is the key to the cities success. Having that linkage both physically and spiritually is going to strongly situate the design. 


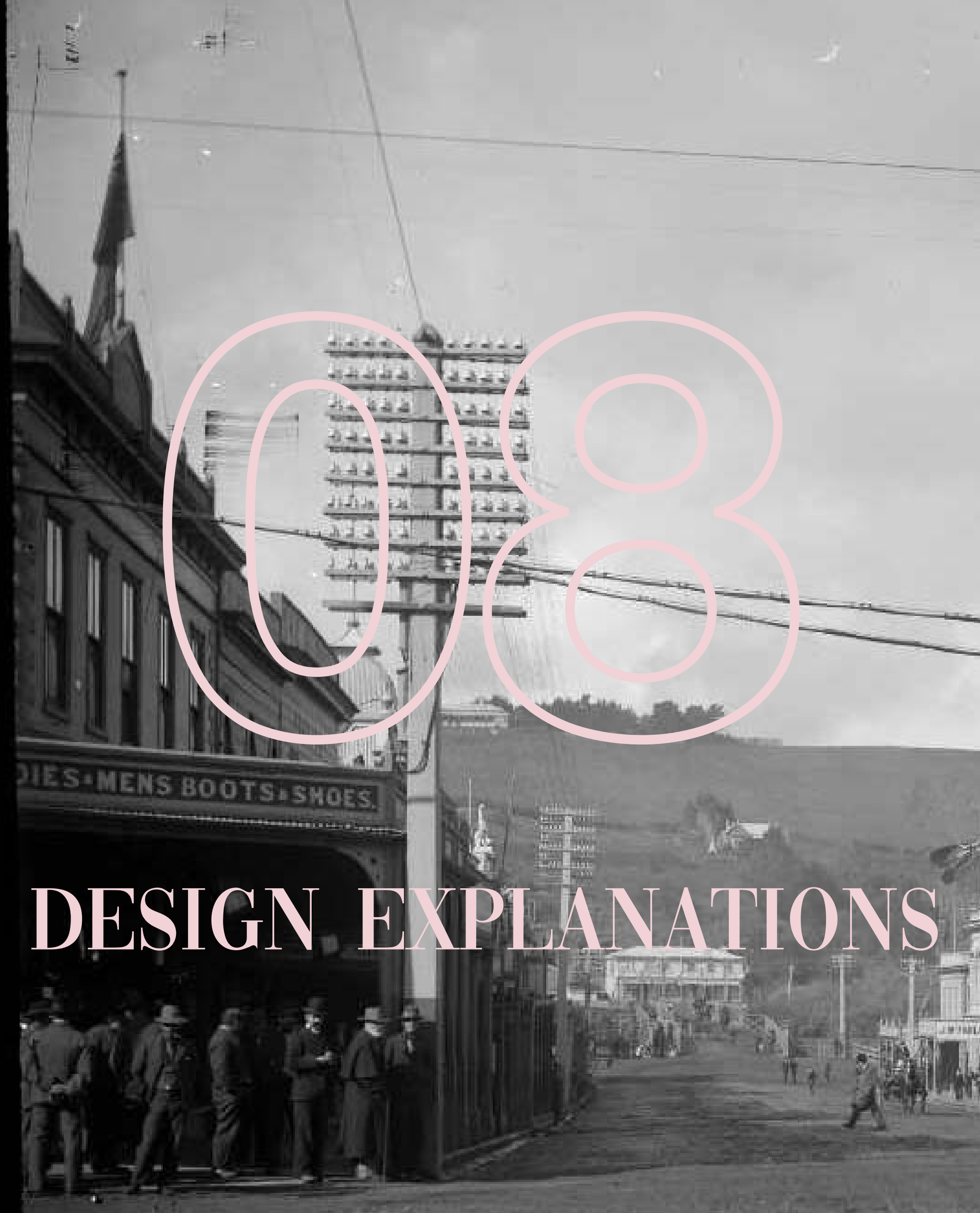




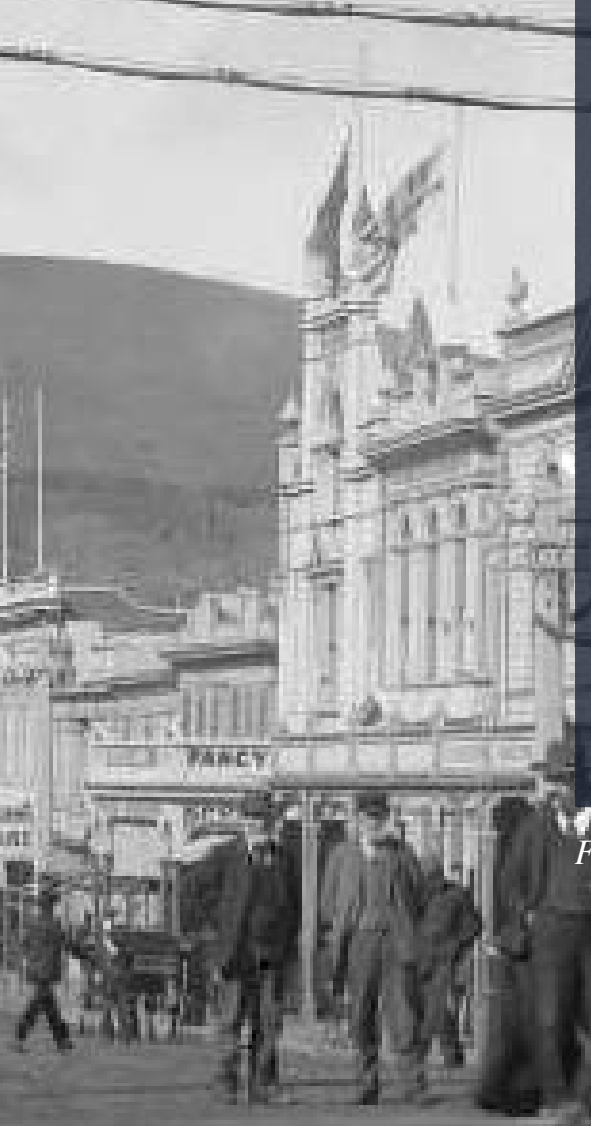
These explanations were undertaken to develop the design process of each building.

Design explanations were explored at three different scales, to construct a better understanding of how design can be used as a tool to achieve the research objectives.

The goal of revitalisation of provincial towns, creating heritage identity and cultural connection to place can be seen at the urban scale and within the well planned Johnston and Company building.

The Johnston and Company building was a well thought out design with multiple stages of review and changes. While the other three buildings were designed to a conceptual stage to therefore illustrate at an urban scale.

The deign of a column gives opportunity to work in detail with an element to create physical connection.
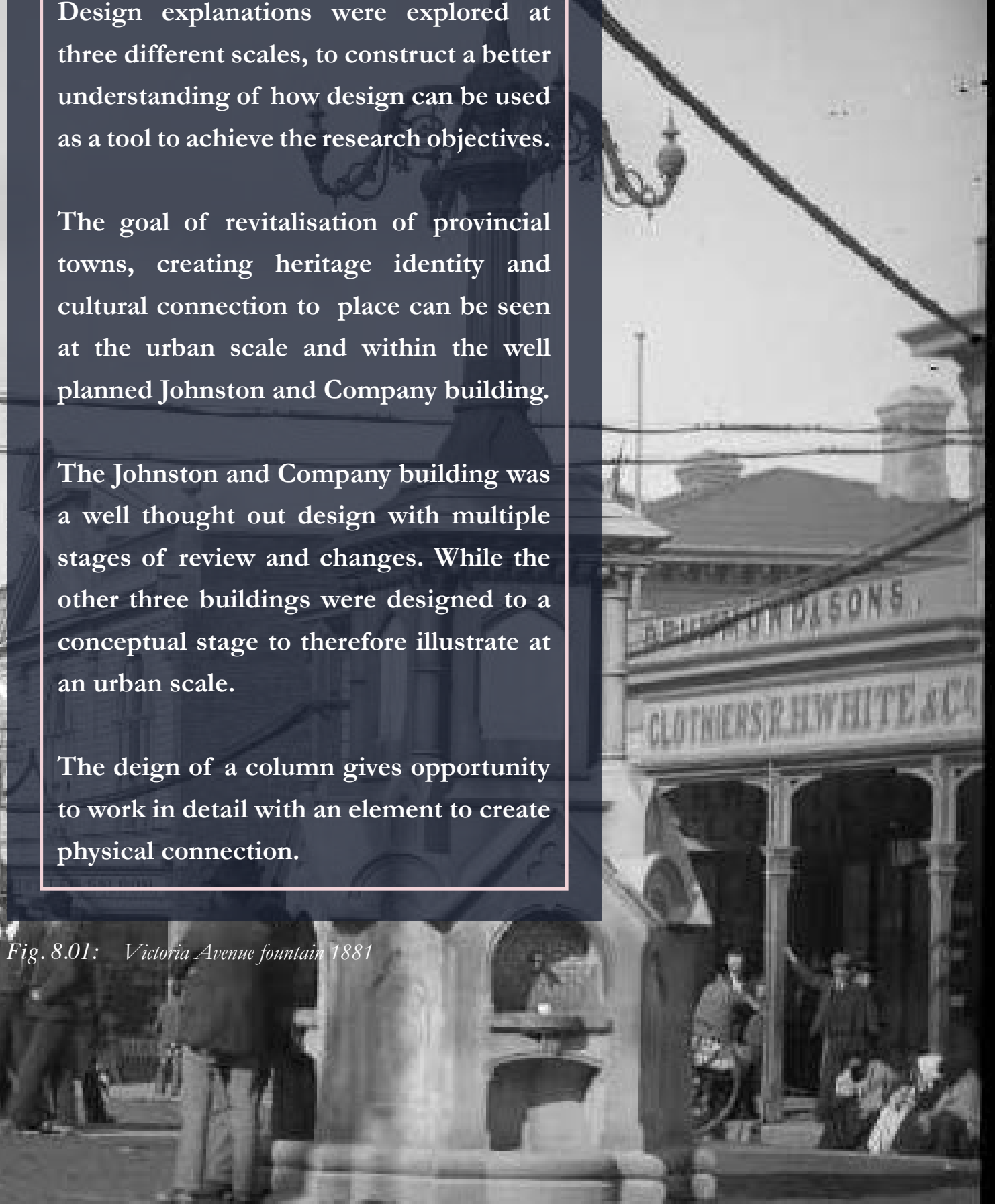


\subsection{PROGRAM CONCEPT DESIGNS}

These initial program bubble diagrams were made to understand the necessary building uses and the linkages between them.

\section{JOHNSTON BUILDING}

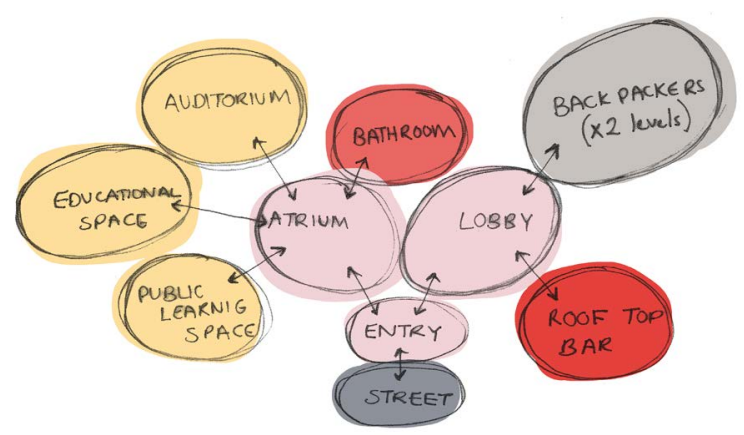

Fig. 8.02: Bubble flow

diagram of Johnston Building

amenities.

\section{FOSTERS HOTEL}

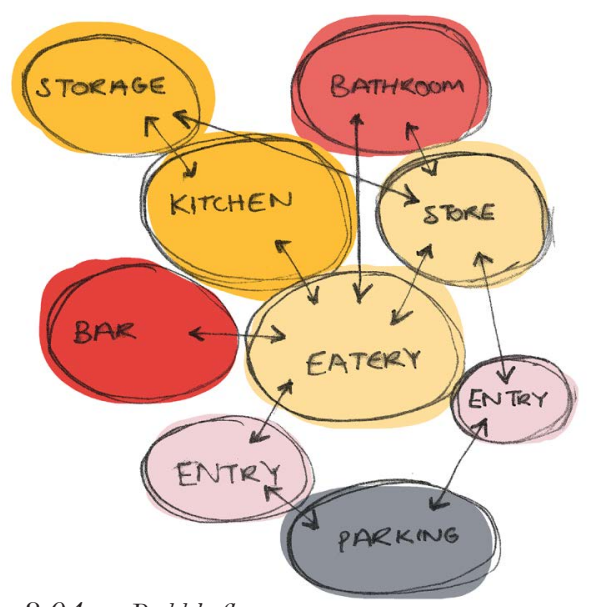

Fig. 8.04: Bubble flow diagram of Fosters Hotel amenities.

\section{THAINS BUILDING}

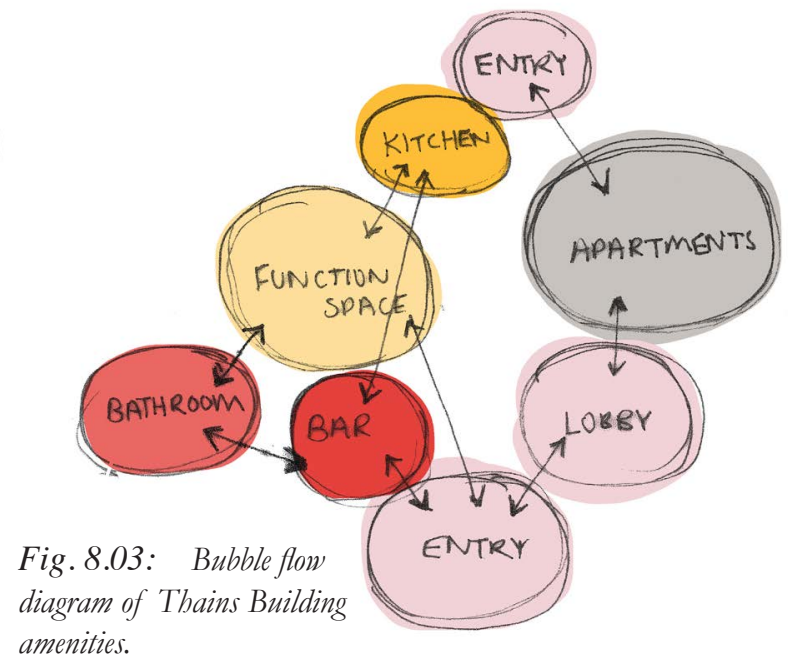

\section{PROPERTY BROKERS BUILDING}

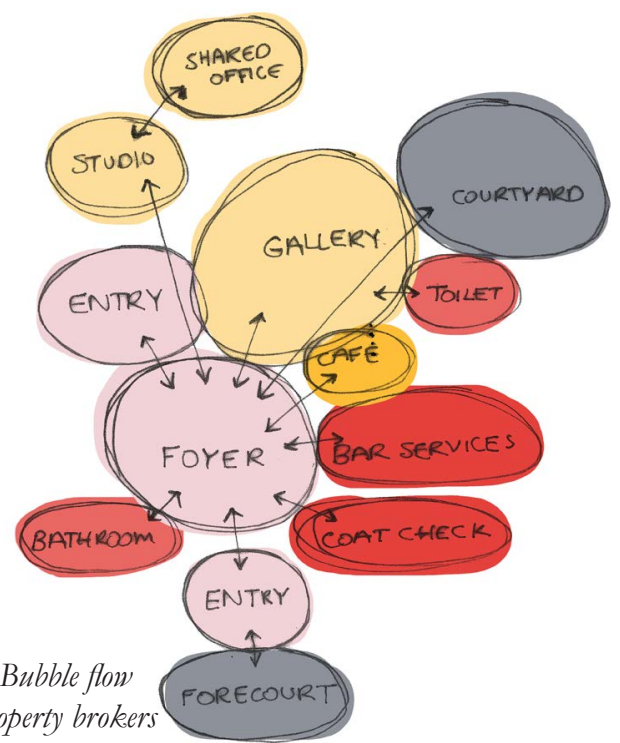

Fig. 8.05: Bubble flow diagram of Property brokers Building amenities. 
Before the decision of which amenities will be located in the existing buildings, the literate gave an overview of how adaptation is possible. The site analysis was also used to better understand the community needs and the surrounding setting, precedent studies provided an outlook on possibilities of adaptive reuse projects. While most of all the existing building structure was analysed to critique and understand the heritage elements and the story within each of the buildings.

The design process was more thoroughly illustrated on the Johnston \& Company building to create a more in depth understanding of the strategy generated throughout this research.

The other three buildings, Property Brokers building, Thains/Dalgety building and Fosters Hotel have been designed at conceptual scale to better recognise the overall scheme at an urban scale. 


\subsection{JOHNSTON AND COMPANY BUILDING FLOOR PLAN EXPLORATION}

1.

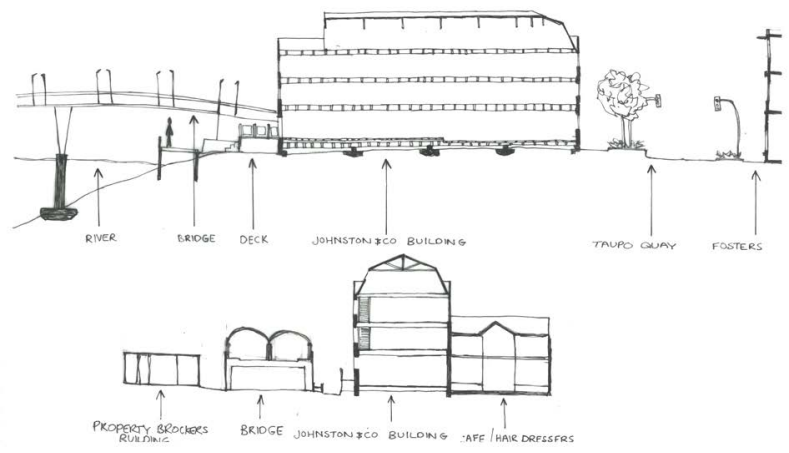

Fig. 8.06: Two sectional views of the Buildings surrounding context.

Understanding the surrounding built environment, including the river, bridge and surrounding buildings.
2.
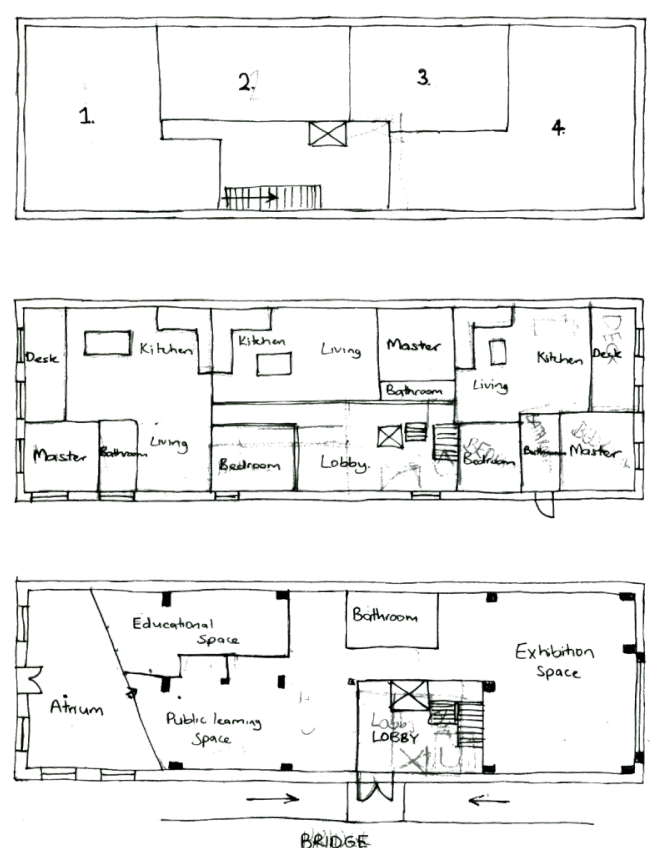

Fig. 8.07: Early conceptual diagrams of floor layouts.

The initial idea was to have apartments to bring more people into the site. While also creating a safer area due to passive surveillance. The ground floor can be used as a learning and exhibition space, as well as the lobby. 
3.
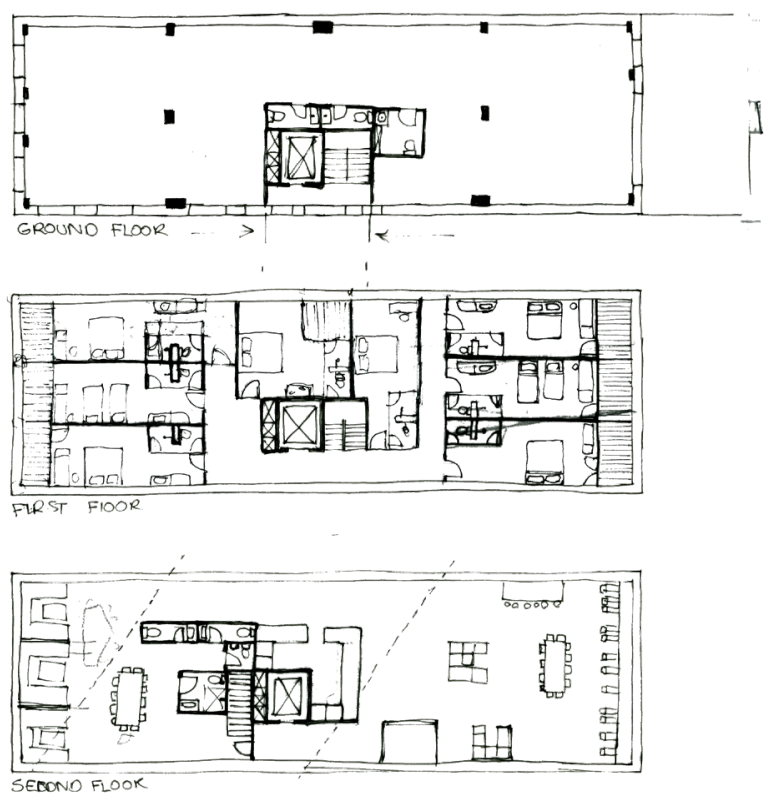

Fig. 8.08: Private decks for the rooms as well as a roof top bar.

After more research into what the community needs, the idea of a boutique backpackers was created. The rooms would have their own private decks and bathrooms with a shared communal space on the second floor. The dashed line indicates the roof line symbolic to the relationship between mountain and sea.
4.
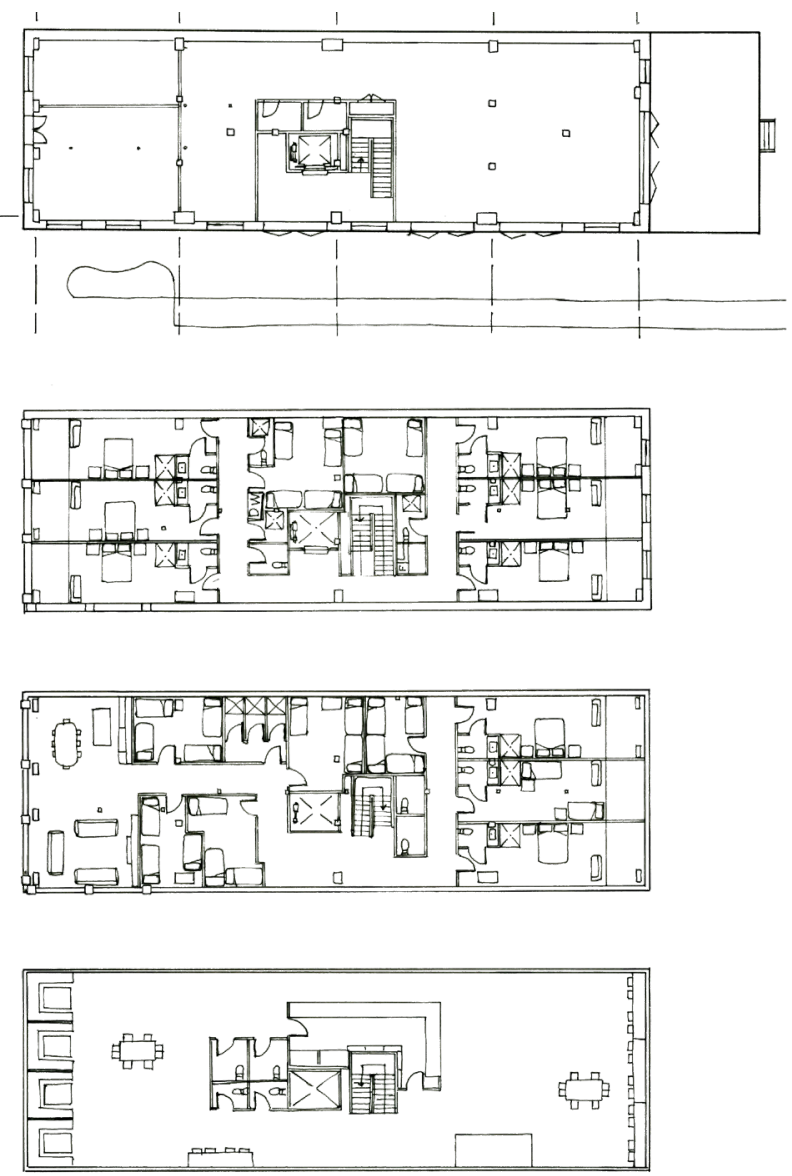

Fig. 8.09: Concepts of floor layout of rooms and rooftop.

The idea of a roof top bar was established. This would be unique in Whanganui and fit in with the surrounding existing night life. On the first and second floor there would be a mix of room options including private and shared rooms. 
5.
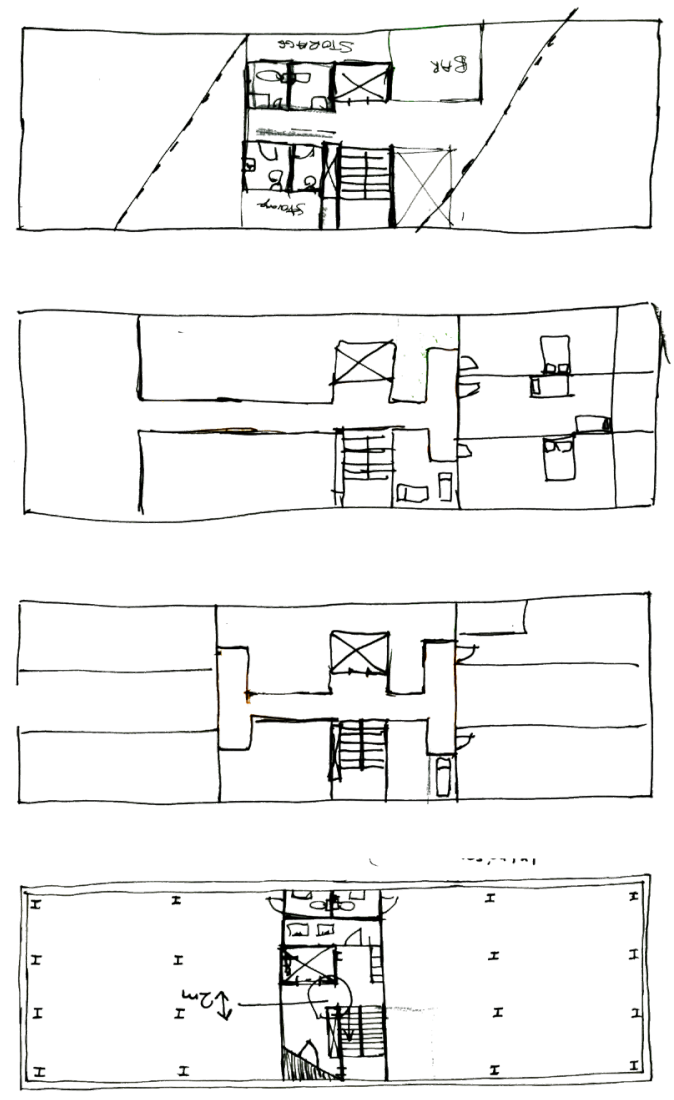

Fig. 8.10: Concepts of circulation and lobby layout.

The location of the core is key to developing a successful building layout. The lobby area needs to be located in the centre of the building for the best use of space and minimise circulation space. These basic sketches illustrate the rooms and circulation at each level.
6.
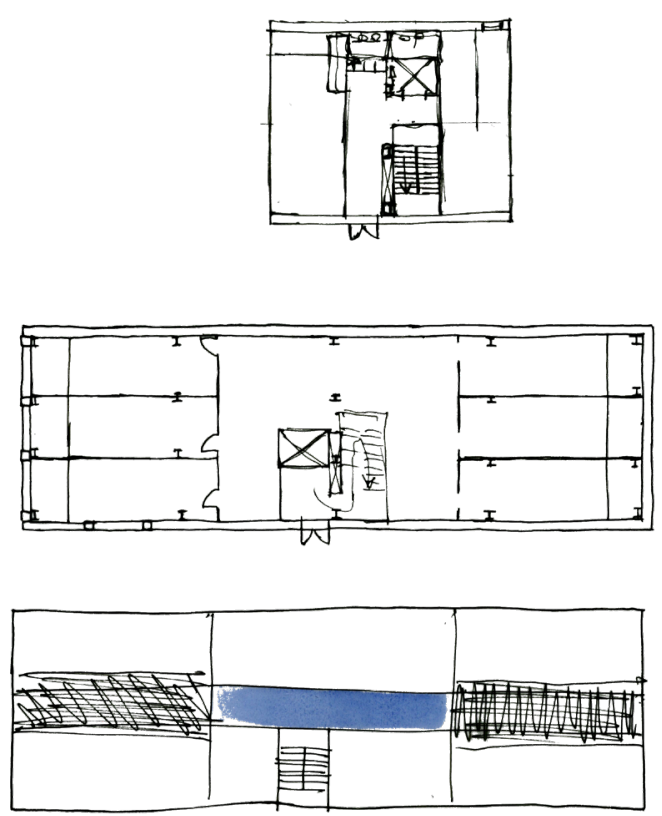

Fig. 8.11: Concepts of structural elements penetrating through floors.
Services need to be thought about, how they will be directed through the building. A boxed out universal column creates room for services to be distributed from floor to floor. Also rubbish will be an issue as there is no back to the building, and therefore no car park. 
7.
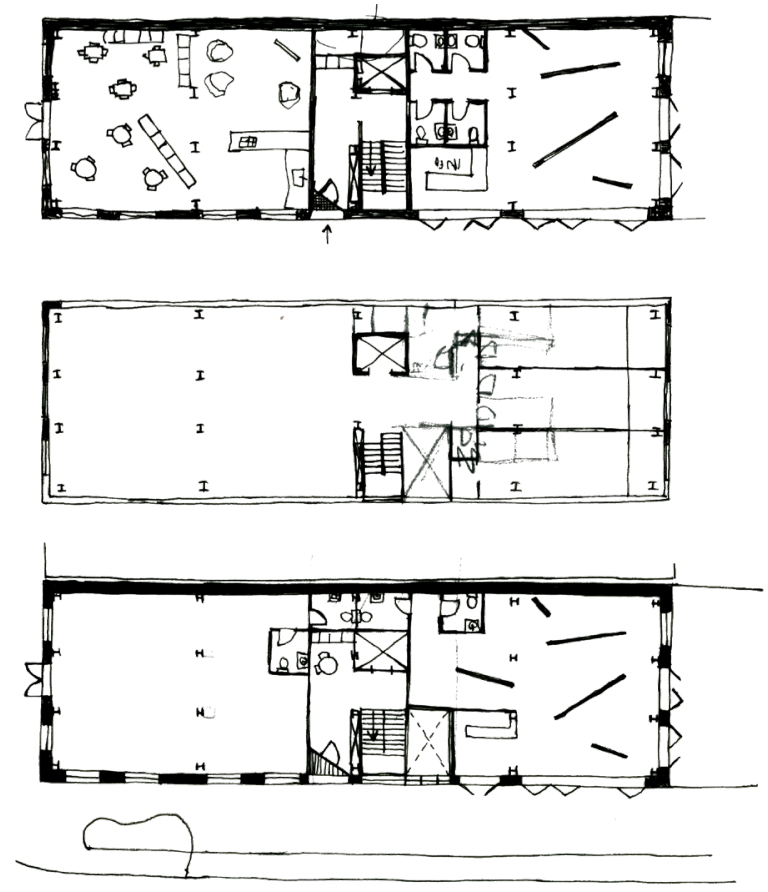

Fig. 8.12: Core concepts and ground floor layout.

Re-figuring the core of the building to fit all the required elements including suitable fire safety design, which meant closable doors at each floor. The structural elements and existing heritage facade will need to be taken into account when doing floor plans.
8.
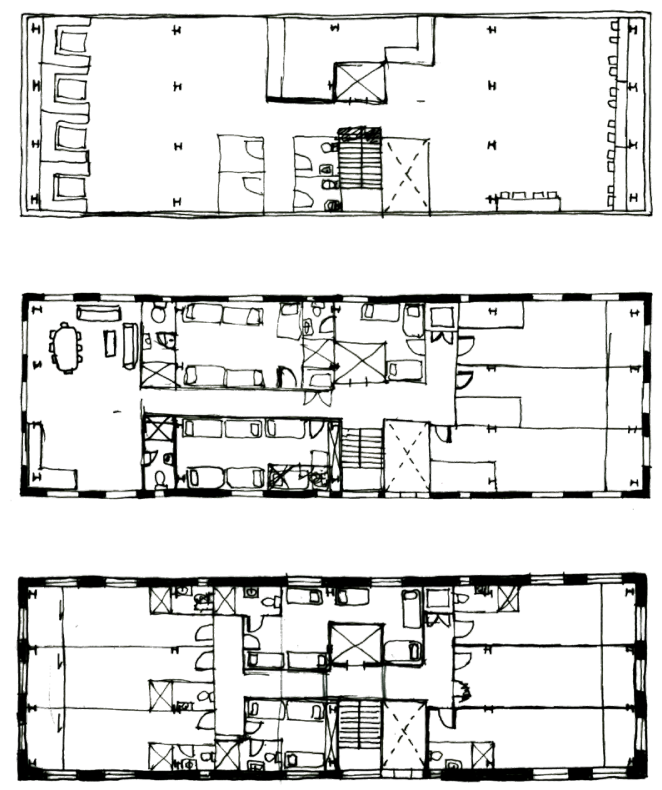

Fig. 8.13: Stacked bathroom for ease of services concept floor plans.
Bathroom and bedroom layout was explored to maximise the best possible circulation for each room.

Having the bi-folding doors on the ground floor narrow enough to fold into the wall width was a design feature to encourage access through the interior space. 
9.
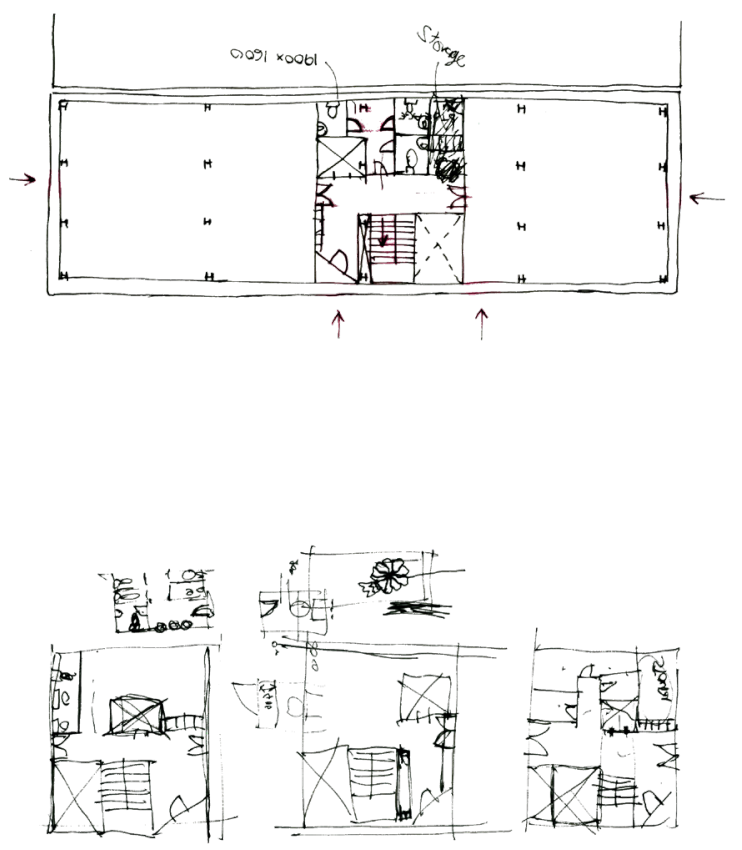

Fig. 8.14: Fernery bringing light into the building as well as linking all the floors through the atrium.

An introduction of a fernery linking all the floors in the buildings core creates a larger hole in the buildings diaphragm adjacent to the buildings staircase. The core / lobby space needed to be redesigned.
10.

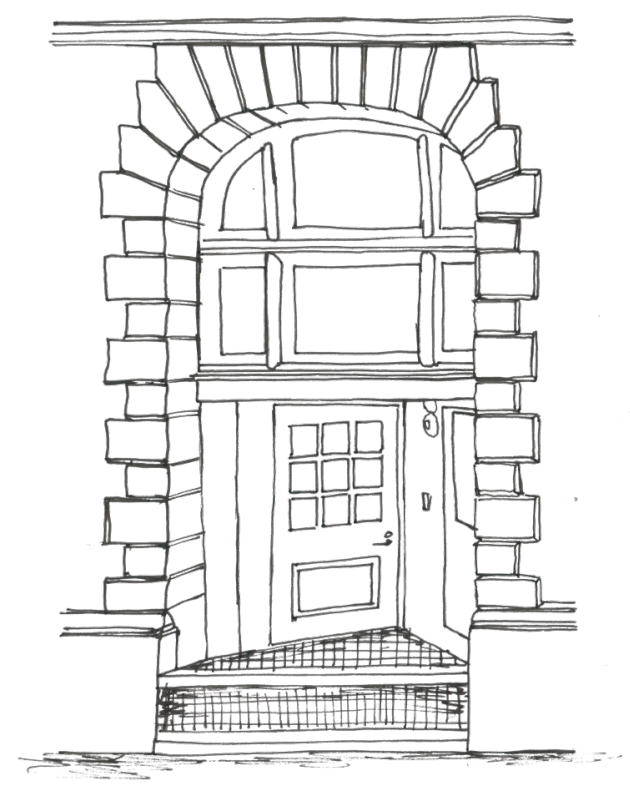

Fig. 8.15: Concept entrance to the hostel and roof top bar through the side alleyway.

An angled entrance way subtracting into the ground floor was created to form an entrance due to the minimal space between the building and bridge. 
11.

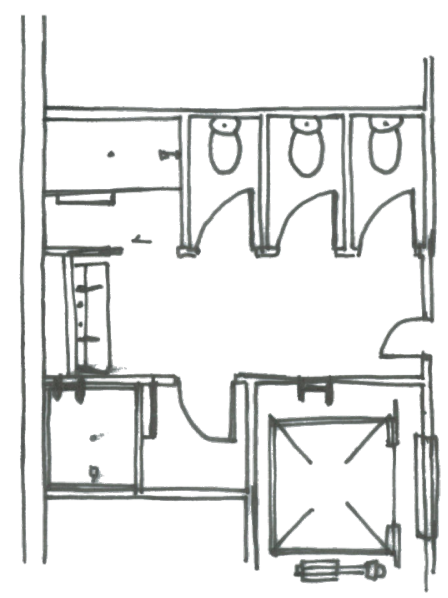

Fig. 8.16: Concept of batbroom layout.

Communal bathrooms at each level were stacked for ease of services.
12.

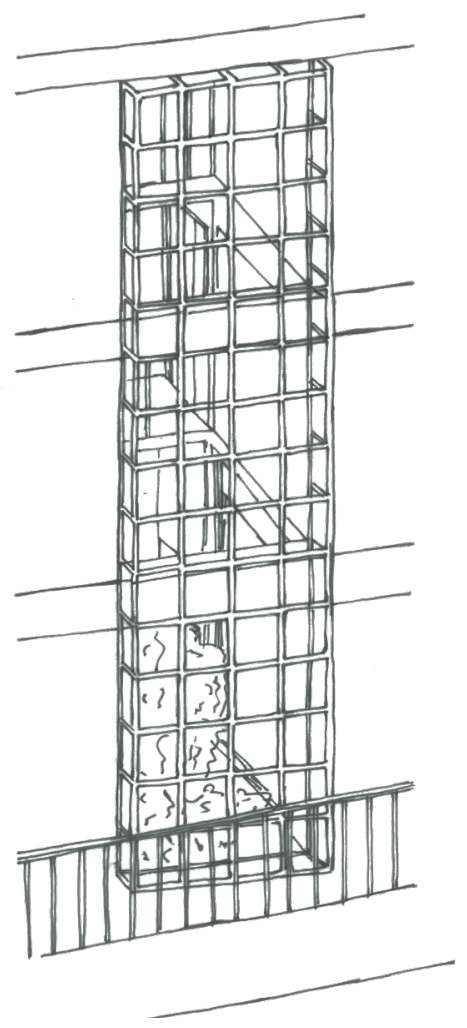

Fig. 8.17: Glass extrusion bringing light into floor levels and circulation areas.

Having the fernery extrude $400 \mathrm{~mm}$ into the alleyway from the existing building line, reduces the width of the alleyway. However, this was a conscious decision to allure the community into the building. It is an unique feature which the extrusion further highlights. 


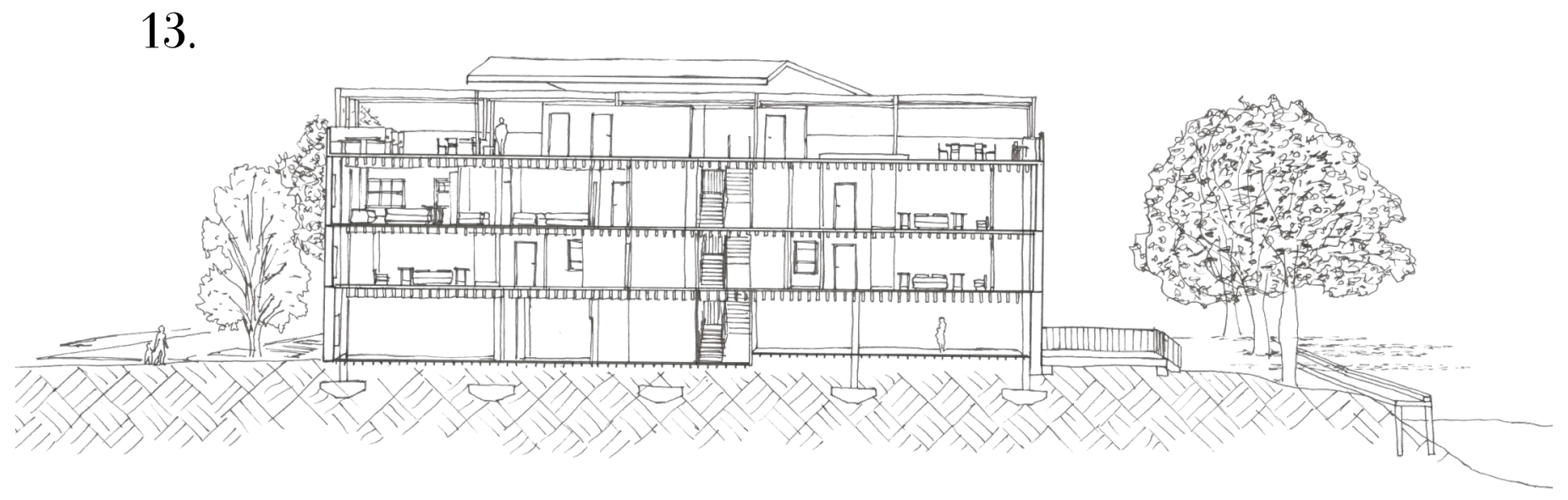

Fig. 8.18: Concept section in relation to site.

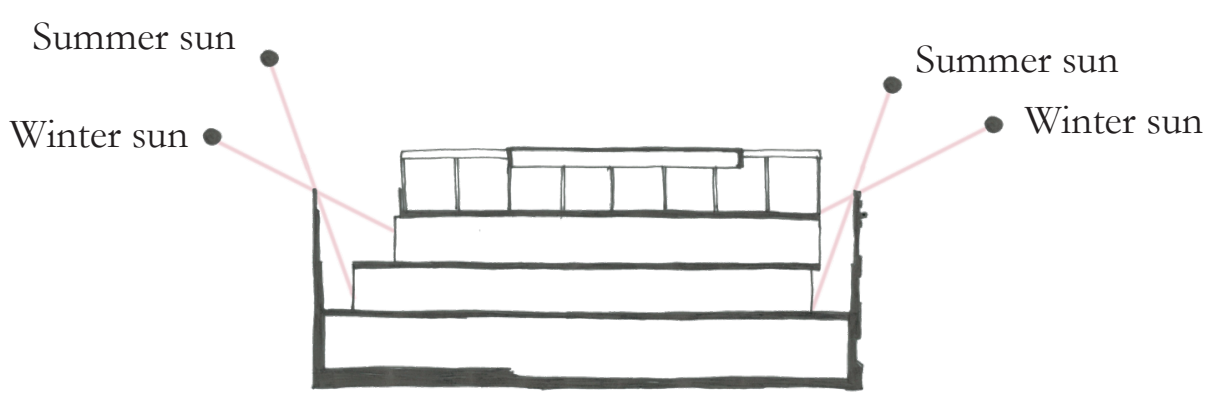

Fig. 8.19: Concept of stepped back facade allowing light into the lower floor levels.

A stepped back floor from the existing heritage facade at each floor, allows for more light to access the lower floors and allowing each floor have a unique vantage point through the old facade. This also allows each room to gain its own private deck. 


\subsection{THAINS - DALGETY BUILDING CONCEPT}

The initial design of this building was to design a new building connected to the existing heritage facade as it needed earthquake strengthening.

Due to the building being denied demolition due to being a heritage building this thesis proposed keeping the buildings facade but designing a modern building behind it. However since the building suffered severe fire damage mid 2019, a new building became the only option.

A mixed use building was the proposed to bring people into the space. On the ground floor, an educational space as well as two retail spaces along Victoria Avenue have been designed. Large bi-folding doors out onto the backyard would be a feature of the educational area. As well as large wall dividers allowing the space to be adaptable for large group sizes and multiple groups at one time. The backyard will habitat a community vegetable garden as well as hangi pits.
On the first floor, a shared studio with numerous different types of workspaces will cater for different work environments. The services and toilet block has been stacked for ease of services. While on the top floor their is residential apartments. These were designed as one or two bedroom apartments to contribute to the lack of housing in Whanganui's centre. The apartment is low maintenance and easily accessible. Its unique location also makes the building very attractive in the property market.

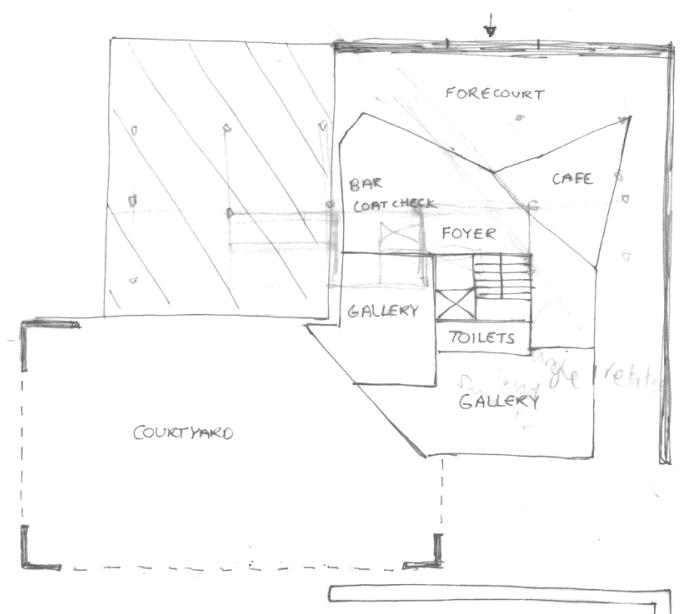

Fig. 8.20: Above Ground floor concept of art gallery.

Fig. 8.21: Right - First floor of Art Gallery as a shared work studio.

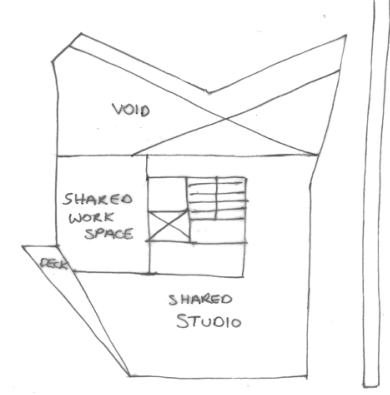




\subsection{PROPERTY BROKERS BUILDING}

The current one story property brokers building is in prime location to the Whanganui river. It has much more potential to bring people into the space and create a community feel.

Through change in use, the design can revitalise the building and with it, its surrounding area. On the ground floor, it is an eatery which will provide the community with a casual, modern outpost for coffee, seasonal breakfast and lunch eats. While also being accompanied by an organic fruit \& veg, groceries, and wholefoods store.

The eatery serves people during the daytime everyday, while can be transformed into a bar and restaurant at night for events. The key change being variation in lighting and furniture layout. The loose furniture allows for an open plan function space which could be hired out for temporary events or art exhibitions.

An additional two floors were added to allow the 1970's building to fit in with its surrounding context and make use of the views looking out across the river.
Occupying the building on the first and second floor would be large offices which could be leased out by a large firm. This opens opportunity to bring more jobs to the town. The office layout will have multiple different settings for different types of work.

Surrounding the upper stories is a metal mesh which shades the amount of light and glare into the building. While deliberately creating a minimal facade, it highlights the surrounding heritage buildings.

Linking the two office floors is large pop out windows. These serve different purposes, as the first floor window can be walked into while the second floor is more of a balcony form only letting light in.

Overall the addition of the two floors creates the successful revitalisation bringing more foot traffic into the space. While the mesh has been used as architectural decoration to compliment the surrounding building heritage features. 


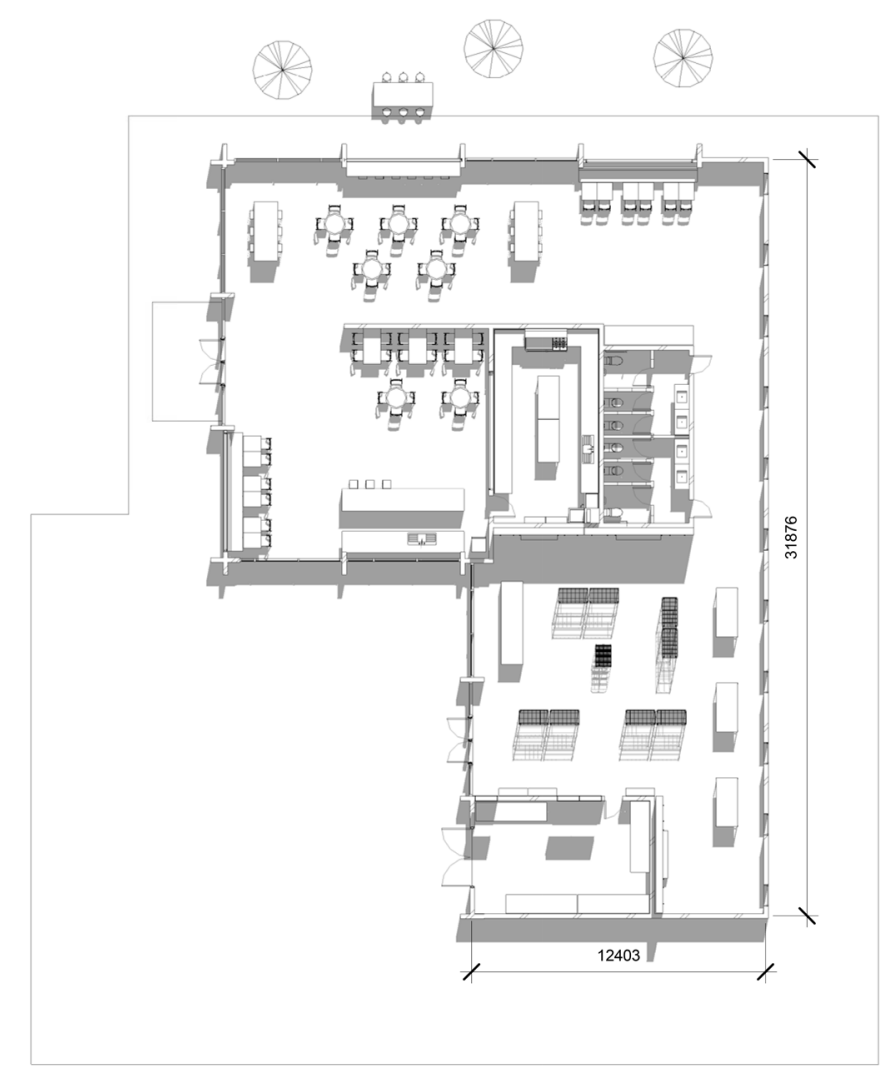

Fig. 8.22: Ground Floor layout of potential eatery and super market.

Fig. 8.23: Isometric of exterior illustrating the existing facade still in contact. 


\subsection{FOSTERS HOTEL}

Due to the ground floor of the Fosters hotel still in use as a restaurant, bar and function room, little design changes were made on this level. Storage and accessibility of toilets were the main design changes.

On the first and second floors, are one and two bedroom apartments. Each room has a private outdoor area. This was done without extruding from the heritage facade. This meant the verandah had to be set back behind the facade.

As the Fosters hotel underwent many alterations over its time, it was striped away of its heritage decoration. Bringing detail back into the facade through the re-installation of the fire exit, as well as the canopy verandah is are key to allowing the building to be proportional again.

A roof top garden was also added to the top of the ground floor roof, in the centre of the 'C'. This allows the apartments to look out over the garden instead of the corrugated iron roof. 

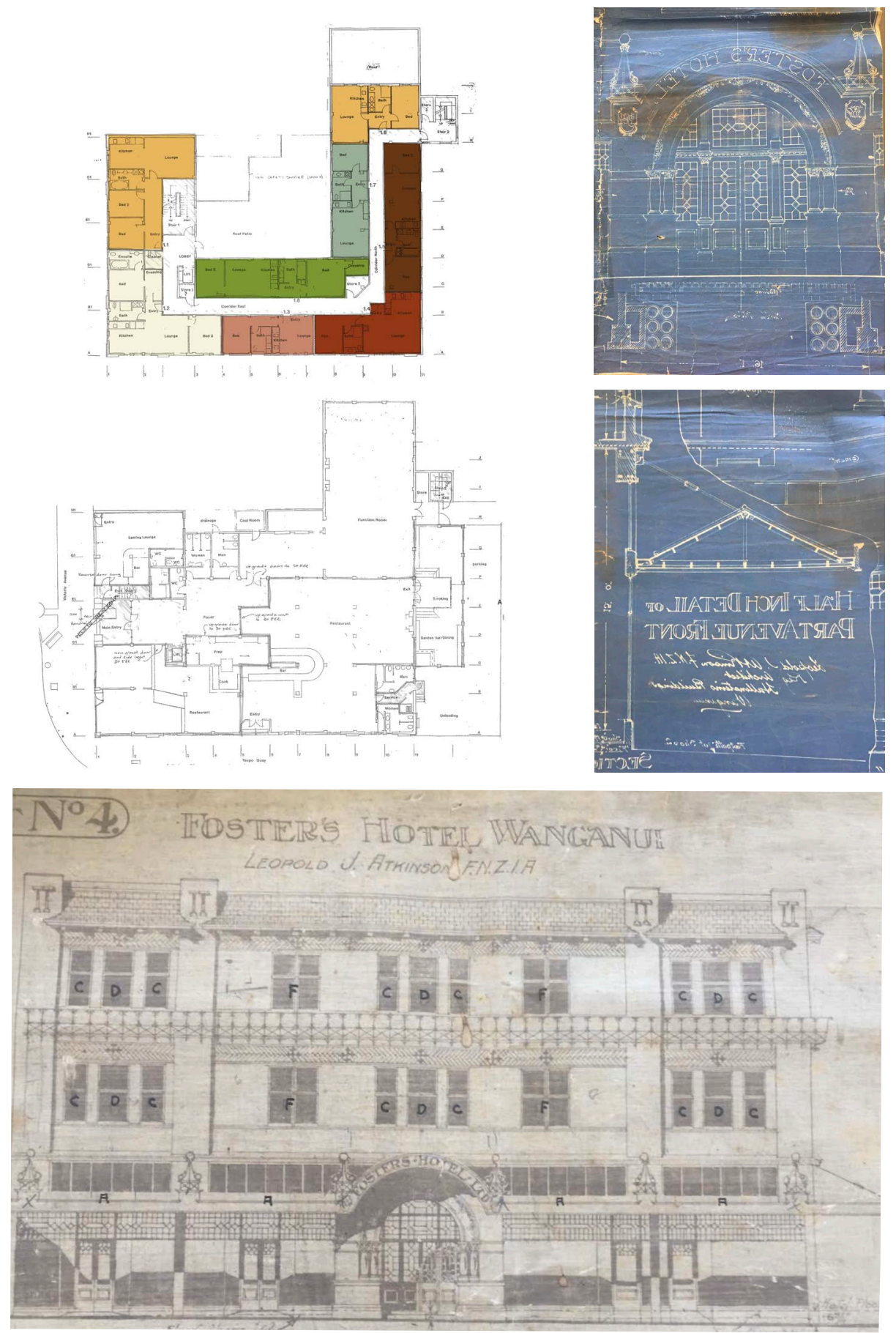

Fig. 8.24: Floor plan of existing building with each apartment colour coded.
Fig. 8.25: Elevation view of historic entrance way and verandah illustrating the heritage detail which has been altered.

Fig. 8.26: Old drawing of the Southern facade emphasizing the symmetrical design which has been lost. 



\section{SITE PLAN}

Fig. 9.02: Site plan illustrating the relationship between the chosen cross roads buildings and the surrounding buildings, streets and river.
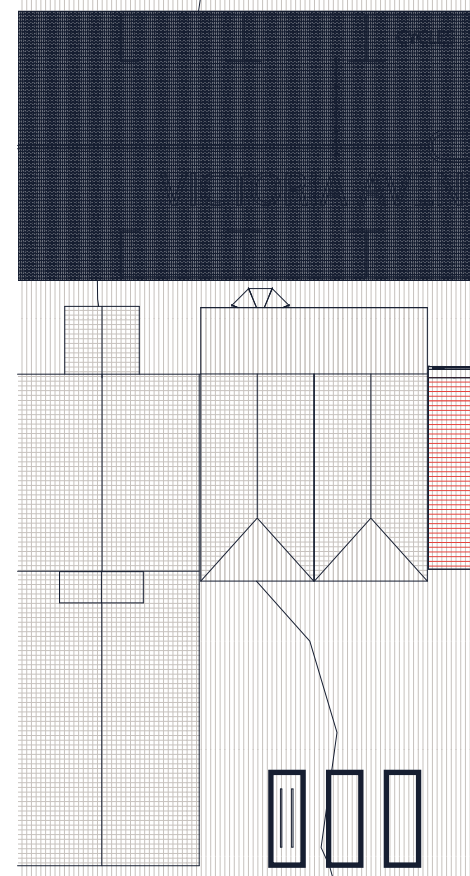


\section{JOHNSTON FLOOR PLANS}

Fig. 9.03: Isometric of the exterior of the Johnston and Company Building showcasing the roof top bar as well as the relationship between the existing heritage facade and the new addition of the glass atrium extrusion. 


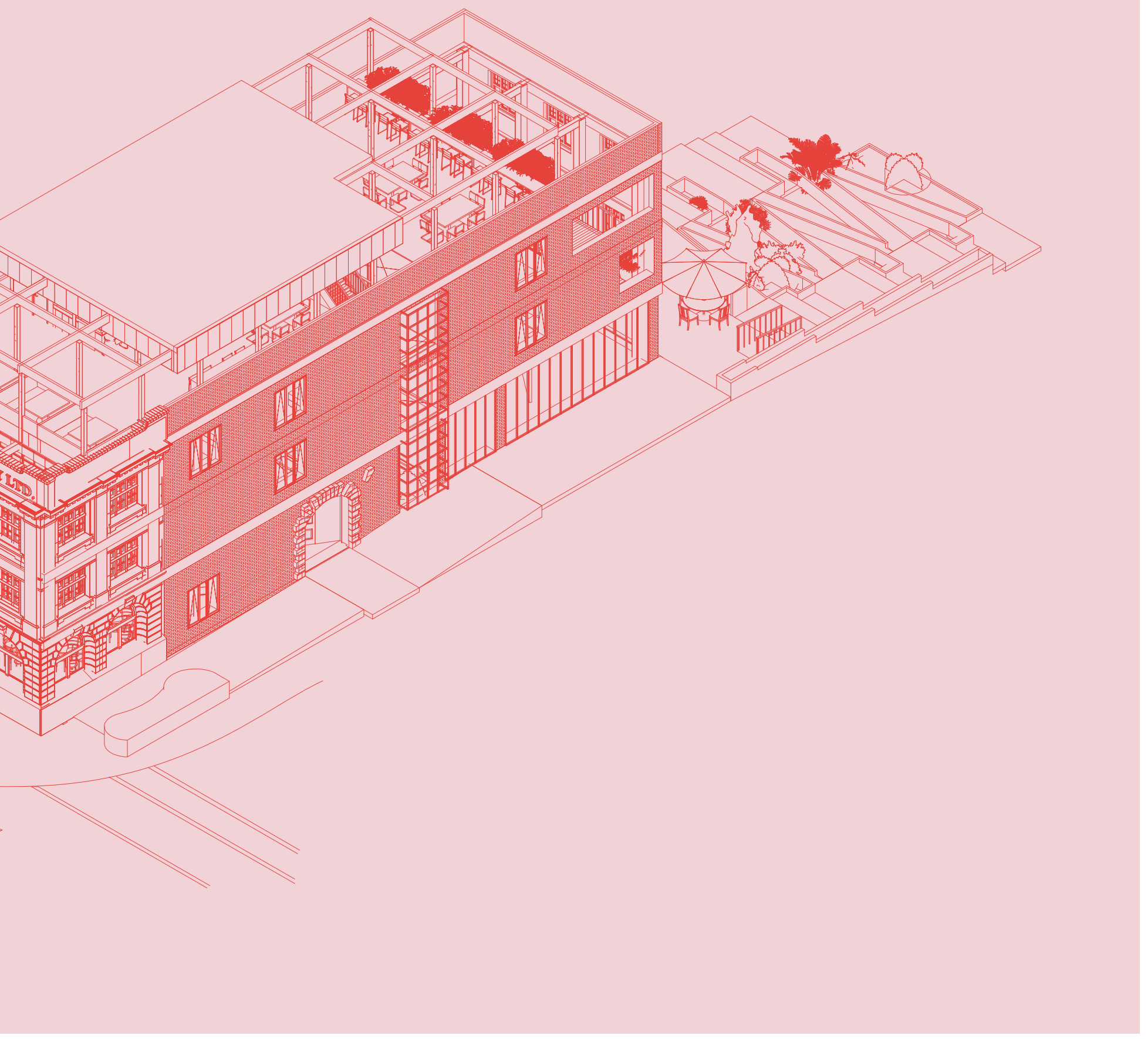




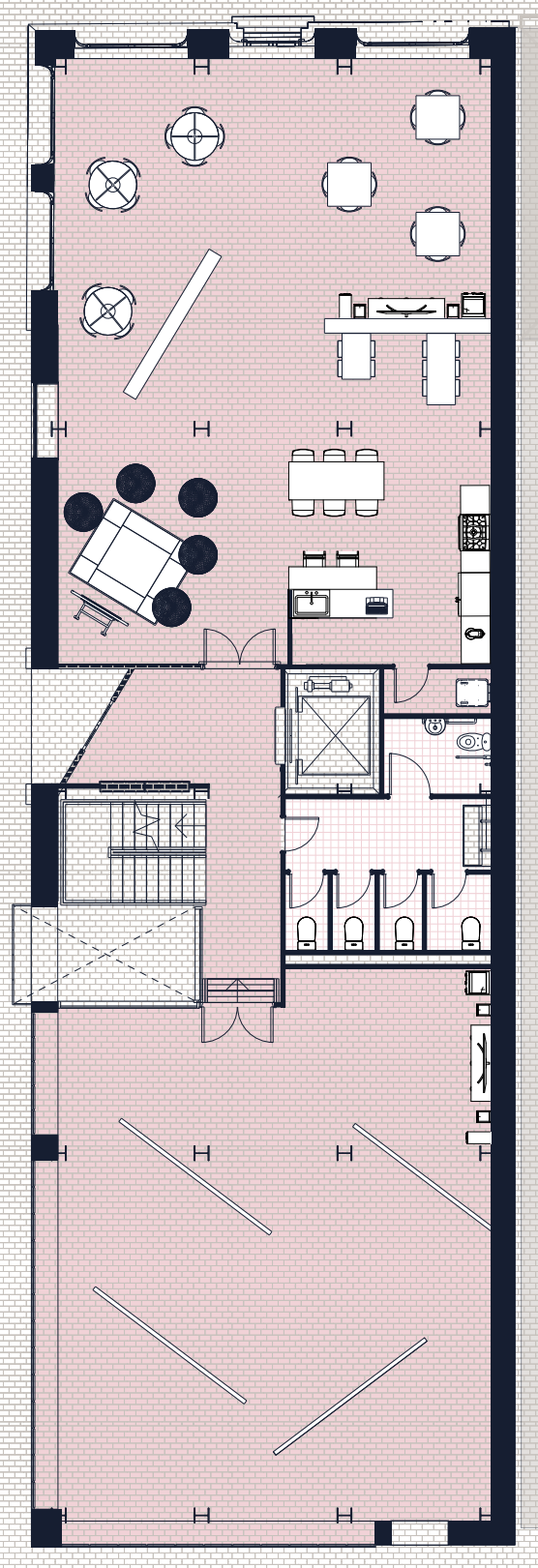

Fig. 9.04: Ground floor plan.

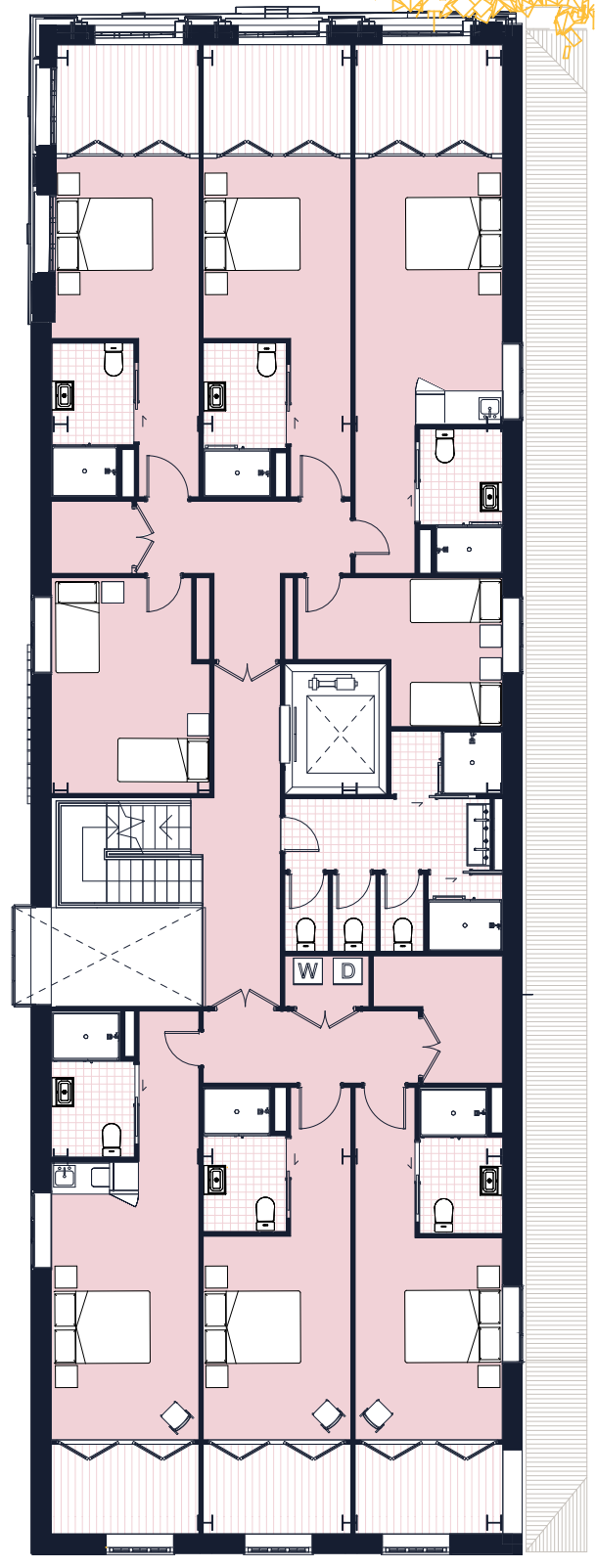

Fig. 9.05: First floor plan. 


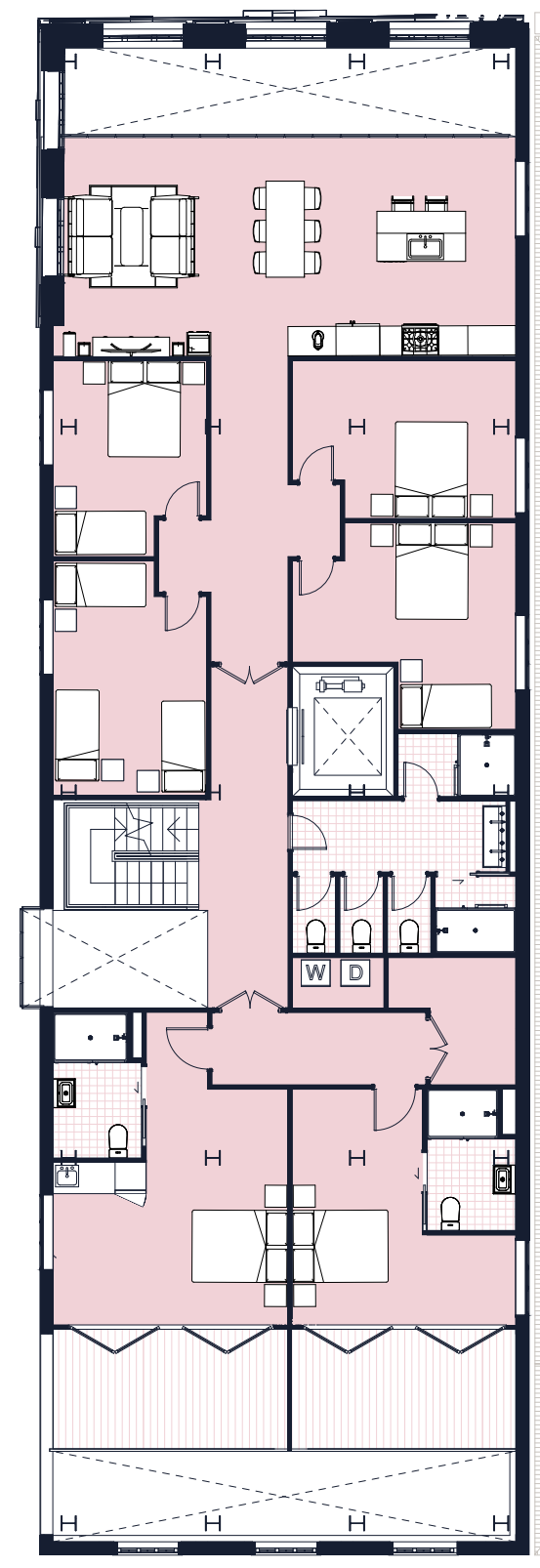

Fig. 9.06: Second floor plan.

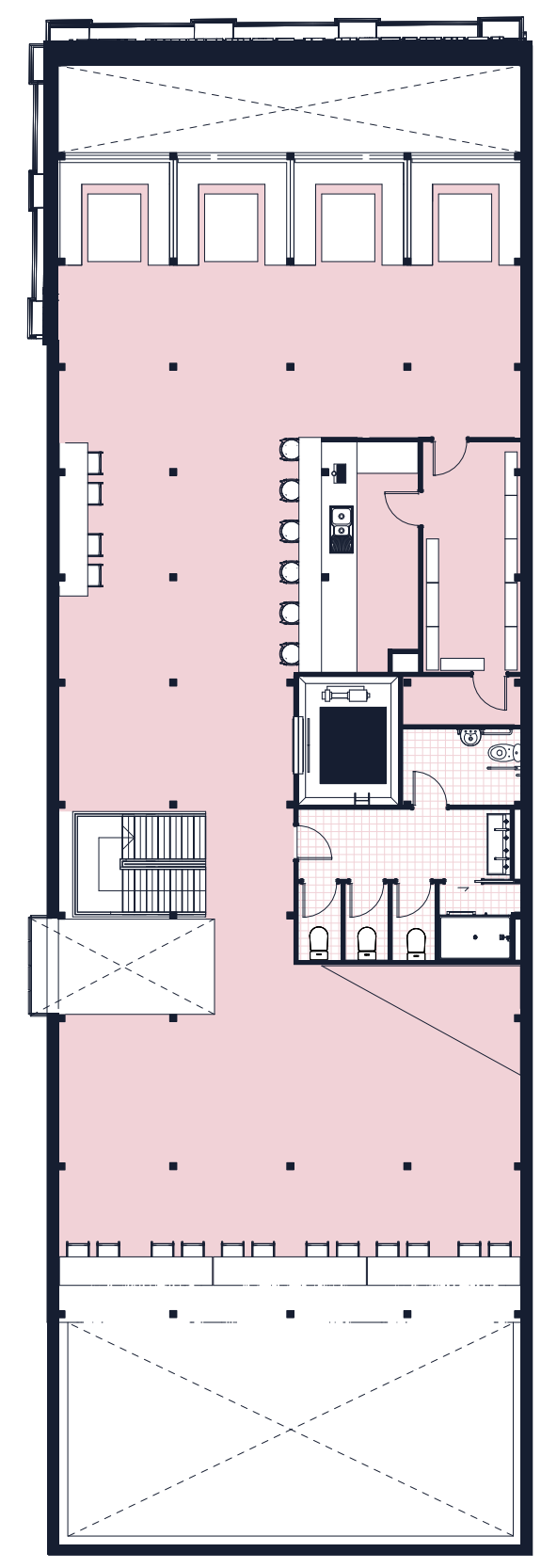

Fig.9.07: Third floor plan. 


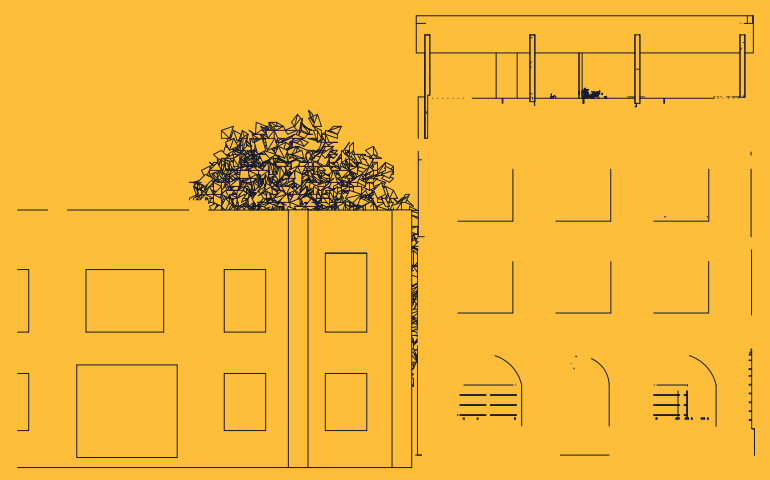

Fig. 9.08: West elevation.

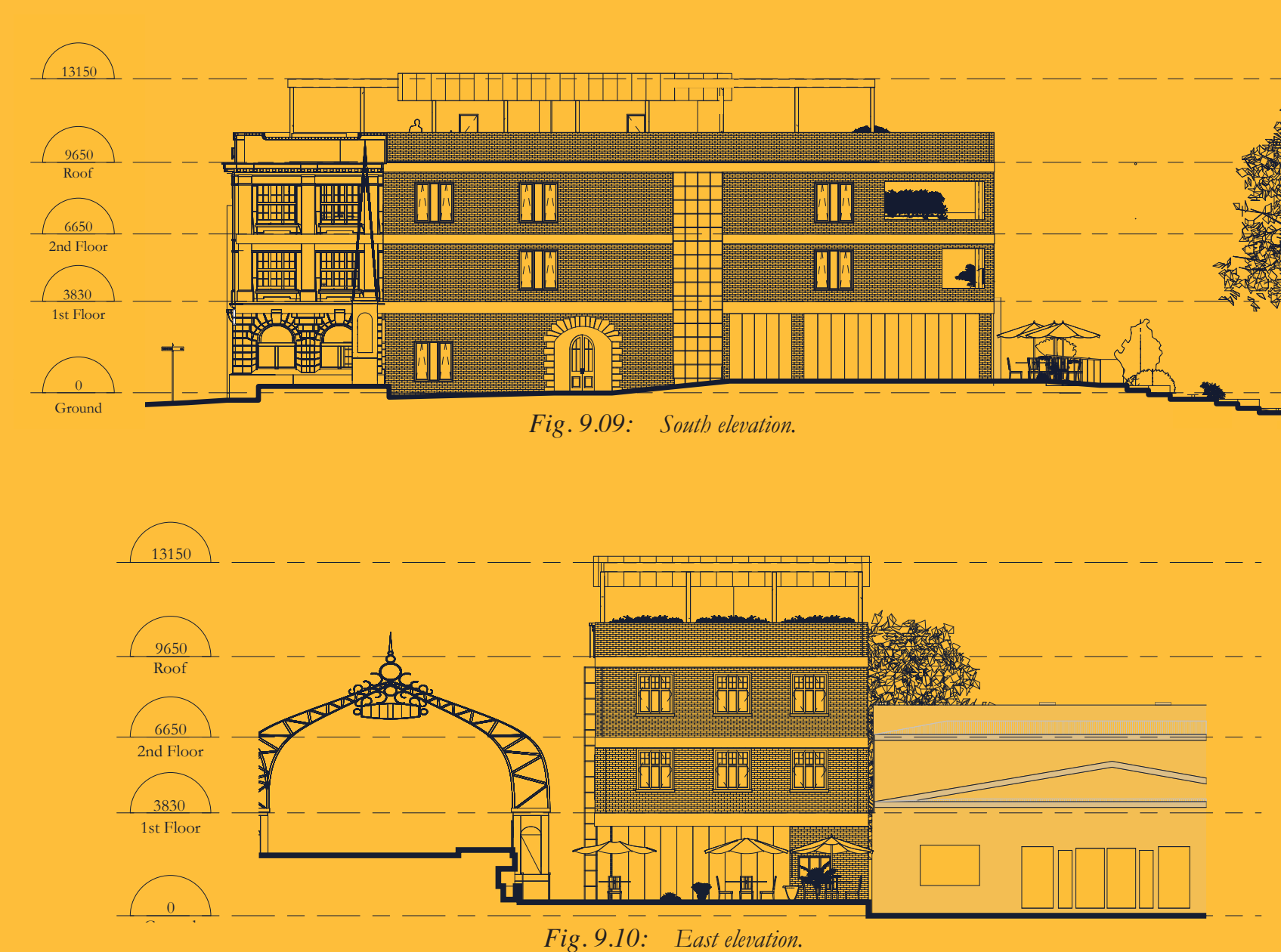

SCALE 1:500 


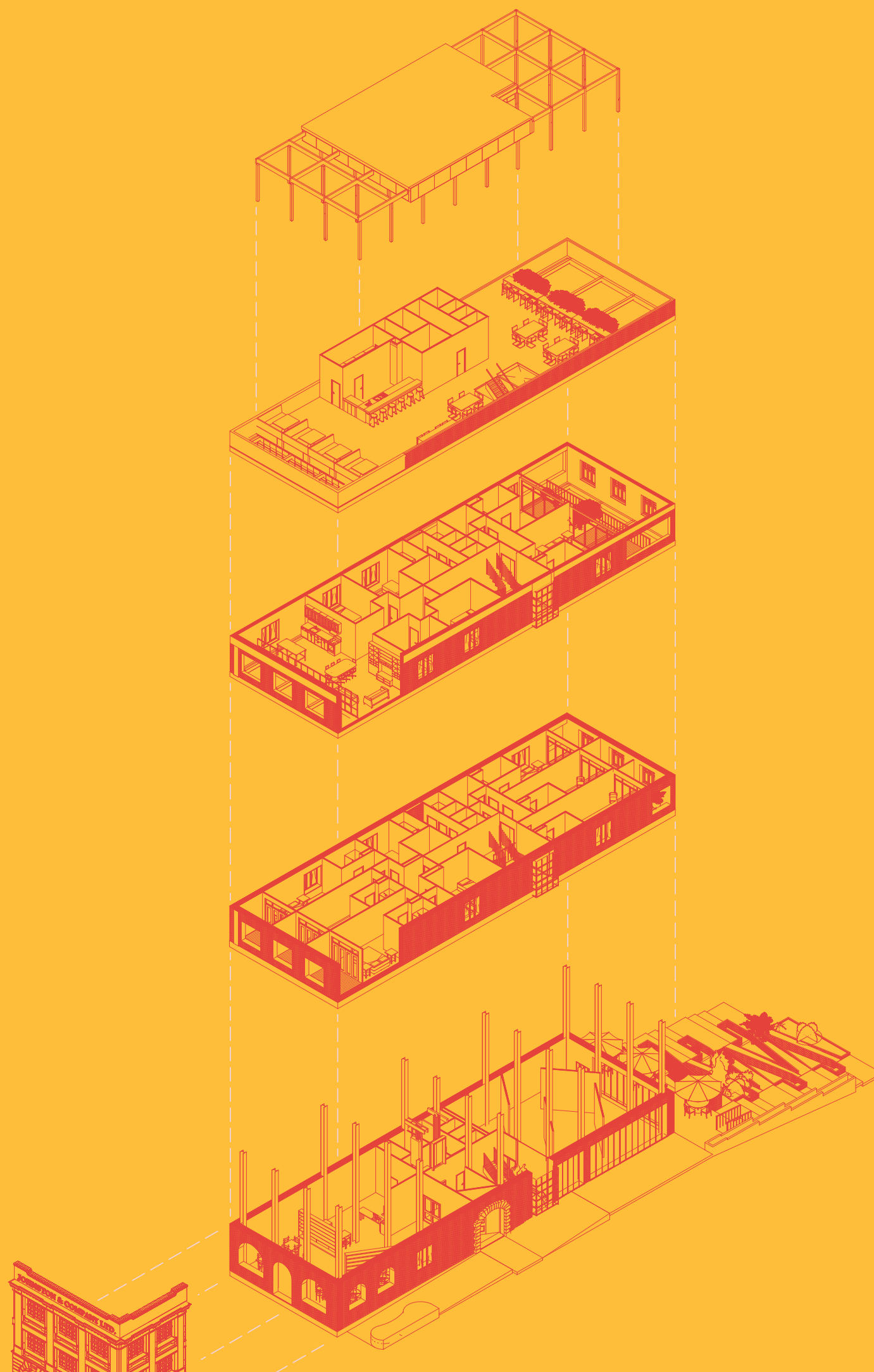

Fig. 9.11: Exploded isometric. 


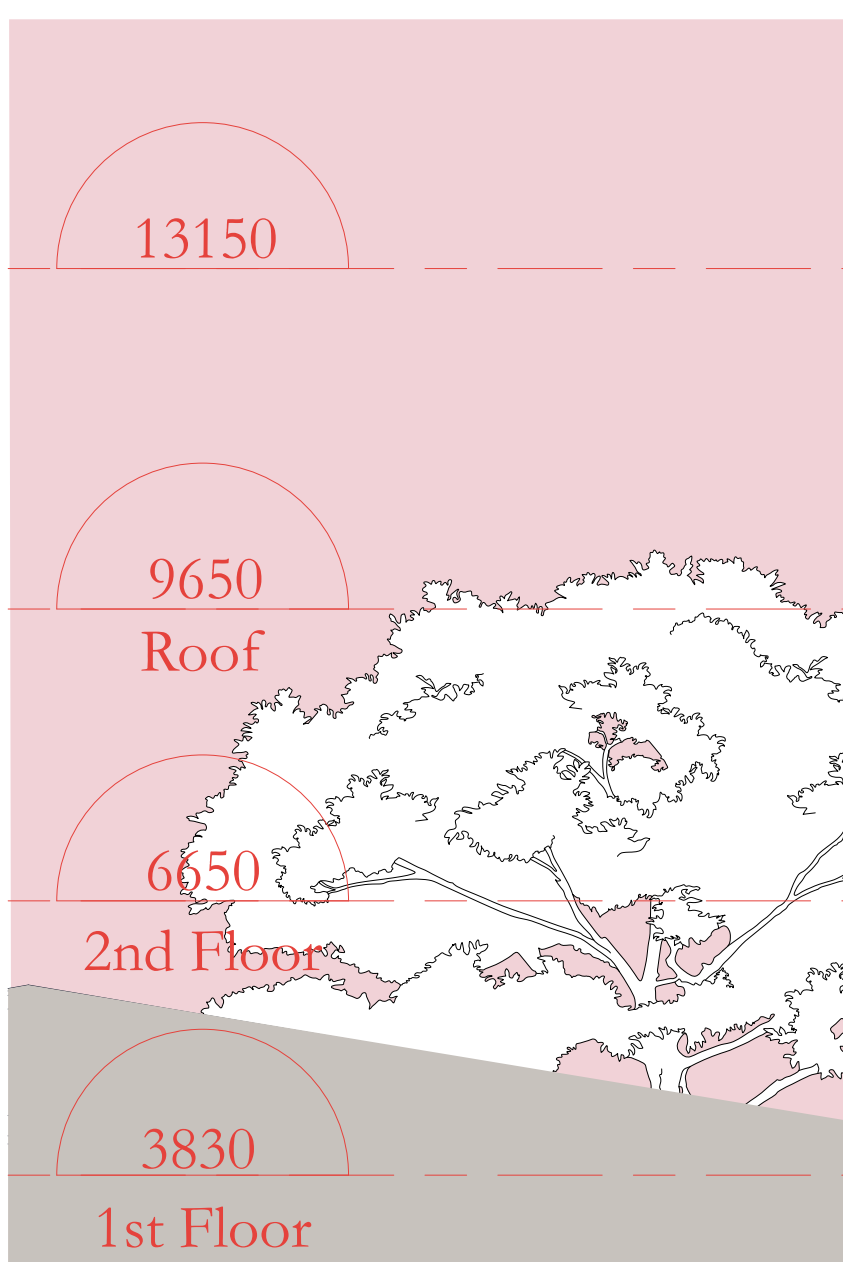

Fig. 9.12: Section A 


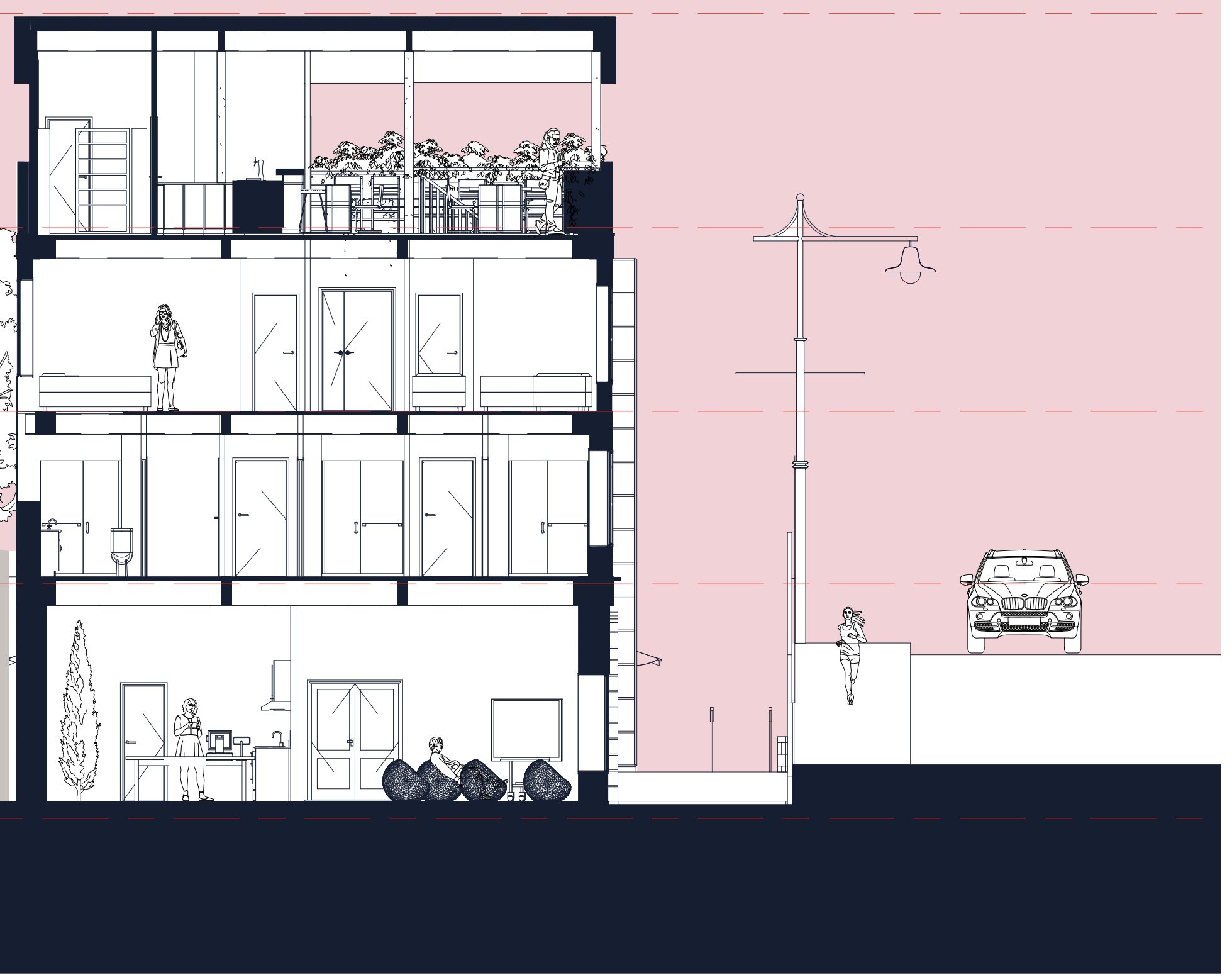




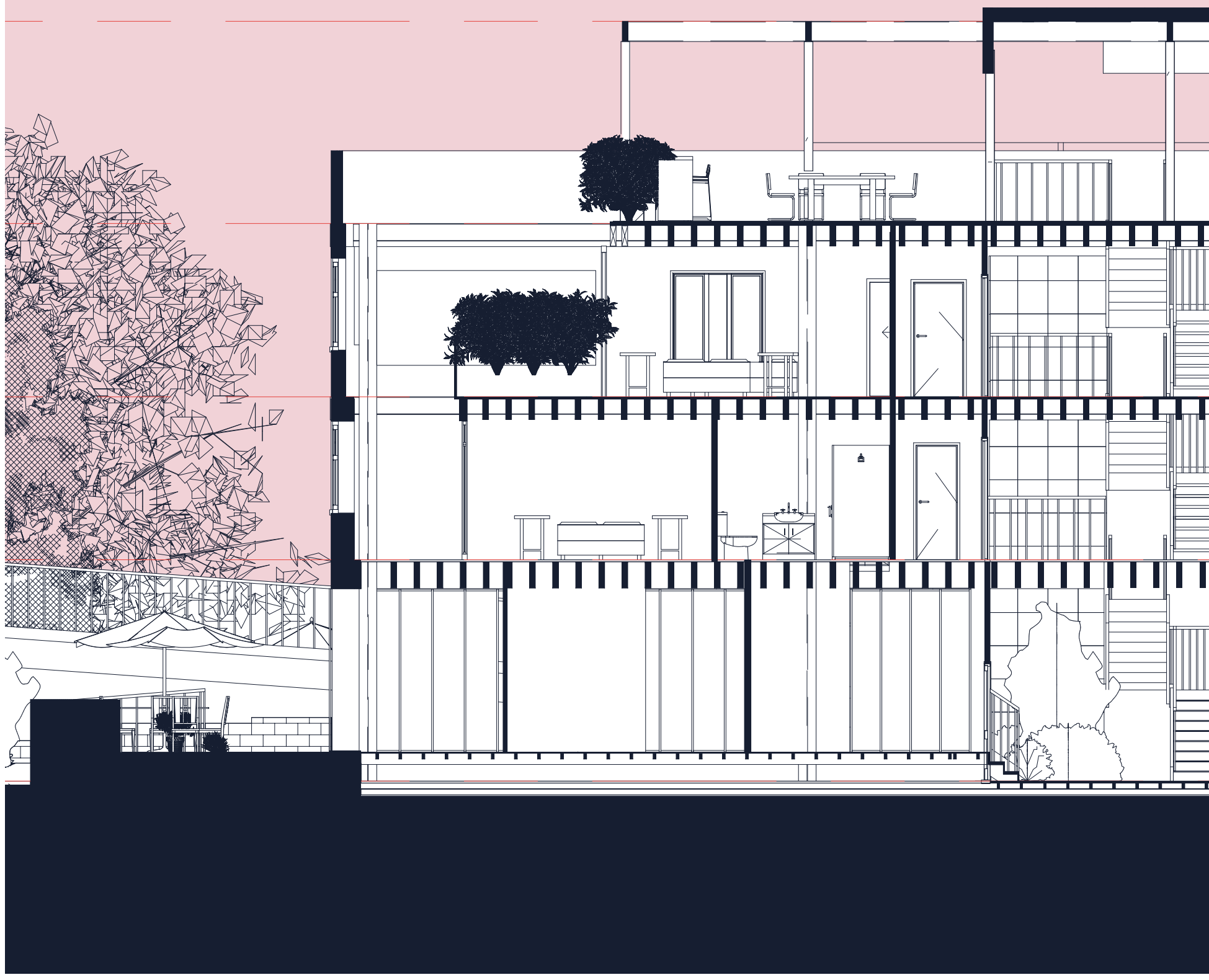

Fig. 9.13: Section B 


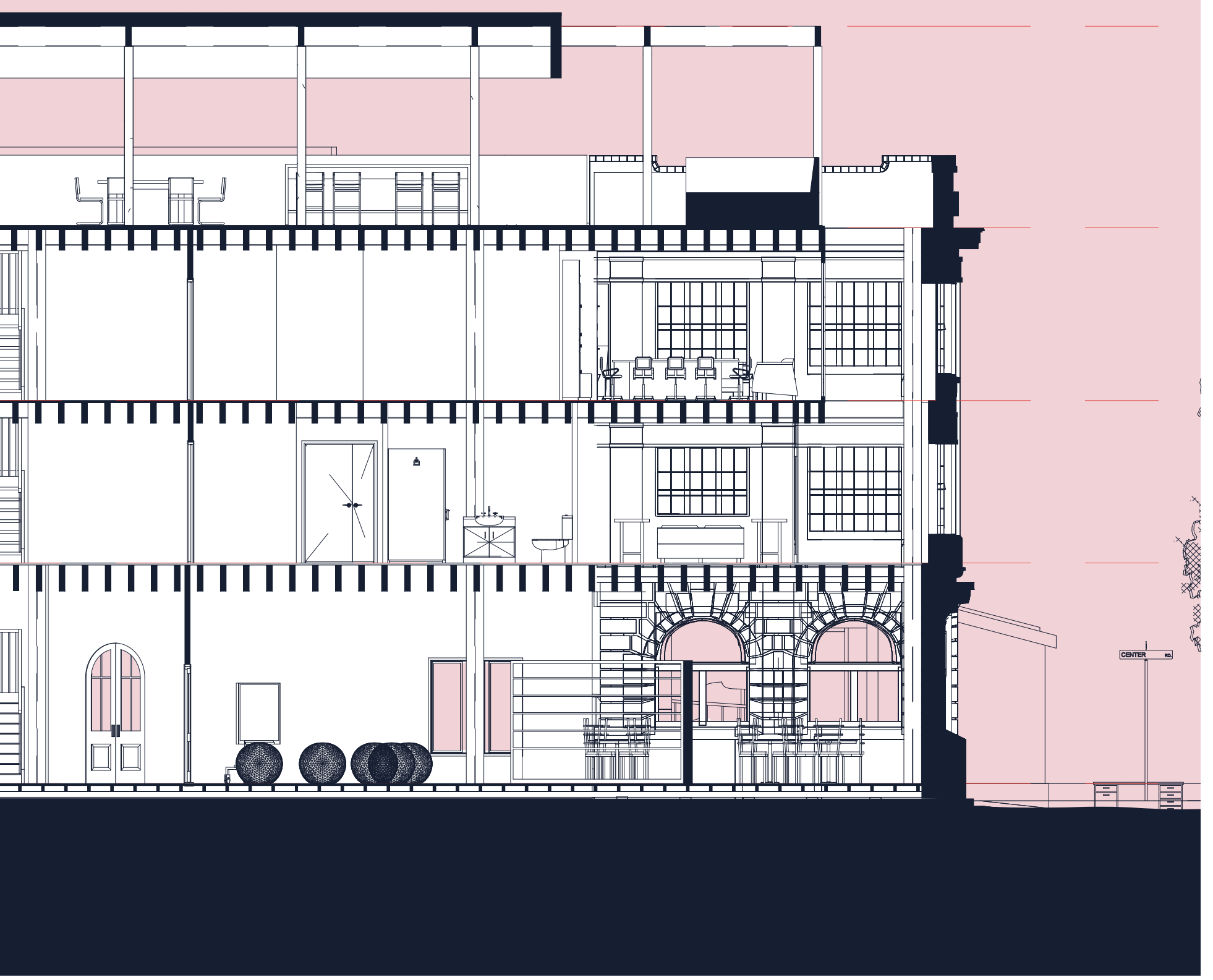


Fig. 9.14: Property Brokers Building Isometric. 


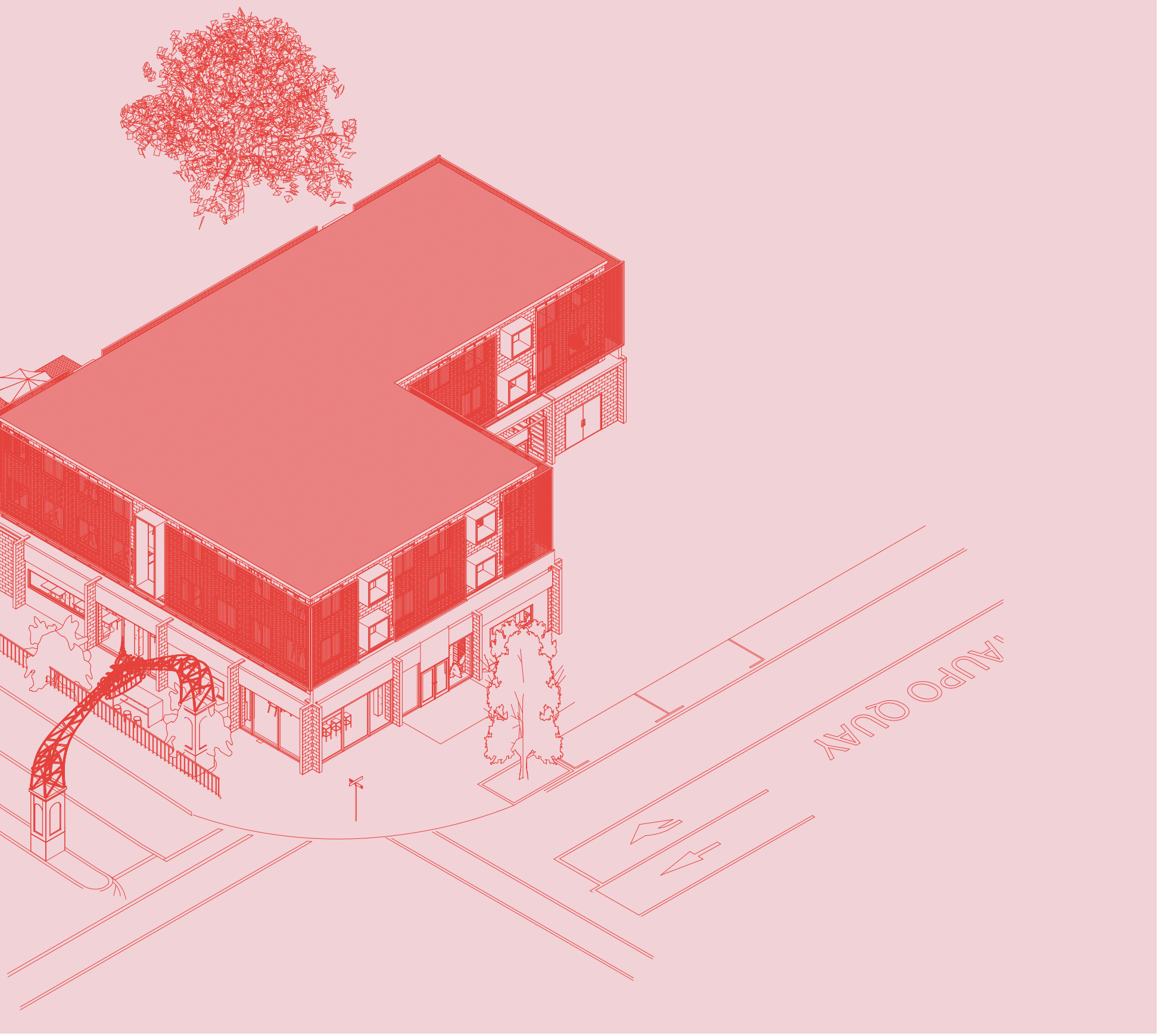




\section{PROPERTY BROKERS FLOOR PLANS}

Fig. 9.15: Ground floor plan.

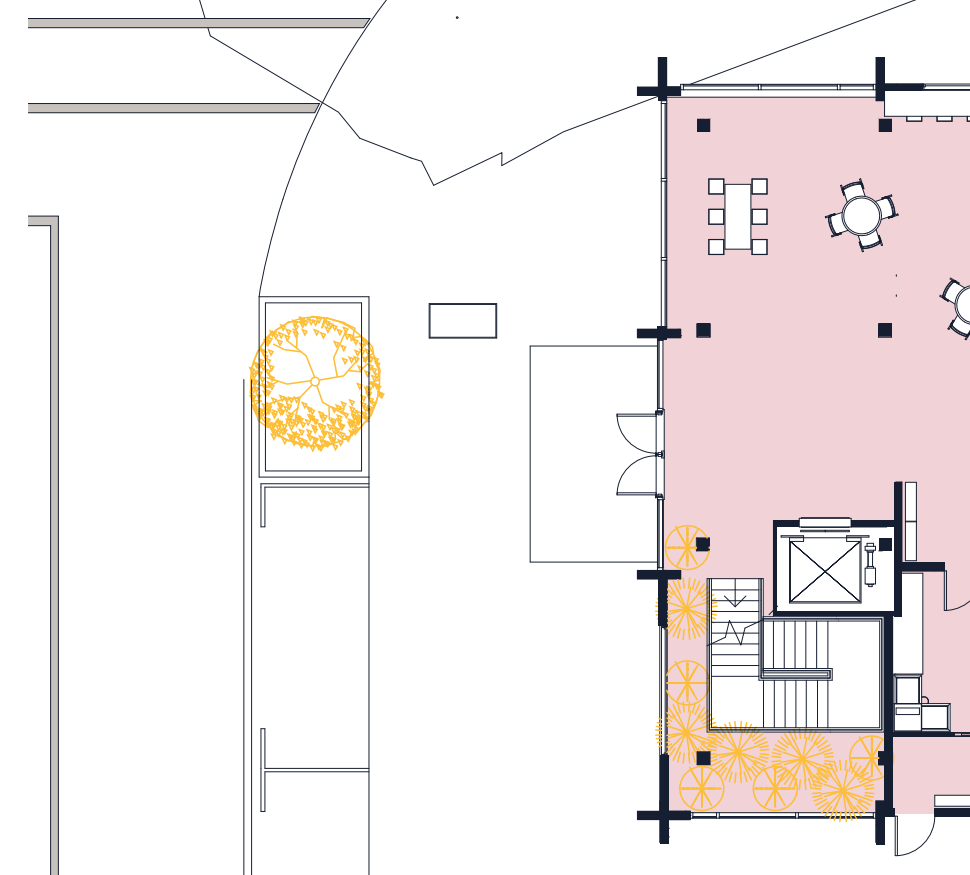




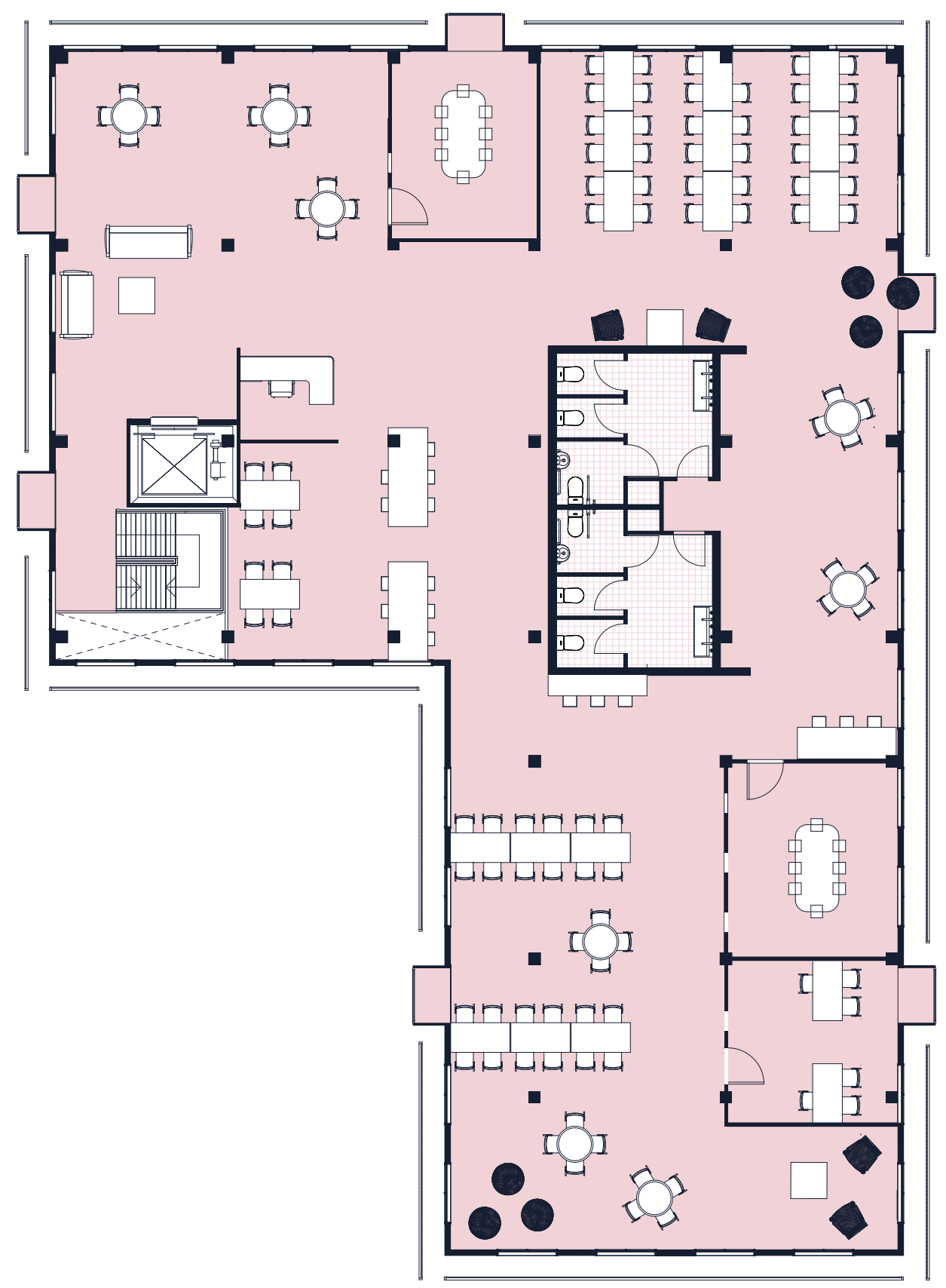

Fig. 9.16: First floor plan. 


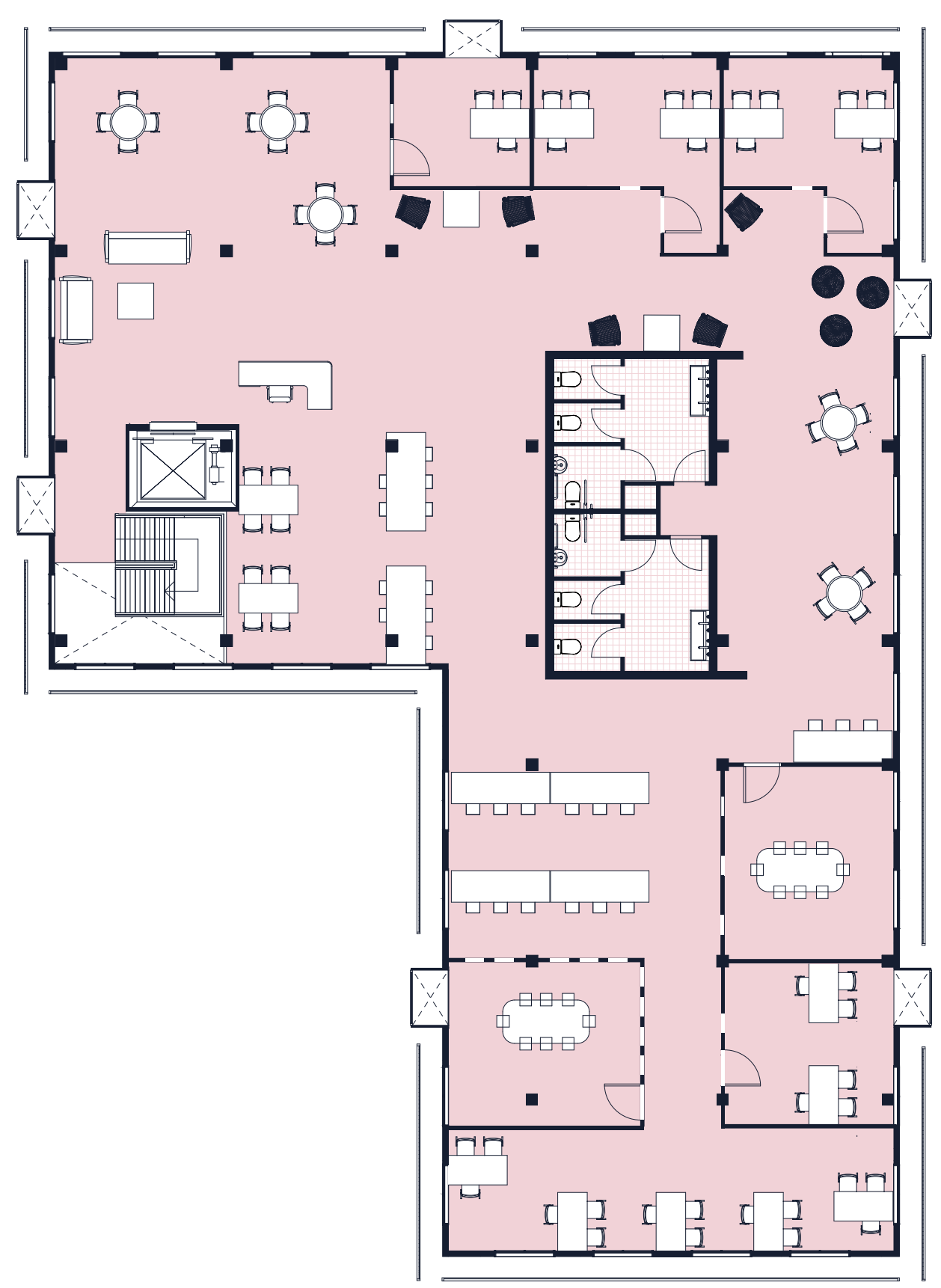

Fig. 9.17: Second floor plan. 


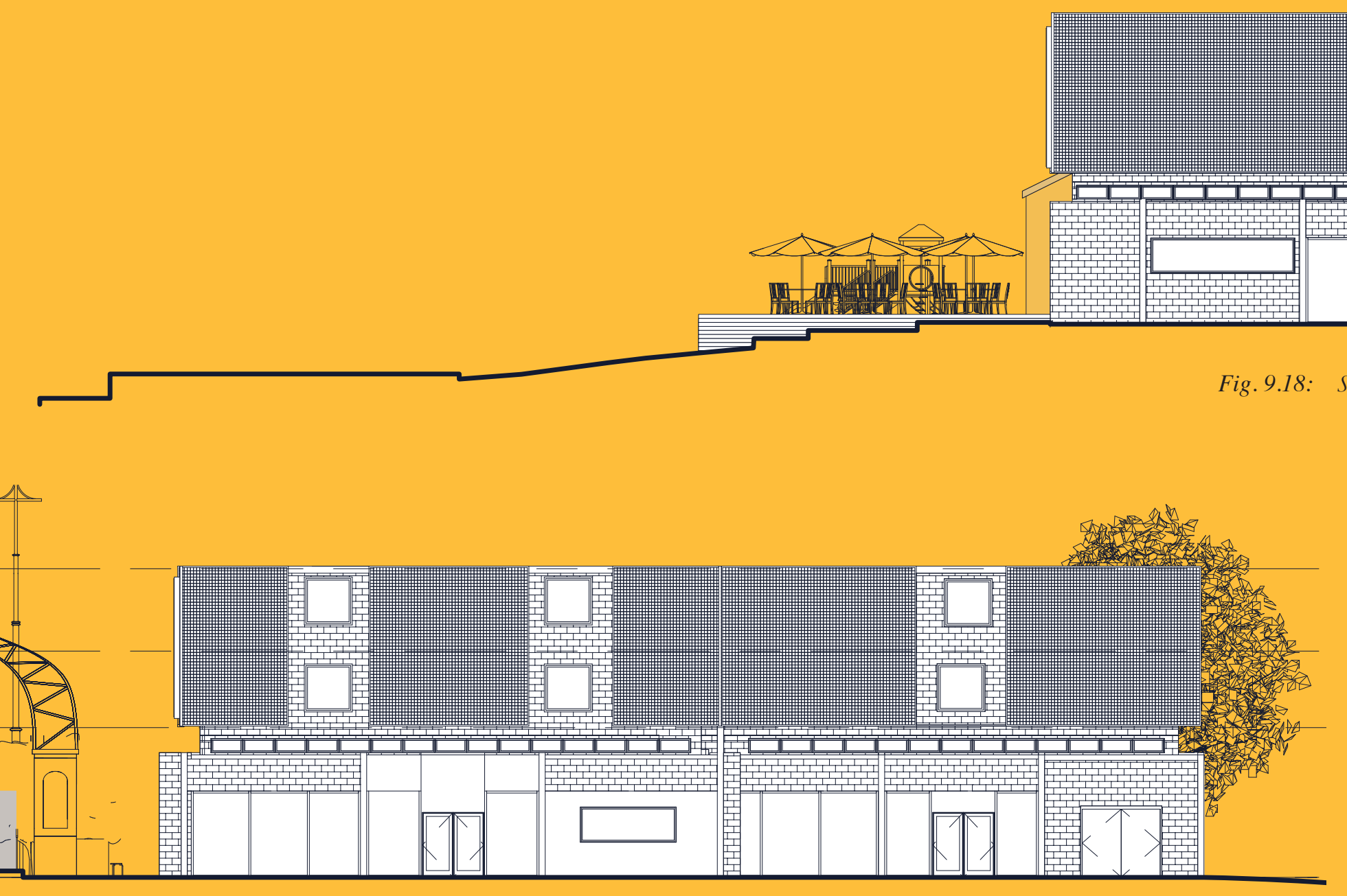

Fig.9.19: West elevation.
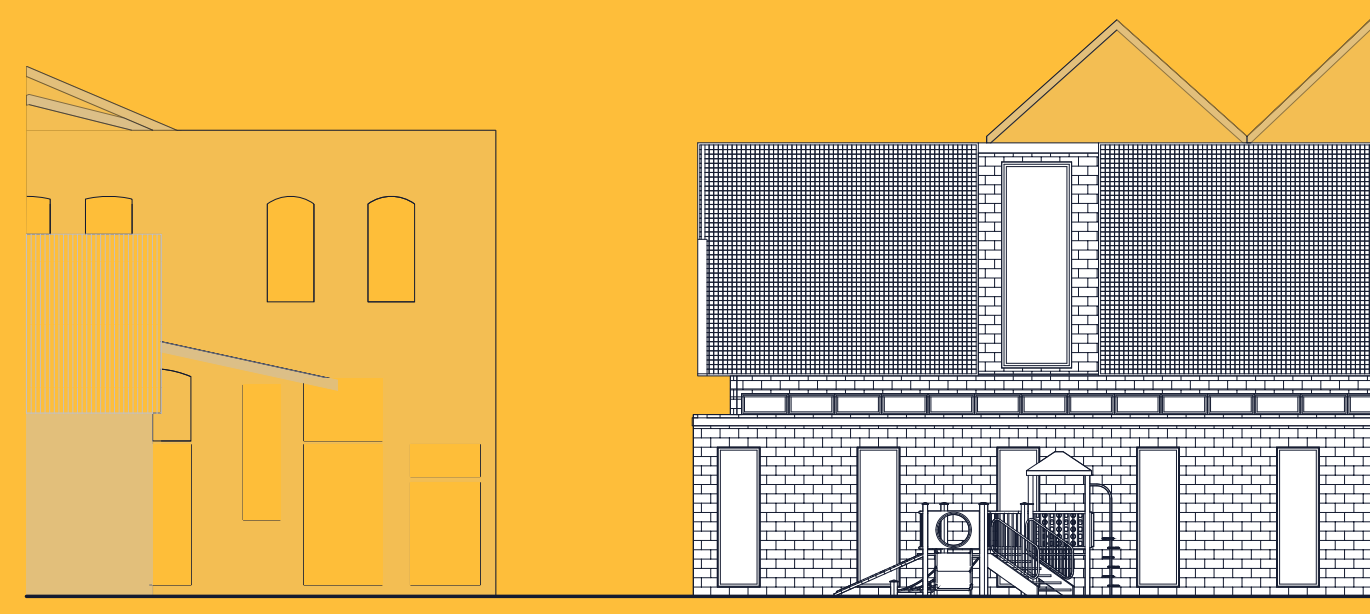

Fig. 9.20: Eas 


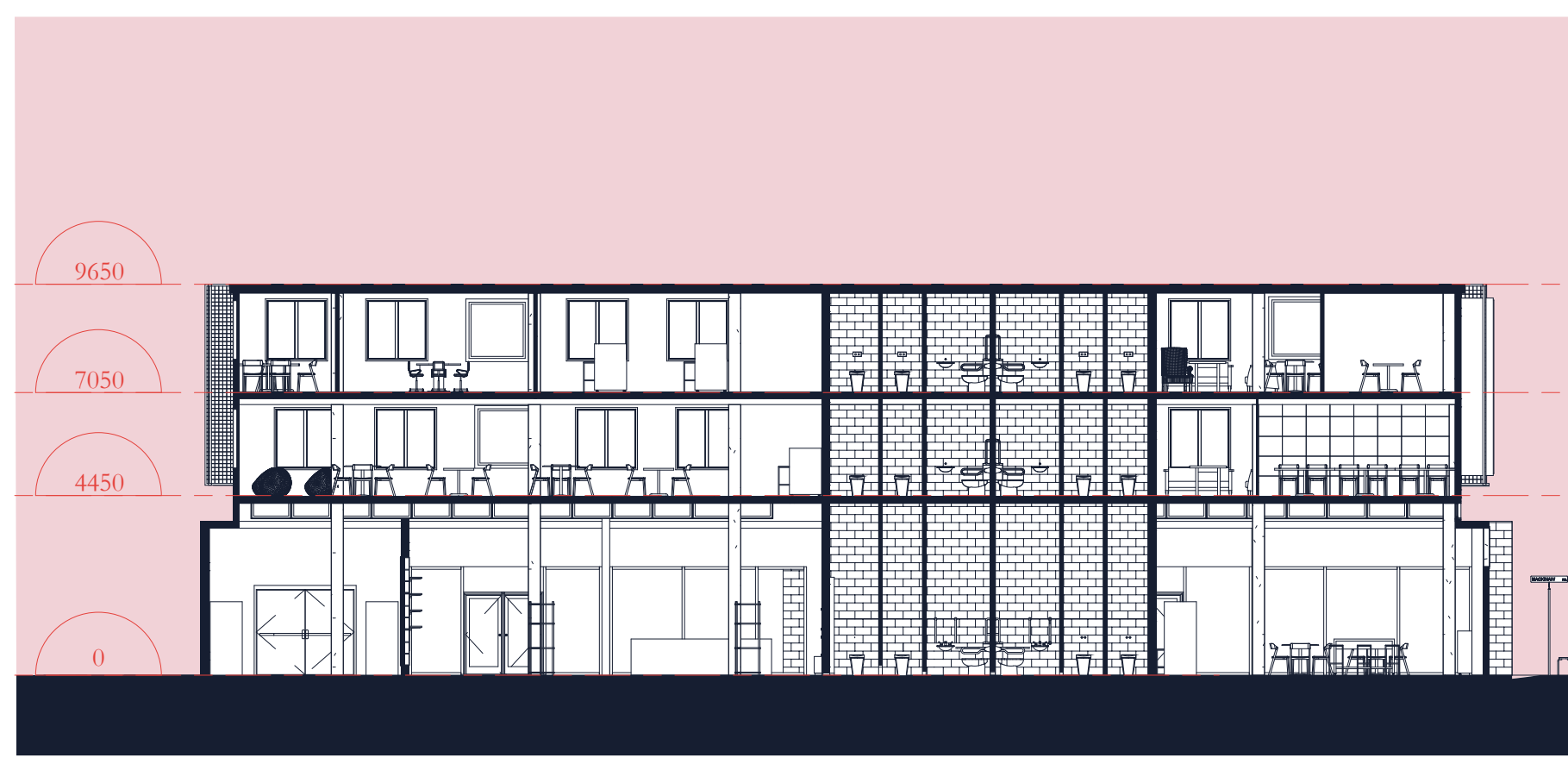

Fig. 9.22: $\quad$ Section $A$

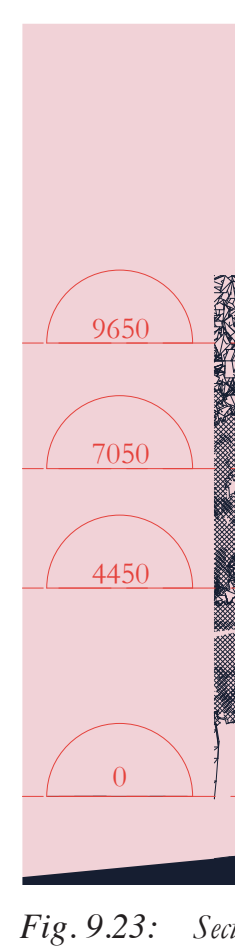


Fig. 9.24: Dalgety / Thains Building Isometric. 


\title{
THAINS DALGETY BUILDING FLOOR PLANS
}

\author{
1 lobby \\ 2 retail shop \\ 3 shared bathroom \\ ه car park/potential shops \\ 5 flexible educational space \\ (6) hangi pits \\ 7 community vedgetable garden \\ (8) courtyard \\ (q) sheltered entry
}

Fig. 9.25: Ground floor plan. 

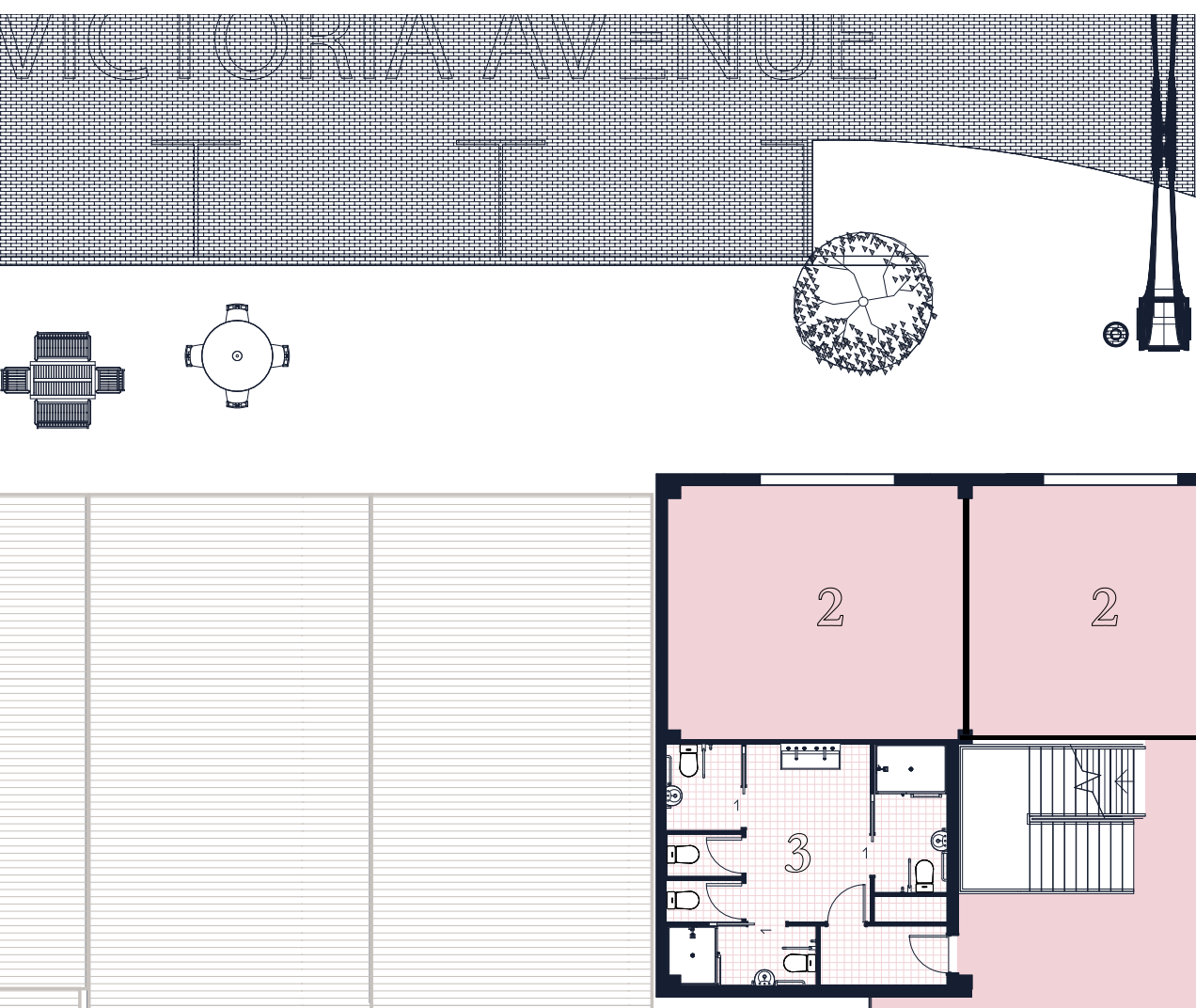
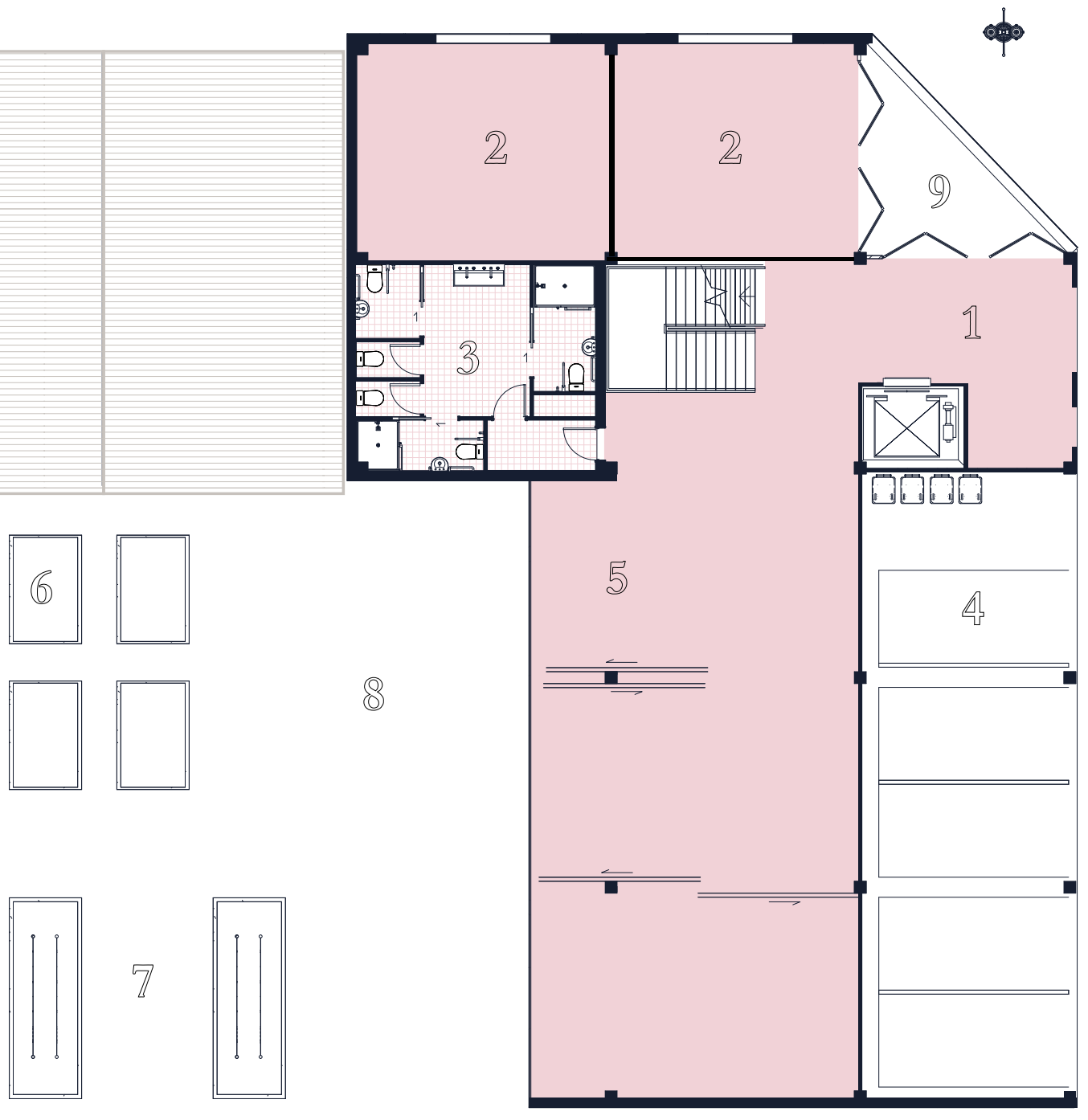


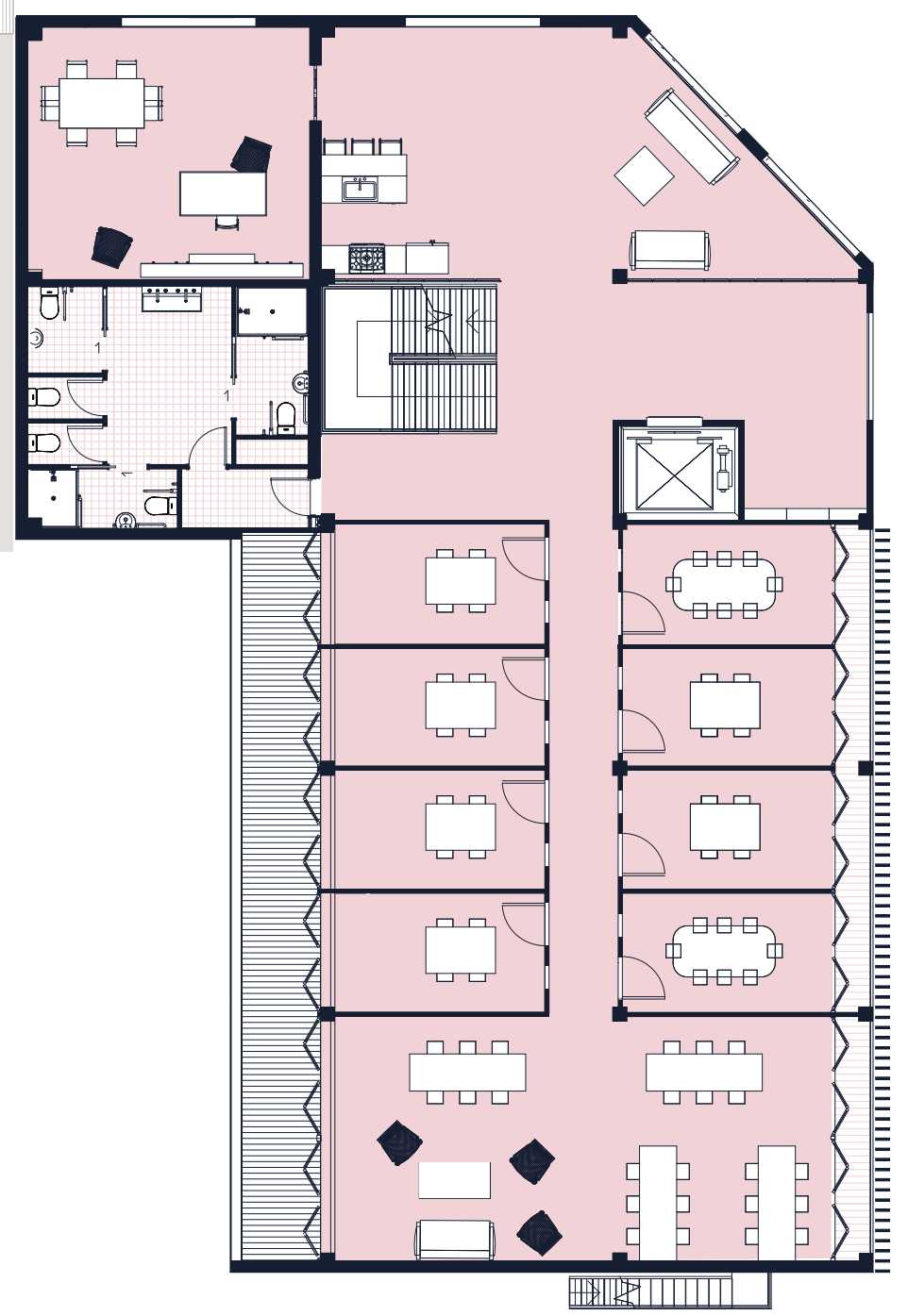

Fig. 9.26: First floor plan. 


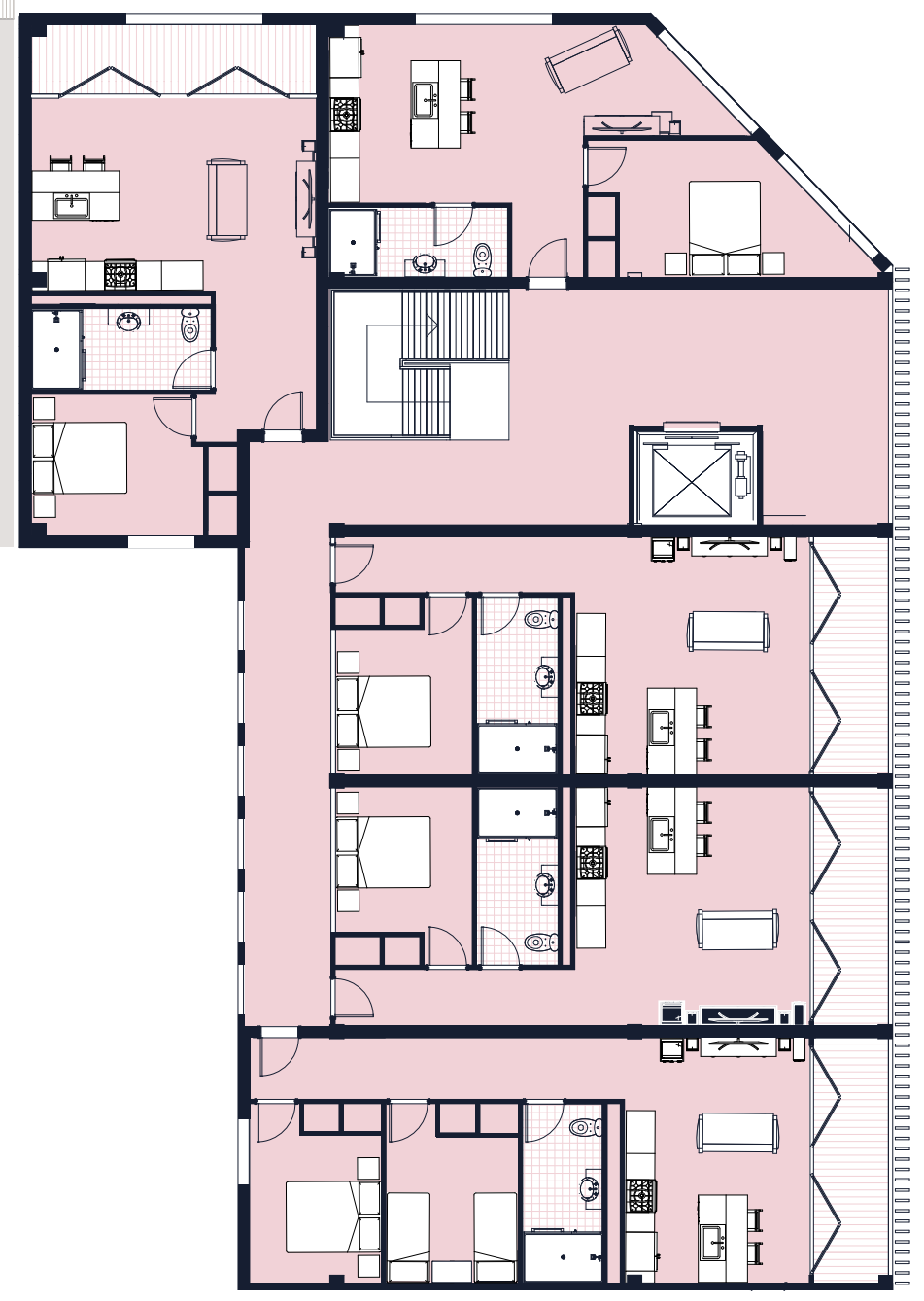

Fig. 9.27: Second floor plan. 


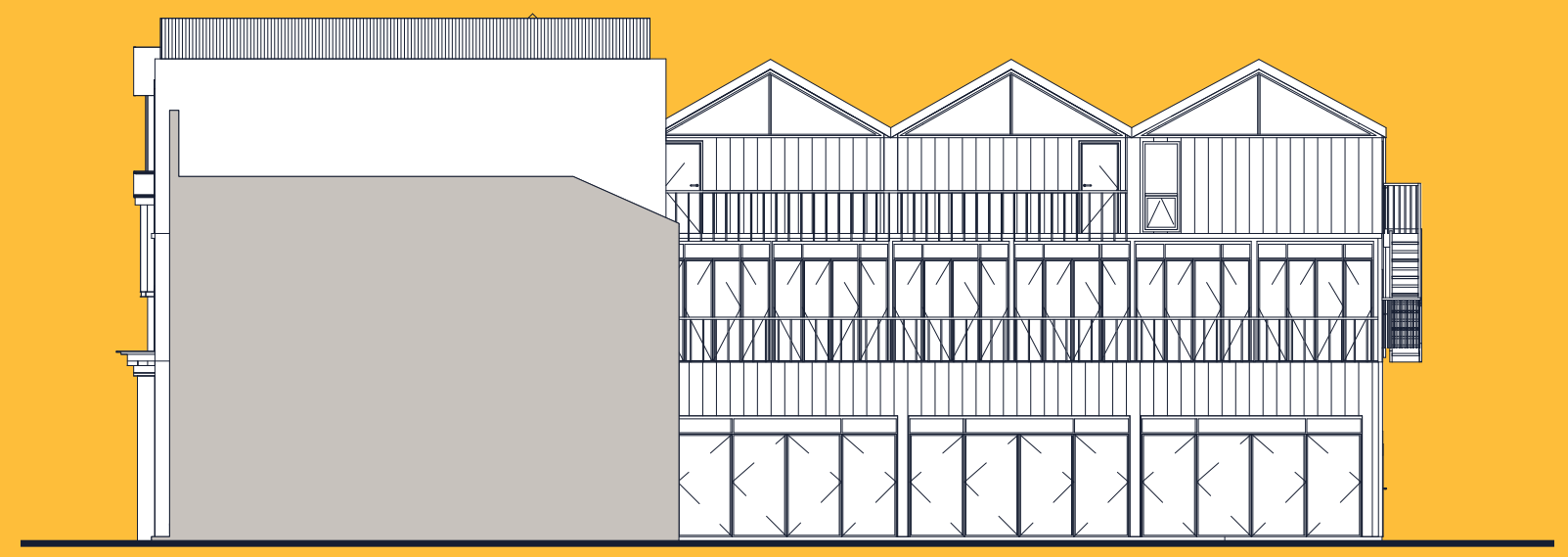

Fig. 9.28: West Elevation. 


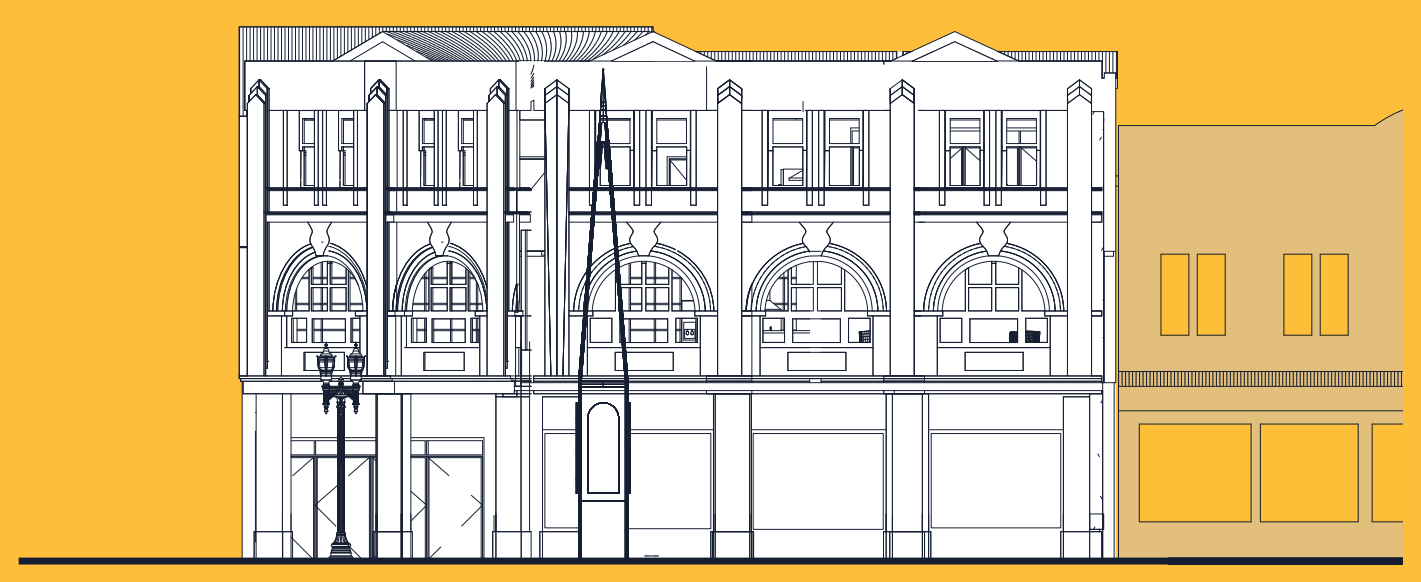

Fig. 9.29: North Elevation. 



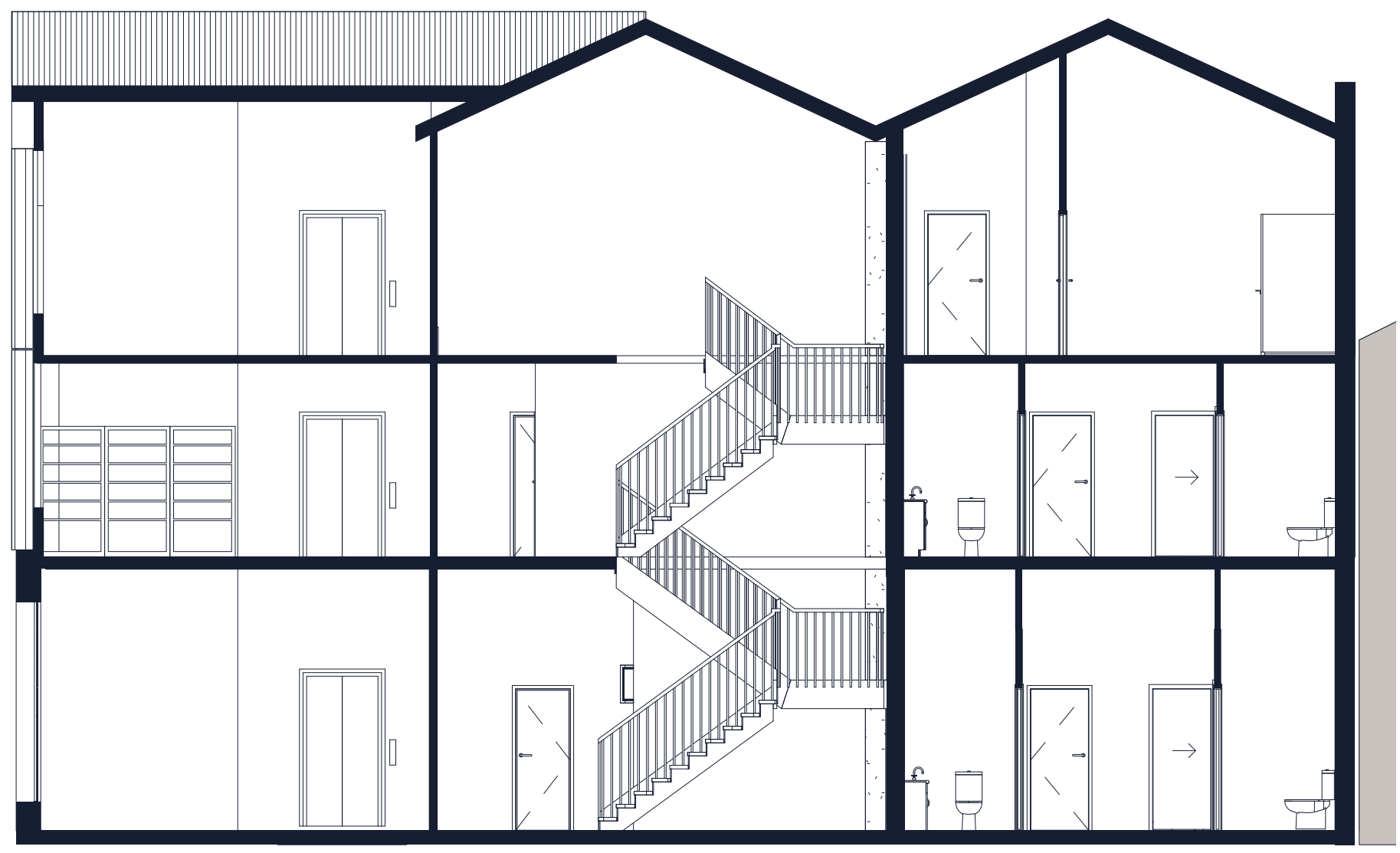

Fig. 9.30: Section B 


\section{FOSTERS FLOOR PLANS}

$\begin{array}{ll}1 & \text { main entry } \\ 2 & \text { foyer } \\ 3 & \text { restaurant } \\ 4 & \text { small bar } \\ 5 & \text { kitchen } \\ 6 & \text { large bar } \\ 7 & \text { dance floor } \\ 8 & \text { iobby } \\ (2) & \text { function room } \\ 11(0) & \text { storage } \\ 11 & \text { dining room } \\ 12 & \text { bathroom 1 } \\ 13 & \text { bathroom two } \\ 14 & \text { outdoor area } \\ 13 & \text { fire exit }\end{array}$

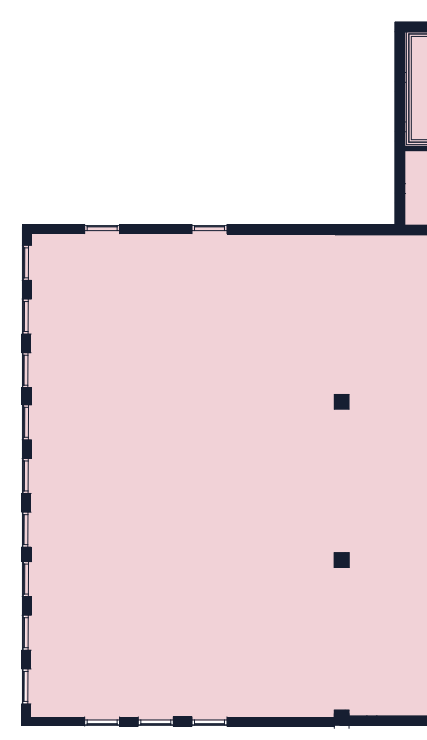

Fig. 9.31: Isometric of Fosters Hotel.

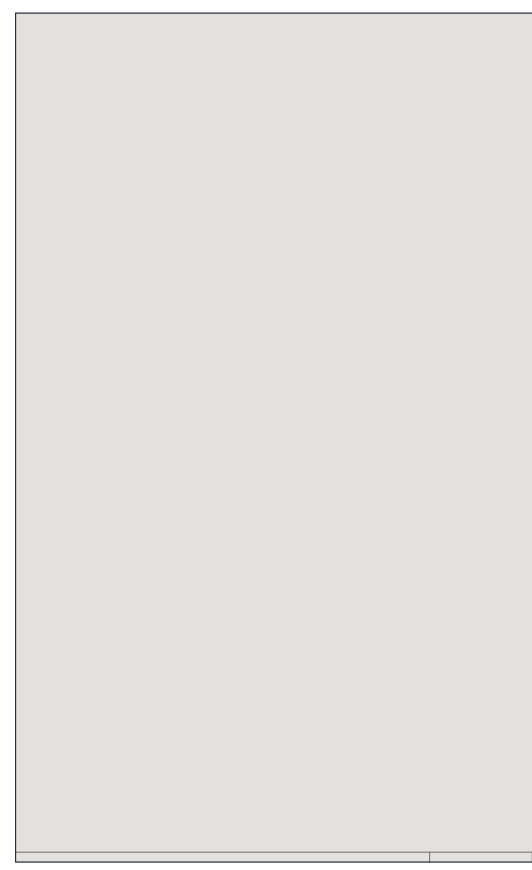




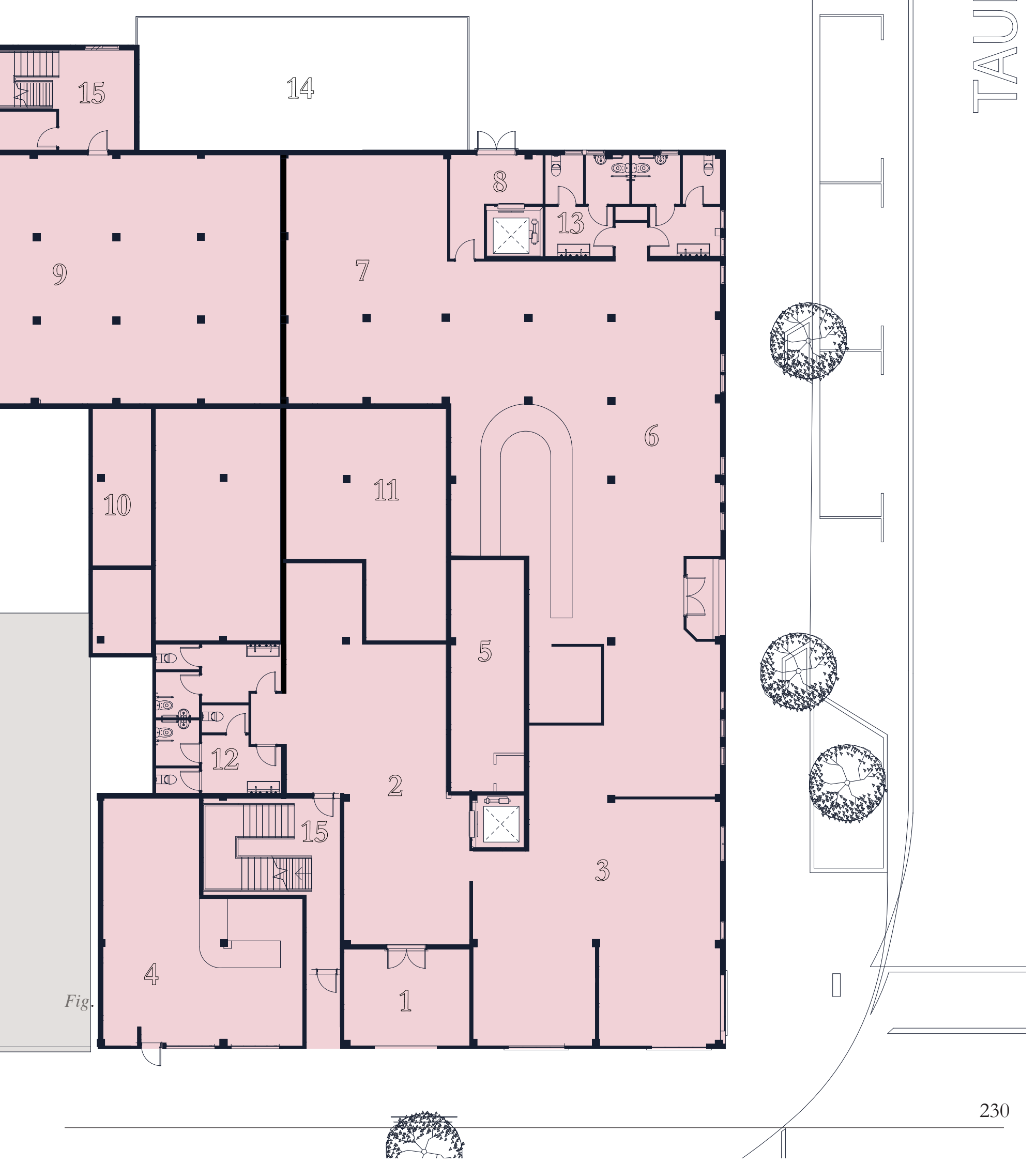




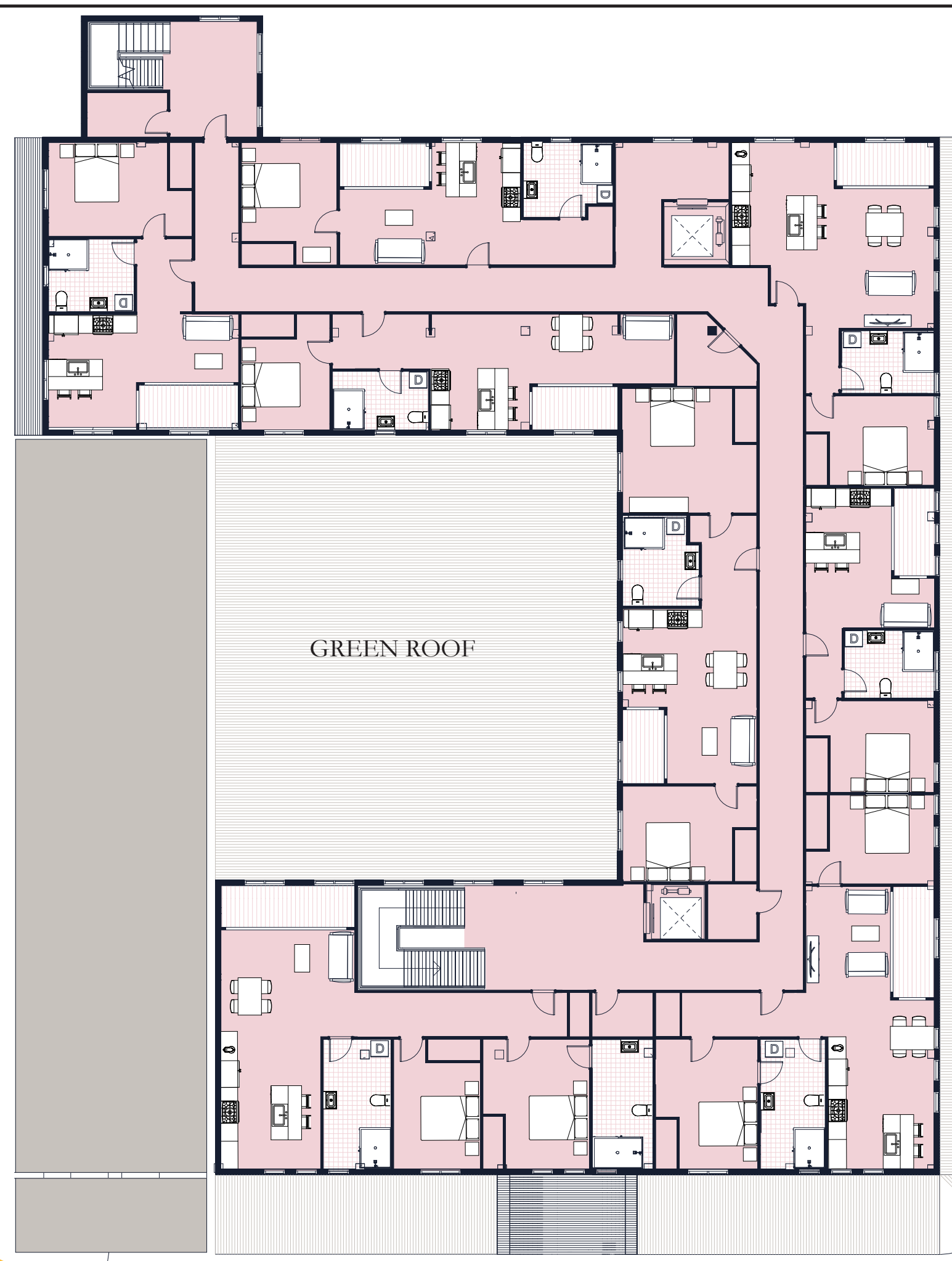

Fig. 9.33: First Floor. 


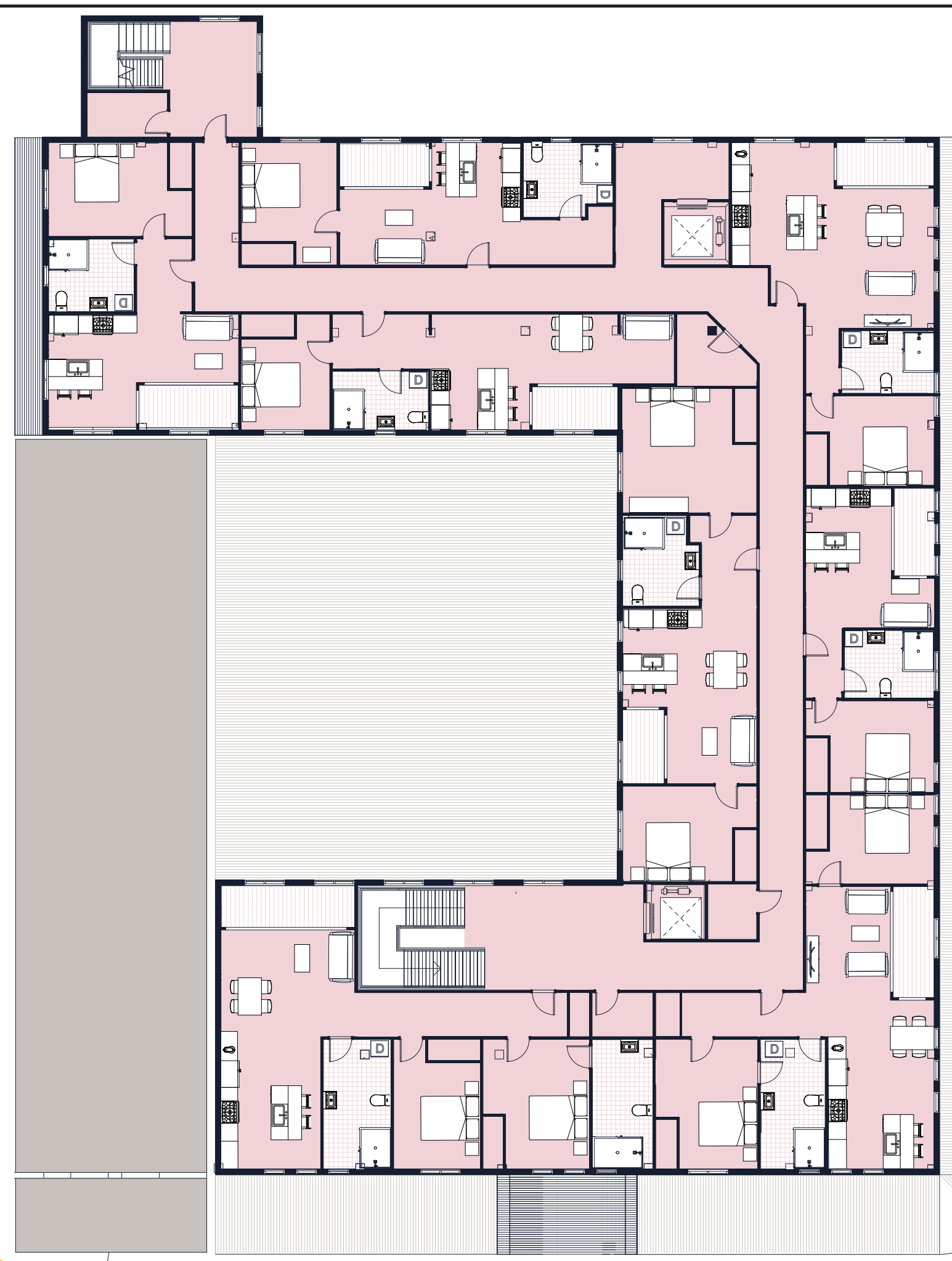

Fig. 9.34: Second Floor. 


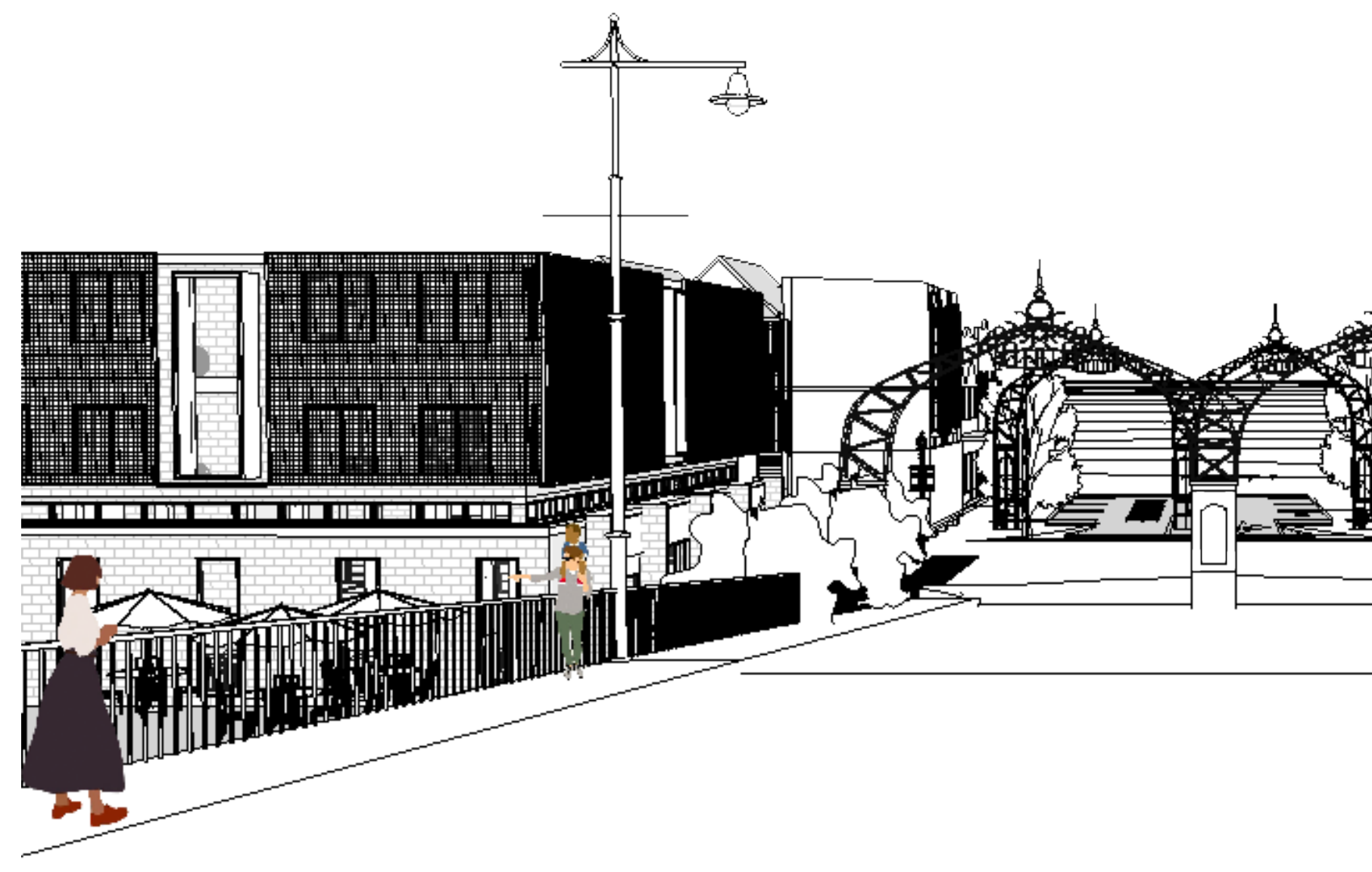

Fig. 9.35: View from City Bridge of the cross roads. 


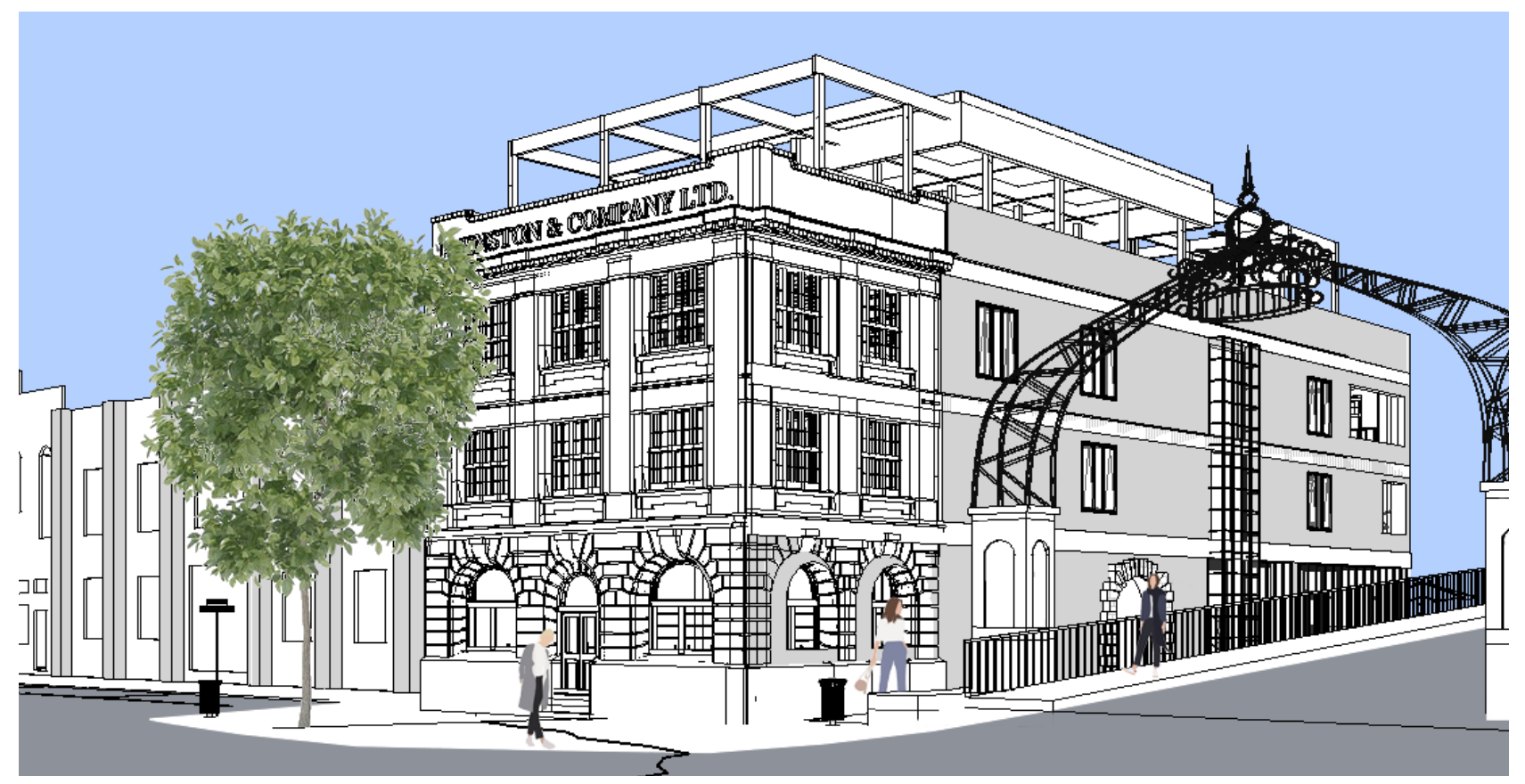

Fig. 9.36: Perspective view of Johnston and Co Building. 


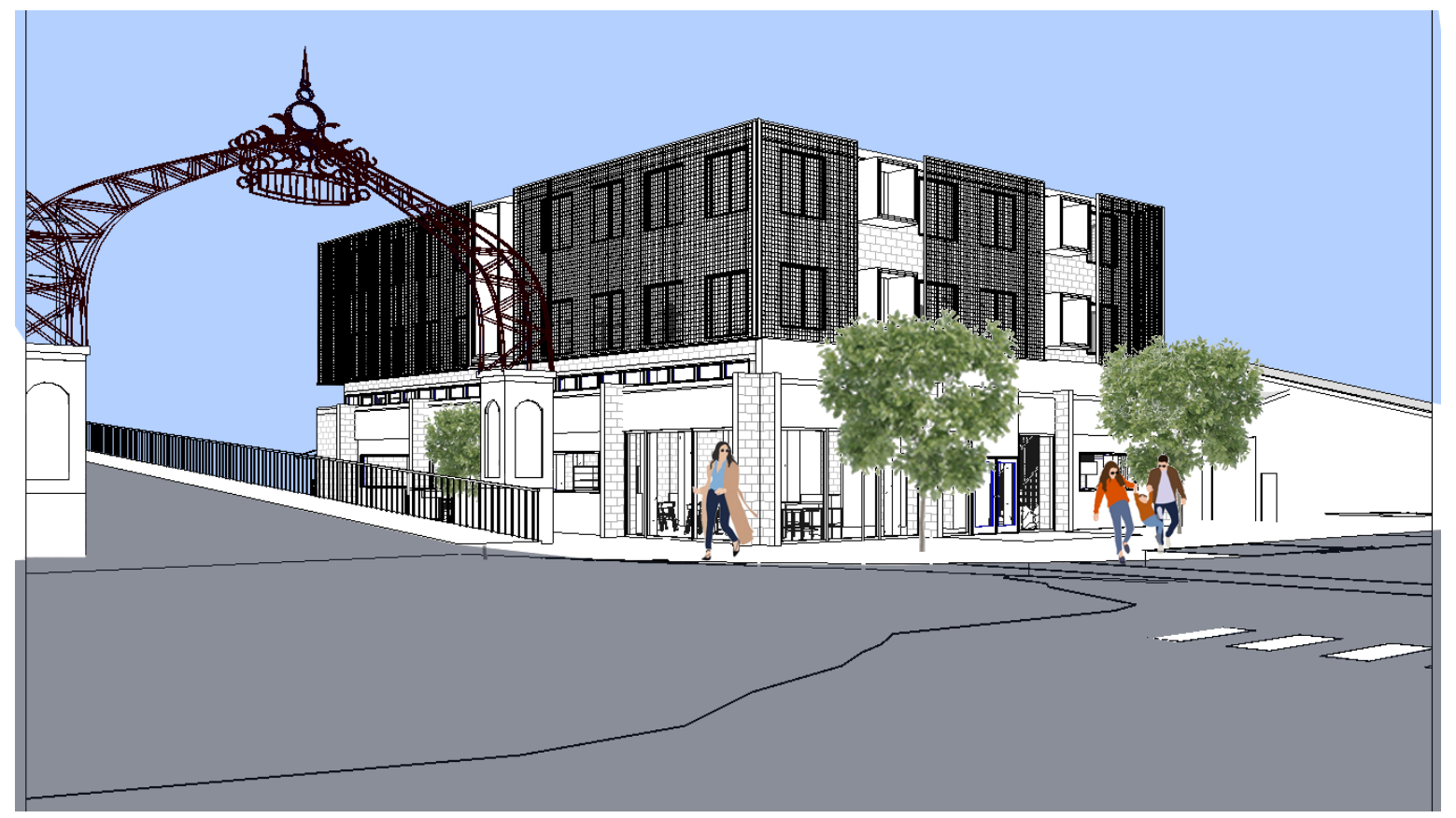

Fig. 9.37: Perspective view of Property Brokers Building. 


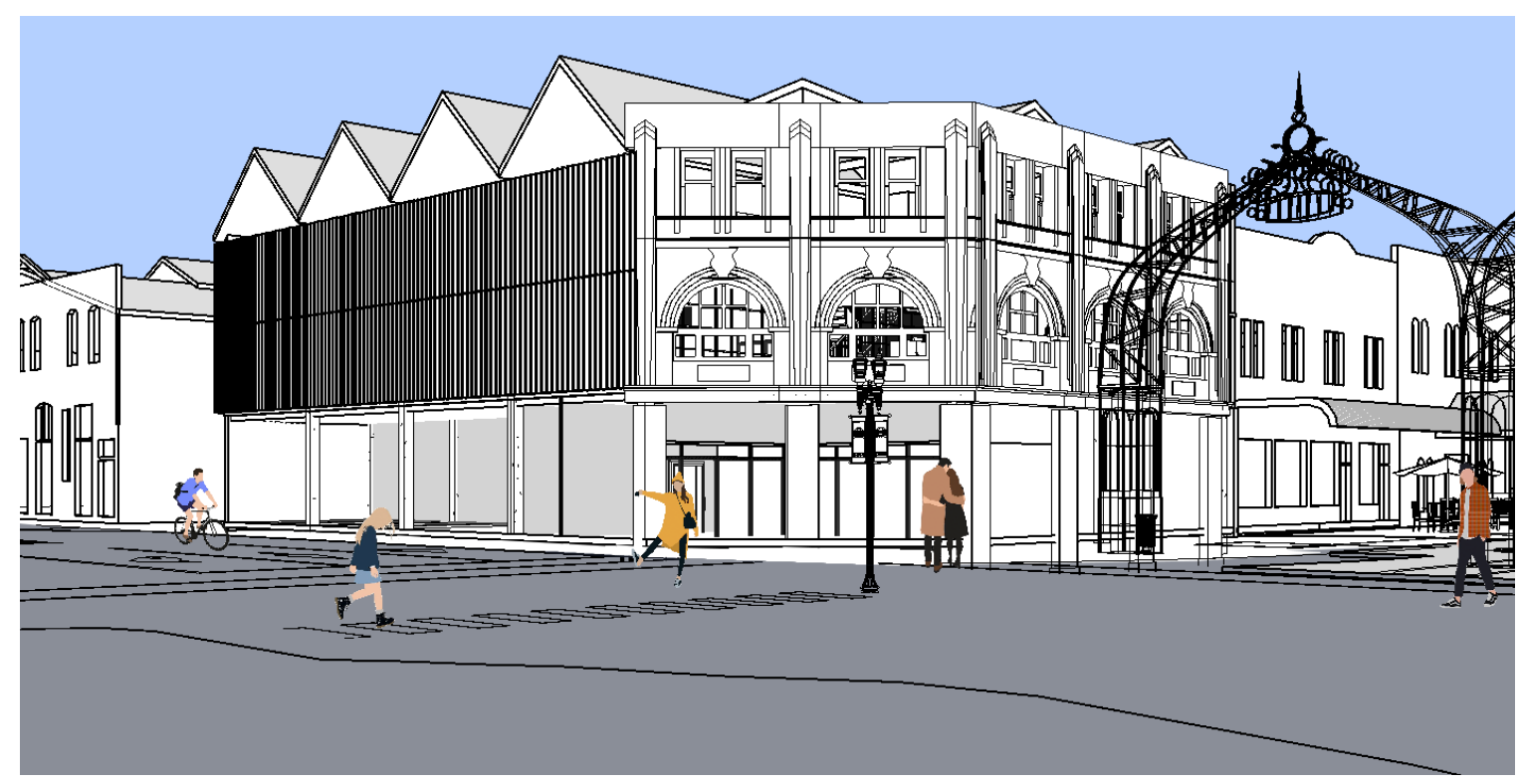

Fig. 9.38: Perspective view of Dalgety / Thains Building. 


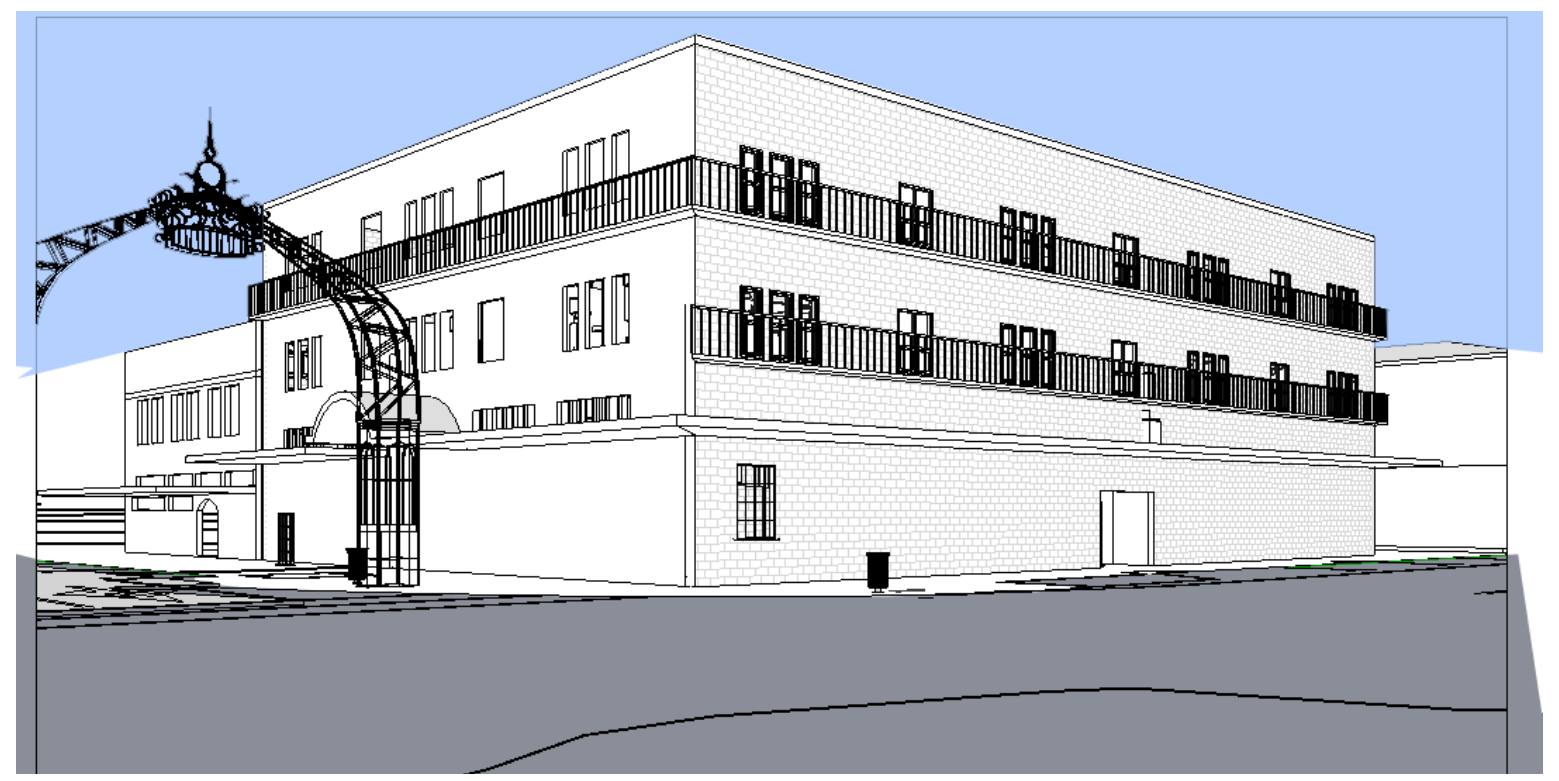

Fig. 9.39: Perspective view of Fosters Hotel. 


\section{PERSPECTIVES}

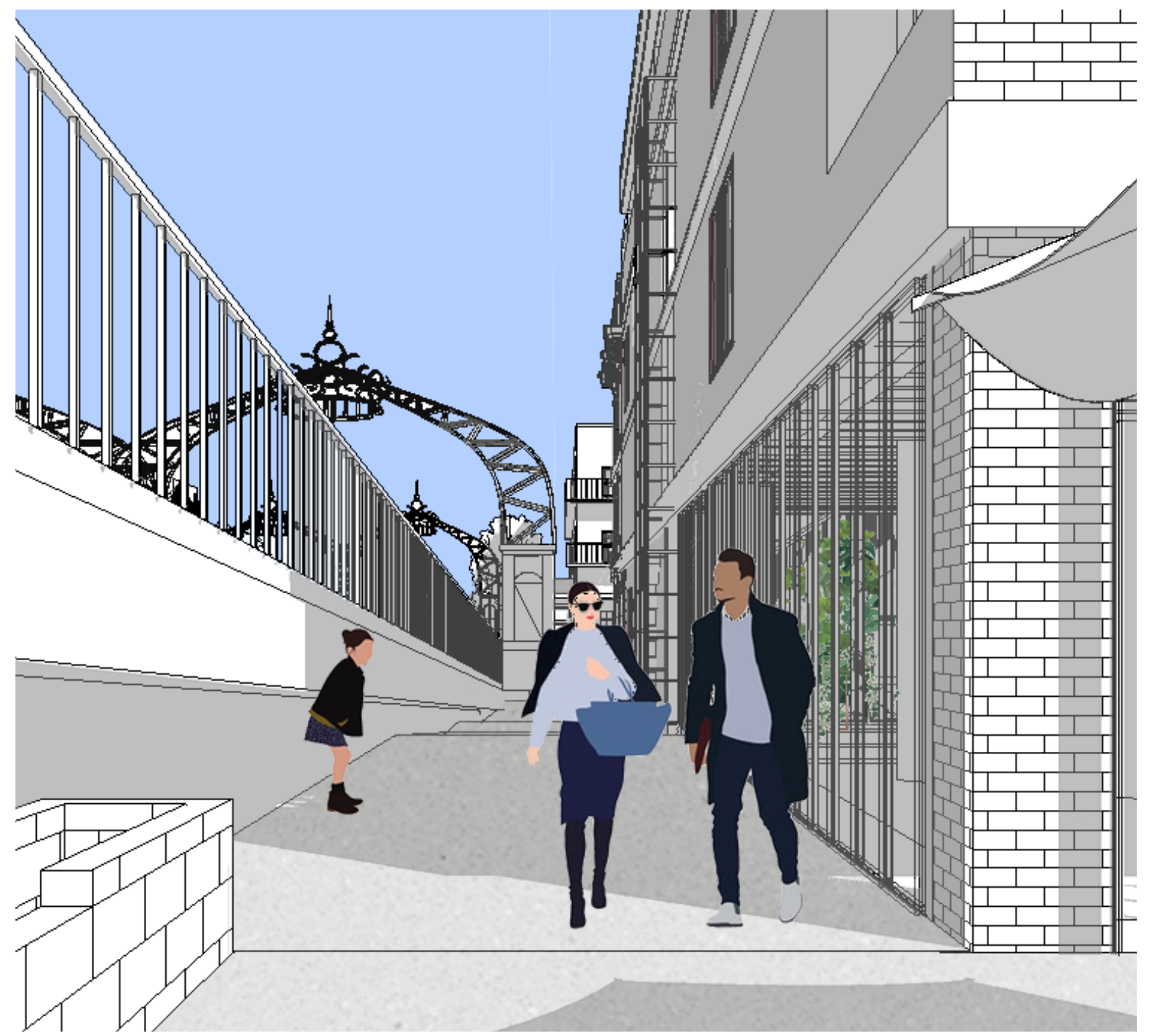

Fig. 9.40: View through alleyway up Victoria Avenue. 


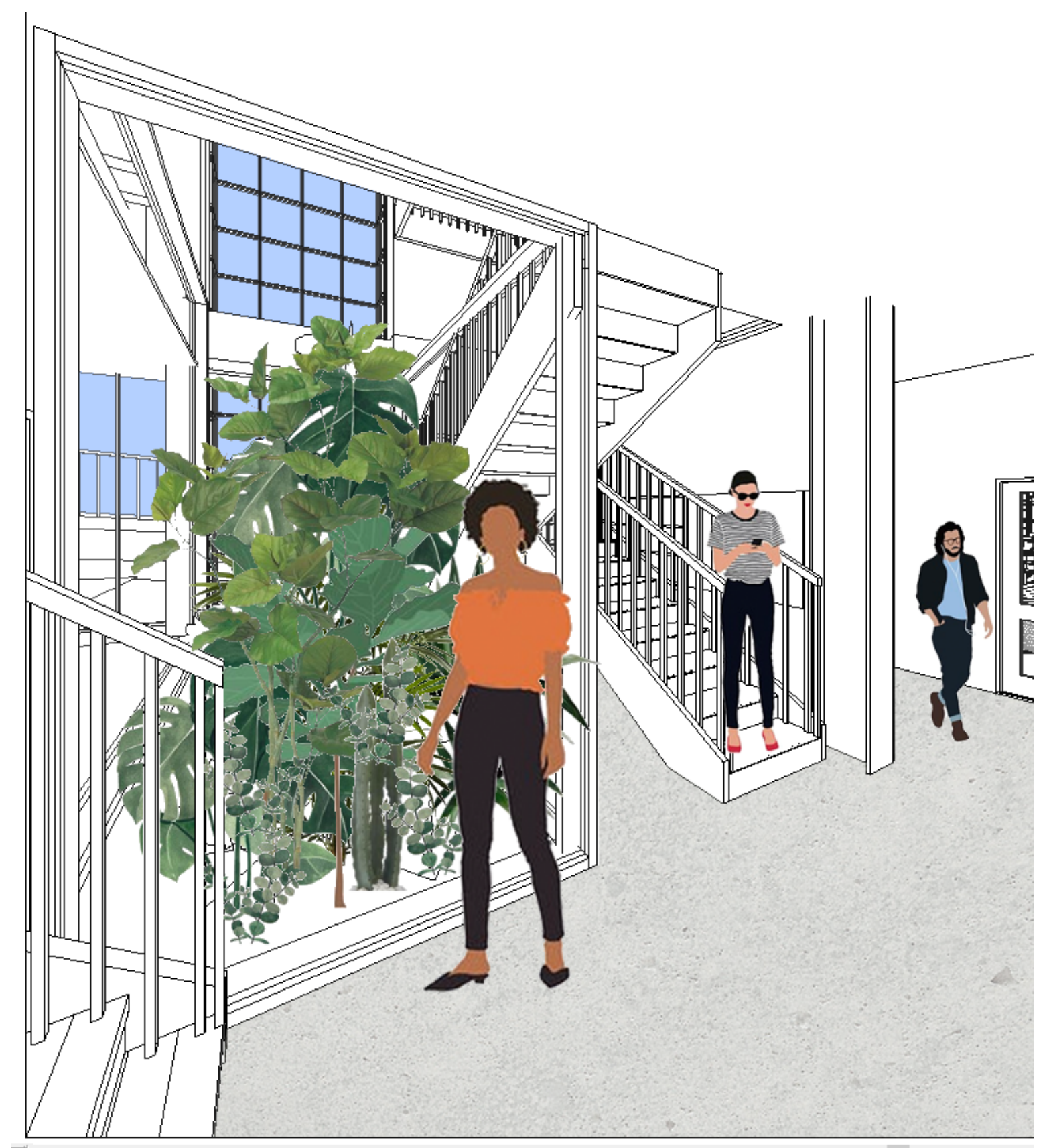

$\overrightarrow{F i g . ~ 9.41: ~ A t r i u m ~ v i e w ~ o f ~ s t a i r c a s e ~ a n d ~ f e r n e r y . ~}$ 


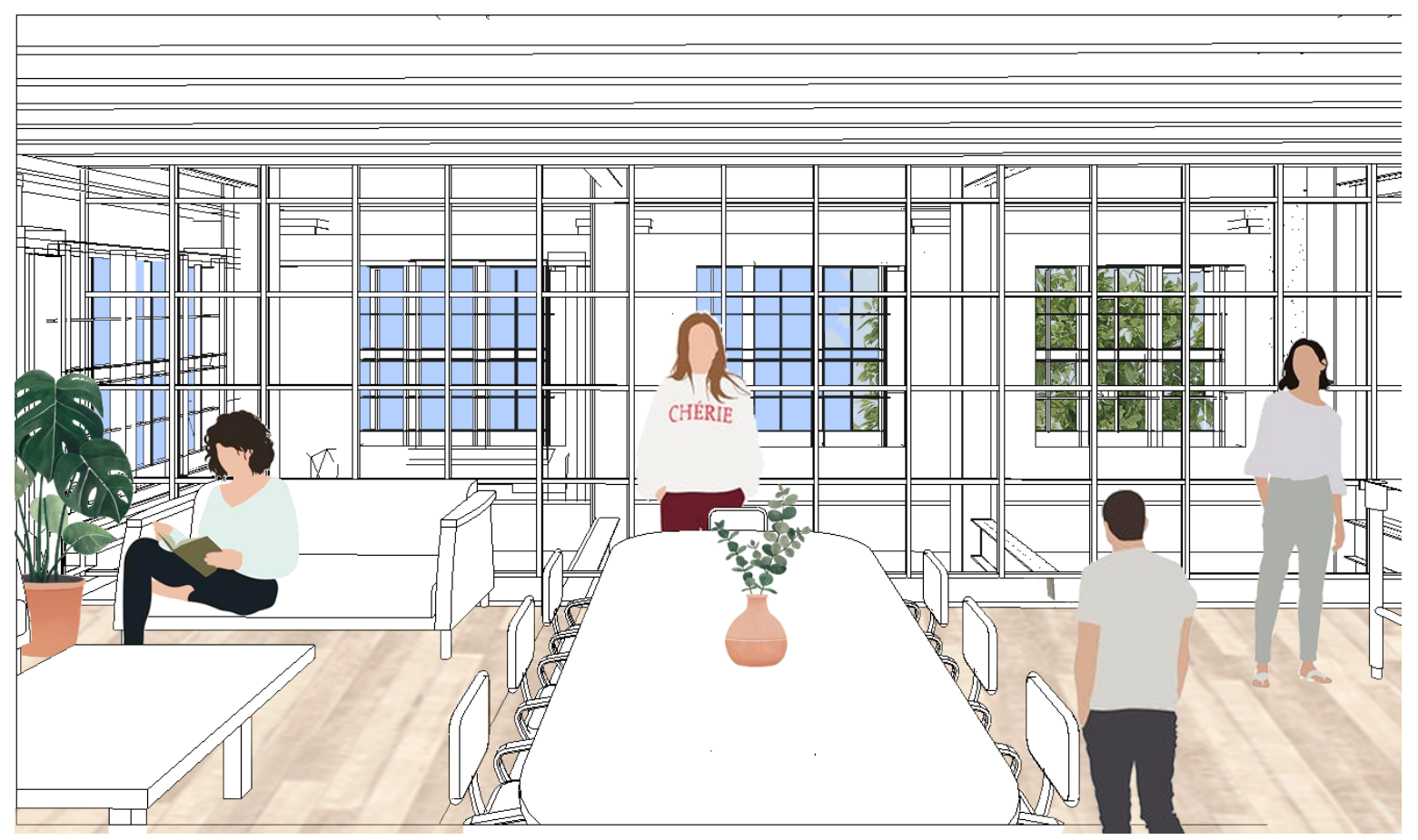

Fig. 9.42: View of shared common area in boutique hostel, looking through stepped back facade. 


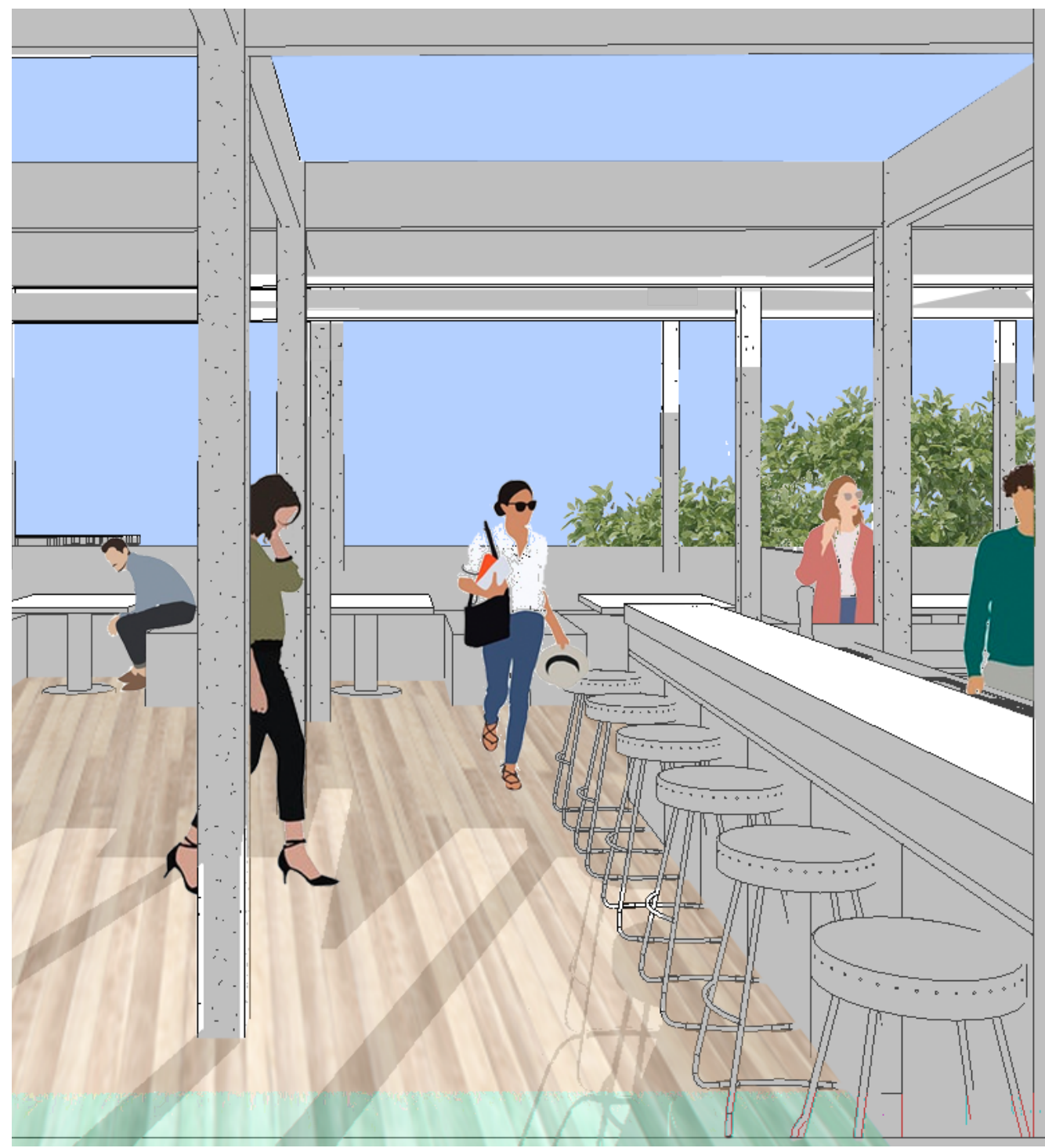

Fig. 9.43: View of rooftop bar. 


\section{PERSPECTIVES}

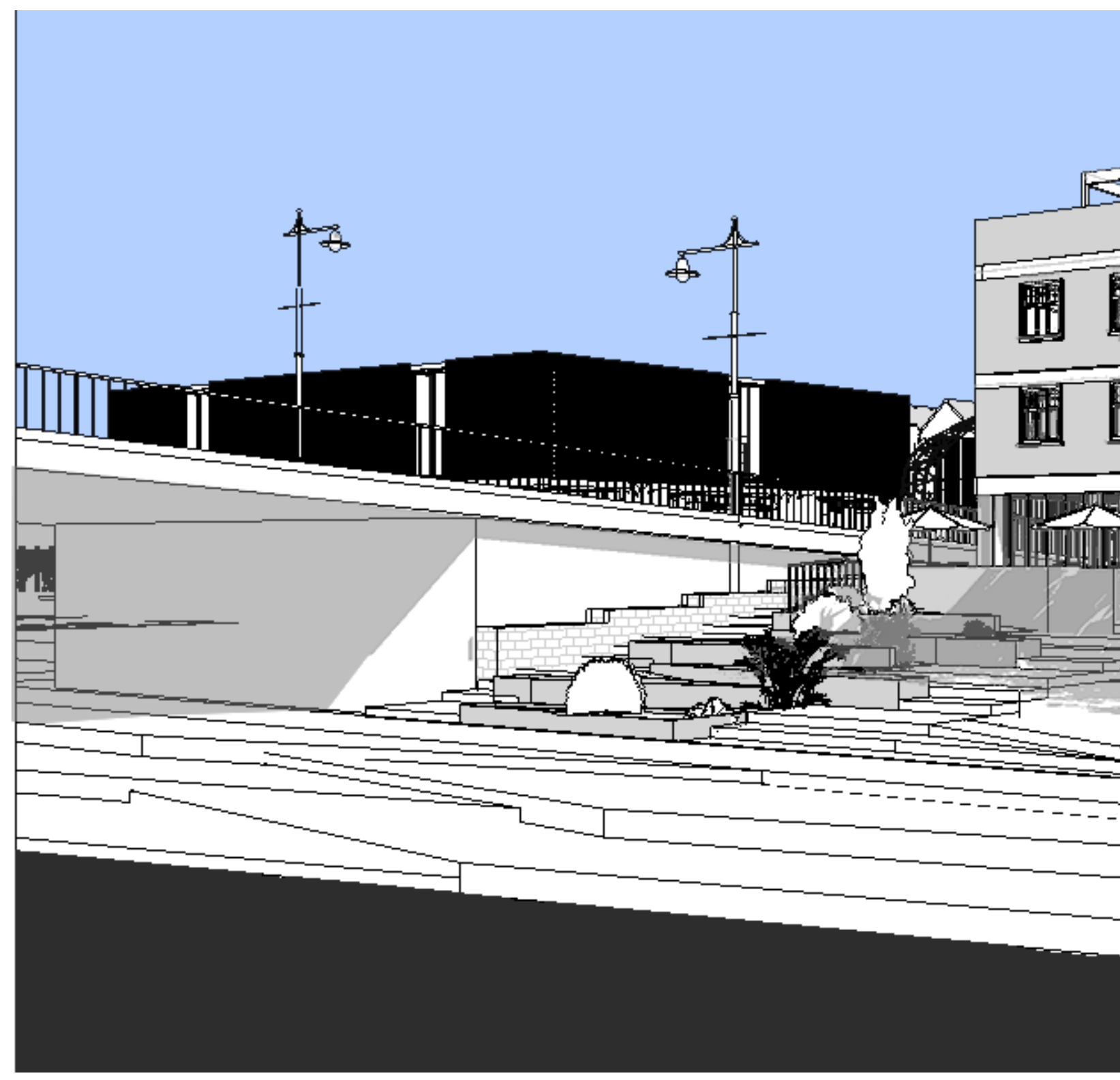

Fig. 9.44: View from river looking towards the cross-roads. 


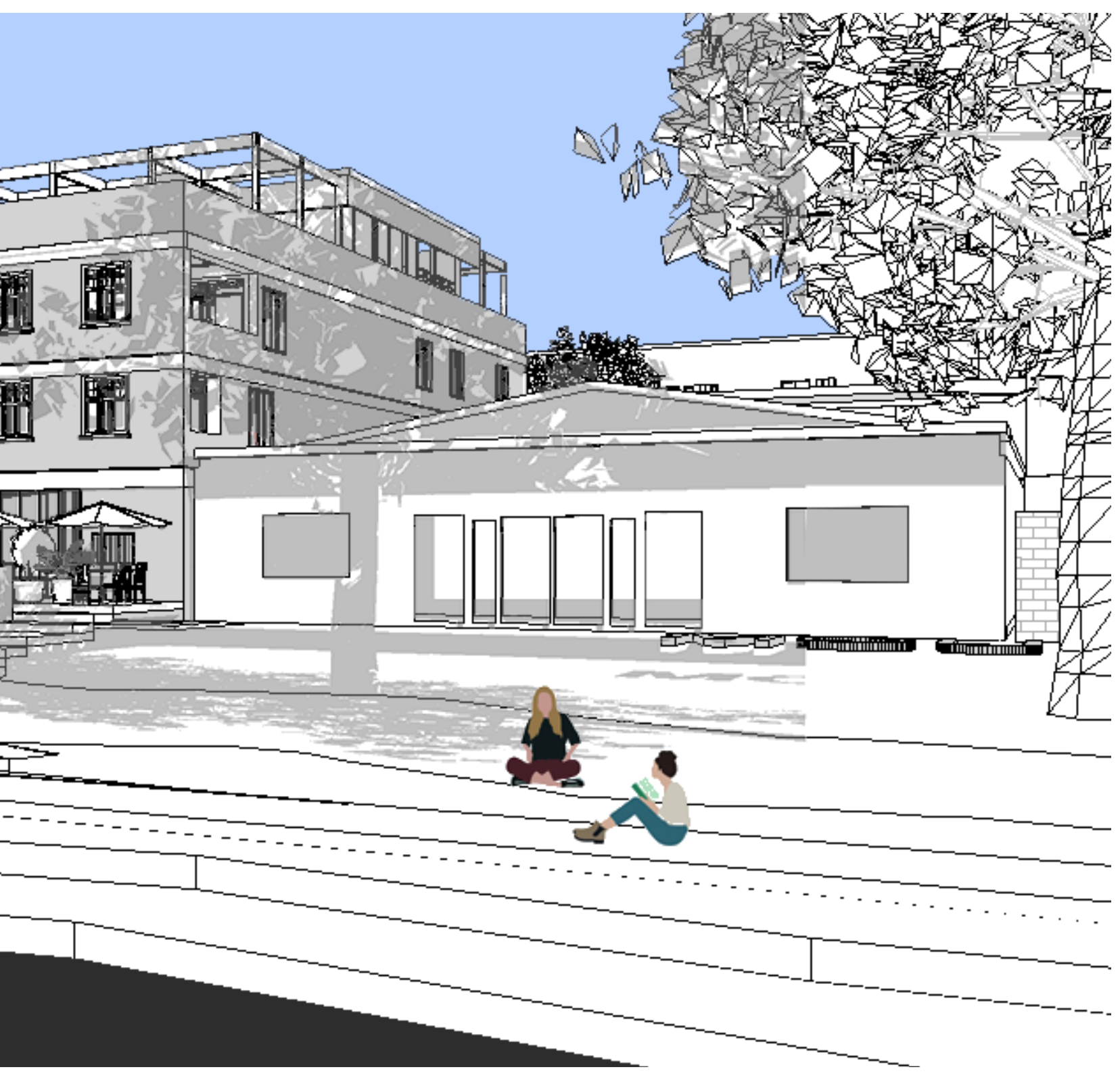


$$
\text { i․ }
$$

1

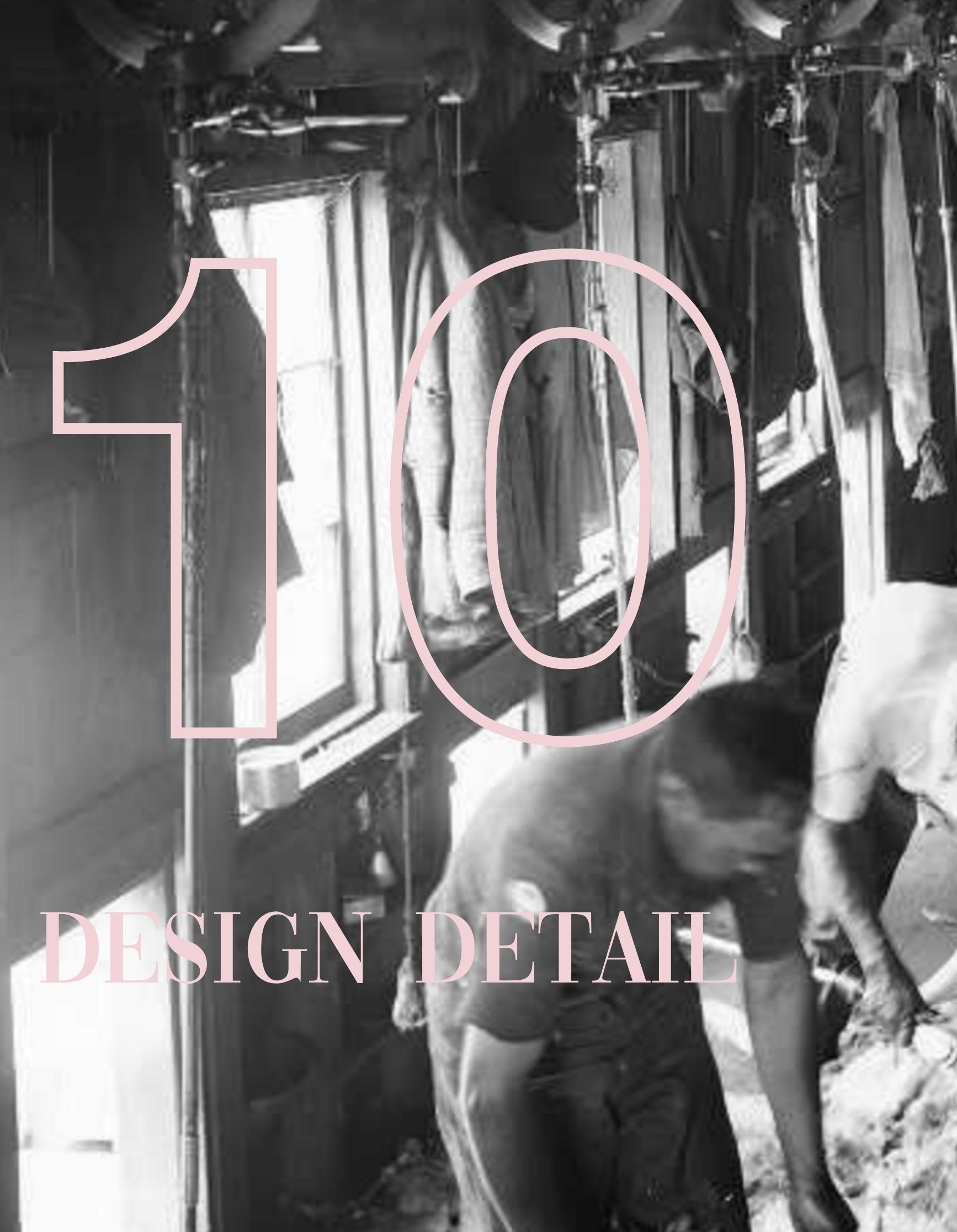





\subsection{COLUMN DESIGN}

Many adaptive reuse projects require earthquake strengthening, which might not receive much careful architectural thought. As illustrated in chapter 7.1 Whanganui's heritage is largely effected by the need to earthquake strengthen.

In many cases, engineers design the structural system, and due to an emphasis on lower costs, the strengthening often results in large steel framing. Hence the use within the design chapter with standard universal columns. These can override other design elements within the space and do not enhance the building's identity or heritage detail, which were aimed to revitalise the space.

It is clear that the prominent use of universal columns is due to the efficient properties of steel compared to that of wood or masonry. This allows for a slim profile that does not impact the footprint too dramatically.
An unique architecturally designed column, which enhances the connection to place, could strengthen the overall adaptive reuse scheme designed for the cross-roads of Whanganui. The role of the structure for strengthening old buildings can be seen as expanding upon theories relating to the process of making, The detailing in that process can enhance the connection to place. The book 'Frampton Studies in Tectonic Culture' details these processes of making and detailing. The column offers an opportunity to make a statement of the identity of Whanganui (Frampton, 2001)

Looking into the identity of Whanganui through the design of the column intensifies the relationship between the city's main street and the river. This will allow these columns to be exclusive and symbolic.

While this conceptual column will be larger than a standard universal column, it has representational value and will act as a feature to the design rather than just a necessity. 
There are many aspects which make flax is also woven as it is seen as a metaphor Whanganui's river special, as acknowledge in for family bonds and human relationships. Chapter 5.6. These include the river's own Many New Zealanders associate it with their legal status, it is the third longest river in homelands.

New Zealand, but also the longest navigable river in New Zealand (Change-makerThe Whanganui River, n.d.). It was once an important communication route to the central North Island and during the 20th century the river was one of New Zealand top tourist attractions with its rugged beauty and Maori villages dotted along its banks. For the local Maori it has both special and spiritual importance (Hindmarsh, n.d.).

The idea of using rope to symbolise the connection between the river and the township came about as 'taura here' binding of ropes symbolises urban kinship used to help retain identity and link people back to their tribal homelands.(Maori Dictionary)

The Maori use flax to make rope as it was readily accessible and perceived as one of the strongest natural fibers in the world. The 


\subsection{EARTHQUAKE STRENGTHENING IN NEW ZEALAND}

Today, capacity design is now well established in the world's leading seismic design codes, it is where the damage on a structure has hierarchy so when inertia forces exceed the design, the damage is concentrated to less vital sacrificial members. (Charleson, 2008)

In New Zealand capacity design was not incorporated into buildings until the 1970's, therefore a lot of our cities building stock is vulnerable. This has resulted in the need of retrofitting and strengthening our existing buildings. (Charleson, 2008)

Seismic resistant design is intended to achieve two objectives; to protect human lives and limit building damage. Through the main seismic resisting systems of structural walls, cross-braced frames and moment frames buildings designed to reduce the risk of the objectives can be achieved. However, looking into current buildings retrofitting is necessary to reduce the building's vulnerability and improve seismic performance. (Charleson, 2008)
Life-safety issues are foremost and, fortunately, there are various approaches which can save historic buildings both from the devastation caused by earthquakes and from the damage inflicted by well-intentioned but insensitive retrofit procedures. Building owners, managers, consultants, and communities need to be actively involved in preparing documents and readying irreplaceable historic resources from these damages (Wong and Augustus).

Retrofitting existing buildings is most often driven by structural engineers and economic concerns rather than architects. New knowledge on seismic strengthening to existing buildings is introduced continually leading to improvements.(Charleson, 2008) 
Utilising the capabilities of the existing structure minimises intervention which is a key to the success of retrofits. Building weight should always try to be reduced as less weight means less seismic force. Reinforcement systems should be in the same style as the existing building and need to be tied and structurally connected to each other. (Charleson, 2008)

The main seismic design approaches for adaptive reuse include upgrading diaphragms, shear walls, braced frames, moment frames and base isolation (Charleson, 2008). New diaphragms can be constructed above or below existing floors or ceilings. Adding concrete shear walls is by far the best seismic retrofit although steel braced frames are most common and cost effective. Steel braced frames also have less impact upon views and intrusion of space. Seismic base isolation is the most severe intervention. Although they are best for its seismic performance in terms of mitigating seismic damage.

(Charleson, 2008)
For greater architectural sensitivity both technical strengthening requirements and architectural conservation need to be balanced. Wong and Augustus recommend using three principles to protect the buildings fabric:

- Historic materials preserved and retained.

- New seismic systems weather exposed or hidden should respect character and integrity as well as being compatible.

- Seismic work should be 'reversible' consequently to allow for future use of improved systems.

(Wong and Augustus)

Columns can be used to carry the gravity load of the building. They will need to have strong connections and typically spaced between 3-5 metres. Wrapping the existing columns with steel casing can create column confinement, bending and shear strength as well as ductility. (Charleson, 2008) 


\subsection{THE ORIGIN OF ANCIENT GREEK COLUMNS GOTTFRIED SEMPER \\ 10.4 THE THEORY OF}

In the past, other civilisations have used the architectural columns to convey symbolic meaning. In many ancient cultures, columns were initially wooden pillars which eventually evolved into the column (Millwork, 2013). Ancient Greek columns are generally tall, symmetrical, balanced, have intricate detail and harmony (Encyclopaedia Britannica, 2016). The recognisable feature is the grooves in the columns known as fluting which gives the feeling of depth and balance.

There are three types of Greek columns called orders, Doric, Ionic and Corinthian. Doric are the most simple type which is the thickest of the Greek style and taper with little to no decoration at the base with simple capital at the top. The ionic column is thinner than the Doric and has a base with the capital decorated with scrolls on each side. Lastly the Corinthian is the most decorative, the capital is decorated with scrolls and leaves of the acanthus plant (Encyclopaedia Britannica, 2016).
Gottfried Semper's theory has been used to better understand the methods of basic building construction of traditional structures.

Gottfried Semper (1803 - 1879) an architect and writer on art and also known as a principal practitioner of the Neo-Renaissance style in Germany. In Semper's influential writings he expressed interpretation of techniques as a source of style, while also proposing colour in decorative arts and architecture.(Gottfried Semper | German architect and writer, n.d.)

In 'Frampton Studies in Tectonic Culture' Semper's general theory of architecture is discussed (Frampton, 2001). Semper considers what assembles and systems are universal in all indigenous primitive structures. It is a theory of which functionalism is a prerequisite to intentionality while also being archaeologically driven. (Frampton, 2001) His theory of 'making' is what has been extracted from the Frampton's studies.

'Semper maintained that the earliest basic 
structural artefact was the knot, from which follows the primary nomadic building culture of the tent and its textile fabric.

( Peter Blake, The Master Builders (New York: Knopf, 1960), p207.)

Semper was fully aware of knot and joint and how both words are connected through binding. He characterised the knot as "the oldest tectonic, cosmogonic symbol". His emphasis on the joint between the base of the building and its tectonic frame curating the transitions are the very essence of architecture. (Frampton, 2001)

In the writings on 'The four elements of architecture' Semper assigned certain tectonic crafts to each of the elements:

- Textiles applied to the art of enclosure (side walls and roof)

- Carpentry to the basic structural frame

- Masonry to the earthwork

- Metallurgy and ceramics to the hearth (Frampton, 2001)

Having an understanding of the traditional making of structures through the use of the knot at the joint gave the idea of binding a column with a beam. In New Zealand's architectural history, the Maori used woven flax to bind the two structural elements.

This concept brings cultural identity into the adaptive reuse project.

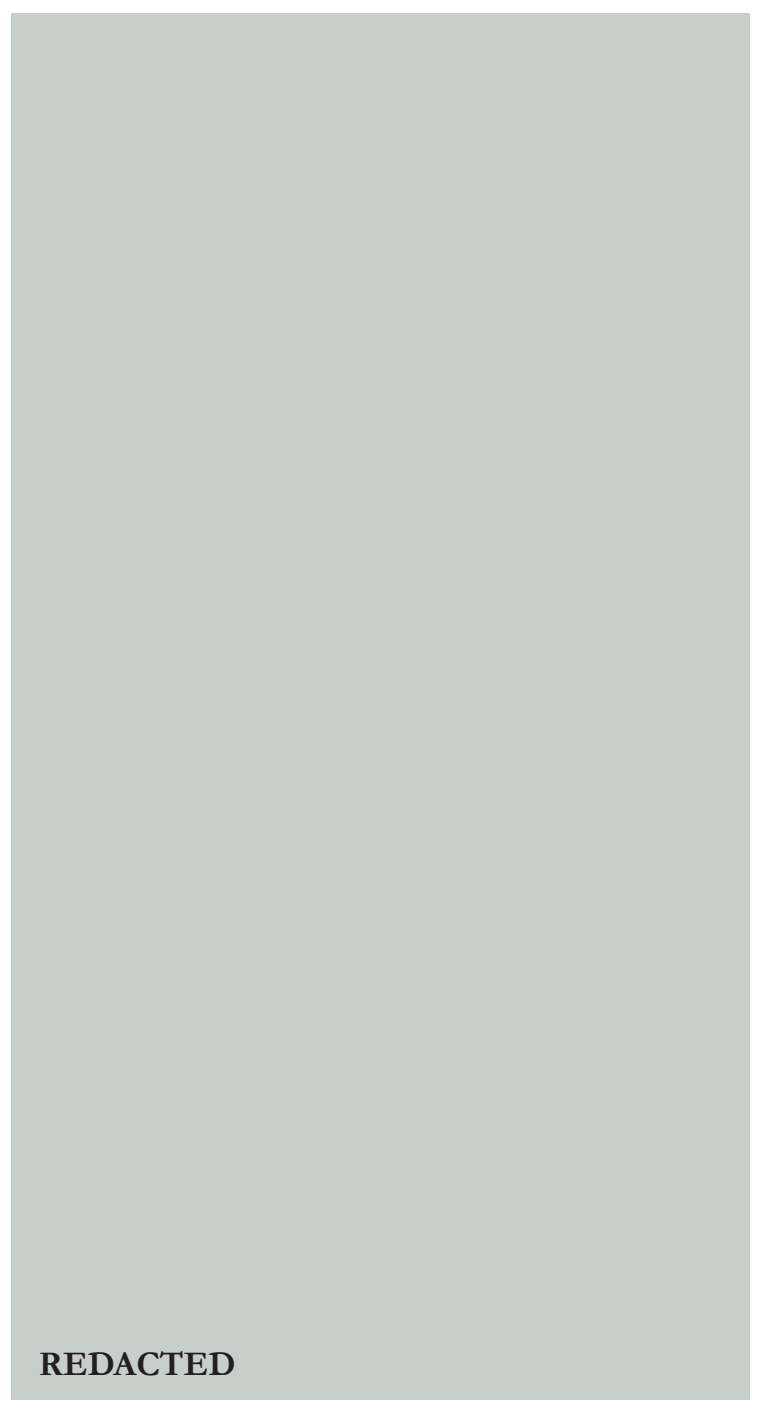

Fig. 10.02: Gottfried Semper. Primitive Hut. 1851. 


\subsection{COLUMN DESIGN CONCEPTS}

\author{
Evaluation Criteria
}

Based on the reviewed material it was possible to formulate the following key design principles. These allow the analysis of physical models to easily form and determine satisfactory outcomes.

- Strengthening capabilities- its essential for the column to carry the gravitational load as well as resist seismic forces in both directions and torsion.

- Materiality - As the column will be used in a heritage context materiality is crucial for the design to fit the existing integrity of the building.

- Design Complexity

- Beauty - The beauty relates to the reasoning behind why the column will be architecturally designed, it needs to be beautiful.

- Functionality - The column needs to be designed to be functional within the space.
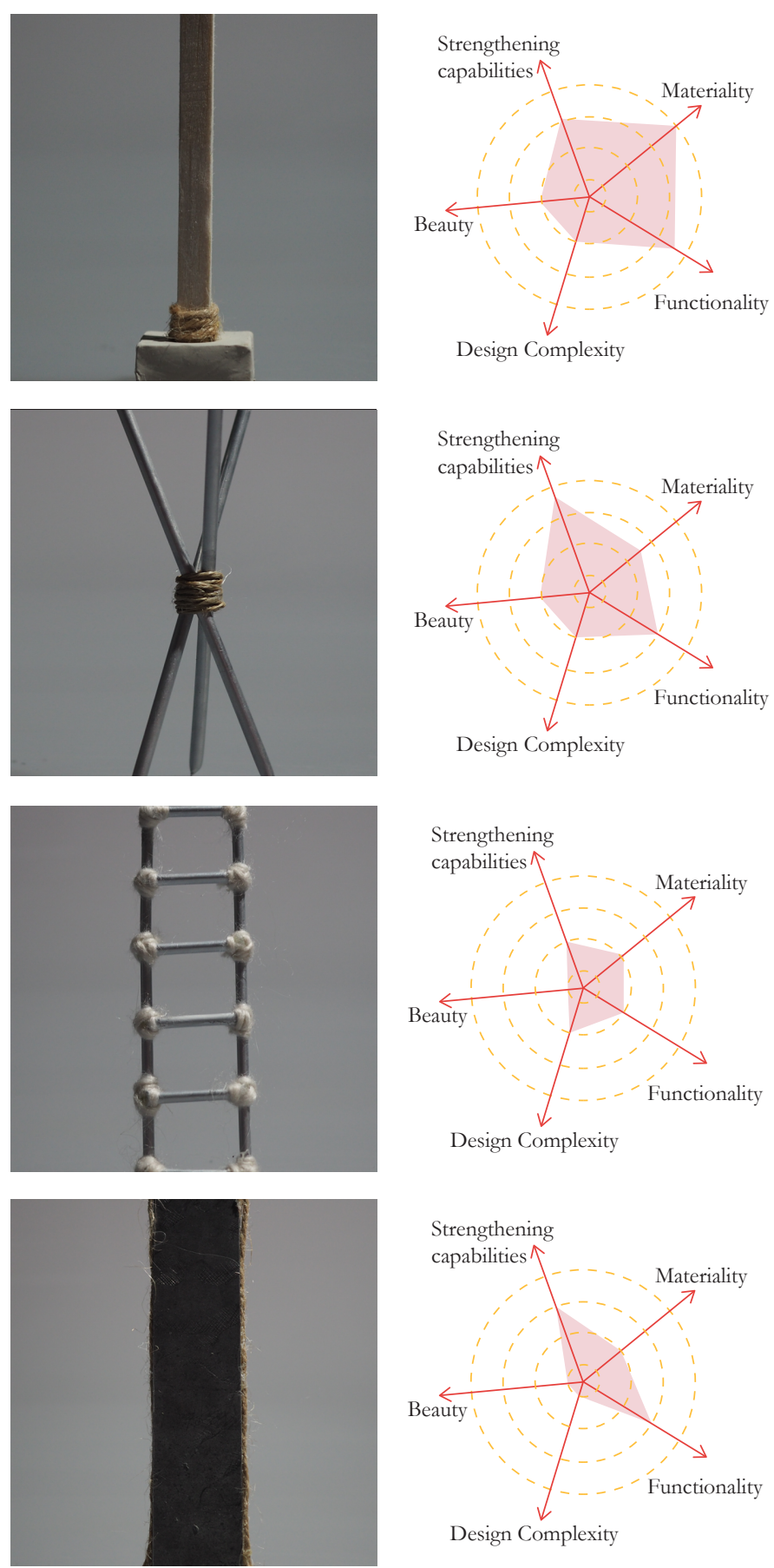

Fig.10.03-Fig. 10.14 Concept series one of Columns with evaluation criteria. 

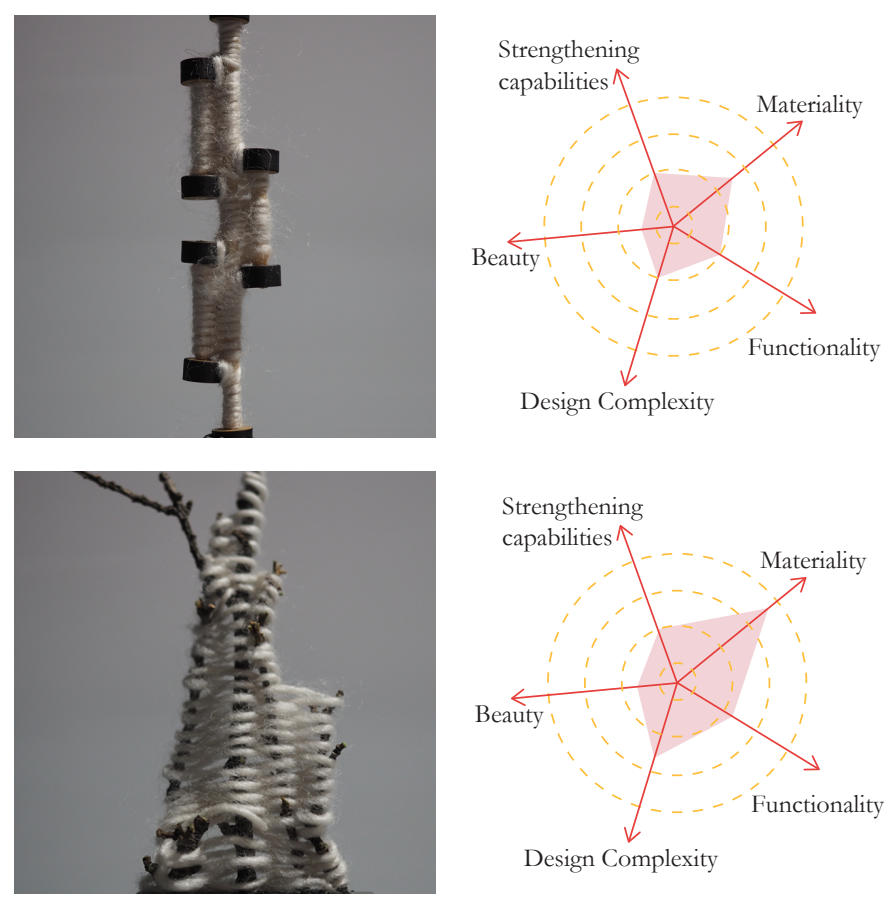

Design Complexity
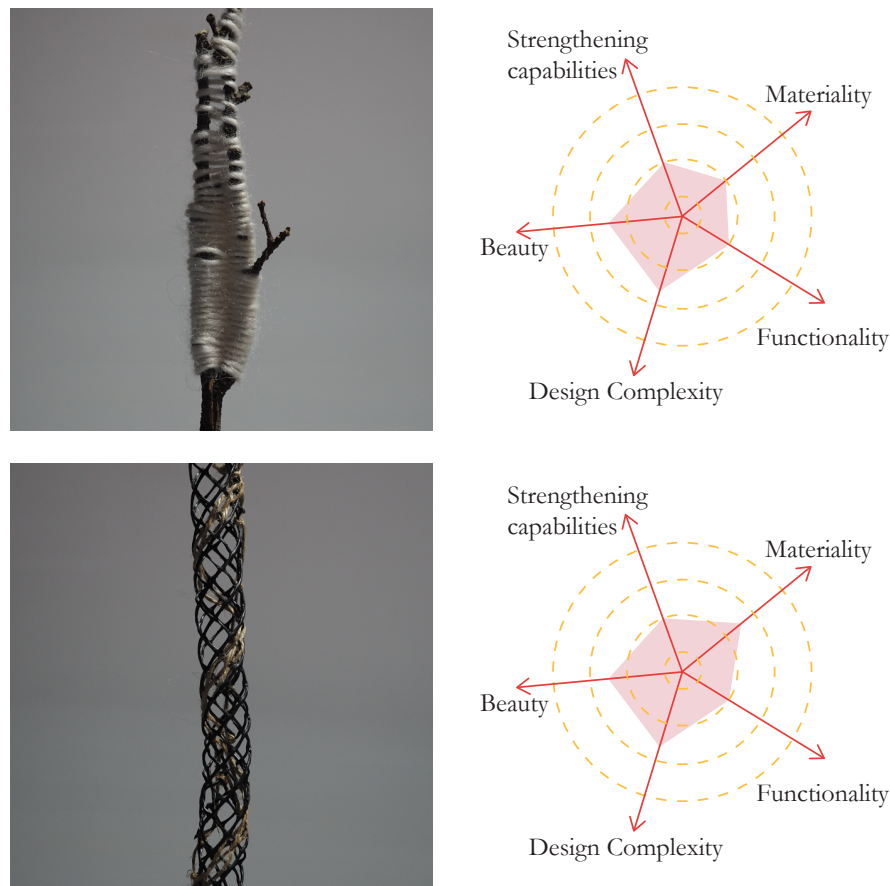

Design Complexity
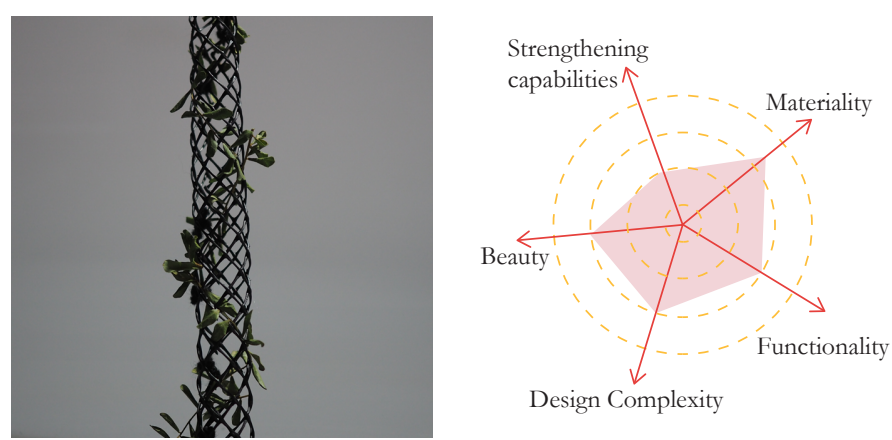

Design Complexity
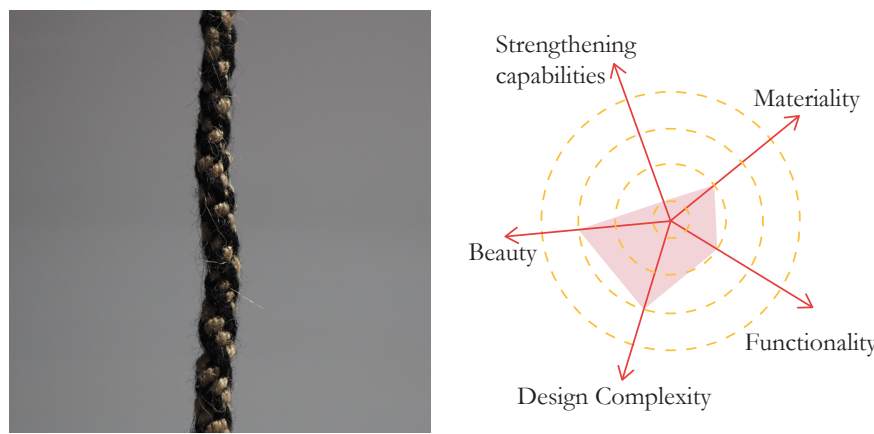

Design Complexity
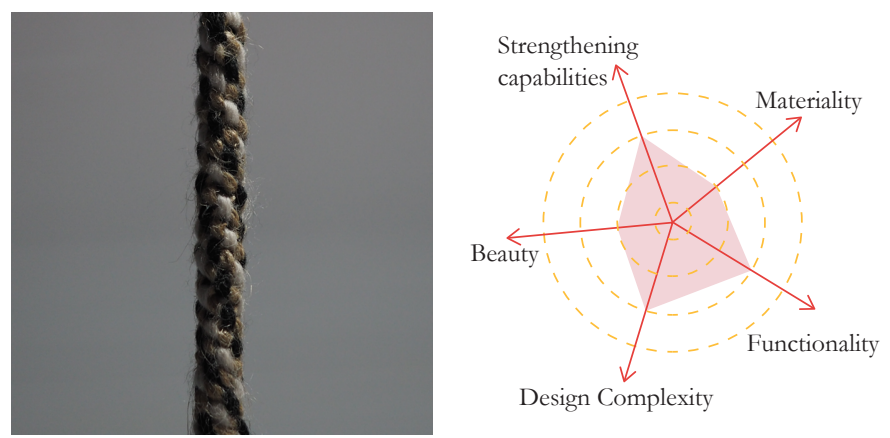

Design Complexity

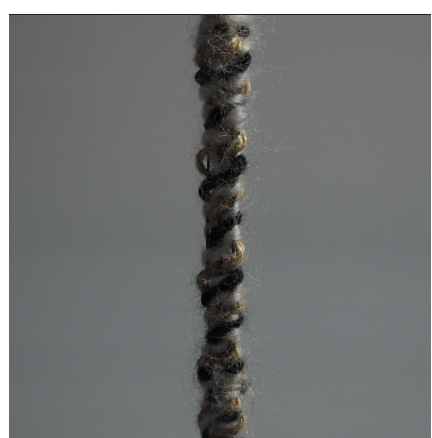

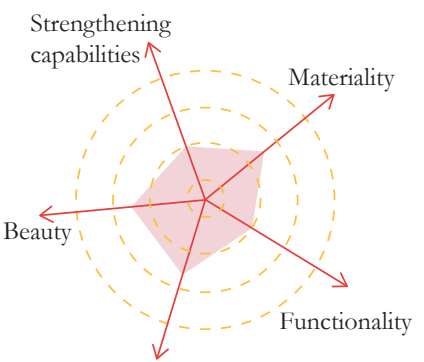

Design Complexity 
With these key principles in mind, a series of design explorations were undertaken. The models in figures 10.03 - 10.43 represent analysis of patterns used to enhance details and all show tensional qualities. The models which represented structural capabilities often had a hidden material creating the strength. This point is taken back to the point of not wanting to create 'fake' architecture. The conclusion from this series was the subsequent work should include a structural material to the design.

The unreinforced masonry building needs to support the additional gravity loads created through the adaptive reuse program, it also needs to support the seismic forces in both directions and torsion. The structurally designed system additionally needs to be tied and connected to the existing buildings structure.

Wood was chosen as the additional material due to its natural appearance as well as it being a local material. The natural material will also work coherently with the existing building and retain some of the original aesthetic qualities the building had initially.
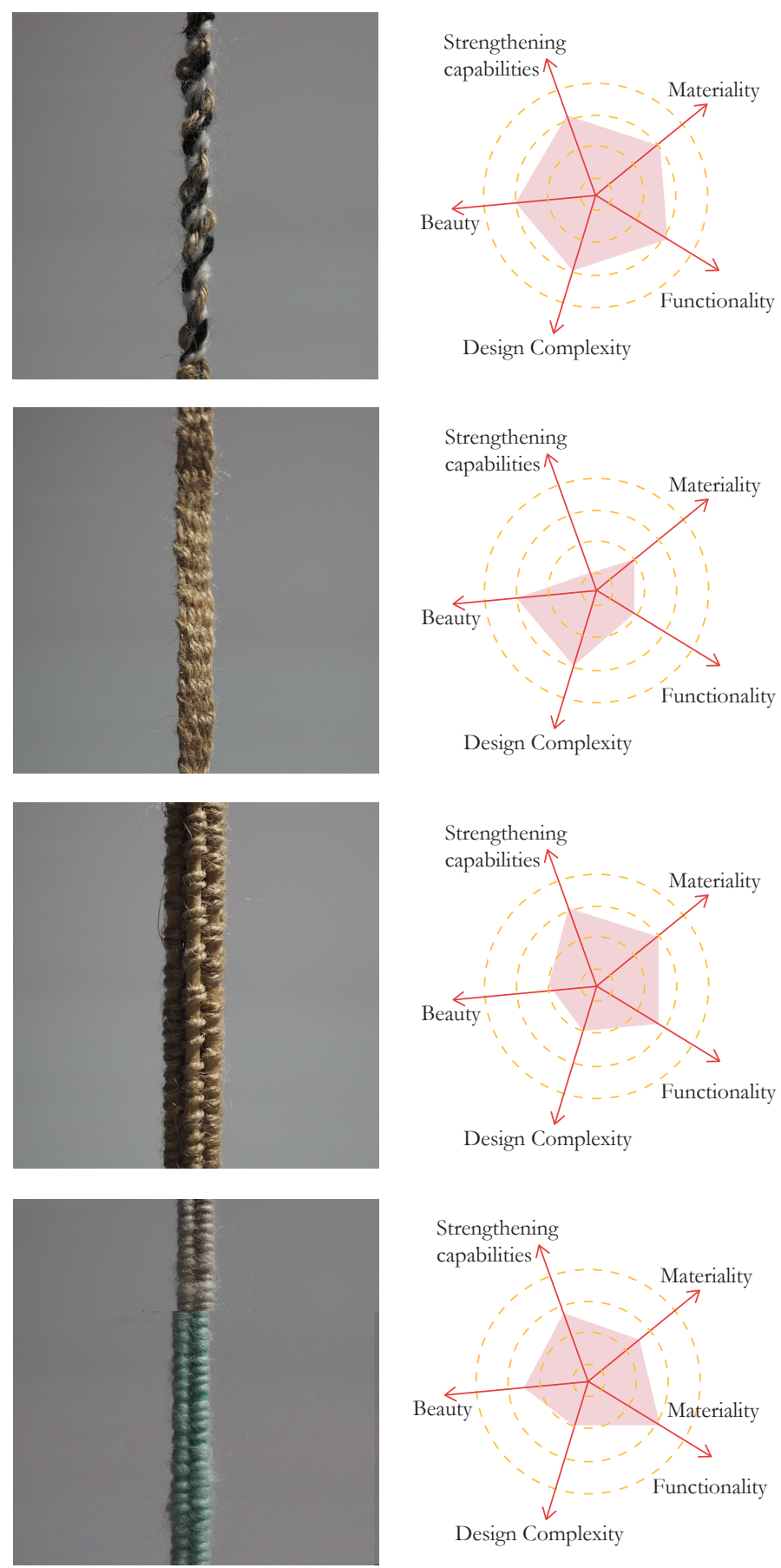

Fig.10.15 - Fig. 10.27 Concept series two of columns with evaluation criteria. 

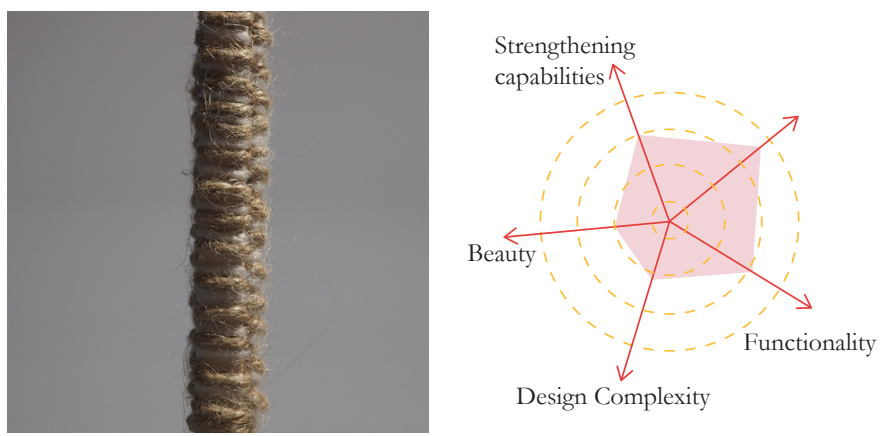

Design Complexity
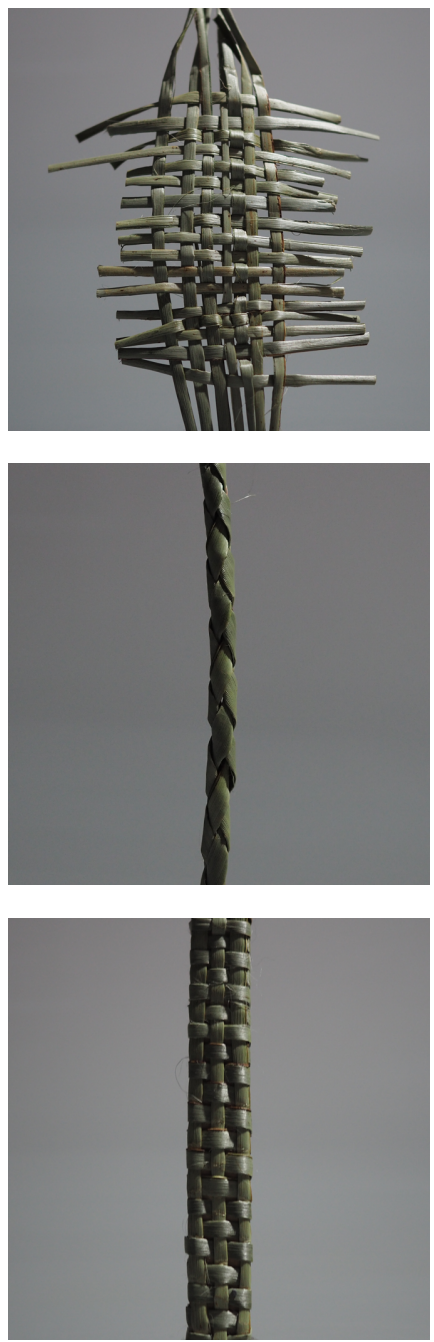

Design Complexity

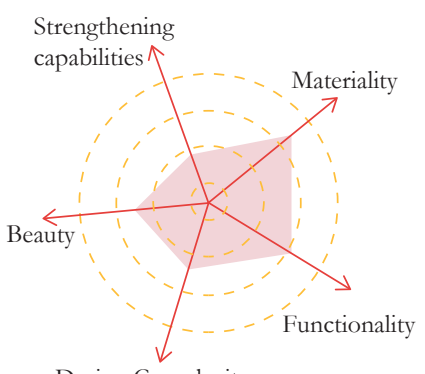

Design Complexity

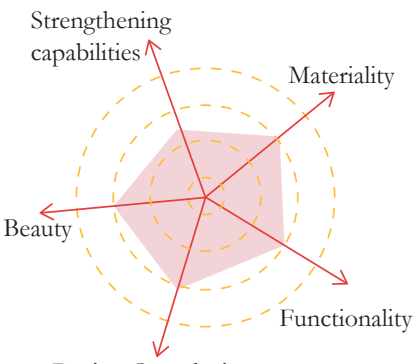

Design Complexity
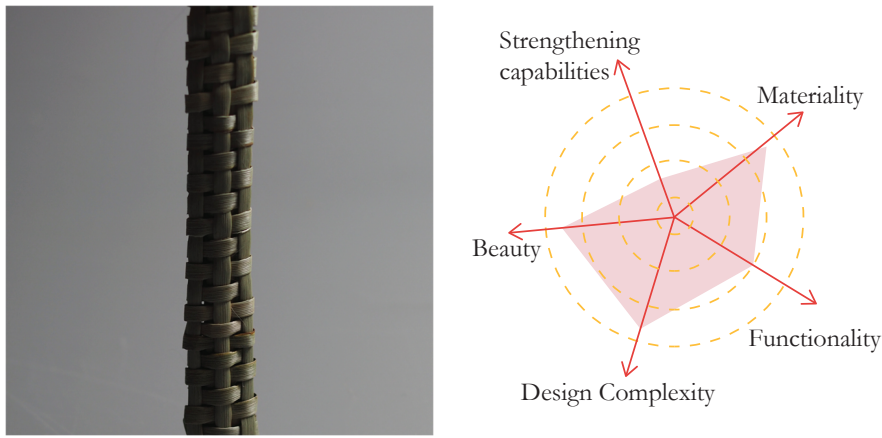

Design Complexity
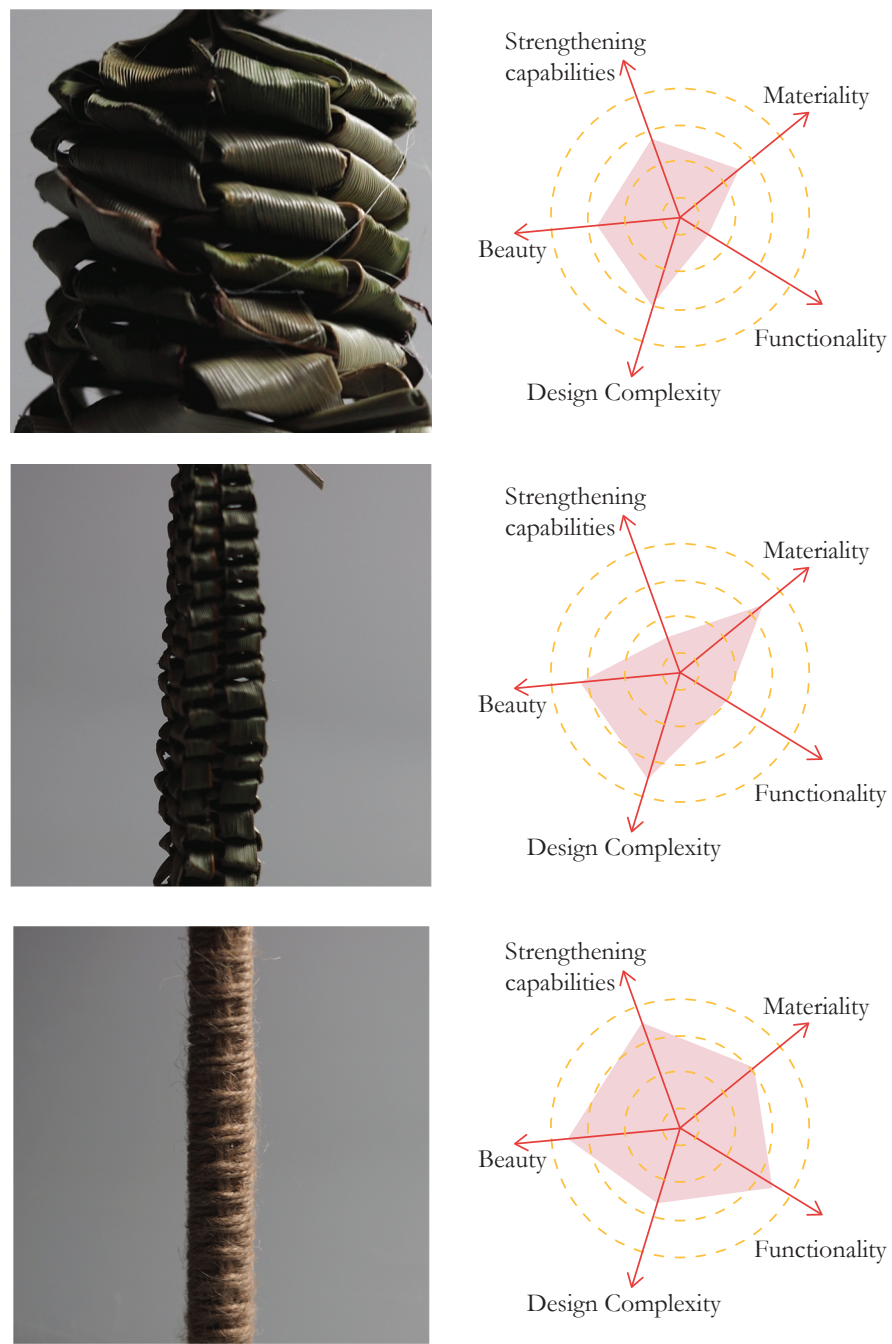

Design Complexity 
This pays respect to its character.

Using the 'making' aspect to join and combine the connection between the column and beam is the step forward in this design. It will then accentuate the detail creating strong connections to both the structure and buildings identity.

The next design development explored the use of string imitating rope and weaving as a way to hold the joint together
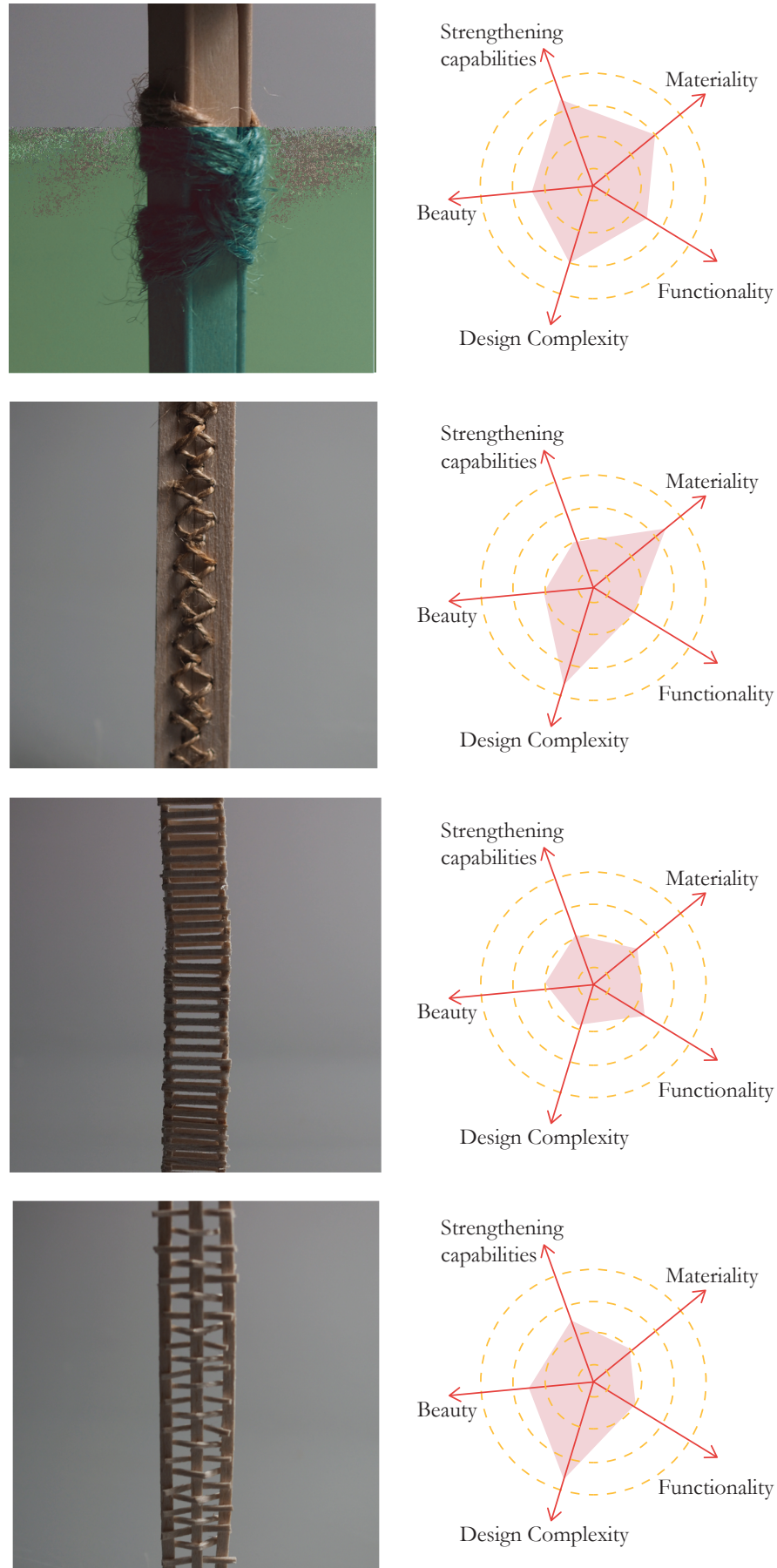

Fig. 10.16 - Fig. 10.35 Concept series three of weaving / binding with evaluation criteria. 

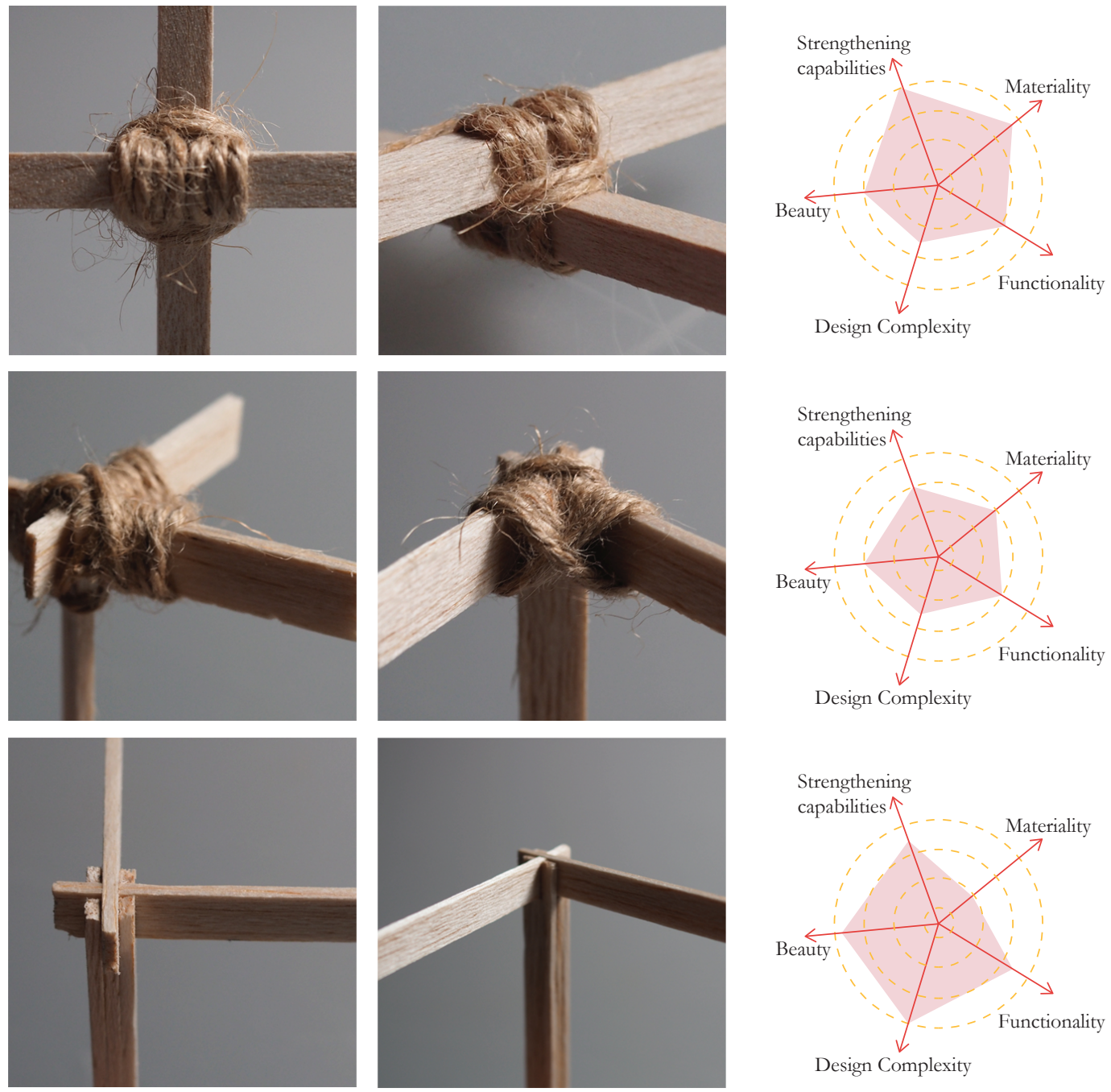

Design Complexity
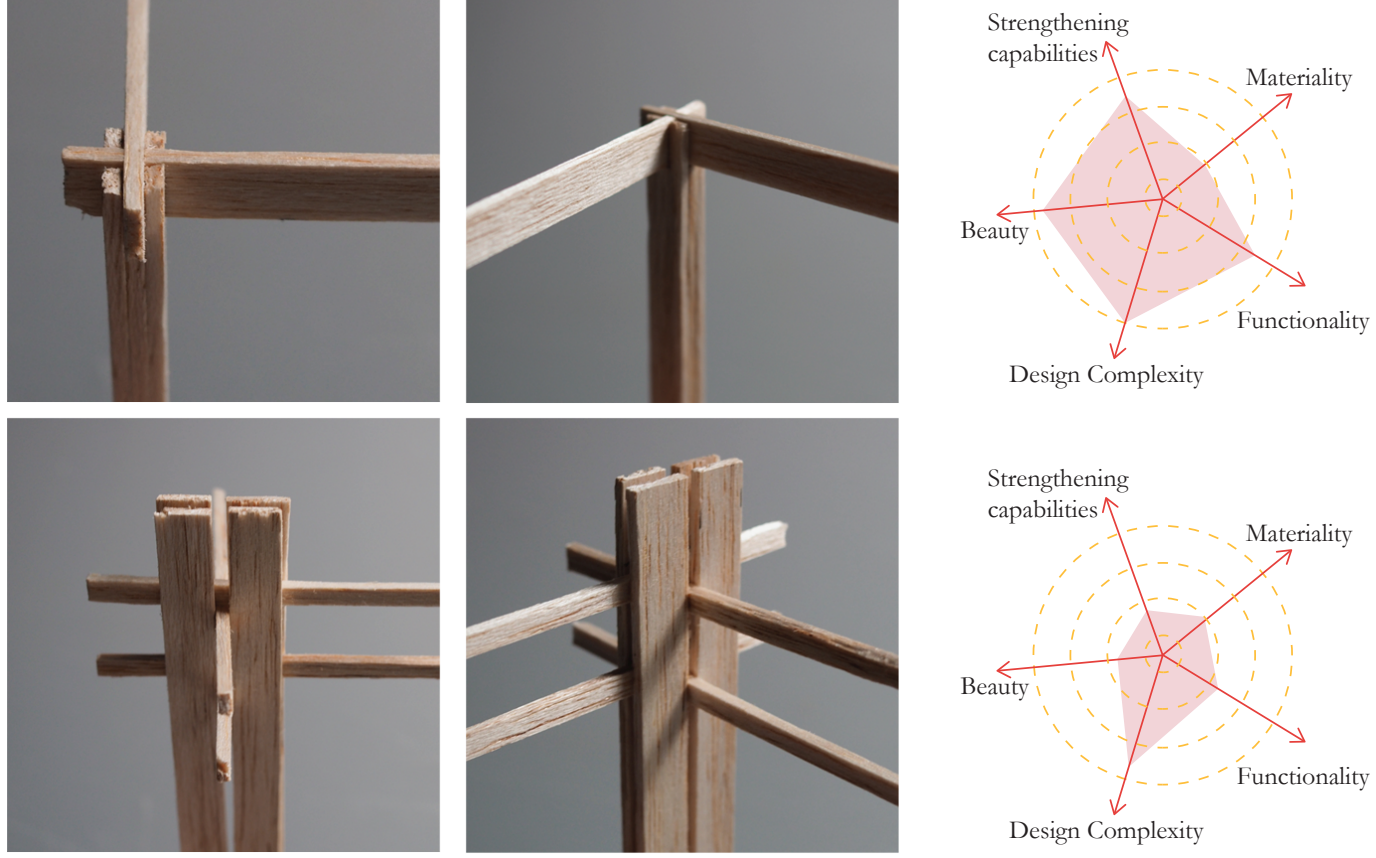

Design Complexity

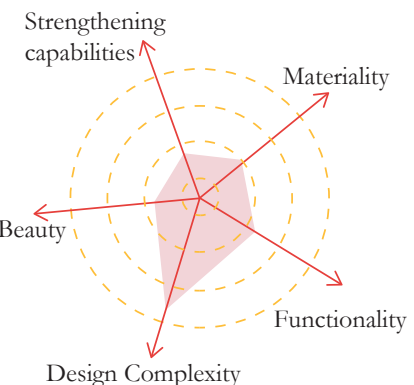

Design Complexity 

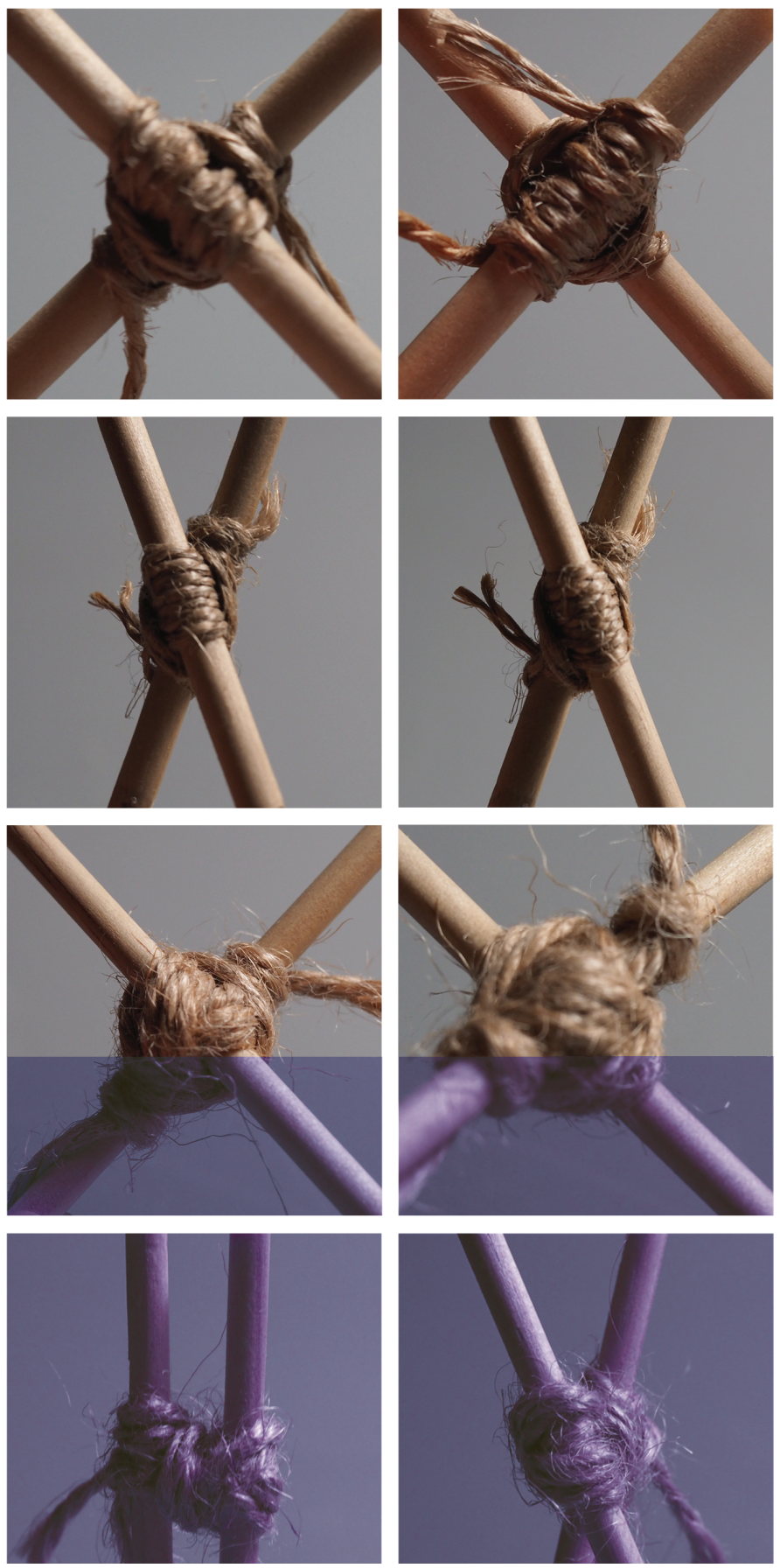

Fig.10.36-Fig.10.39 Concept series four of knotting with evaluation criteria. 

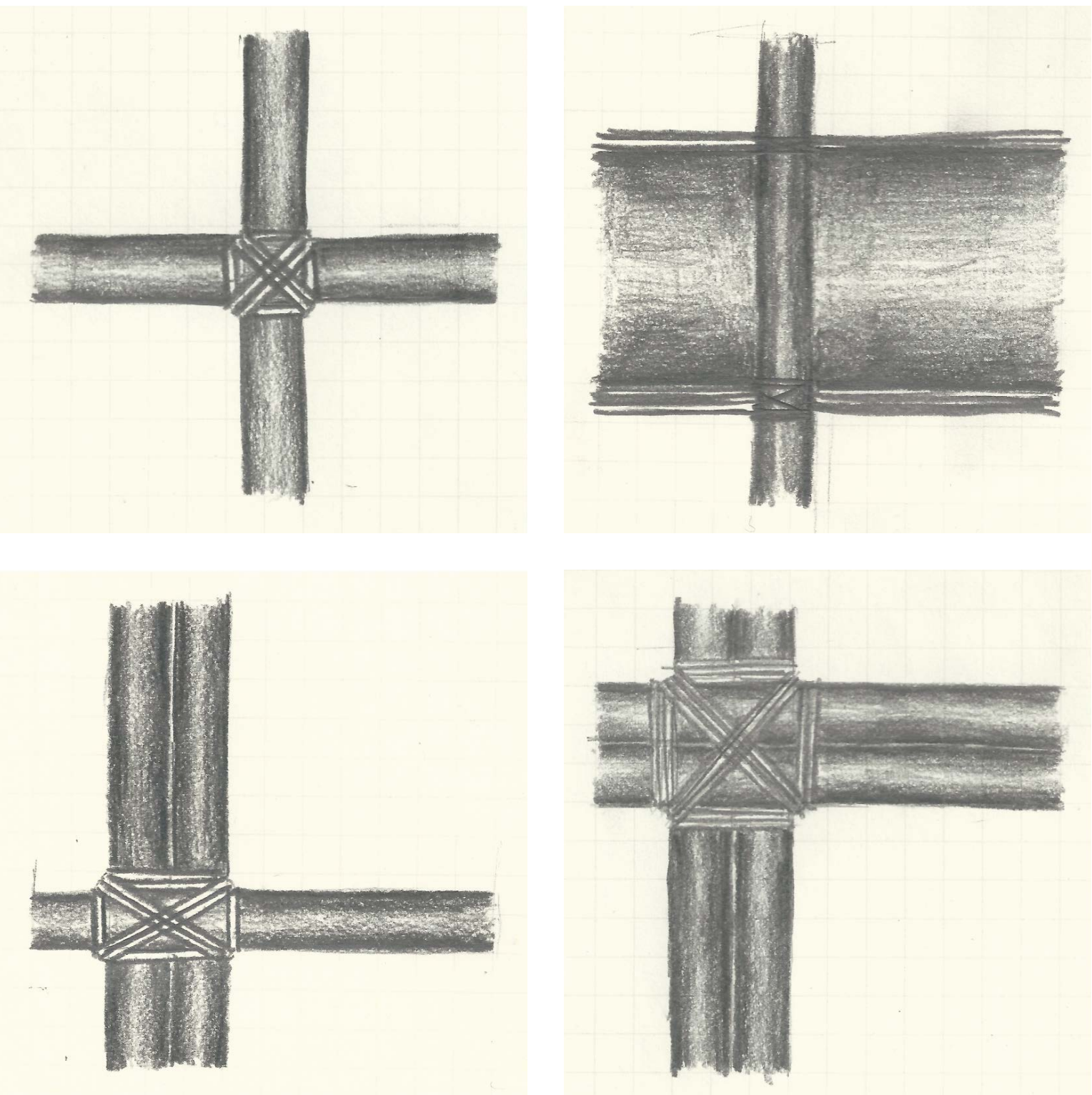

Fig. 10.40 - Fig 10.43 Woven sketches of twine ans wood. 


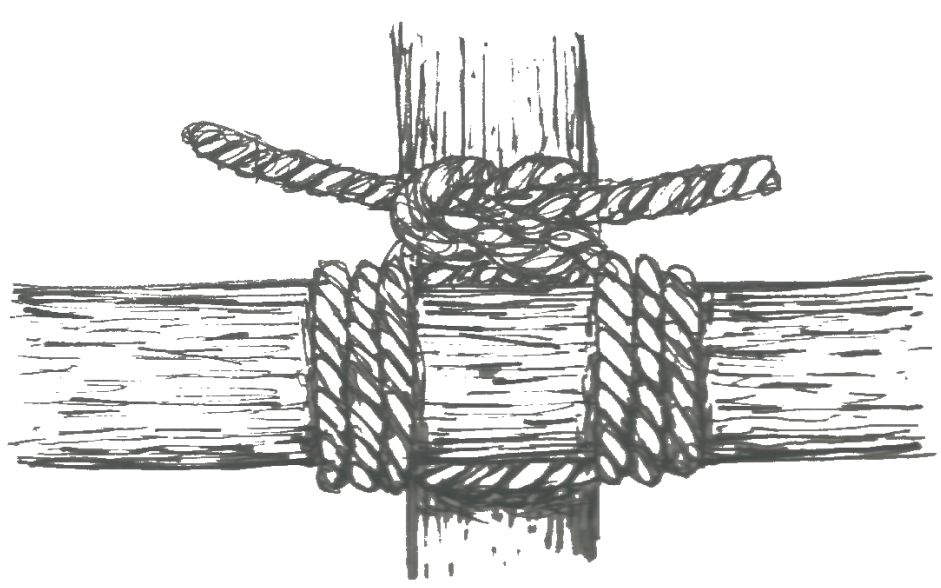

Fig. 10.44 Sketch of binding of wood with rope at intersection.

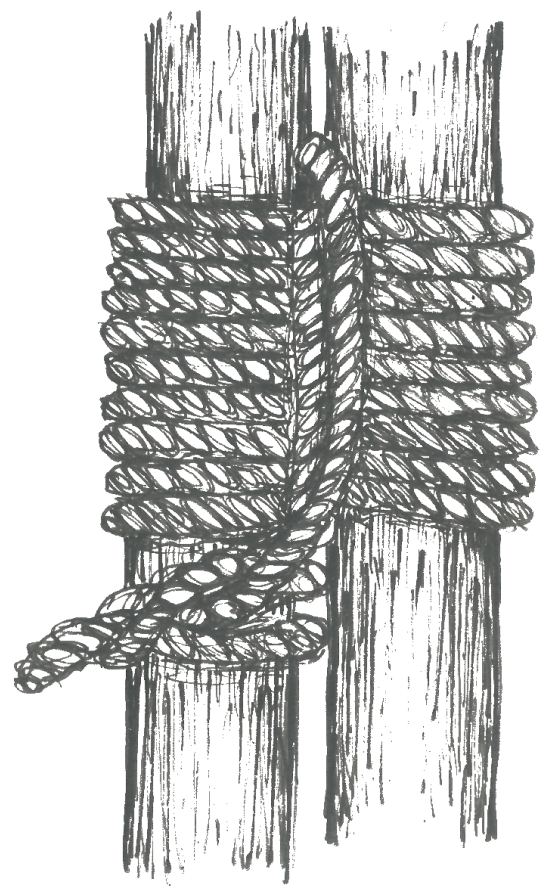

Fig. 10.45 Sketch of binding of two parallel pieces of wood.

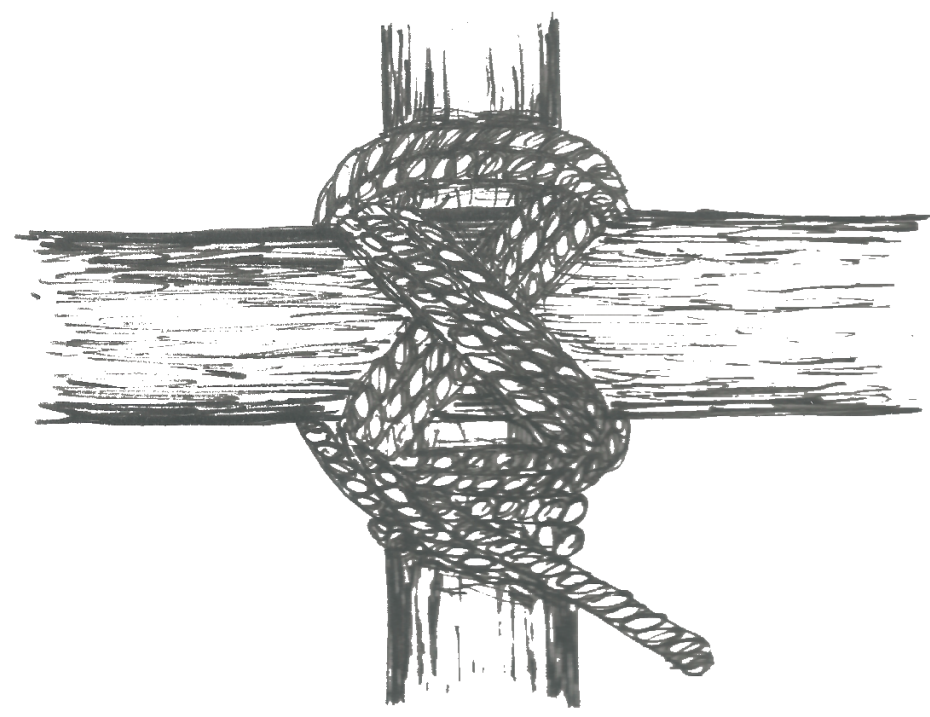

Fig. 10.46 Diagonal connection of binding between wood and rope. 


\section{CONCLUSIONS}

Allowing a more in depth detail of design grants meaning and identity to be a main driver of the design.

The small design change of materiality and construction introduced a lot more cultural significance into the building's design. While using timber makes the addition of earthquake strengthening less intrusive of the space.

Using the rope allowed the design to have multiple linkages including back to Semper and his theories of 'making'. As well as the cultural traditions of Maori and their use of woven flax as a way of binding structures together.

Through more design exploration it would be possible to test these ideas more for the possible impact on the totality of the design.

Overall, the introduction of a column design, is greatly beneficial to this design research. It enhances the connection to Whanganui's heritage through a crucial and functional element. This is particularly successful as it replaces the standard known commodity of steel framing and replaces it with an uniquely designed feature.

While these columns will need further refining and specific engineering, this provides a basis for this new column to be built upon. 


$$
\text { โ1 }
$$




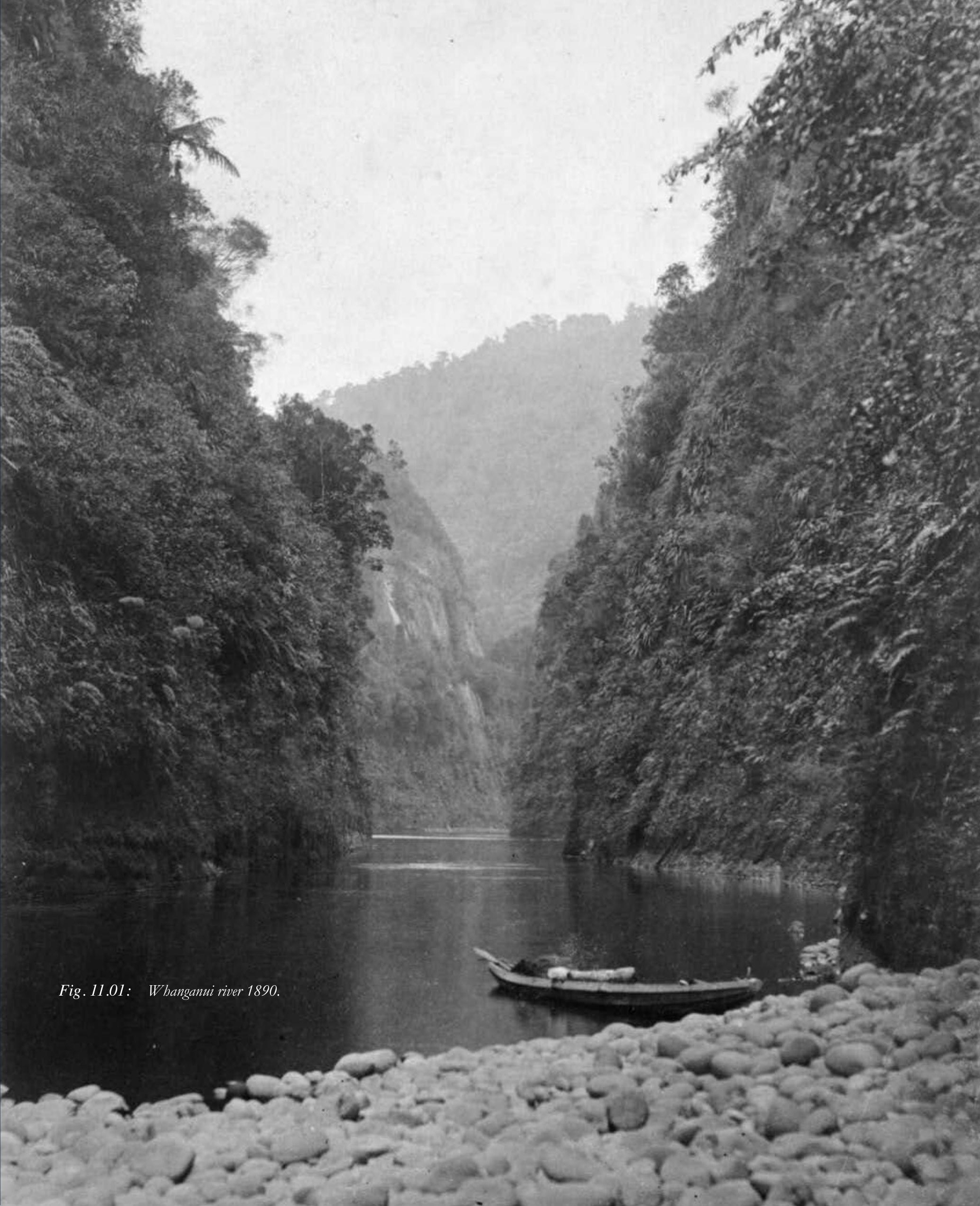




\subsection{CONCLUSIONS}

The concept of adaptive reuse has been widely recognised and researched around the world, although little thought has gone into its relationship with enhancing connection to place.

In New Zealand, Adaptive reuse is more commonly known as a retrofit of an heritage building. Most of these projects having had no thought of character integrity. There is limited New Zealand literature based on this research, although internationally it is much more widely identified. This is due to the heritage architecture in New Zealand being only around 100 years old compared with European buildings which have a significantly older history.

This research shows how the built heritage can enhance connection to place through well thought out design. Having a contextual understanding of the chosen buildings, in terms of heritage, history, environment as well as its needs and opportunities, were crucial to having a successful adaptive reuse project. Whanganui created a great case study for other provincial towns of New Zealand due to its rich variety of architectural heritage.

The research began with a literature review which created a clear picture of Adaptive reuse and what it is today. The design led research was achieved through basing the knowledge gain and design decisions firmly within the research question, aims and objective. The use of drawing was beneficial to the growth of personal understanding of the context. It was a successful tool to see the setting more fully.

One of the main challenges with an adaptive reuse project is that in order to have a succinct and strong design, it is imperative to have a comprehensive understanding of a range of relevant contextual information. This inherent characteristic of the adaptive reuse has influenced this project to respond with a set of important contextual analyses. This in depth review of the context ended up limiting the design of the buildings. 


\subsection{LIMITATIONS}

The initial focus of this project was on an urban re-visualization and activation, which meant that the design work commenced with the work on four buildings, however the scope was too large. The choice to reduce the scope to one building with more detailed design would be beneficial. Narrowing the scope earlier in the project would have lead to a deeper insight on specific areas of the design. However, the chosen path did provide benefits of developing work and insights at a broader context which developments could be had at an urban context.

Cost was not integrated into the thesis scope, although it was an underlying factor due to justification that adaptive reuse is more beneficial than a new build. This thesis promotes the idea that adaptive reuse is more cost effective due to being more sustainable over demolition and a new build. However, most importantly the process of adaptive reuse of our built heritage, if done well, creates better connection to place.
The chosen case studies gave an overall understanding of adaptive reuse around the world. Using international case studies was an intentional decision as there is much more variety and a wider understanding of this particular type of design. This is due to the depth of knowledge built upon through years of adaptive reuse, which New Zealand is yet to achieve. Although this was a strategic decisions, a stronger grounding in New Zealand context could have offered some additional opportunities. Looking at local attempts of adaptive reuse would have been very beneficial even if they were not successful. This would have allowed for an analysis on localised issues that this design could have focused in achieving. 


\subsection{FURTHER RESEARCH}

Upon completing the design led thesis, there were multiple areas which could have been done in a different way. There are also many avenues in which the research can be pushed further if the study were to be ongoing.

A further study, or a series of studies, could be undertaken on the adaptive reuse specifically in New Zealand. The issue highlighted here is that smaller provincial towns have different needs than the large centres. Although heritage architecture can still play an important role in their urban activation. Comparative investigations of a series of provincial towns could have led to identifying some very relevant patterns.

Engagement with the community could have created a richer design. This decision to not consult was due to limited time available under a 12 month research time frame. Enabling community workshops allows the council or building owners to express their thoughts and critique on the design. This input at different stages in the design would have been very valuable for decision making. Information obtained in this way would have been very site specific less beneficial to use in other provincial cities around New Zealand. However, this process could have been repeated for each individual town. Having the insight of public opinion could have gathered more knowledge in addition to the literature. These elements combined could have enhanced the research aimed to bring something new to New Zealand and Whanganui.

The literature gained a perspective of what adaptive reuse is today, while using international cases studies gave international influence. Considering the reasoning of why New Zealand has not faced a high amount of adaptive reuse today could have created a better argument for choosing adaptive reuse in New Zealand's future.

The design development was a step by step process which was a time consuming exercise. Due to time constraints in the research, the outcome was only one design approach. 
If more time was available, multiple design outcomes using the design strategy could have been achieved. This would have given a stronger argument behind the design as refinements could have been made through each iterative concept. A stronger framework to critique the design would allow for a more robust design. This framework would have facilitated a critique and analysis in the conceptual designs to reinforce the research behind it.

This thesis recognises that there is still a large issue surrounding adaptive reuse. This includes the knowledge and the need for earthquake strengthening in New Zealand. This is particularly important in our provincial cities due to the limited access to guidance from heritage specialists.

This thesis pushes the idea of enhancing connection to place through adaptive reuse to revitalise a community. With more research on humans connections to spaces, there could be a shift in perception on adaptive reuse.
Responding to and designing for, human connections will have had another strong effect to many of the design outcomes.

The design of the column initiated the use of adding multiple theory related cultural connections to certain elements of the design. This in particular was through the addition of earthquake strengthening structure that had strong ties to connection to place. Using the design tools gained from chapter 10 , this idea could have been pushed further across other parts of the building. This would have created a more overall cohesive connection to the surrounding context. 


\section{BIBLIOGRAPHY}

Abeling, S., Dizhur, D., \& Ingham, J. (2018). An evaluation of successfully seismically retrofitted URM buildings in New Zealand and their relevance to Australia. Australian Journal of Structural Engineering, 19(3), 234-244.https://doi.org/10.1080/13287982.2018.1491820

"Absolutely incredible" revamp of beritage building | Otago Daily Times Online News. (n.d.). Retrieved January 15, 2020, from https://www.odt.co.nz/news/dunedin/absolutely-incredible-revamp-heritage-building

Adaptive Reuse of the Built Heritage: Concepts and Cases of an Emerging Discipline. (n.d.). CRC Press. Retrieved August 22, 2019, from https:/ / www.crcpress.com/Adaptive-Reuse-of-the-Built-Heritage-Conceptsand-Cases-of-an-Emerging/Plevoets-Cleempoel/p/book/9781138062764

Appleton, E. (2019). DRAFT CITY RIVER STRATEGY FUTURE ASPIRATIONS FOR MELBOURNE'S INNER CITY RIVER. CITY OF MELBOURNE. https://www.melbourne.vic.gov.au/ about-council/committees-meetings/meeting-archive/MeetingAgendaItemAttachments/854/15253/ APR 19\%20FMC2\%20AGENDA \%20ITEM $\% 206.1 \% 20$ size $\% 20$ reduced.pdf

APR19 FMC2 AGENDA ITEM 6.1 size reduced.pdf. (n.d.). Retrieved December 19, 2019, from https:// www.melbourne.vic.gov.au/about-council/committees-meetings/meeting-archive/MeetingAgendaItemAttachments/854/15253/APR19\%20FMC2\%20AGENDA $\% 20$ ITEM $\% 206.1 \% 20$ size $\% 20$ reduced.pdf

architecture in existing fabric - Google Search. (n.d.). Retrieved March 27, 2020, from https:/ /www.google.com/ search?gs ssp=eJzj4tFP1zc0SiqwSCs3MzVg9JJPLErOyCxJTS4pLUpVyMxTSK3ILC7JzEtXSEtMKspMBgBrDhA3\&q=architecture + in + existing + fabric\&oq $=$ architecture + in + existing + fabroc\&aqs $=-$ chrome.1.69i57j46j012.15003j0j7\&sourceid = chrome\&ie $=$ UTF-8

Brown, M., \& Buranakarn, V. (2003). Emergy indices and ratios for sustainable material cycles and recycle options. Resources, Conservation and Recycling, 38, 1-22. https://doi.org/10.1016/S0921-3449(02)00093-9

Bush, S. (2017). Warehouse Home: Industrial Inspiration for Twenty-first-century Living. Thames \& Hudson.

Change-maker-The Whanganui River. (n.d.). Retrieved December 17, 2019, from https://natlib.govt.nz/ he-tohu/learning/social-inquiry-resources/cultural-interaction/cultural-interaction-supporting-activities-and-resources/change-maker-whanganui-river

Charleson, A. (2008). Seismic Design for Architects. Routledge. http://ebookcentral.proquest.com/lib/vuw/ detail.action?docID $=405228$

Cochran, C. (1990a). Wanganui heritage study / for the Wanganui District Council; Chris Cocbran \& Murray North Limited. The Council.

Cochran, C. (1990b). Wanganui heritage study / for the Wanganui District Council; Chris Cochran \& Murray North Limited. The Council.

Corbusier, L. (1973). The Athens charter. New York: Grossman Publishers.

Corner sites-Auckland Design Manual. (n.d.). Retrieved January 23, 2020, from http:/ / www.aucklanddesignmanual.co.nz/sites-and-buildings/mixed-use/guidance/thebuilding/mixeduseconfigurations/designingforcorners

Cramer, J., \& Breitling, S. (2007). Architecture in Existing Fabric: Planning design and building. https://www.book- 
depository.com/Architecture-Existing-Fabric-Johannes-Cramer/9783764377526

CUR FINAL Whanganui TC Strategy Report-161216.pdf. (n.d.). Retrieved April 1, 2019, from https://www.whanganui.govt.nz/our-district/major-projects/town-centre/Documents/CUR\%20FINAL\%20Whanganui\%20 TC $\% 20$ Strategy $\% 20$ Report $\% 20-\% 20161216$.pdf

Douglas, J. (2006). Building Adaptation. Butterworth-Heinemann.

Dunham-Jones, E. (2009a). Retrofitting suburbia: Urban design solutions for redesigning suburbs / Ellen Dunbam-Jones and June Williamson. John Wiley \& Sons.

Dunham-Jones, E. (2009b). Retrofitting suburbia: Urban design solutions for redesigning suburbs / Ellen Dunham-Jones and June Williamson. John Wiley \& Sons.

The Editors of Encyclopaedia Britannica. (2016, June 23). Column. Retrieved June 7, 2020, from https://www. britannica.com/technology/column-architecture

Egbelakin, D. T. (2017, December 21). Provincial New Zealand towns face abandoned town centres, loss of heritage. Stuff. https://www.stuff.co.nz/manawatu-standard/opinion/100029748/provincial-new-zealand-towns-faceabandoned-town-centres-loss-of-heritage

Fernandez-Galiano, L. (2000). Fire and Memory: On Arcbitecture and Energy. https://epdf.pub/fire-and-memory-on-architecture-and-energy.html

Former Standard Insurance building 201 Princes St, Dunedin | What if? Dunedin... (n.d.). Retrieved January 15, 2020, from https:// dunedinstadium.wordpress.com/2011/10/24/former-standard-insurance-building-201-princes-st-dunedin/

Frampton, K. (2001). Studies in Tectonic Culture: The Poetics of Construction in Nineteenth and Twentieth Century Architecture (J. Cava, Ed.; Reprint edition). The MIT Press.

Gospodini, A. (2006). Portraying, classifying and understanding the emerging landscapes in the post-industrial city. Cities, 23(5), 311-330. https://doi.org/10.1016/j.cities.2006.06.002

Gotffried Semper | German architect and writer. (n.d.). Encyclopedia Britannica. Retrieved February 27, 2020, from https://www.britannica.com/biography/Gottfried-Semper

Heritage Equip. How much funding is available? (n.d.). Retrieved from https://heritageequip.govt.nz/funding-your-project/heritage-equip-funding/how-much-funding-available

Hindmarsh, G. (n.d.). Flax - the enduring fibre. Retrieved from https://www.nzgeo.com/stories/flax-the-enduring-fibre/

Historic Places Trust. (n.d.). Heritage redesigned. Adapting historic places for contemporary New Zealand. file://stustocoiscifs1/FAD Users\$/dalgetphil/Downloads/AdaptiveReuse \%20(4).pdf

Hodgson, T. E. R. (1990). Looking at the architecture of New Zealand / Terence Hodgson; [edited by Anna Rogers]. Grantham House.

ICOMOS. (1964). The Venice Charter: International charter for the conservation and restoration of monuments and sites.

ICOMOS. (2013). Burra Charter. Australia: ICOMOS. Retrieverd from https:/ / australia.icomos.org/wp-context/ uploads/ The-Burra-Charter-2013-Adopted-31.10.2013.pdf.

ILT proposing to demolish historic building to save money on botel. (n.d.). Stuff. Retrieved January 7, 2020, from https:// 
www.stuff.co.nz/southland-times/news/106478049/ilt-proposing-to-demolish-historic-building-to-save-moneyon-hotel

Inside the office: Strategy Design and Advertising | Stuff.co.nz: (n.d.). Retrieved January 15, 2020, from http://www.stuff. co.nz/business/unlimited/innovation/10700241/Inside-the-office-Strategy-Design-and-Advertising

ILT proposing to demolish bistoric building to save money on botel. (2018, August 22). Retrieved from bttps:/ / wmw.stuff.co.n / / southland-times/news/106478049/ilt-proposing-to-demolish-bistoric-building-to-save-money-on-botel

Kilmister, S. (2018, September 14). Small towns could be marred beyond recognition in earthquake-prone buildings saga. Retrieved from bttps: / wmw.stuff.co.nz/ national/ nz-earthquake/106805921/small-towns-could-be-marred-beyond-recognition-in-earthquakeprone-buildings-saga

Kiroff, L., \& Tan, X. (2015). Adaptive reuse of industrial buildings in a new precinct in Auckland's CBD. https://unitec.researchbank.ac.nz/handle/10652/3178

Kouzminova, A. (2012). The Adaptive Reuse of Warehouse and Factory Buildings into Residential Living Spaces in Wellington, New Zealand. Victoria University of Wellington.

Krejcisz, C. A. (2012). The Craft of Conversion: Enhancing New Zealand's Industrial Heritage through Adaptive Reuse. Victoria University of Wellington.

Langston, C., Wong, F. K. W., Hui, E. C. M., \& Shen, L.-Y. (2008). Strategic assessment of building adaptive reuse opportunities in Hong Kong. Building and Environment, 43(10), 1709-1718. https://doi.org/10.1016/i.buildenv.2007.10.017

Lehmann, S., \& Crocker, R. (2012). Designing for zero waste: Consumption, technologies and the built environment / edited by Steffen Lebmann and Robert Crocker. EarthScan.

Leupen, B., \& Mooij, H. (2012). Housing Design: A Manual (2nd ed. edition). nai010 publishers.

Li, H.-W., \& Lui, W.-B. (2013). Sustainable reuse of derelict industrial area buildings - case studies in Taiwan, Japan, and Germany. International Journal of Sustainable Building Technology and Urban Development, 5(1), 1-9. https://doi.org $\angle 10.1080 / 2093761 X .2013 .865571$

Ltd, B. (2020). Minimising waste when building. http:/ / www.level.org.nz/material-use/minimising-waste/

Machado, R. (1976). Old Buildings as palimpsest: Towards a theory of remodelling. Progressive Architecture.

Manawatü-Whanganui Growth Study Opportunities Report July 2015. (n.d.). 285.

Martin, L. E. (1987a). Points of view: In praise of the New Zealand built environment / Lewis E. Martin. Price Milburn.

Martin, R. (2017, September 21). Heritage entbusiasts fear domino effect. Retrieved from bttps:/ / www.rnz.co.nz/news/national/339928/ heritage-enthusiasts-fear-domino-effect

Maslin, J. (2019, February 20). Government boost for Whanganui's heritage building owners. https:/ /www.nzherald.co.nz/whanganui-district-council/news/article.cfm?c id=1504487\&objectid=12205679

Millwork, W. (2013, October 1). Brief History on Columns/ Pillars. Retrieved June 7, 2020, from https://blog.worthingtonmillwork.com/bid/201549/Brief-History-on-Columns-Pillars

New Zealand's industrial heritage / Geoffrey G. Thornton. - 64VUW. (n.d.). Retrieved March 15, 2019, from https:// tewaharoa.victoria.ac.nz/primo-explore/fulldisplay?docid=64VUW INST21135853250002386\&contex-

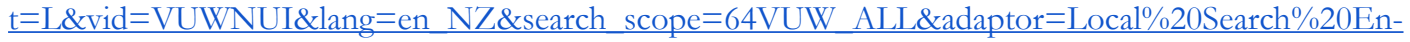


gine $\&$ tab $=$ all \&query $=$ any,contains, new $\% 20$ zealand $\% 20$ industrial $\% 20$ heritage $\&$ sortby $=$ rank $\&$ offset $=0$

NZ “losing its heritage buildings at a massive rate." (2019, August 3). RNZ. https://www.rnz.co.nz/news/national/395904/nz-losing-its-heritage-buildings-at-a-massive-rate?fbclid=IwAR0XI1prDcAhKszF-FKymJuaU1PQ IQxP8mlexf0a wXrJdFODBJeTadq2I

Paramount House Hotel / Breathe Architecture | ArchDaily. (n.d.). Retrieved January 15, 2020, from https:/ /www. archdaily.com/914140/paramount-house-hotel-breathe-architecture

Petković-Grozdanovića, N., Stoiljković, B., Keković, A., \& Murgul, V. (2016). The Possibilities for Conversion and Adaptive Reuse of Industrial Facilities into Residential Dwellings. Procedia Engineering, 165, 1836-1844. https://doi.org/10.1016/i.proeng.2016.11.931

Plevoets, B., \& Cleempoel, K. V. (2019). Adaptive Reuse of the Built Heritage: Concepts and Cases of an Emerging Discipline (1 edition). Routledge.

Provincial New Zealand towns face abandoned town centres, loss of heritage. (n.d.). Stuff. Retrieved January 7, 2020, from https://www.stuff.co.nz/manawatu-standard/opinion/100029748/provincial-new-zealand-towns-faceabandoned-town-centres-loss-of-heritage

Robert, P. (1989). Adaptations: New uses old buildings. (Editions: du Moniteur).

Robiglio, M. (2017). RE-US A: 20 American stories of adaptive reuse, a toolkit for post-industrial cities / Matteo Robiglio; foreword by Donald K. Carter. Jovis Verlag GmbH.

Sandler, D. (2011). Counterpreservaion: Decrepitude and memory in post-unification Berlin.

Scally, B. (2017). Forget me not: Critical intervention of Tötara North's decaying industrial heritage; Research question: How can a derelict and forgotten piece of significant industrial heritage be revived and made purposeful through strategic architectural intervention? http://hdl.handle.net/10652/3934

Schumacher, T. (2002). "The outside is the result of the inside": Some sources of one of modermisms most persisten doctrines. Journal of Architectural Education.

Scott, F. (2008). On altering arcbitecture.

Securing parapets and facades on unreinforced masonry buildings. (2018). 88.

Southcombe, M. (2014). [Re] Cuba: Renegotiating seismic resilience in Cuba Street Wellington / Mark Southcombe \& Andrew Charleson. Wellington City Council.

Strategic assessment of building adaptive reuse opportunities in Hong Kong-ScienceDirect. (n.d.). Retrieved March 27, 2020, from https://www.sciencedirect.com/science/article/abs/pii/S036013230700203X

Strategy circa 1877. (n.d.). Retrieved January 15, 2020, from https://www.strategycreative.com/jp/news/strategy-circa-1877

Sulfaro, N. (2014). A memory of Shadows and of Stone: Traumatic Ruins, Conservation, Social Processes. ArcHistR.

Sydney's Paramount House Hotel Recalls The Golden Era Of The Movies | OPUMO. (n.d.). Retrieved January 15, 2020, from https://www.opumo.com/magazine/sydneys-paramount-house-hotel-recalls-the-golden-era-of-themovies/

Taonga, N. Z. M. for C. and H. T. M. (n.d.). 5. - Papatūanuku - the land - Te Ara Encyclopedia of New Zealand [Web page]. Retrieved December 17, 2019, from https://teara.govt.nz/en/papatuanuku-the-land/page-5 
Teal, D. (2013). Rewriting History Through Adaptive Reuse. Environmental Design + Construction, 16(12), 31-35.

The Abbotsford Warehouse Apartments / ITN Architects | ArcbDaily. (n.d.). Retrieved January 15, 2020, from https:// www.archdaily.com/269623/the-abbotsford-warehouse-apartments-itn-architects

The Green Building / (fer) studio | ArcbDaily. (n.d.). Retrieved January 15, 2020, from https:/ /www.archdaily. com/118709/the-green-building-fer-studio

The Green Building in Louisville, Kentucky by (FER) Studio. (n.d.). Retrieved January 15, 2020, from https://www10. aeccafe.com/blogs/arch-showcase/2011/03/25/the-green-building-in-louisville-kentucky-by-fer-studio/

Thornton, G. G. (1982). New Zealand's industrial heritage / Geoffrey G. Thornton. Reed.

Urbanismplus Ltd. (2016). Making Whanganui Visable -Regeneration Strategy for the Whanganui Town Centre. Whanganui District Council.

Vair-Piova, M. (n.d.). FORMER GROSVENOR HOTEL AND SETTING - 367 MOORHOUSE AVENUE, CHRISTCHURCH. 4.

Völker, S., \& Kistemann, T. (2013). Reprint of: "I'm always entirely happy when I'm here!” Urban blue enhancing human health and well-being in Cologne and Düsseldorf, Germany. Social Science \& Medicine, 91, 141-152. https://doi.org/10.1016/j.socscimed.2013.04.016

Vujadinovic, M. (2004). Preserving old buildings: Adaptive use for residential purposes in Montreal. National Library of Canada $=$ Bibliothèque nationale du Canada.

Wang, J., \& Zeng, Z. T. (2007). Conservation and adaptive-reuse of historical industrial building in Cbina in the post-industrial era. Frontiers of Architecture and Civil Engineering in China. https://link.springer.com/article/10.1007/ s11709-007-0064-5

Wanganui Town Planning Dept. (1978). Historic places, Wanganui / prepared by Town Planning Department, Wanganui City Councill. Wanganui Town Planning Dept.

Warne, Kennedy. (2019, April 24). This river in New Zealand is a legal person. How will it use its voice? Retrieved from https://www.nationalgeographic.com/culture/2019/04/maori-river-in-new-zealand-is-a-legal-person/

Whanganui-Heritage-Guide-04_17.pdf. (n.d.). Retrieved April 1, 2019, from http://www.stagingvisitwhanganui.nz/ wp-content/uploads/2017/04/Whanganui-Heritage-Guide-04 17.pdf

Wilkinson, S. J., Langston, C., Remøy, H., \& Remoy, H. (2014). Innovation in the Built Environment: Sustainable Building Adaptation: Innovations in Decision-Making. John Wiley \& Sons, Incorporated. http:/ / ebookcentral. proquest.com/lib/vuw/detail.action?docID $=1597997$

Young, D. (1998). Woven by Water: Histories from the Whanganui River. Huia Publishers. 


\section{LIST OF FIGURES}

\section{Unless otherwise stated, all images are authors own.}

Fig 0.01 Whanganui Regional Museum. W-ST-131. (1975). Victoria Avenue form Durie Hill.photograph, Whanganui.

Fig 1.01 Overlooking Wanganui. Ref: 1/1-020999-G. Alexander Turnbull Library, Wellington, New Zealand. / records/23202404

Fig 1.02 Langlands Building on the corner of Dee and Don streets. Stuff. Kavind Herath. Southland times. 106478049

Fig 1.03 Central City Demolition. Linda McGaw. March 2019 Invercargill City Council.

Fig 2.01 Victoria Avenue, Wanganui. Ref: 1/1-021063-G. Alexander Turnbull Library, Wellington, New Zealand. / records/23012760

Fig 2.02 - 2.03 Considerations influenced by: Douglas, J. (2006). Building Adaptation. Butterworth-Heinemann.

Fig 2.04 The range of interventions. Adapted from Figure 1.1 in Douglas, J. (2006). Building Adaptation. Butterworth-Heinemann.

Fig 2.05 The two elements of performance management (adapted from Henket, 1992) Influenced by Figure 1.6. in Douglas, J. (2006). Building Adaptation. Butterworth-Heinemann.

Fig 2.06 Model of decision-making factors in building adaptation. Adapted from Figure 2.2. Wilkinson, S. J., Langston, C., Remøy, H., \& Remoy, H. (2014). Innovation in the Built Environment: Sustainable Building Adaptation: Innovations in Decision-Making. John Wiley \& Sons, Incorporated.

Fig 3.01 Sheep grazing, Wanganui. Wells, Robert E, 1905-2006 :Photographic negatives, prints and transparencies of the Mokau and other rural North Island districts, 
and scenic views of New Zealand. Ref: 1/4-091729-F. Alexander Turnbull Library, Wellington, New Zealand. / records/23056282

Fig 4.01 Wharves at Wanganui with steamers. Ref: 1/1-007337-G. Alexander Turnbull Library, Wellington, New Zealand. / records/22836377.

Fig 4.02 Former Grosvenor Hotel and Setting - 367 Moorhouse Avenue, Christchurch. M.Vair-piova. 15/12/2014. Christchurc City Council.

Fig 4.03 Image sourced from Abeling, S., Dizhur, D., \& Ingham, J. (2018). An evaluation of successfully seismically retrofitted URM buildings in New Zealand and their relevance to Australia. Australian Journal of Structural Engineering, 19(3), 234-244. https:/ / doi.org/10.1080/13287982.2018.1491820

Fig 4.04 Image sourced from Abeling, S., Dizhur, D., \& Ingham, J. (2018).

An evaluation of successfully seismically retrofitted URM buildings in New Zealand and their relevance to Australia. Australian Journal of StructuralEngineering,19(3),234-244.https://doi.org/10.1080/13287982.2018

Fig 4.05 A sketch of an image sourced from Abeling, S., Dizhur, D., \& Ingham, J. (2018). An evaluation of successfully seismically retrofitted URM buildings in New Zealand and their relevance to Australia. Australian Journal of Structural Engineering, 19(3), 234-244. https://doi.org/10.1080/13287982.2018.1491820

Fig 4.06 - 4.12 Images sourced from "The Abbotsford Warehouse Apartments / ITN Architects” 05 Sep 2012. ArchDaily. Accessed 8 May 2020. <https://www. archdaily.com/269623/the-abbotsford-warehouse-apartments-itn-architects /> ISSN 0719-8884

Fig 4.13 - 4.20 Images sourced from “The Green Building / (fer) studio” 09 March 2011. ArchDaily. Accessed 8 May 2020. < https://www.archdaily.com/118709/the- 
green-building-fer-studio/> ISSN 0719-8884

Fig 4.21 - 4.22 Images sourced from Pearl, M. (2011, March

30). The Green Building in Louisville, Kentucky by (FER)

Studio designed using 3ds MAX and AutoCAD. Retrieved from

https://www10.aeccafe.com/blogs/arch-showcase/2011/03/25the-

green-building-in-louisville-kentucky-byferstud

io/?fbclid=IwAR0BbP6v338jHkf892CJc2vNEG

QaDtwjCJIp2Bbm4jHq131QimUtpSQFYak

Fig 4.23 - 4.32 Images sourced from "Paramount House Hotel / Breathe Architecture" 08 Apr 2019. ArchDaily. Accessed 8 May 2020. <https://www.archdaily. com/914140/paramount-house-hotel-breathe-architecture/> ISSN 0719-8884

Fig 4.33 - 4.34 Images sourced from, Lewis, J. (2017, April 26). Former pigeons' slum wins supreme award. Retrieved from https://www.odt.co.nz/news/dunedin/ former-pigeons-slum-wins-supreme-award.

Fig 4.35 - 4.38 Images sourced from, Gibb, J. (2015, June 2). 'Absolutely incredible' revamp of heritage building. Retrieved from https://www.odt.co.nz/news/dunedin/ absolutely-incredible-revamp-heritage-building

Fig 5.01 Drafting sheep at a woolshed, Mangamahu. Wells, Robert E, 1905-2006 :Photographic negatives, prints and transparencies of the Mokau and other rural North Island districts, and scenic views of New Zealand. Ref: 1/4-110341-F. Alexander Turnbull Library, Wellington, New Zealand. / records $/ 22743968$.

Fig 5.05 - 5.07 Own images with information from Earth's Data Platform. (n.d.). Retrieved from https://koordinates.com/ 
Fig 5.13 Our District. (n.d.). Retrieved from https://www.whanganui.govt.nz/AboutWhanganui/Our-District

Fig 5.16 Estwing. (2015, July 7). The Pope and the Flood: Whanganui, 2015.

Retrieved from https:/ / ecothriftylife.com/2015/06/22/the-pope-and-theflood-whanganui-2015/

Fig 5.17 - 5.19 “Memories of old Whanganui" Photos courtesy of Tesla Studios, L. Teki and Tesla Studios

Fig 5.20 Whanganui river. (2013, August 24). Retrieved from https://axeoneverest.c om/whanganui-river-dtred/

Fig 5.28 Victoria Avenue from the bridge, Wanganui. Ref: 1/1-020910-G. Alexander Turnbull Library, Wellington, New Zealand. / records/22831712

Fig 5.29 Warren, C. (n.d.). Kev's Wanganui Riverboat History page. Retrieved from https://www.facebook.com/kevsriverpage/photos

Fig 5.31 - 5.33 "Memories of old Whanganui" Photos courtesy of G.B \& J.A Potts, L. Teki and ML Lampe Collection.

Fig 5.37 "Memories of old Whanganui” Photos courtesy of G.B \& J.A Potts, L. Teki and ML Lampe Collection.

Fig 6.01 Fosters Hotel, Taupo Quay, Wanganui. Ref: 1/1-021559-G. Alexander Turnbull Library, Wellington, New Zealand. /records/22868429

Fig 6.07 - 6.21 49 Taupo Quay. (n.d.). Retrieved from https://propertyonly.co.nz/exception/

Fig7.01 Employees outside the confectionery shop of W S Dustin, Wanganui. Ref: 1/1-024401-G. Alexander Turnbull Library, Wellington, New Zealand. / records/22597171 
Fig 7.02 - 7.07 Diagrams adapted from Urbanismplus Ltd. (2016). Making Whanganui Visible_-Regeneration Strategy for the Whanganui Town Centre. Whanganui District Council.

Fig 7.09 - 7.11 Diagrams adapted from Urbanismplus Ltd. (2016). Making Whanganui Visible_-Regeneration Strategy for the Whanganui Town Centre. Whanganui District Council.

Fig 7.18 - 7.19 "Memories of old Whanganui”" Photos courtesy of G.B \& J.A Potts

Fig 8.01 The Watt Fountain on Victoria Avenue, people walking and standing on street, Whanganui. Ref: 1/1-000194-G. Alexander Turnbull Library, Wellington, New Zealand. / records/23125882

8.24 - 8.26 Images of plans from Whanganui Regional Museum. April 2019. Whanganui.

Fig 9.01 Victoria Avenue, Wanganui. Ref: 1/1-000266-G. Alexander Turnbull Library, Wellington, New Zealand. / records/22677748

Fig 10.01 Denton, Frank James, 1869-1963. Shearers, Wanganui District. Ref: 1/ 1-020875-G. Alexander Turnbull Library, Wellington, New Zealand. / records/22871837

Fig 10.02 Gottfried Semper, G. (2016). Retrieved from https://www.researchgate.net/ figure/Gottfried-Semper-Primitive-Hut-1851_fig85_319183489

Fig 11.01 View of the Wanganui River. Ref: PA1-q-075-41-2. Alexander Turnbull Library, Wellington, New Zealand. / records/22634930 

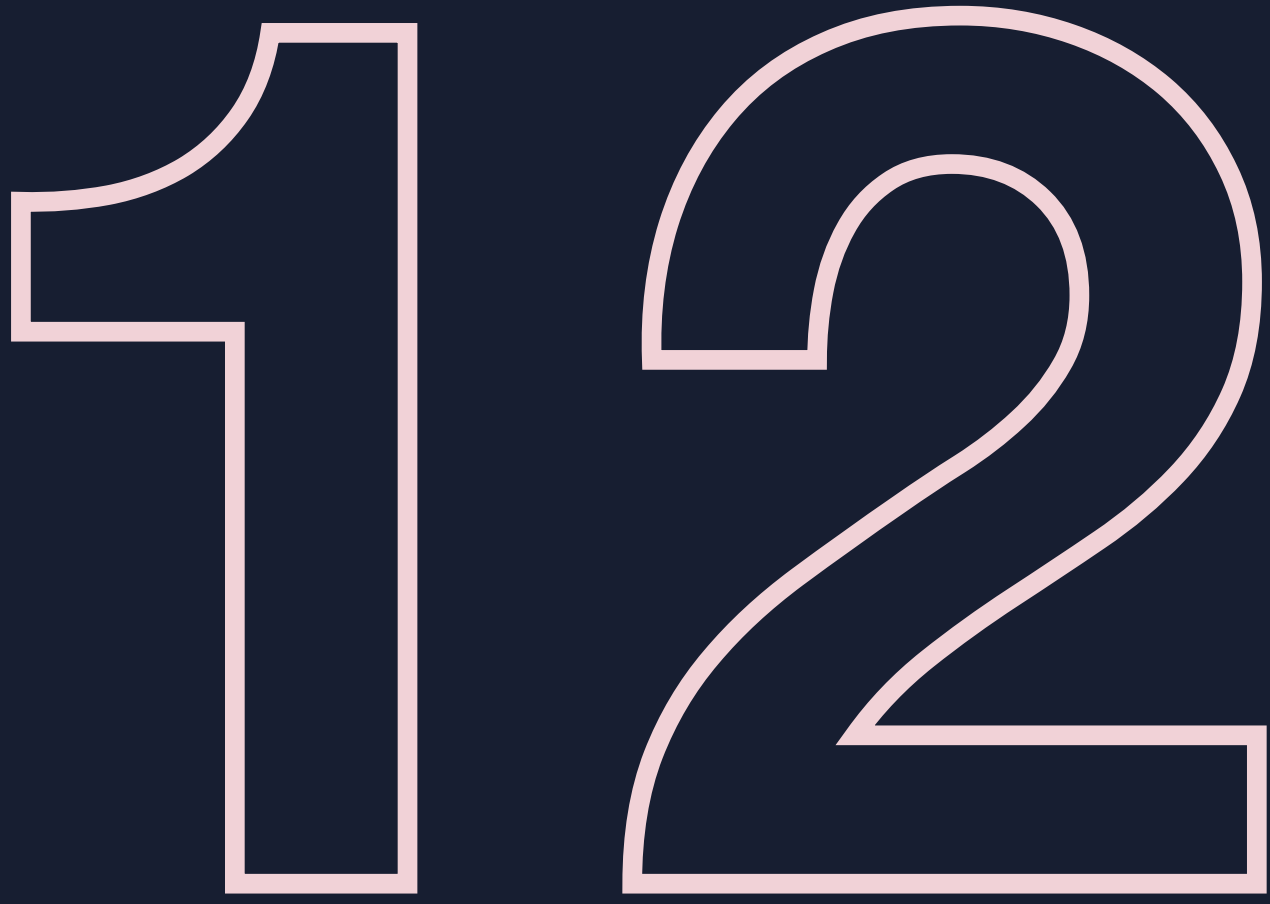

ADDENDUM 


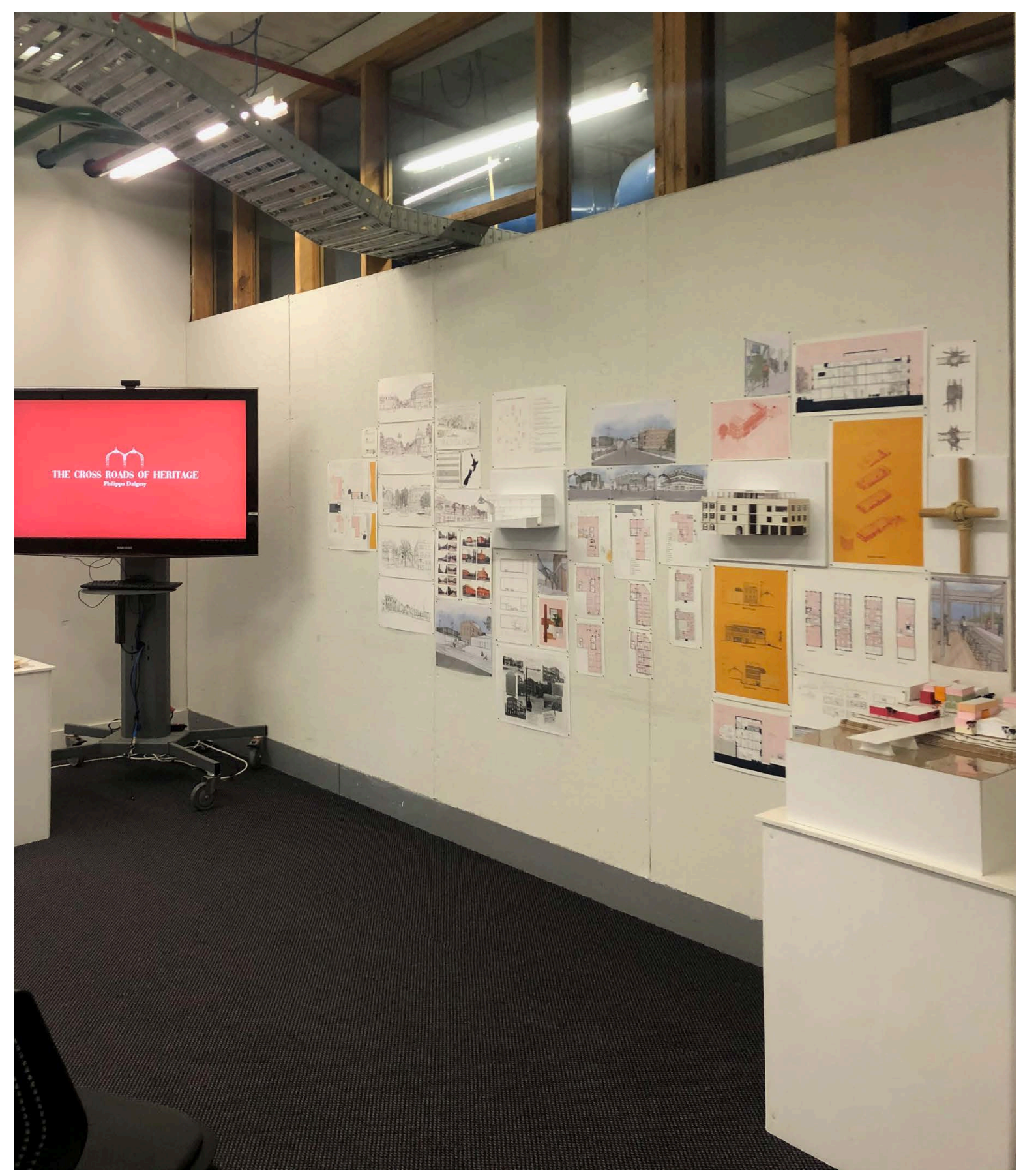



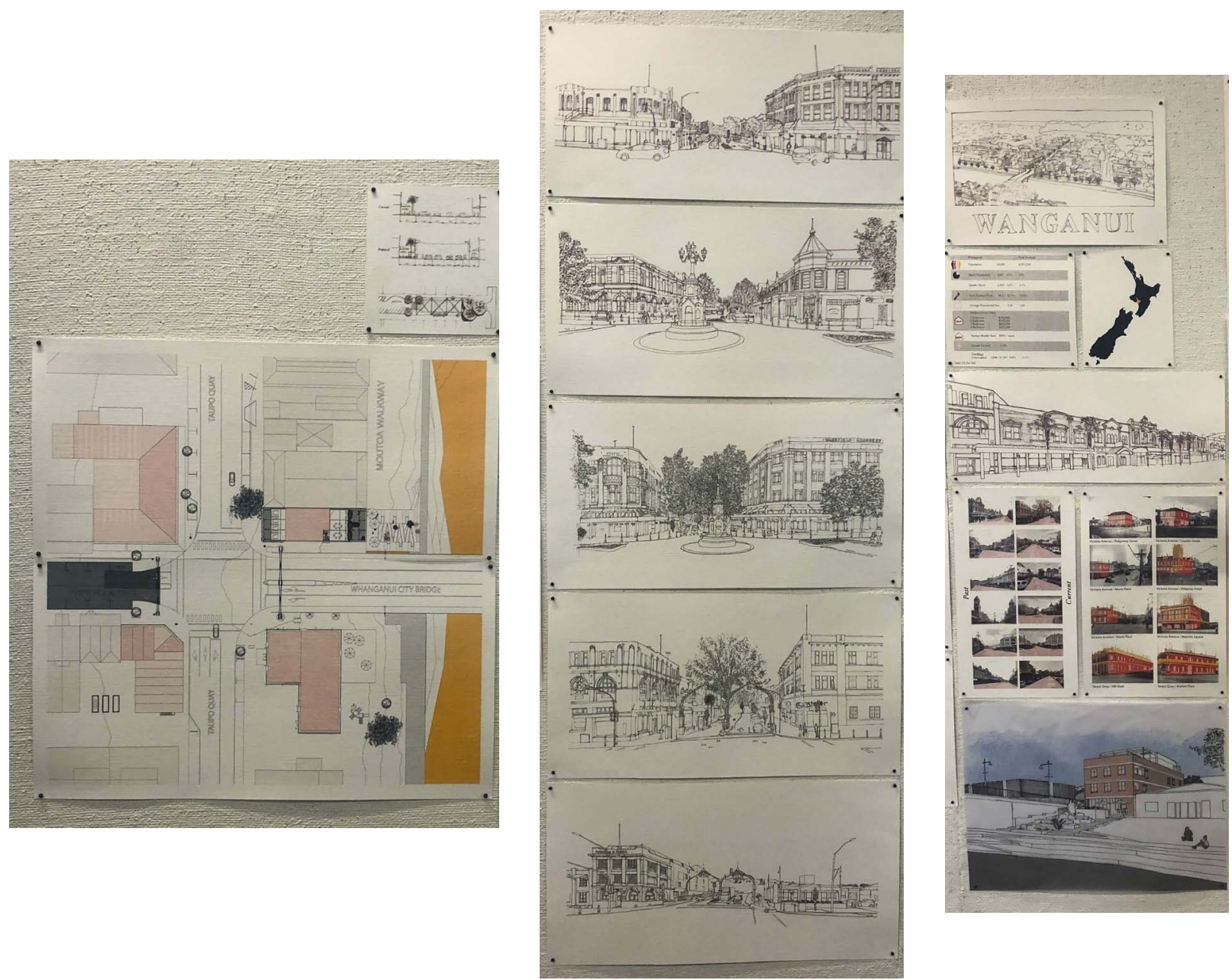

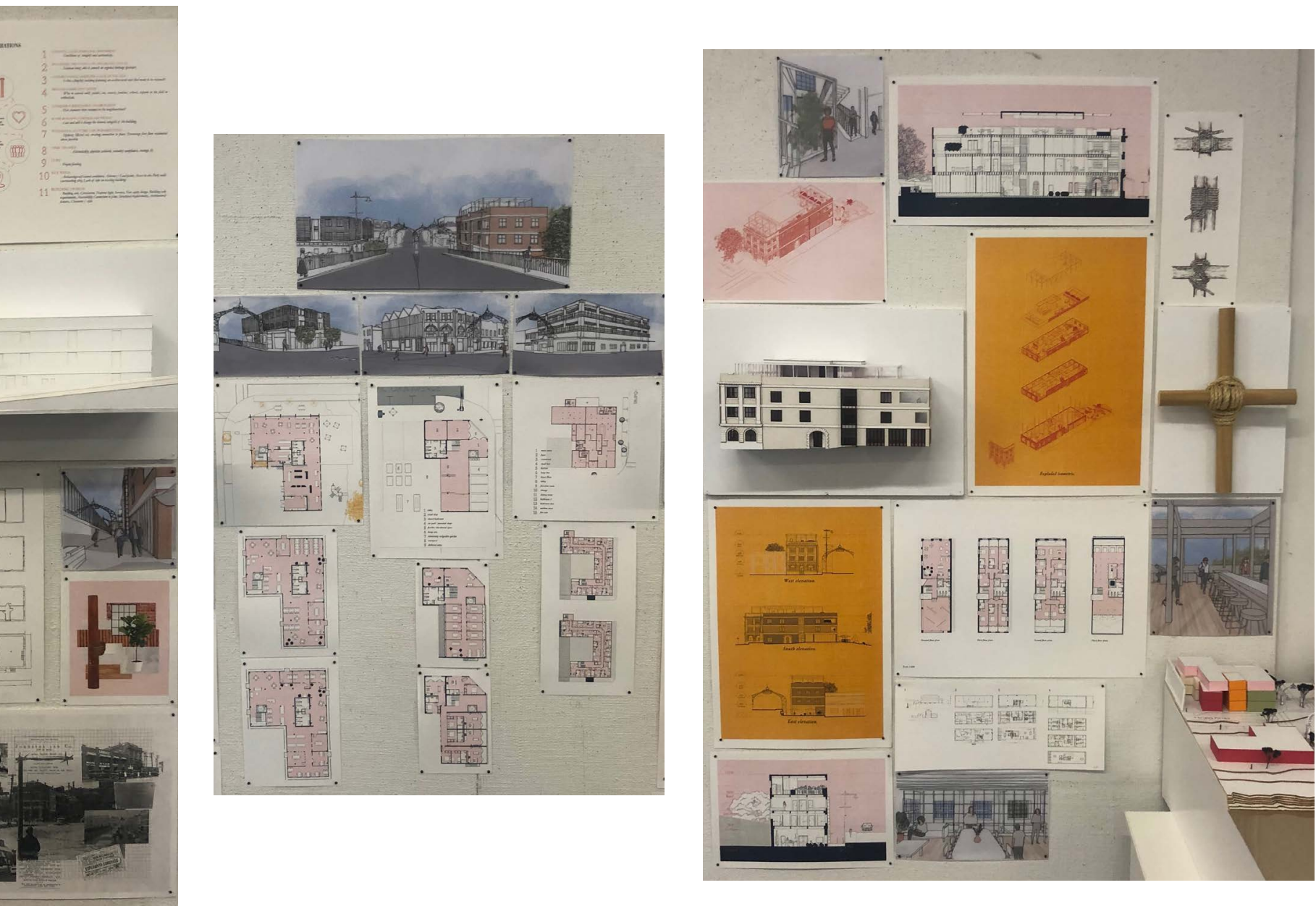

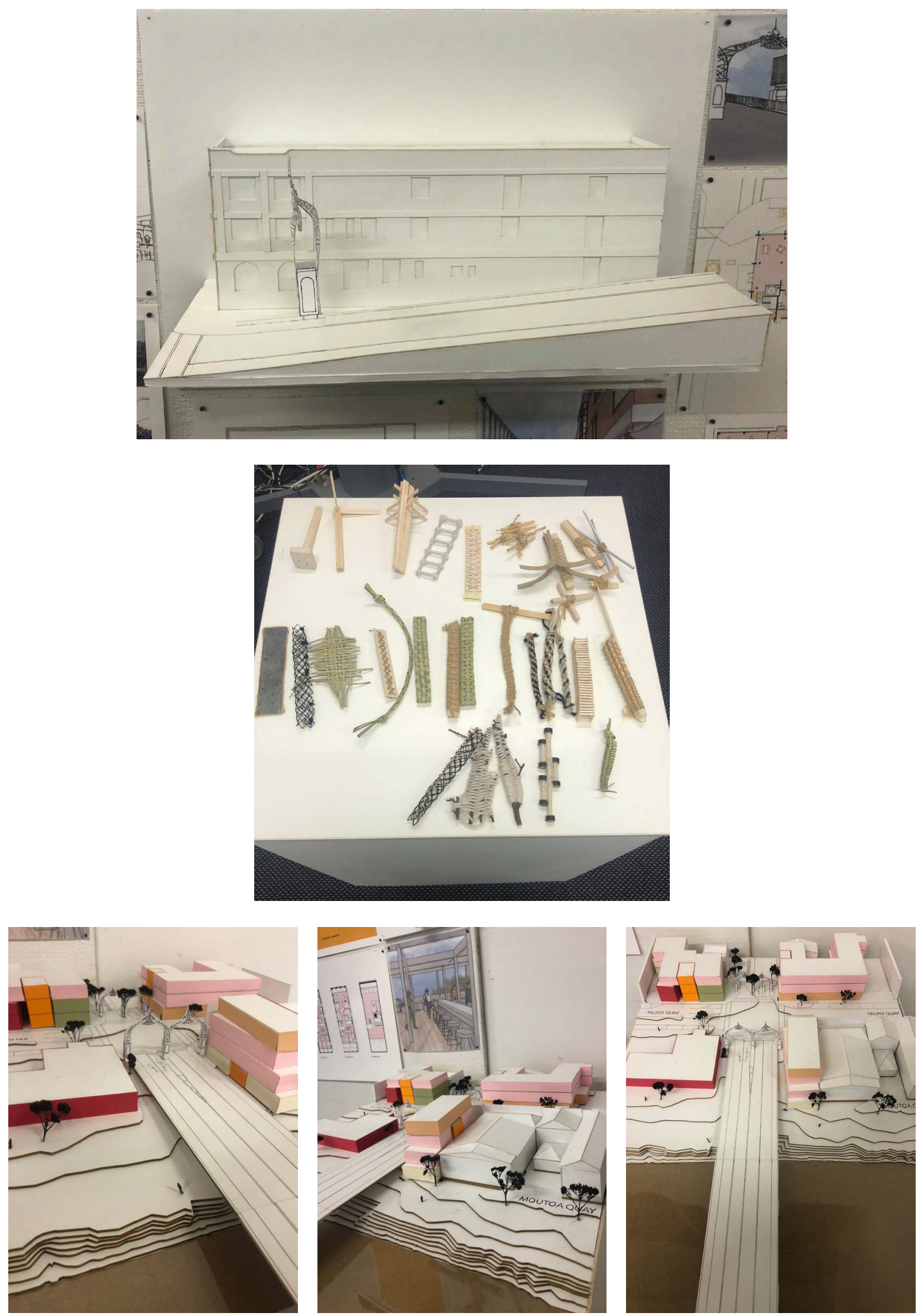


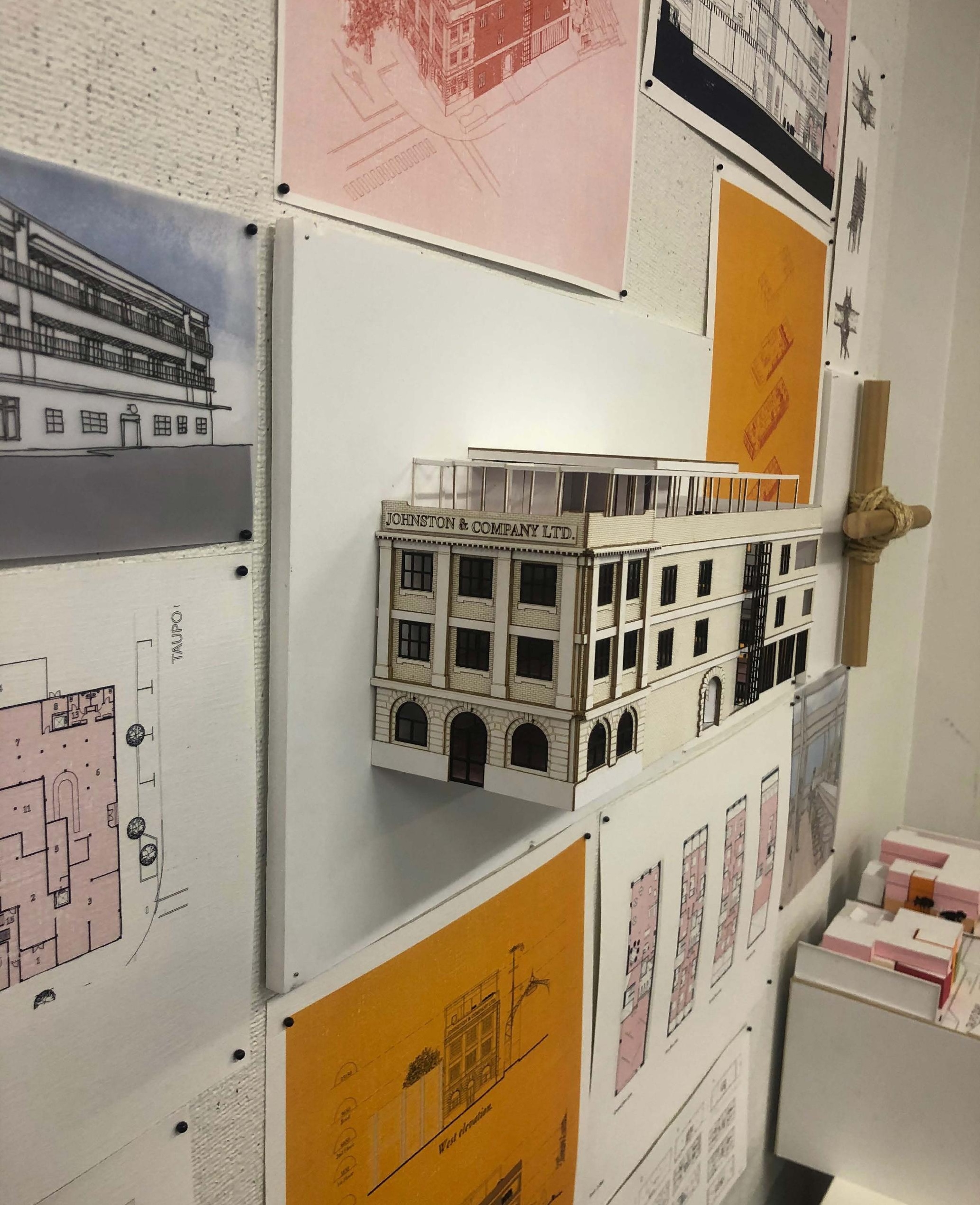




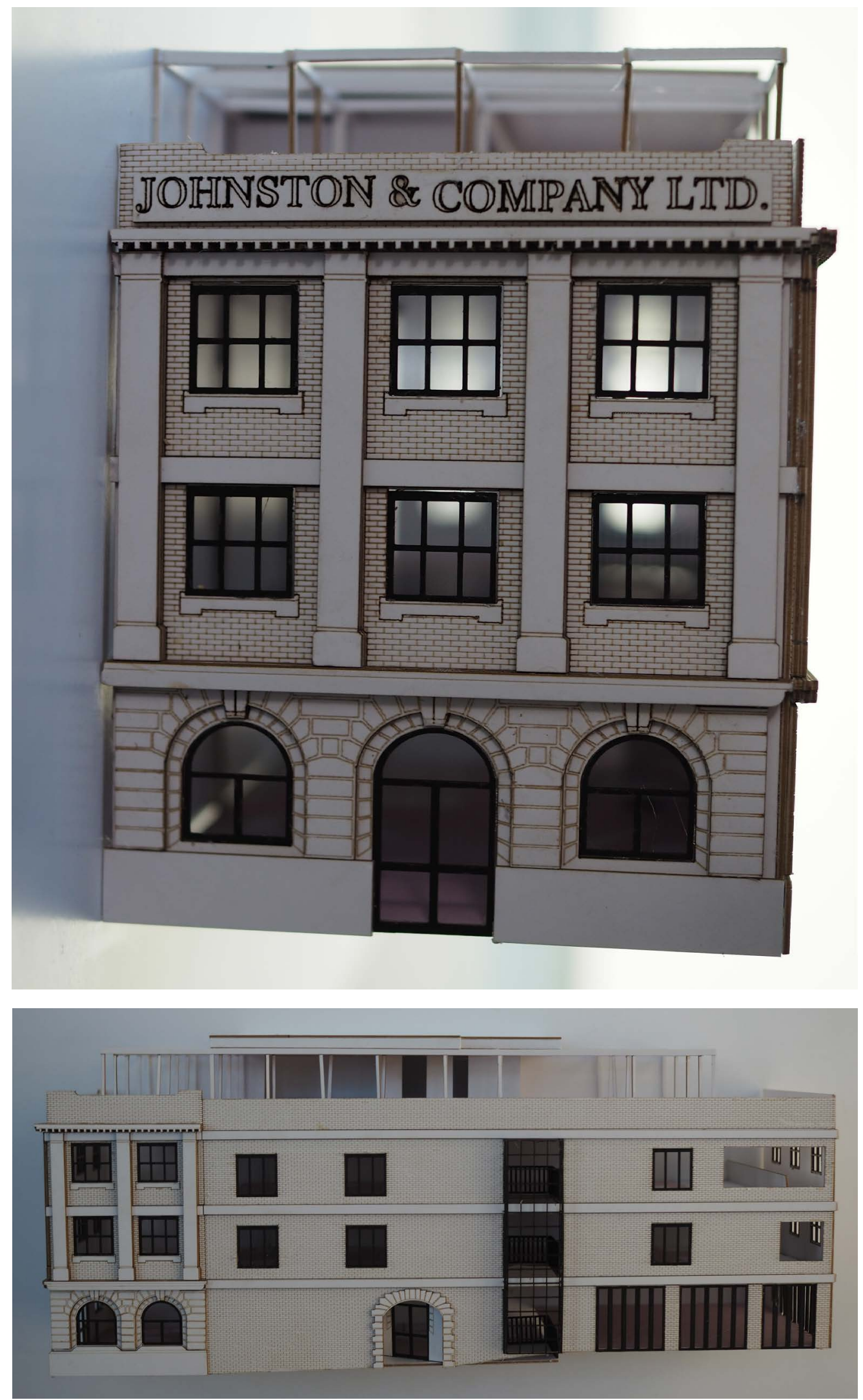



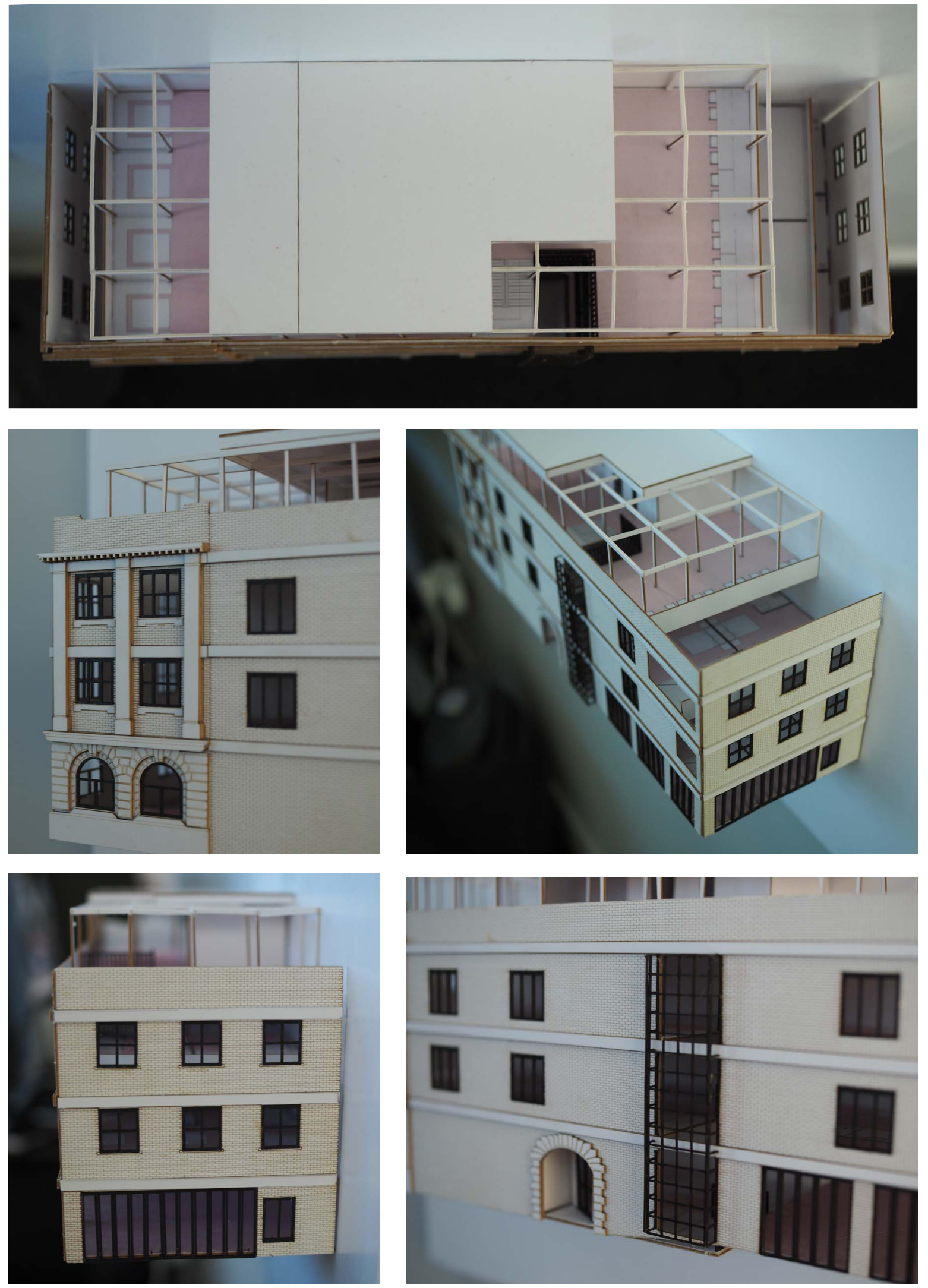


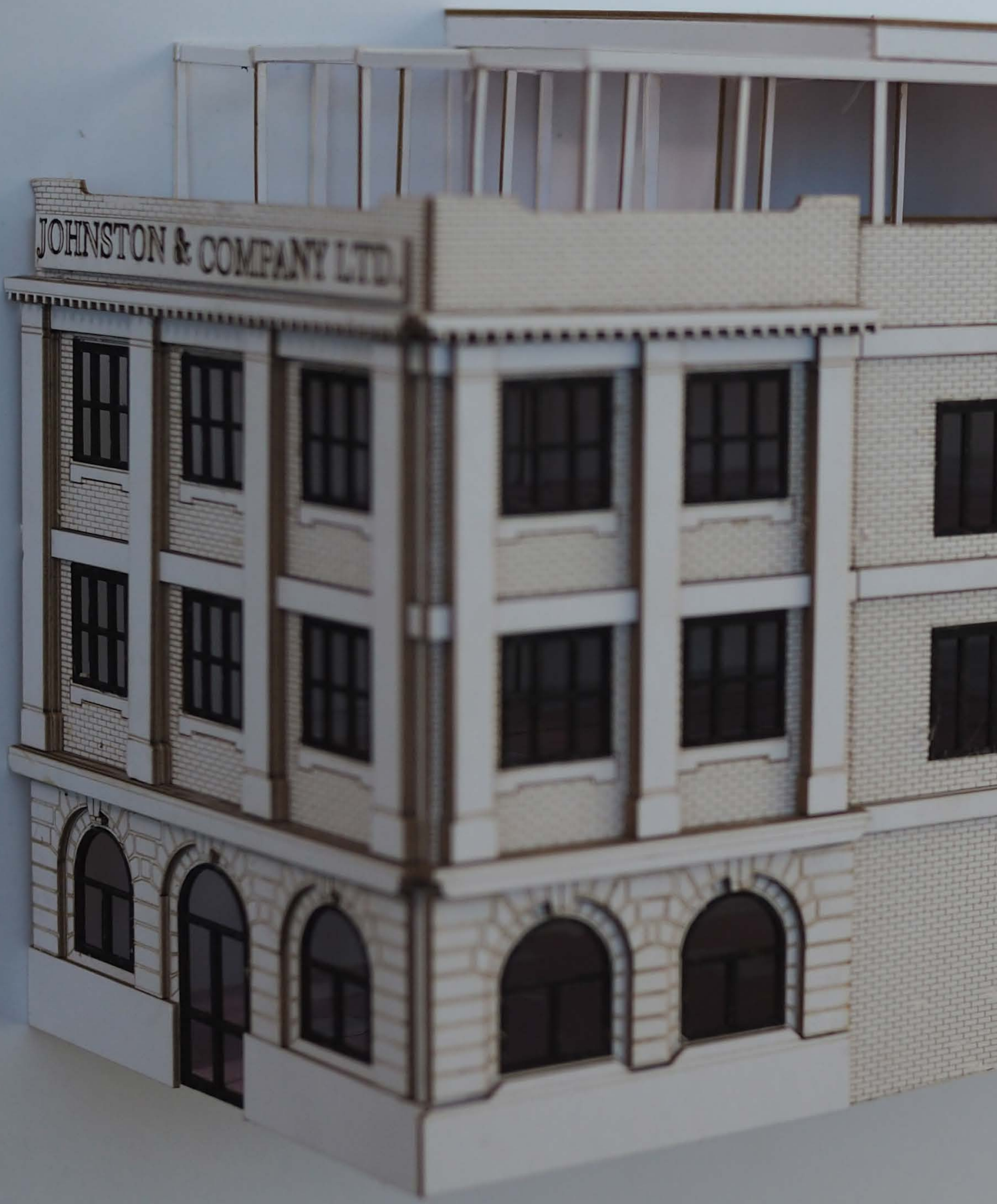




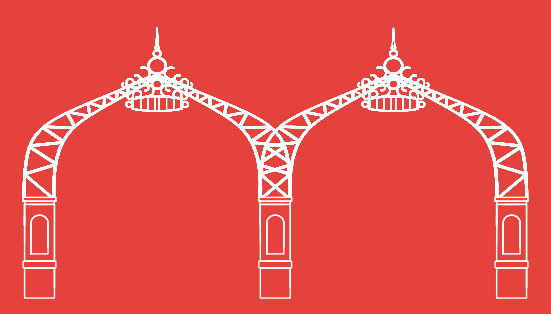

\section{Philippa Dalgety}

